Gilberto Akio Oliveira Watanabe

\title{
Marés internas semi-diurnas na plataforma continental amazônica
}

\author{
Dissertação apresentada ao Instituto \\ Oceanográfico da Universidade de São \\ Paulo, como parte dos requisitos para \\ obtenção do título de Mestre em Ciências, \\ Programa de Oceanografia Física. \\ Orientador: Prof. Dr. Belmiro Mendes de \\ Castro Filho
}

São Paulo 


\section{Universidade de São Paulo \\ Instituto Oceanográfico}

Marés internas semi-diurnas na plataforma continental amazônica

Gilberto Akio Oliveira Watanabe

Dissertação apresentada ao Instituto Oceanográfico da Universidade de São Paulo, como parte dos requisitos para obtenção do título de Mestre em Ciências, Programa de Oceanografia Física.

\section{Versão Corrigida}

Julgada em

Conceito

$\operatorname{Prof}(a) . \operatorname{Dr}(a)$.

Conceito

Prof(a). Dr(a).

Conceito

$\operatorname{Prof}(a) \cdot \operatorname{Dr}(a)$ 


\section{Sumário}

Resumo xii

$\begin{array}{ll}\text { Abstract } & \text { xiii }\end{array}$

1 Introdução 1

2 Área de Estudo $\quad 8$

3 Hipótese e Objetivos $\quad 16$

4 Conjunto de Dados 17

5 Metodologia $\quad 26$

5.1 Pré-processamento e análise dos dados termohalinos dos cruzeiros hidrográficos 26

5.2 Pré-processamento e análise dos dados correntográficos e termohalinos dos fundeios . . . . . . . . . . . . . . . . 32

5.2.1 Análise Espectral . . . . . . . . . . . . . . . . 36

5.2.2 Análise Harmônica de Marés . . . . . . . . . . . . . . . . . . . 37

5.2.3 Funções Empíricas Ortogonais - FOE . . . . . . . . . . . . . . 38

5.2 .4 Correlação . . . . . . . . . . . . . . . . . 40 40

6 Resultados e Discussão 42

6.1 Cruzeiros hidrográficos . . . . . . . . . . . . . . . . . . . 42

6.2 Fundeios . . . . . . . . . . . . . . . . 50

6.2.1 Análise gráfica das séries de correntes . . . . . . . . . . . . . 50

6.2.2 Análise espectral das séries de corrente . . . . . . . . . 66

6.2 .3 Análise Harmônica . . . . . . . . . . . . . . . . . . . . . . . . . 74

6.2.4 Funções Empíricas Ortogonais - FOE . . . . . . . . . . . . . . 93

6.2.5 FOE - Reconstrução da velocidade . . . . . . . . . . . . . . . . 99

6.2.6 FOE - Influencia do $2^{\circ}$ modo estatístico na dinâmica de propriedades 110

6.2 .7 FOE - Correlação . . . . . . . . . . . . . . . . . . . 121 
6.2.8 FOE - Densidade de potência espectral . . . . . . . . . . . . . 132

7 Considerações Finais $\quad 142$

7.1 Sumário . . . . . . . . . . . . . . . . . . . . . . . . 142

7.2 Conclusões . . . . . . . . . . . . . . . . . . . . . . 148

$\begin{array}{ll}\text { Referências } & \mathbf{1 5 0}\end{array}$ 


\section{Lista de Figuras}

1 Figura explicativa de ondas internas. . . . . . . . . . . . 2

2 Locais de ocorrência de Sólitons. . . . . . . . . . . . . . . . 6

3 Local de ocorrência de Sólitons na PCA. . . . . . . . . . . . . . . 7

4 Localização da área de estudo . . . . . . . . . . . . . . . . . . . . . 9

5 Classificação de plataformas . . . . . . . . . . . . . . . . . . . . . . 10

$6 \quad$ Localização das estações do cruzeiro I8909. . . . . . . . . . . . . . . . . 18

7 Localização das estações do cruzeiro I9002 . . . . . . . . . . . . . . . . . 19

8 Localização das estações do cruzeiro I9004. . . . . . . . . . . . . . . . . 20

9 Localização das estações do cruzeiro I9113L3. . . . . . . . . . . . . . . 21

10 Localização das estações do cruzeiro I9114L4. . . . . . . . . . . . . . 22

11 Localização dos fundeios AMASSedS . . . . . . . . . . . . . . . 23

12 Parâmetros coletados e período amostral dos Fundeios AMASSedS. . . . 25

13 Janela utilizada para filtrar os dados. . . . . . . . . . . . . . . . . 28

14 Comparação dos dados de temperatura filtrados . . . . . . . . . . . . . . 29

15 Velocidade observada e barotrópica - Fundeio F1 . . . . . . . . . . . . 34

16 Velocidade observada e barotrópica - Fundeio F2. . . . . . . . . . . . 35

17 Velocidade observada e barotrópica - Fundeio F3 . . . . . . . . . . 36

18 Possíveis locais geradores de maré interna para a componente $\mathrm{M}_{2}$ durante o cruzeiro I8909, agosto de $1989 \ldots \ldots$. . . . . . . . . . . . . 43

19 Possíveis locais geradores de maré interna para a componente $\mathrm{M}_{2}$ durante o cruzeiro 19002 , março de $1990 \ldots \ldots$. . . . . . . . . . . . . 44

20 Possíveis locais geradores de maré interna para a componente $\mathrm{M}_{2}$ durante o cruzeiro I9004, de maio a junho de $1990 \ldots \ldots$. . . . . . . . . 45

21 Possíveis locais geradores de maré interna para a componente $\mathrm{M}_{2}$ durante o cruzeiro I9113L3, primeira pernada, em novembro de 1991. . . . . . . 46

22 Possíveis locais geradores de maré interna para a componente $\mathrm{M}_{2}$ durante o cruzeiro I9113L4. . . . . . . . . . . . . . . . . . . . 47

23 Velocidade perpendicular às isóbatas - $u$, para Fundeio F1. . . . . . . . . 52 
24 Velocidade paralela às isóbatas, $u$ para os correntógrafos do Fundeio M1.

25 Velocidade perpendicular às isóbatas, $u$ para os correntógrafos do Fundeio F2. . . . . . . . . . . . . . . . . . 55

26 Velocidade paralela às isóbatas, $u$ para os correntógrafos do Fundeio F2. . 57

27 Velocidade perpendicular às isóbatas, $u$ para os correntógrafos do Fundeio F3. . . . . . . . . . . . . . . . . . 60

28 Velocidade paralela às isóbatas, $u$ para os correntógrafos do Fundeio F3. . 61

29 Correntes baroclínicas para o Fundeio F1. . . . . . . . . . . . . . . 63

30 Correntes baroclínicas para o Fundeio F2. . . . . . . . . . . . . . . . . 64

31 Correntes baroclínicas para o Fundeio F3. . . . . . . . . . . . . . . 65

32 Estimativa de densidade espectral para as séries de velocidade a $3 \mathrm{~m}$ no Fundeio F1. . . . . . . . . . . . . . . . . . . . 66

33 Estimativa de densidade espectral para as séries de velocidade a $16 \mathrm{~m}$ no Fundeio F1. . . . . . . . . . . . . . . . . . 67

34 Estimativa de densidade espectral para as séries de velocidade a $3 \mathrm{~m}$ no Fundeio F2. . . . . . . . . . . . . . . . . . . . 68

35 Estimativa de densidade espectral para as séries de velocidade a $32 \mathrm{~m}$ no Fundeio F2. . . . . . . . . . . . . . . . . . . . . . . . . . . . 69

36 Estimativa de densidade espectral para as séries de velocidade a $54 \mathrm{~m}$ no Fundeio F1. . . . . . . . . . . . . . . . . . . 70

37 Estimativa de densidade espectral para as séries de velocidade a $62 \mathrm{~m}$ no Fundeio F2. . . . . . . . . . . . . . . . . . . 71

38 Estimativa de densidade espectral para as séries de velocidade a $32 \mathrm{~m}$ no Fundeio F3. . . . . . . . . . . . . . . . . . . 72

39 Estimativa de densidade espectral para as séries de velocidade a $93 \mathrm{~m}$ no Fundeio F3. . . . . . . . . . . . . . . . . . . . 73

40 Resultado da análise harmônica da corrente barotrópica para o fundeio F1. 74

41 Resultado da análise harmônica da corrente baroclínica a 3 m para o fundeioF1. . . . . . . . . . . . . . . . . 75 
42 Resultado da análise harmônica da corrente baroclínica a $16 \mathrm{~m}$ para o fundeio F1. . . . . . . . . . . . . . . . . . 76

43 Resultado da análise harmônica da corrente barotrópica para o fundeio F2. 78

44 Resultado da análise harmônica da corrente baroclínica a $3 \mathrm{~m}$ para o fundeio F2. . . . . . . . . . . . . . . . . . . . 79

45 Resultado da análise harmônica da corrente baroclínica a $32 \mathrm{~m}$ para o

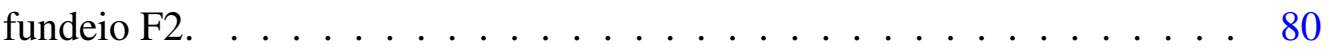

46 Resultado da análise harmônica da corrente baroclínica a $54 \mathrm{~m}$ para o fundeio $\mathrm{F} 2 . \ldots \ldots \ldots \ldots$. . . . . . . . . . . . . . . . . . . .

47 Resultado da análise harmônica da corrente baroclínica a $62 \mathrm{~m}$ para o fundeio F2. . . . . . . . . . . . . . . . . . . 82

48 Resultado da análise harmônica da corrente barotrópica para o fundeio F3. 84

49 Resultado da análise harmônica da corrente baroclínica a $32 \mathrm{~m}$ para o fundeio F1. . . . . . . . . . . . . . . . 85

50 Resultado da análise harmônica da corrente baroclínica a $93 \mathrm{~m}$ para o fundeio F3. . . . . . . . . . . . . . . . 86

51 Elipses de maré, $\mathrm{M}_{2}$, barotrópica para o fundeio F2 . . . . . . . . . . . 89

52 Elipses de maré baroclínica, componente $\mathrm{M}_{2}$, para os fundeios. . . . . . . 90

53 Série temporal das elipses de maré $\mathrm{M}_{2}$ baroclínica, para os fundeios . . . . 91

54 Amplitude dos modos estatístico para a velocidade $u$ no ponto F2. . . . . 96

55 Amplitude dos modos estatístico para a velocidade $v$ no ponto F2. . . . . 97

56 Evolução da fase da componente semi-diurna para as séries de velocidade, temperatura e salinidade. . . . . . . . . . . . . . . . . . . . . . 98

57 Comparação dos modos estatísticos com o observado para sub-série 1. . 100

58 Comparação dos modos estatísticos com o observado para sub-série 2. . . 101

59 Comparação dos modos estatísticos com o observado para sub-série 3. . . 102

60 Comparação dos modos estatísticos com o observado para sub-série 4. . . 103

61 Comparação dos modos estatísticos com o observado para sub-série 5. . . 104

62 Comparação dos modos estatísticos com o observado para sub-série 6. . . 105 
63 Comparação dos modos estatísticos com o observado para sub-série 7. . . 106

64 Comparação dos modos estatísticos com o observado para sub-série 8. . . 107

65 Comparação dos modos estatísticos com o observado para sub-série 9. . . 108

66 Comparação do $2^{\circ}$ modo estatístico com a anomalia de salinidade observada para a sub-série $1 \ldots \ldots \ldots 111 \ldots \ldots \ldots$

67 Comparação do $2^{\circ}$ modo estatístico com a anomalia de salinidade observada para a sub-série $2 \ldots \ldots$. . . . . . . . . . . . . . . 112

68 Comparação do $2^{\circ}$ modo estatístico com a anomalia de salinidade observada para a sub-série $3 \ldots \ldots \ldots 113$

69 Comparação do $2^{\circ}$ modo estatístico com a anomalia de salinidade obser-

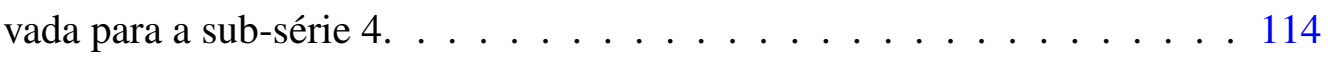

70 Comparação do $2^{\circ}$ modo estatístico com a anomalia de salinidade observada para a sub-série $5 \ldots \ldots \ldots$. . . . . . . . . . . . 115

71 Comparação do $2^{\circ}$ modo estatístico com a anomalia de salinidade observada para a sub-série $6 \ldots \ldots \ldots$. . . . . . . . . . . . 116

72 Comparação do $2^{\circ}$ modo estatístico com a anomalia de salinidade observada para a sub-série $7 \ldots \ldots \ldots 117$

73 Comparação do $2^{\circ}$ modo estatístico com a anomalia de salinidade observada para a sub-série $8 \ldots \ldots \ldots$. . . . . . . . . . . . 118

74 Comparação do $2^{\circ}$ modo estatístico com a anomalia de salinidade obser-

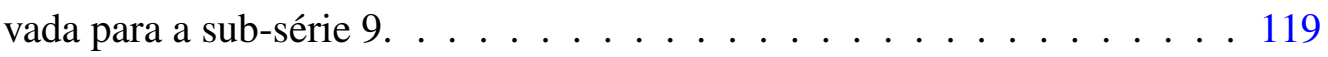

75 Correlação cruzada a $3 \mathrm{~m}$ de profundidade entre as sub-séries 1 . . . . . . 122

76 Correlação cruzada a $3 \mathrm{~m}$ de profundidade entre as sub-séries 2. . . . . . 123

77 Correlação cruzada a $3 \mathrm{~m}$ de profundidade entre as sub-séries $3 . \quad$. . . . . 124

78 Correlação cruzada a $3 \mathrm{~m}$ de profundidade entre as sub-séries 4 . . . . . . 125

79 Correlação cruzada a $3 \mathrm{~m}$ de profundidade entre as sub-séries 5. . . . . . 126

80 Correlação cruzada a $3 \mathrm{~m}$ de profundidade entre as sub-séries 6 . . . . . 127

81 Correlação cruzada a $3 \mathrm{~m}$ de profundidade entre as sub-séries $7 . \quad$. . . . . 128

82 Correlação cruzada a $3 \mathrm{~m}$ de profundidade entre as sub-séries 8 . . . . . 129 
83 Correlação cruzada a $3 \mathrm{~m}$ de profundidade entre as sub-séries $9 . \quad$. . . . . 130

84 Densidade de potência espectral da velocidade quase-perpendicular às isóbatas nas sub-séries. . . . . . . . . . . . . . . . . 133

85 Densidade de potência espectral da velocidade quase-paralela às isóbatas nas sub-séries. . . . . . . . . . . . . . . . . . . . . . . 134

86 Densidade de potência espectral do $1^{\circ}$ modo estatístico da velocidade $u$ nas sub-séries. . . . . . . . . . . . . . . . . 135

87 Densidade de potência espectral do $2^{\circ}$ modo estatístico da velocidade $u$ nas sub-séries. . . . . . . . . . . . . . . . 136

88 Densidade de potência espectral da Temperatura nas sub-séries. . . . . . . 137

89 Densidade de potência espectral da salinidade nas sub-séries. . . . . . . . 138

90 Evolução da Densidade espectral na frequência semi-diurna. . . . . . . . . 139

91 Possível Efeito da subtração da velocidade barotrópica. . . . . . . . . . . . 145 


\section{Lista de Tabelas}

1 Características das Massas de Água na Plataforma Continental Amazônica 14

2 Direção das componentes escalares $u$ e $v$, considerando o Norte como

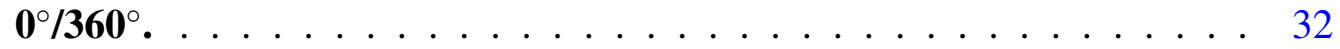

3 Estatística básica para o Fundeio F1. $u$ é a componente da velocidade quase-perpendicular às isóbatas e $v$ é a componente da velocidade quase-paralela às isóbatas. . . . . . . . . . . . . . . . . . . 54

4 Estatística básica para o Fundeio F2. $u$ é a componente da velocidade quase-perpendicular às isóbatas e $v$ é a componente da velocidade quase-paralela às isóbatas. . . . . . . . . . . . . . . . . 58

5 Estatística básica para o Fundeio F3. $u$ é a componente da velocidade quase-perpendicular às isóbatas e $v$ é a componente da velocidade quase-paralela às isóbatas.

6 Parâmetros das elipses das marés baroclínica e barotrópica para o fundeio F1. O semi-eixo maior, em $\mathrm{ms}^{-1}$, corresponde à coluna "Maior"; o semi-eixo menor, em ms $^{-1}$, à coluna "Menor"; a inclinação, em graus, à coluna "Inc"e a fase em relação à Greenwich, em graus, à coluna "fase". As colunas "Erro"correspondem ao erro relativo de cada um dos parâmetros

7 Parâmetros das elipses das as maré baroclínica e barotrópica para o fundeio F2. O semi-eixo maior, em $\mathrm{ms}^{-1}$, corresponde à coluna "Maior"; o semi-eixo menor, em ms ${ }^{-1}$, à coluna "Menor"; a inclinação, em graus, à coluna "Inc"e a fase em relação à Greenwich, em graus, à coluna "fase". As colunas "Erro"correspondem ao erro relativo de cada um dos parâmetros $\ldots \ldots$. . . . . . . . . . . . . . . . . . 83 
8 Parâmetros das elipses das marés baroclínica e barotrópica para o fundeio F3. O semi-eixo maior, em $\mathrm{ms}^{-1}$, corresponde à coluna "Maior"; o semi-eixo menor, em ms ${ }^{-1}$, à coluna "Menor"; a inclinação, em graus, à coluna "Inc"e a fase em relação à Greenwich, em graus, à coluna "fase". As colunas "Erro"correspondem ao erro relativo de cada um dos parâmetros . . . . . . . . . . . . . . . . . . . 87

9 Percentual de variância explicada por cada modo estatístico para a componente quase-perpendicular de velocidade no ponto F2 . . . . . 95

10 Máximos e mínimos de velocidade para a componente quase-perpendicular, u, em ms $\mathbf{m s}^{-1}$, observados a 3 m. . . . . . . . . . . . . . . . . . . . 109 


\section{Agradecimentos}

Agradeço primeiramente minha família, meus pais, irmãos, tios e primos por todo apoio sempre, principalmente durante a confecção desta Dissertação. Sem o apoio e a presença, mesmo que eventualmente, dessas pessoas, não teria sentido nem ter vindo à São Paulo.

Aos amigos da Faculdade de Oceanografia do Estado do Rio de Janeiro, em especial aos que vieram me visitar e aos amigos do Instituto Oceanográfico pelo momentos de descontração e pela amizade sincera. Não vou citar nomes pois certamente vou esquecer de alguém importante. Quem se der o trabalho de ler esta Dissertação, sinta-se abraçado.

Sou grato pela experiência de ter tido como companheiros(as) de república os grandes Dalton Sasaki, Felipe Maneschy, Jéssica Carvalho, Márcio Yamashita, Felipe Freitas e Natalia D’Ávila. Sempre será um prazer.

Agradeço aos companheiros de LHICO, LOS e LADO: Zero, Lucas, Olavo, Franzé, Paulo, Du, Lara e Carine, Sebá, Wandrey, Bia e Gui, Biló, Cascão, Ana, Mestre e outros tantos pelas inúmeras horas, regadas a muito café, dedicadas a trocas de conhecimentos e pela ajuda na confecção desta Dissertação. À vocês, agradeço muito pelos pitacos.

Aos professores do Instituto Oceanográfico, Ilson Silveira, Marcelo Dottori e Paulo Polito pelas dúvidas sanadas e pela amizade. Em especial, agradeço muitíssimo ao Professor Belmiro Mendes de Castro Filho, pela orientação, apoio e paciência durante esses 3 anos. Aprendi muito com seus ensinamentos e correções, essenciais à elaboração desta Dissertação.

À Patricia Baldasso, agradeço por todo apoio, carinho e paciência durante o período crítico de finalização desta Dissertação, que durou quase 6 meses. Obrigado por todo esse tempo. Que continuemos nossa caminhada juntos.

Por fim, agradeço à Fundação de Amparo à Pesquisa do Estado de São Paulo (FAPESP) pelo financiamento deste trabalho de pesquisa (bolsa de mestrado), processo 2011/053007. 
“Don't Worry about a thing 'cause every little thing is gonna be alright."

Bob Marley 


\section{Resumo}

Ondas internas são movimentos ondulatórios que ocorrem no interior da coluna de água, associadas à estratificação de densidade. Ondas internas cuja frequência de oscilação se assemelha à das marés são chamadas marés internas. Estas ocasionam escoamentos intensos que influenciam a dinâmica de sedimentos, os processos de mistura e a produtividade primária. Em um ambiente energético como a Plataforma Continental Amazônica (PCA), localizada na costa norte brasileira, a estratificação varia consideravelmente, tanto espacial quanto temporalmente, de acordo com o balanço entre as diversas forçantes presentes. Na região da PCA alguns autores sugerem a presença de marés internas, entretanto, estudos específicos acerca do tema não figuram na literatura. Dessa forma, desenvolvemos neste trabalho um estudo da maré interna na região da PCA. Como objetivo, procuramos comprovar a ocorrência de marés internas na PCA, caracterizar seu comportamento e verificar sua itermitência. Para tal foram realizadas análises de dados provenientes do programa AMASSedS (A Multidisciplinary Amazon Shelf Sediment Study). Para caracterizar as marés internas, aplicamos dois métodos distintos para obtenção do campo baroclínico. O primeiro foi fundamentado no estabelecimento de uma corrente barotrópica préviamente obtida atráves de simulações numéricas. O segundo método empregado embasou-se na aplicação das funções empíricas ortogonais para a separação em modos estatísticos. Verificamos que as ondas internas na PCA estão ligadas à vazão do Rio Amazonas e são observadas, principalmente, na frequência semi-diurna. Aparentemente, as marés internas semi-diurnas influenciam não somente a hidrodinâmica da PCA como também são responsáveis por parte da variabilidade da salinidade próximo à superfície.

Palavras Chaves: Marés Internas, FOE, Plataforma Continental Amazônica, AMASSedS 


\begin{abstract}
Internal waves are oscillatory motions that occur within the density stratified ocean. The ones with tidal frequency are then called internal tides or baroclinic tides, and are, on several locations around the planet, responsible for strong fluxes that affect several processes, like sediment transport, mixing processes and primary production. In such a strong environment as the Amazon Continental Shelf (ACS), located at the northern brazilian coast, it's stratification changes considerably with time and space, accordingly with the balance between the several forcing variables present. In this region, some authors suggest that internal tides occur, however, none research have been made about it on the ACS. That being said, we propose a study on internal tides on the ACS. As we hypothesize that internal tides occur, we look forward to characterize it's behavior and verify it's intermittency on the ACS. To do so, the data collected during the AMASSedS project (A Multidisciplinary Amazon Shelf Sediment Study) is going to be analyzed. In order to characterize it, two different method were applied to obtain the baroclinic field. The first method was the definition of a modeled-based barotropic current of the ACS obtained on the literature. The second method was the application of Empirical Orthogonal Functions in order to split the field on statistical modes of variability and analyze them separately. Our results indicate that internal tides on the ACS occur preferentially on the semi-diurnal frequency and it's generation is intimately connected to river discharge. Also, the analysis of the salinity anomaly field indicates that internal tides are responsible for part of the variability of the later on the surface on mid-shelf.
\end{abstract}

Keywords: Internal Tides, EOF, Amazon Continental Shelf, AMASSedS. 


\section{Introdução}

Ondas podem ser definidas como um sinal/distúrbio, ou uma certa quantidade de energia, que se propaga em um meio. Neste trabalho trataremos de oscilações específicas cujo meio será a água do mar. Ondas na superfície dos oceanos, que se propagam na interface entre a água e a atmosfera, são um fenômeno familiar à maioria das pessoas. Entretanto este estudo abordará ondas que dificilmente são vistas a olho nu, e que ocorrem no interior da coluna d'água, abaixo da superfície, chamadas de ondas de gravidade internas (OGI).

As OGI são movimentos ondulatórios que ocorrem no interior da coluna de água, associadas à estratificação vertical de densidade. Ao contrário das ondas superficiais, que ocorrem na interface água-ar e ao longo dela se propagam, as ondas internas possuem também propagação vertical. Nas OGI, a força de empuxo responsável pela restauração é cerca de 100 vezes menor do que aquela existente na interface água-ar. Com isto, ondas de gravidade internas têm amplitudes maiores, da ordem de $10^{2} \mathrm{~m}$, do que aquelas observadas nas ondas de gravidade superficiais (Figura 1) (LEBLOND e MYSAK, 1978; PEDLOSKY, 2003; VLASENKO et al., 2005).

As ondas de gravidade internas aparecem na literatura a mais de um século, inicialmente com relatos de mudanças substanciais e oscilações de dezenas de metros em perfis verticais de temperatura (HELLAND-HANSEN e NANSEN, 1909). Há o clássico exemplo das "Dead Waters", águas mortas numa tradução livre, fenômeno observado pelo Prof. Fridtjof Nansen em meados de 1898 e explicado pelo Prof. Vagn Walfrid Ekman. Segundo o último, as águas mortas estão relacionadas à dificuldade de progressão de uma embarcação em certas localidades costeiras com águas estratificadas. A explicação reside no dispêndio de parte energia da embarcação, na geração de ondas internas, pelo hélice, reduzindo a energia disponível para a propulsão da mesma (GILL, 1982). 


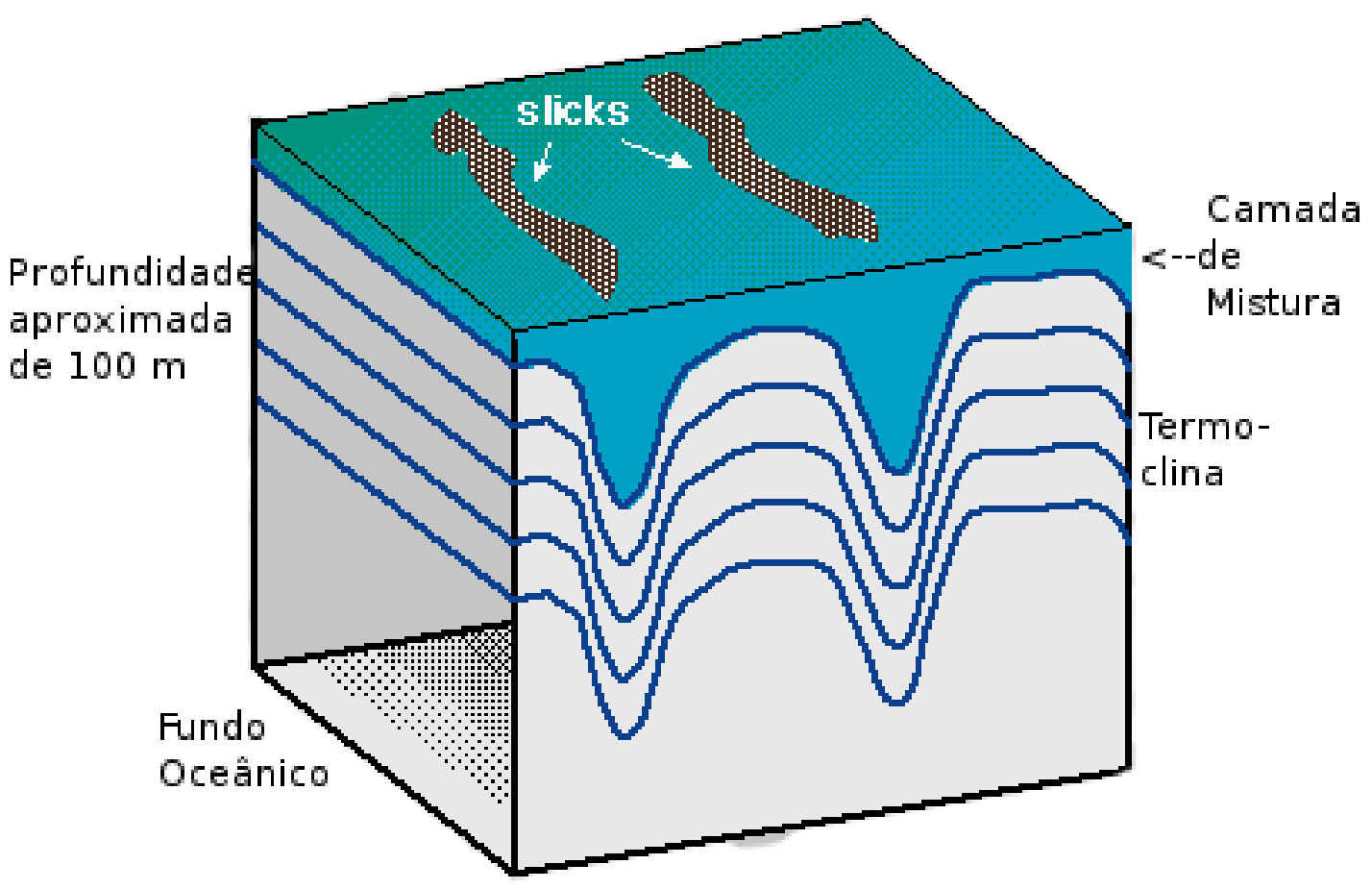

Figura 1: Figura esquemática das características de uma onda interna. Adaptado de Tomczak (2000).

Uma forma de se observar OGI no interior do oceano é coletando informações contínuas de parâmetros com resolução alta tanto vertical quanto temporalmente, ou através de fundeios oceanográficos ou de lançamentos repetidos de aparelhos. Ademais, essas ondas podem deixar sinal na superfície durante a propagação (Figura 1), devido à convergência existente na crista e divergênca no cavado. A convergência ocasiona aumento da rugosidade das águas na superfície do mar, chamada de "Slicks" (Figura 1), que pode ser observada tanto a olho nu quanto através de satélites (SAWYER, 1983).

Outra forma de se observar OGI é usando séries temporais de velocidade, inferindo o campo barotrópico e subtraindo-o da série observada, obtendo assim o campo baroclínico. A partir do campo baroclínico é possível, através de análise harmônica, estimar a importância e a influência das componentes maregráficas baroclínicas. Para obter o campo barotrópico, Gibbs e Middleton (1997), Kurapov et al. (2003), Osborne et al. (2011), entre outros, utilizaram a média em profundidade das observações de velocidade, 
o que pode levar a erros na interpretação dos resultados caso a resolução vertical não seja adequada, como atesta o trabalho de Edwards e Seim (2008).

Além de promoverem acentuado deslocamento vertical das superfícies isopicnais, as OGI provocam cisalhamento vertical das velocidades horizontais associadas ao movimento ondulatório, podendo gerar instabilidade e turbulência. Nesses casos, a mistura resultante afeta a estrutura termohalina, a circulação local, e conduz a fluxos verticais de água e de nutrientes (GARRETT e KUNZE, 2007).

Além da influência na dinâmica dos sedimentos, na disponibilidade de nutrientes e plâncton e consequentemente na produção primária, nos últimos anos, surgiram indicações que marés internas são importantes para mistura dos oceanos profundos e uma componente significante na manutenção da sua estrutura termohalina (KANTHA e TIERNEY, 1997; MUNK, 1997; VLASENKO et al., 2005).

A geração das OGI é explicada por Gerkema e Zimmerman (2008) pela ação de duas forçantes. A primeira são perturbações atmosféricas (ventos), que causam variações na base da camada de mistura e esta, após o cessar ou alteração dessas pertubações, evolui para o equilibrio no ajuste geostrófico. Durante esse processo de ajuste, ondas internas são geradas, tendo frequência mais comum próxima à frequência inercial, sendo chamadas de ondas quase-inerciais (GILL, 1982). A segunda forçante é a maré astronômica, responsável pelas variações determinísticas do nível do mar, devido às forças gravitacionais no sistema Terra-Lua-Sol. As marés, além de provocarem variações do nível do mar, causam correntes de maré com a mesma variabilidade temporal. A interação entre as correntes de maré barotrópicas e irregularidades na batimetria do fundo oceânico cria perturbações verticais na estrutura de densidade da coluna d'água. Tais perturbações podem se propagar tanto em direção à costa quanto ao oceano profundo como OGI com períodos distintos, mas por vezes com frequências iguais às da sua forçante original (ZEILON, 1912; ZEILON, 1914; RATTRAY, 1960; WUNSCH, 1975), sendo, então, chamadas marés internas ou marés baroclínicas.

Marés internas são geradas com maior intensidade e observadas com frequência em regiões com forte gradiente topográfico, como taludes, quebras da plataforma conti- 
nental (HUTHNANCE, 1989) e nas bordas de montanhas submarinas, ilhas e cordilheiras (HOLLOWAY e MERRIFIELD, 1999; RUDNICK et al., 2003). Também, há indícios de geração próximo a cânions submarinos (PETRUNCIO et al., 1998; KUNZE et al., 2002) e deltas subaquáticos (GEYER et al., 1996; NITTROUER e DEMASTER, 1996).

Em várias regiões dos oceanos, marés internas ocasionam escoamentos intensos que influenciam a dinâmica de diversos processos. Noble et al. (1988) sugerem que, no Guyot Horizon, um monte submarino localizado no pacífico, marés internas são um importante processo para a dinâmica local, e as correntes resultantes são responsáveis por ressuspensão e alterações na mobilidade e deposição sedimentar. Sangrà et al. (2001) avaliaram os processos de mistura e soerguimento de isopicnais à camada fótica pela passagem dessas ondas nas ilhas Canárias, onde ondas internas semi-diurnas são responsáveis por aumento na quantidade de clorofila na camada de mistura, tanto por aumentar a disponibilidade de nutrientes quanto por elevar à camada analisada agregados de plâncton. Ondas internas são, ainda, responsáveis por alterações consideráveis da velocidade de propagação acústica, influenciando atividades de detecção de comunicação submarinas (CAZENAVE, 2008; CASAGRANDE et al., 2011).

Uma forma de avaliar o potencial de uma região para a geração de marés internas é através do índice de criticidade $\alpha$ (BAINES, 1982; PEREIRA et al., 2007). Este índice compara, considerando um oceano idealizado, a inclinação das características das ondas internas (ângulo do vetor velocidade de grupo com relação ao plano horizontal) com a inclinação do leito oceânico. A fórmula para obter a inclinação do vetor velocidade de grupo é obtida da relação de dispersão para Ondas de Poincaré Internas num oceano linearmente estratificado (MUNK, 1981; BAINES, 1982; CRAIG, 1987):

$$
c^{2}=\frac{\omega^{2}-f^{2}}{N^{2}-\omega^{2}}
$$

onde $\omega$ é a frequência da componente maregráfica; $f$ é a frequência de Coriolis, e $\mathrm{N}$ é a frequência de Brünt-Väissälä. A inclinação do fundo oceânico $\gamma$ é:

$$
\gamma=\frac{\operatorname{dist}(a, b)}{h b-h a}
$$


onde $\operatorname{dist}(a, b)$ é à distância entre dois pontos genéricos a e b e $h a$ e $h b$ são as profundidades dessas estações.

O índice de criticidade é (BAINES, 1982; PEREIRA et al., 2007):

$$
\alpha=\frac{\gamma}{c}
$$

Regiões em que $\alpha=1$ (inclinação crítica) ou $\alpha>1$ (inclinação supercrítica) são propícias para a geração e propagação de marés internas. Além disso, inclinações críticas sugerem propagação em direção à costa enquanto que inclinações supercríticas sugerem propagação em direção ao largo. Nas áreas em que $\alpha<1$ (inclinação subcrítica) não há, potencialmente, geração de marés internas (BAINES, 1982; CRAIG, 1987).

Na plataforma continental, Rattray (1960) afirma que a geração de marés internas depende do acoplamento entre a maré astronômica e, principalmente, à variações marcantes na profundidade. Podendo, também, ser influenciada pela distribuição local de propriedades oceanográficas.

Na Plataforma Continental Amazônica (PCA) a maré barotrópica é a forçante dominante na dinâmica local. Sugestões da ocorrência de marés internas foram apontadas na região da PCA por Geyer et al. (1996) e Nittrouer e DeMaster (1996), que associaram essas ondas às interações da maré barotrópica com o delta subaquático na presença da pluma do Rio Amazonas. Apesar disso, Linhares (1995) afirma que as correntes de maré atuam preferencialmente no modo barotrópico.

Jackson e Apel (2004) estudaram a geração, propagação e estrutura de ondas internas solitárias, ou sólitons, ao redor do planeta, numa coleção de imagens de satélite no Atlas Global de Ondas Internas Solitárias. Neste trabalho, a presença desse tipo de onda na região da PCA é observada (Figura 2). Os sólitons são ondas de gravidade internas não lineares desenvolvidas a partir da geração de marés internas em períodos de maré astronômica vazante que, devido à processos não lineares, sofrem um aumento na esbeltez (razão entre a amplitude e o comprimento de onda). Nestas regiões, há a liberação de ondas que podem ser observadas como uma única crista ou como pacotes, sempre com frequências superiores às maregráficas. Estas ondas não serão abordadas no decorrer 
desta Dissertação; no entanto, a presença confirmada deste tipo de ondas na região para o dia 07 de outubro de 1994, período de vazão decrescente do Rio Amazonas (Figura 3), reforça os indícios de que marés internas na PCA são possíveis.

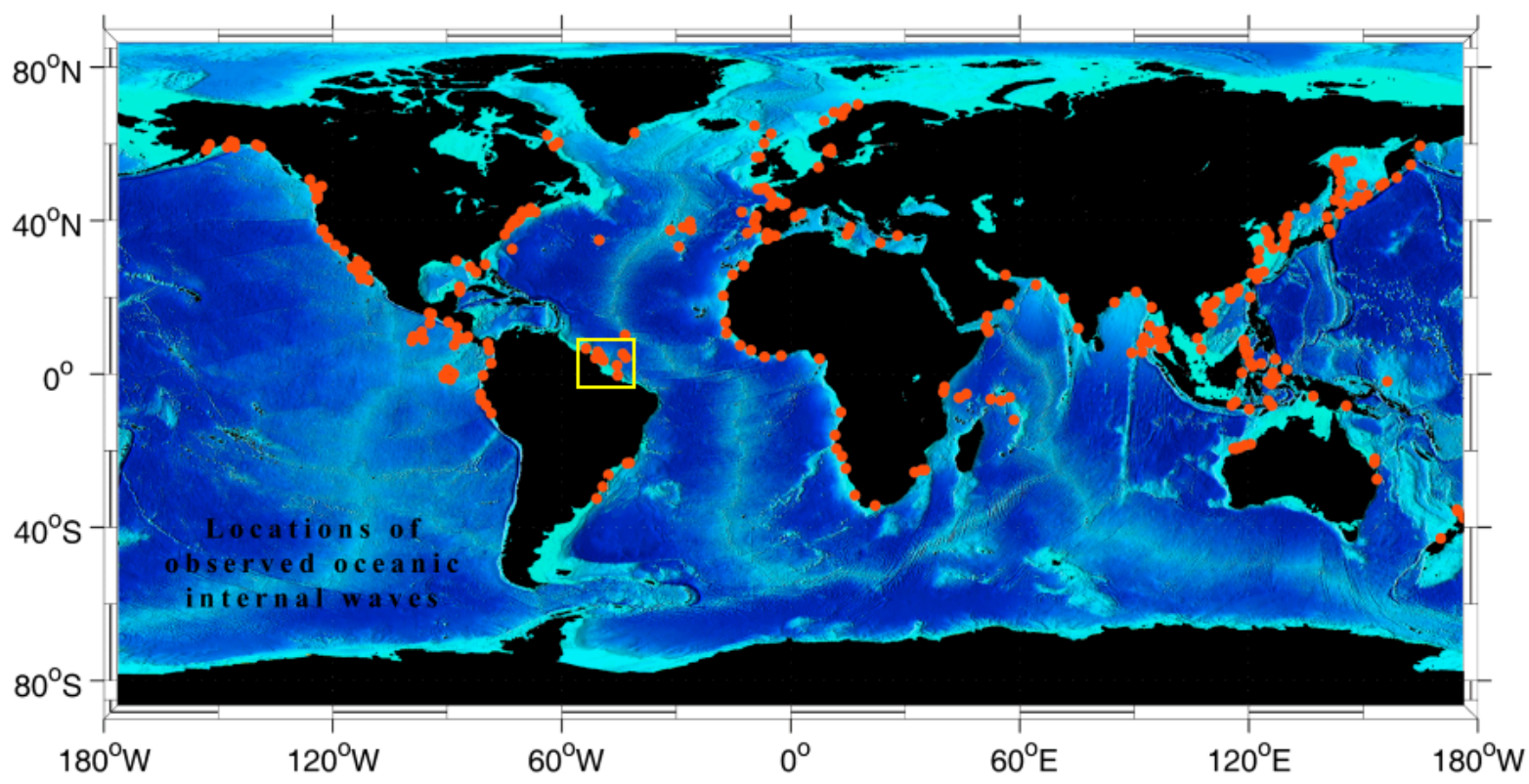

Figura 2: Locais de ocorrência de ondas internas solitárias (sólitons) nos oceanos. A grande maioria dos pontos foi observada a partir de imagens de satélite. A região da Plataforma Continental Amazônica está assinalada pelo quadrado amarelo. Verifica-se a presença de sólitons como um indício de marés internas. Adaptado de Jackson e Apel (2004). 


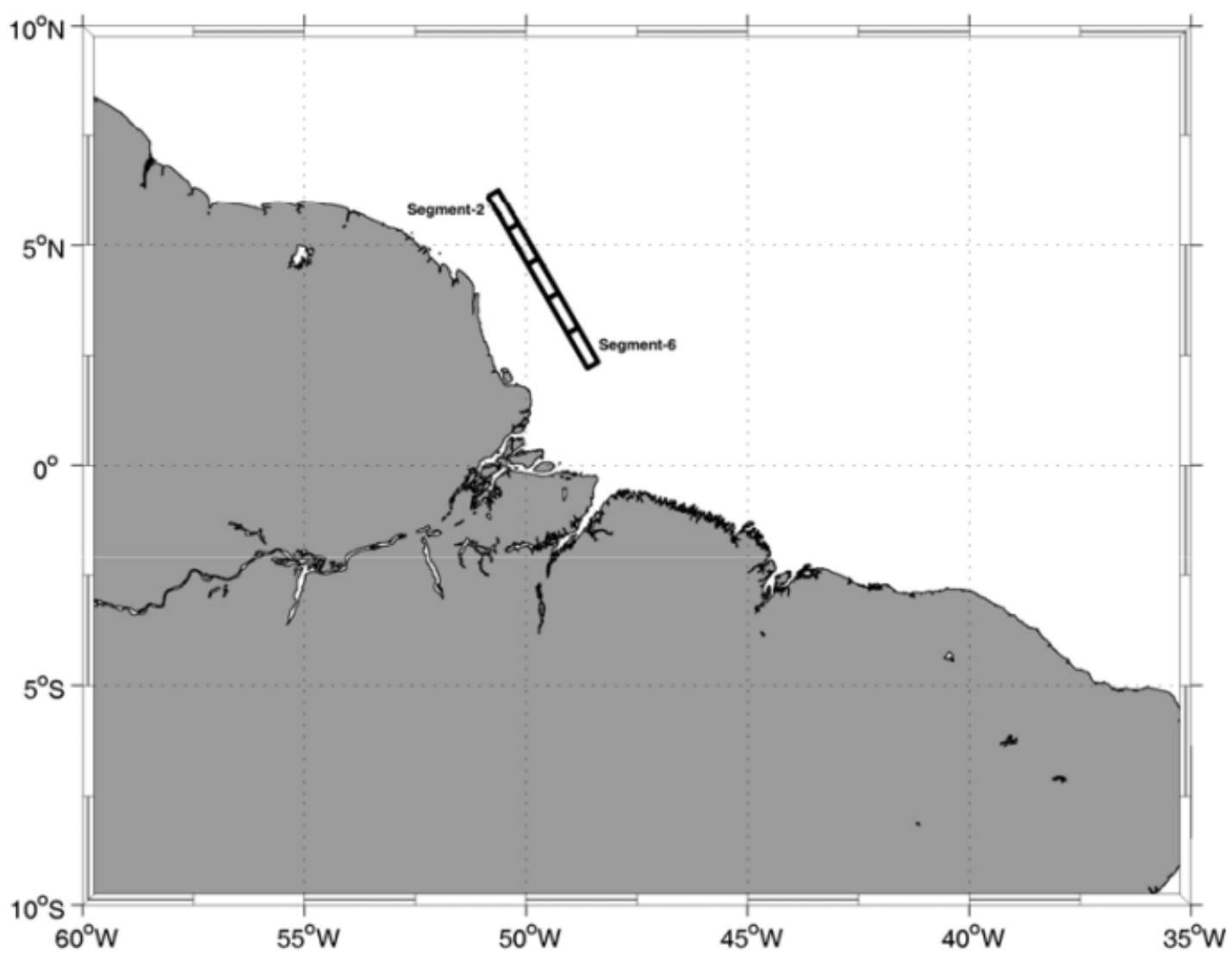

Figura 3: Local de ocorrência de Sólitons na região da Plataforma Continental Amazônica com propagação em direção ao largo. Retirado de Jackson e Apel (2004).

Não há, na literatura científica, trabalhos sobre marés internas na PCA. Esta Dissertação tem como motivação o entendimento da real importância baroclínica de uma região tão dinamicamente ativa como a PCA. 


\section{2 Área de Estudo}

A PCA, localizada na região norte do litoral brasileiro (Figura 4), é delimitada na costa pelo Cabo Orange $\left(\sim 4^{\circ} 30^{\prime} \mathrm{N}\right)$, no estado do Amapá, e a Baía de Turiaçu $\left(\sim 2^{\circ}\right.$ S) no Maranhão (CASTRO e MIRANDA, 1998). Nesta longa plataforma continental aproximadamente $1000 \mathrm{~km}$ entre os limites supracitados - a largura varia entre $125 \mathrm{~km}$ nas proximidades do Cabo Orange e $165 \mathrm{~km}$ na baía de Turiaçu até a parte mais larga nas proximidades da foz do Rio Amazonas (RA), onde alcança $\sim 320 \mathrm{~km}$. Além de larga, a PCA possui baixa inclinação, como pode-se notar na Figura 4, onde as isóbatas de 20 $\mathrm{m}$ e $50 \mathrm{~m}$ se encontram distantes centenas de quilômetros da costa em alguns pontos. A quebra da plataforma continental se encontra bem próxima da isóbata de $100 \mathrm{~m}$. 


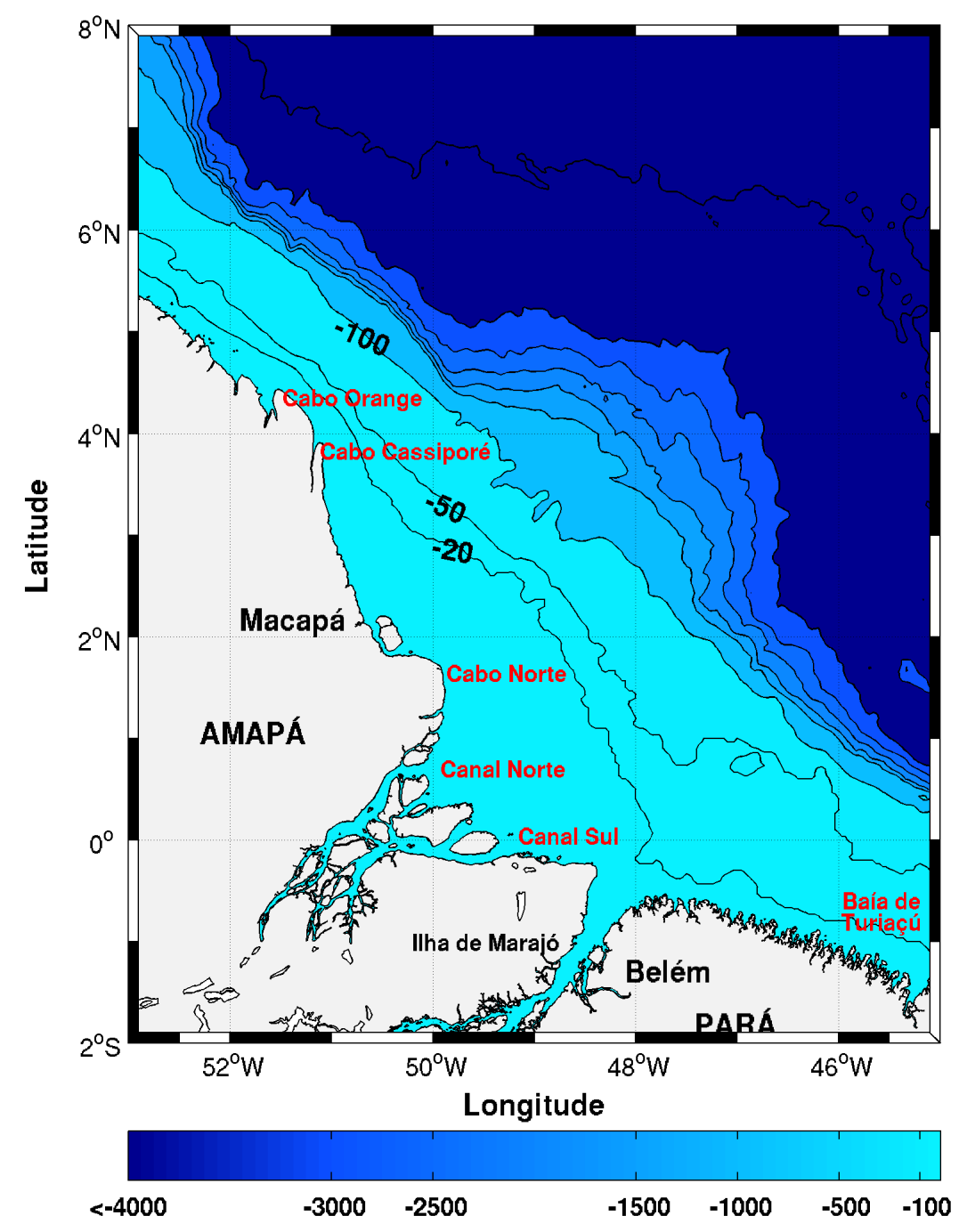

Figura 4: Localização da área de estudo e batimetria da plataforma continental amazônica e adjacências. A isóbata de $100 \mathrm{~m}$ corresponde à quebra da plataforma continental. A escala de cores indica a profundidade, em metros.

Podemos classificar a PCA dinamicamente a partir de Loder et al. (1998) como uma plataforma do tipo A (Figura 5). É uma plataforma larga, com corrente de contorno próximo à quebra de plataforma, a Corrente Norte do Brasil (CNB). A PCA constitui um ambiente energético, onde a circulação estabelece-se como resposta a diversas forçantes. 
Segundo Geyer et al. (1996) e Castro e Miranda (1998), a PCA é influenciada pela enorme vazão do Rio Amazonas (RA) e, também, pela grande carga de sedimentos associada a esse fluxo; pela presença da Corrente Norte do Brasil (CNB) nas proximidades da quebra da plataforma; pela ação dos ventos alísios persistentes e pela amplificação das marés barotrópicas.

\section{Plataformas Continentais de Borda Oeste \\ a) Plataforma larga \\ CCO na quebra \\ de plataforma \\ c) Plataforma estreita

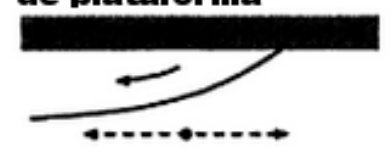 \\ CCO na costa
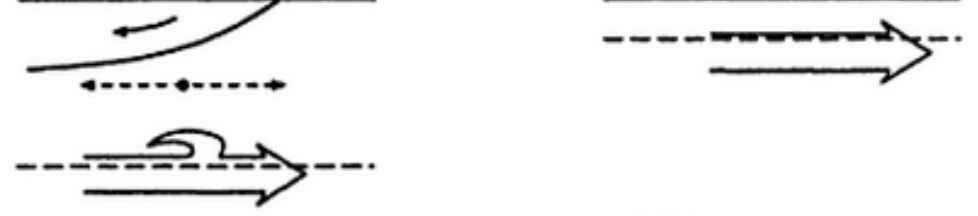 \\ LEGENDA:}

b) Plataforma larga
cco longe da quebra
de plataforma
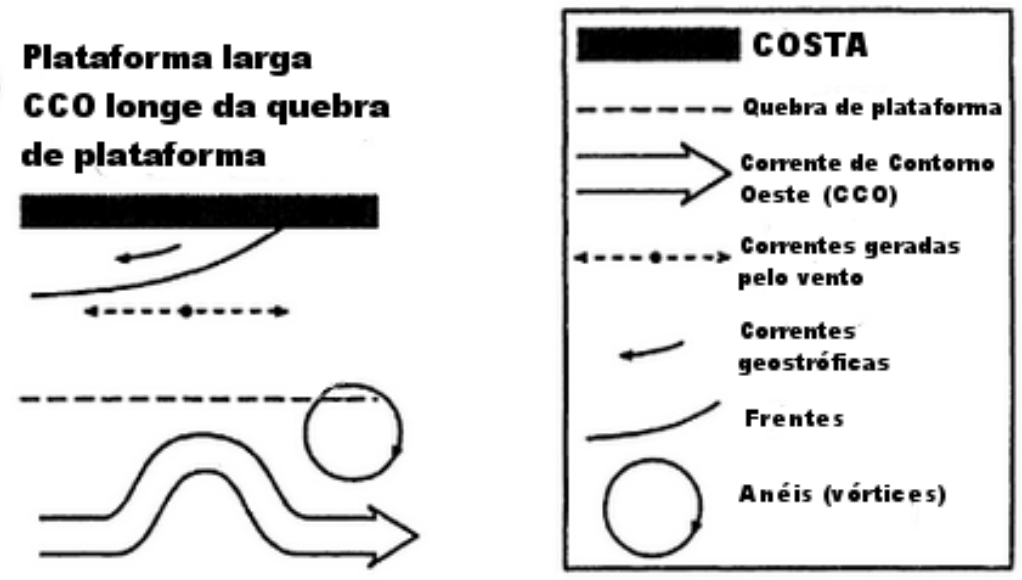

Figura 5: Classificação de plataformas continentais de borda oeste. Adaptado de Loder et al. (1998).

O RA figura entre os maiores rios do mundo, tanto em comprimento quanto em vazão; esta última chega a 0,2 Sv (1 Sv $\left.=10^{6} \mathrm{~m}^{3} \mathrm{~s}^{-1}\right)($ OLTMAN, 1968; FFIELD, 2005; MIRANDA et al., 2012), representando cerca de $16 \%$ de toda água doce que deságua nos oceanos anualmente (MULLER-KARGER et al., 1988), sendo assim a maior fonte pontual de água doce do planeta. As vazões máxima (maio-julho) e mínima (outubro- novem- 
bro) são estimadas em $1,2 \times 10^{5} \mathrm{~m}^{3} \mathrm{~s}^{-1}$ e $2,0 \times 10^{5} \mathrm{~m}^{3} \mathrm{~s}^{-1}$, respectivamente (RICHEY et al., 1986). Entretanto, essa vazão tem sido estimada nas proximidades da cidade de Obidos, localizada a $\sim 800 \mathrm{~km}$ rio acima, no limite da influência da maré no corpo d'água do rio. Essa vazão não engloba, por exemplo, rios tributários como o Rio Negro e o Rio Solimões. A real vazão do rio, em sua foz, nunca foi medida.

A carga de sedimentos associada à descarga do RA é de aproximadamente $1,3 \times$ $10^{9}$ ton.ano $^{-1}$ (MEADE et al., 1985; MEADE, 1994). Esses sedimentos formam grandes concentrações próximo ao fundo, denominadas lama fluida (GEYER et al., 1996), diminuindo o atrito com o fundo e, assim, influenciando as características hidrodinâmicas locais. Essa é uma das razões para que as correntes sejam mais intensas e as amplitudes de maré sejam um pouco maiores nas proximidades da costa (BEARDSLEY et al., 1995; GABIOUX, 2002; FONTES et al., 2008).

O RA deságua no Atlântico através de dois canais: o canal Norte e o canal Sul. Estes canais desembocam em uma plataforma interna larga e rasa, com profundidades inferiores a $15 \mathrm{~m}$ e que se estende até $\sim 200 \mathrm{~km}$ de distância da desembocadura do rio. Ao norte desta, o banco do Cabo Norte (Cabo Norte Shoal) impede que o fluxo do RA flua diretamente junto à costa, defletindo-o para o largo (GEYER et al., 1996).

Segundo Miranda et al. (2012), a melhor definição de estuário é:

\footnotetext{
Um corpo costeiro semi-fechado com ligação livre com o oceano aberto, estendendo-se rio acima até o limite da influência da maré, sendo que em seu interior a água do mar é mensuravelmente diluída pela água doce oriunda da drenagem continental.
}

Entretanto, como consequência da enorme vazão do RA as águas marinhas não penetram nos canais norte e sul. Desta forma, o estuário do RA encontra-se na região interna da PCA (GEYER e KINEKE, 1995), sendo delimitado pela costa e, aproximadamente, pela isobatimétrica de $20 \mathrm{~m}$, sem limites laterais definidos, não se encaixando, portanto, nas definições clássicas de estuário. Ainda assim, sua estrutura perpendicular à costa e suas variações espaço-temporais são similares àquelas observadas no interior de estuários de cunha salina influenciados pela maré (FONTES, 2000). 
A extensão horizontal no oceano da influência da descarga do rio, denominada pluma estuarina (MIRANDA et al., 2012), pode ser traçada na PCA por águas de baixa salinidade $(<34$ unidades práticas de salinidade $(\mathrm{PSU}))$ e se estende por centenas de quilômetros, variando em tamanho sazonalmente, tanto vertical quanto horizontalmente, podendo chegar a $1500 \mathrm{~km}$ de extensão (LENTZ, 1995). Identificada por milhares de quilômetros quadrados no oceano Atlântico Norte, a descaraga do RA forma a maior pluma estuarina identificável no oceano (MIRANDA et al., 2012). Geyer et al. (1996) define-a, em geral, com espessura entre 5 e $10 \mathrm{~m}$ e salinidade entre 20 e 30 PSU. Segundo Nittrouer, C. A. ${ }^{1}$ e Figueiredo, A. G. ${ }^{2}$ (Contato pessoal, 2013) na foz do RA, por conta da imensa força da maré, as águas do rio fluem no sentido contrário em momentos de maré enchente de sizígia. Entretanto, apesar do fluxo rio acima, não há intrusão de águas salinas. Estas não ultrapassam os limites da plataforma interna.

Por ser uma plataforma larga, as marés na PCA são co-oscilantes, em sintonia com o oceano profundo, apresentando propagação quase-perpendicular à costa. Entretanto, a maré barotrópica, principalmente as componentes semi-diurnas, apresentam grande amplificação na PCA por consequência do fenômeno de quase-ressonância, que ocorre em plataformas co-oscilantes de largura próxima a 1/4 do comprimento da onda de maré, causando uma diferença de fase muito pequena entre a quebra de plataforma e a costa. Esse fato é explicado por Beardsley et al. (1995) em razão da presença de uma onda de maré estacionária. A maré na PCA foi descrita como semi-diurna, sendo as componentes $\mathrm{M}_{2}, \mathrm{~S}_{2}$ e $\mathrm{N}_{2}$ as mais importantes, nesta ordem (CASTRO et al., 1991; BEARDSLEY et al., 1995). Os autores descrevem a maré $\mathrm{M}_{2}$ como uma onda quaseressonante na região do Cabo Norte e Cabo Cassiporé, apresentando grandes amplitudes, com variações de até $3 \mathrm{~m}$. As correntes de maré geradas são caracterizadas como fluxos intensos que podem chegar a $2,0 \mathrm{~ms}^{-1}$, preferencialmente polarizadas na direção perpendicular à costa.

\footnotetext{
${ }^{1}$ Professor Ph.D. na University of Washington. Mais detalhes em: http://www.ess.washington.edu

${ }^{2}$ Professor Titular no Departamento de Geologia da Universidade Federal Fluminense. Mais detalhes em: http://www.geologiaegeofisica.uff.br
} 
As massas de água na PCA, descritas de acordo com as análises de Linhares (1995) de diagramas T-S a partir dos cruzeiros do AMASSedS, são 3: Água do Rio (AR), caracterizada por níveis nulos a muito baixos de salinidade e temperatura em torno de $28^{\circ}$ C; Água Oceânica Sub-Superficial (AOSS), caracterizada por alta salinidade (> 36 PSU) e temperatura também em torno de $28^{\circ} \mathrm{C}$ e; Água Central do Atlântico Sul (ACAS), caracterizada por baixas temperaturas, entre 6 e $18^{\circ} \mathrm{C}$, e salinidade entre 34 e 36 PSU. O trabalho de Linhares (1995) considerou apenas as estações com profundidades superiores a 30 m. O trabalho de Curtin (1986) define outras duas massas d'água na região, ambas em profundidades inferiores a $30 \mathrm{~m}$, que são a Água Superficial de Alta Temperatura, localizada entre as isóbatas de 10 e 15 m, caracterizada por alta temperatura, entre 29,1 e $30,3^{\circ} \mathrm{C}$ e salinidade bem variável, entre 9 e 34 PSU, e localizada acima da isóbata de 30 m, a Água da Camada de Contorno de Fundo (ACCF), com temperaturas entre 26 a $29^{\circ}$ C e salinidade superior a 35 PSU. O trabalho de Linhares (1995) mostra a concentração das três massas d'água (AR, AOSS e ACAS), em diferentes profundidades, da superfície ao fundo e que num período de maior vazão a influência da AR chega à quebra da PCA, enquanto que em outros períodos se limita às proximidades da costa. Este autor ressalta ainda, a importância do vento na contenção do avanço da pluma estuarina em direção ao largo, mantendo-a junto à costa em períodos de ventos mais intensos. Pode-se identificar, em trabalhos mais recentes (CASTRO e MIRANDA, 1998), a AR também como Água Costeira e a AOSS como Água Tropical transportada pela CNB. A tabela 1 mostra as características das massas d'água definidas por Curtin (1986). 
Tabela 1: Características das Massas de Água na Plataforma Continental Amazônica

\begin{tabular}{|c|c|c|c|c|}
\hline \multirow[b]{2}{*}{ Massas D’Água } & \multirow[b]{2}{*}{$\begin{array}{c}\text { Temperatura } \\
\left({ }^{\circ} \mathbf{C}\right)\end{array}$} & \multirow[b]{2}{*}{ Salinidade } & \multicolumn{2}{|c|}{ Localização } \\
\hline & & & $\begin{array}{c}\text { Isóbatas } \\
\text { (m) }\end{array}$ & $\begin{array}{c}\text { Vertical } \\
(\mathbf{m})\end{array}$ \\
\hline Água do Rio (AR) & $27,5-29,5$ & 0 & Foz do Rio & $0-12$ \\
\hline $\begin{array}{l}\text { Água Superficial de } \\
\text { Alta Temperatura } \\
\text { (ASAT) }\end{array}$ & $29,1-30,3$ & $9-34$ & $10-15$ & $0-10$ \\
\hline $\begin{array}{l}\text { Água Oceânica } \\
\text { Sub-superficial } \\
\text { (AOSS) }\end{array}$ & $24-28$ & $36,3-36,8$ & $>30$ & $5-80$ \\
\hline $\begin{array}{l}\text { Água da Camada de } \\
\text { Contorno de Fundo } \\
\text { (ACCF) }\end{array}$ & $26-29,1$ & $>34$ & $<30$ & $0-30$ \\
\hline
\end{tabular}

Os ventos alísios de Nordeste (NE) e de Sudeste (SE), dominantes na região equatorial e que convergem na Zona de Convergência Intertropical (ZCIT), são uma importante forçante para os movimentos na PCA. A ZCIT migra latitudinalmente durante o ano, posicionando-se mais ao norte em agosto-setembro e mais próxima do Equador em março-abril. Os ventos variam em magnitude e orientação de acordo com a migração sazonal da ZCIT, sendo mais intensos entre janeiro e abril, com orientação preponderante de nordeste, e mais fracos entre julho e outubro, quando sopram preferencialmente para oeste/noroeste (CASTRO e MIRANDA, 1998).

Correntes na PCA foram descritas por Linhares (1995) e por Geyer et al. (1996). Segundo esses autores, as correntes superficiais apontam preferencialmente para noroeste (NO), forçadas pela tensão de cisalhamento do vento paralelo à costa e apresentam variabilidade subdiurna principalmente. As correntes de maré têm, em geral, direção perpendicular à costa.

A influência da circulação oceânica de larga escala na PCA é devida à CNB. Segundo Johns et al. (1998), a mesma possui transporte máximo de $36 \mathrm{~Sv}$ na latitude $4^{\circ}$ 
$\mathrm{N}$, em julho-agosto, e transporte mínimo de $13 \mathrm{~Sv}$ em abril-maio. Ainda segundo esses autores, a CNB varia de um fluxo estreito e raso na primavera a um fluxo largo e profundo no outono.

Dentre os trabalhos consultados para elaborar esta Dissertação, os resultantes do projeto AMASSedS (A Multidisciplinary Amazon Shelf Sediment Study, Estudo Multidisciplinar dos Sedimentos da Plataforma Continental Amazônica, numa tradução livre) ainda são as principais referências no que tange à hidrodinâmica da PCA. Este projeto foi uma cooperação científica que envolveu pesquisadores dos EUA e do Brasil com o intuito de estudar os processos sedimentares da plataforma adjacente à desembocadura do RA, tendo sido realizado entre 1989 e 1993. A participação brasileira no que tange à Oceanografia Física foi financiada pela FAPESP, através do projeto intitulado Circulação Costeira na Região Amazônica (CICRAM), coordenado pelo Prof. Dr. Belmiro Mendes de Castro Filho.

Fontes (2000) estudou a influência das forçantes supracitadas na dinâmica da pluma de água doce do RA, utilizando um modelo hidrodinâmico oceânico-costeiro, tridimensional e baroclínico, o ECOM-Si (Estuarine and Coastal Ocean Model - Semiimplicit) (BLUMBERG e MELLOR, 1987). Os resultados de Fontes (2000) e Fontes et al. (2008) mostram a importância dos sedimentos na dinâmica da PCA, tanto do tamanho do grão quanto de sua distribuição, alterando o atrito de fundo significativamente, ressaltando a importância dos bancos de lama fluida. Mostram ainda a relevância da maré na determinação da posição da frente de pluma e o papel da presença do vento para a deriva para NO da pluma estuarina. 


\section{Hipótese e Objetivos}

O estudo das marés internas da PCA é importante devido às indicações da presença desse fenômeno na região e à escassez de publicações acerca do tema. Dessa forma, desenvolvemos um estudo que contemplou a investigação dessas ondas na PCA.

Este trabalho tem como hipótese que a geração de marés internas ou baroclínicas na PCA é um processo intermitente, estando relacionada às condições de vazão do Rio Amazonas e de intrusões de águas oceânicas em direção à costa. Para verificar essa hipótese, estabelecemos como objetivo geral a comprovação de que marés internas ocorrem na PCA, conforme sugerido por Beardsley et al. (1995) e Geyer et al. (1996). Os objetivos específicos são:

1. Mapear regiões propícias para geração de marés internas na PCA;

2. Caracterizar o comportamento destas ondas internas na região, identificando as frequências mais importantes e direções preferenciais de propagação, e

3. Verificar a intermitência de tais ondas, bem como os processos responsáveis por tal comportamento. 


\section{Conjunto de Dados}

Este estudo foi conduzido através da análise de parte do conjunto de dados hidrográficos e correntográficos coletados no âmbito do projeto AMASSedS. Este projeto teve como uma de suas 5 diretrizes estudar a oceanografia física da PCA, de forma a: caracterizar a variabilidade temporal e espacial da pluma do Rio Amazonas; determinar os processos que influenciam a dinâmica da pluma e investigar os processos físicos que influenciam a dinâmica sedimentar local (ALESSI et al., 1992). Para tal, coletas com CTD (Conductivity; Temperature; Depth - respectivamente, Condutividade, Temperatura e Pressão) foram realizadas durante 4 cruzeiros oceanográficos. Ademais, foram realizados 3 fundeios de linhas de correntógrafos, simultâneos, situados nas regiões interna, média e externa da PCA. Adicionalmente, realizaram-se lançamentos de derivadores, análise de imagens de satélite e coletas de velocidade de correntes com perfiladores acústicos. Entretanto, neste trabalho utilizaremos somente os dados hidrográficos (Temperatura e Salinidade) coletados nos cruzeiros e os dados coletados nos fundeios.

Os cruzeiros visaram uma caracterização das condições das águas da plataforma durante 4 momentos referentes à vazão do Rio Amazonas. Situação de vazão crescente, máxima, decrescente e mínima, nos períodos de 02-03/1990, 06/1990, 08/1989 e 11/1991, respectivamente (Figuras 6 a 10). Nomearemos os cruzeiros da seguinte forma:

- Cruzeiro I8909 - 86 estações - agosto-setembro de 1989, vazão decrescente (Figura 6).

- Cruzeiro I9002 - 234 estações - fevereiro-março de 1990, vazão crescente (Figura 7).

- Cruzeiro I9004 - 256 estações - junho de 1990 - Vazão Máxima (Figura 8).

- Cruzeiros I9113L3 e I9113L4 - 55 e 121 estações, respectivamente - novembro de 1991, vazão mínima (Figuras 9 e 10). 


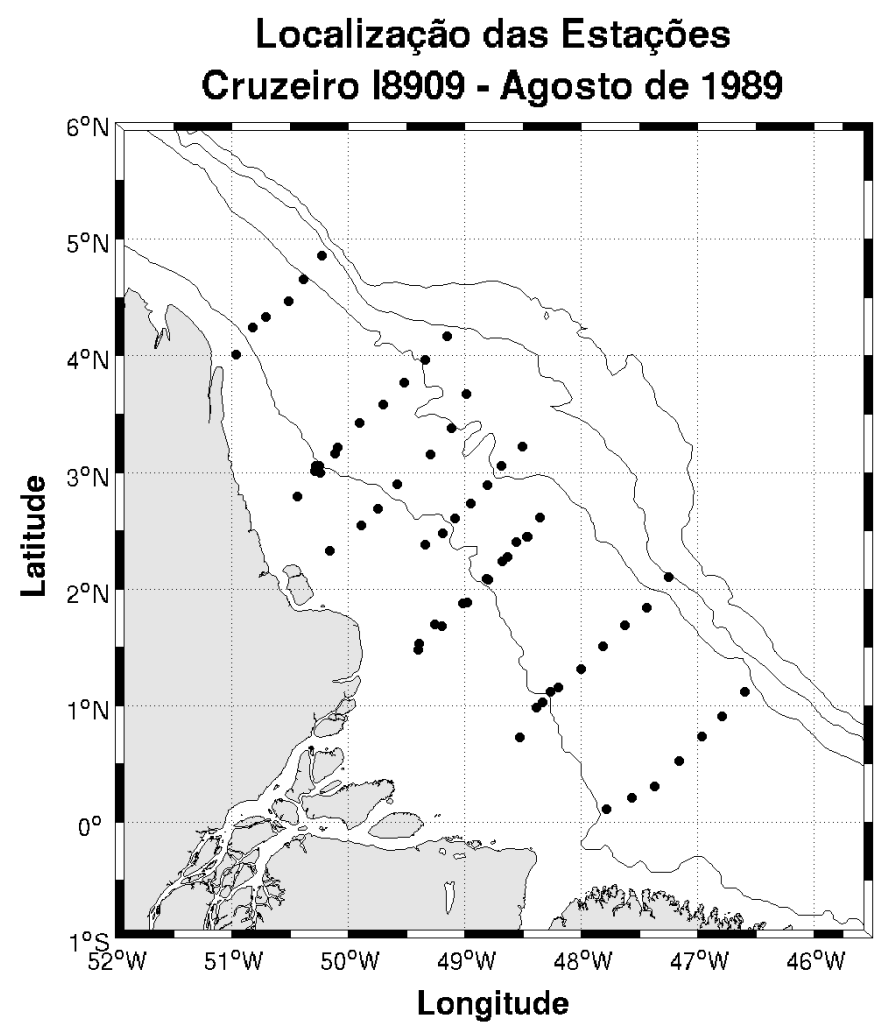

Figura 6: Localização das estações do cruzeiro hidrográfico I8909 realizado em agosto de 1989 durante o projeto AMASSedS. As linhas isobatimétricas representam as profundidades de $20 \mathrm{~m}$, $100 \mathrm{~m}, 1000 \mathrm{~m}$ e $2000 \mathrm{~m}$. 


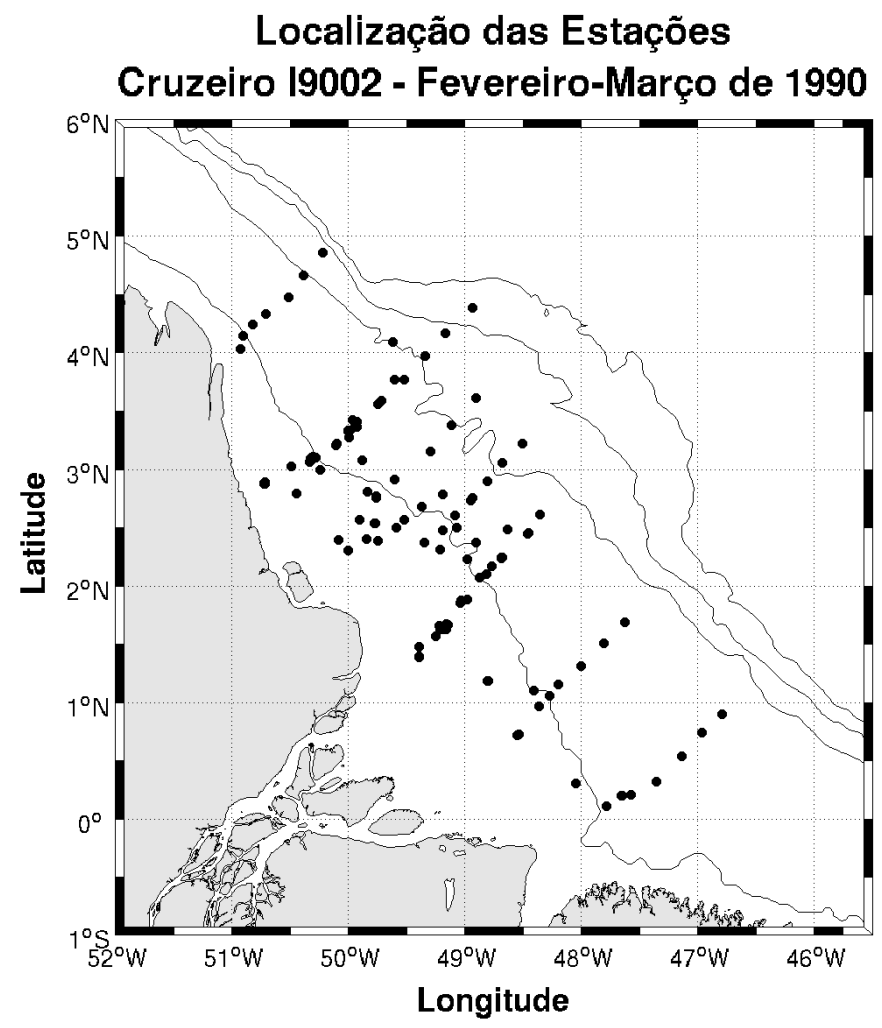

Figura 7: Localização das estações do cruzeiro hidrográfico 19002 realizado em fevereiro - março de 1990 durante o projeto AMASSedS. As linhas isobatimétricas representam as profundidades de $20 \mathrm{~m}, 100 \mathrm{~m}, 1000 \mathrm{~m}$ e $2000 \mathrm{~m}$. 


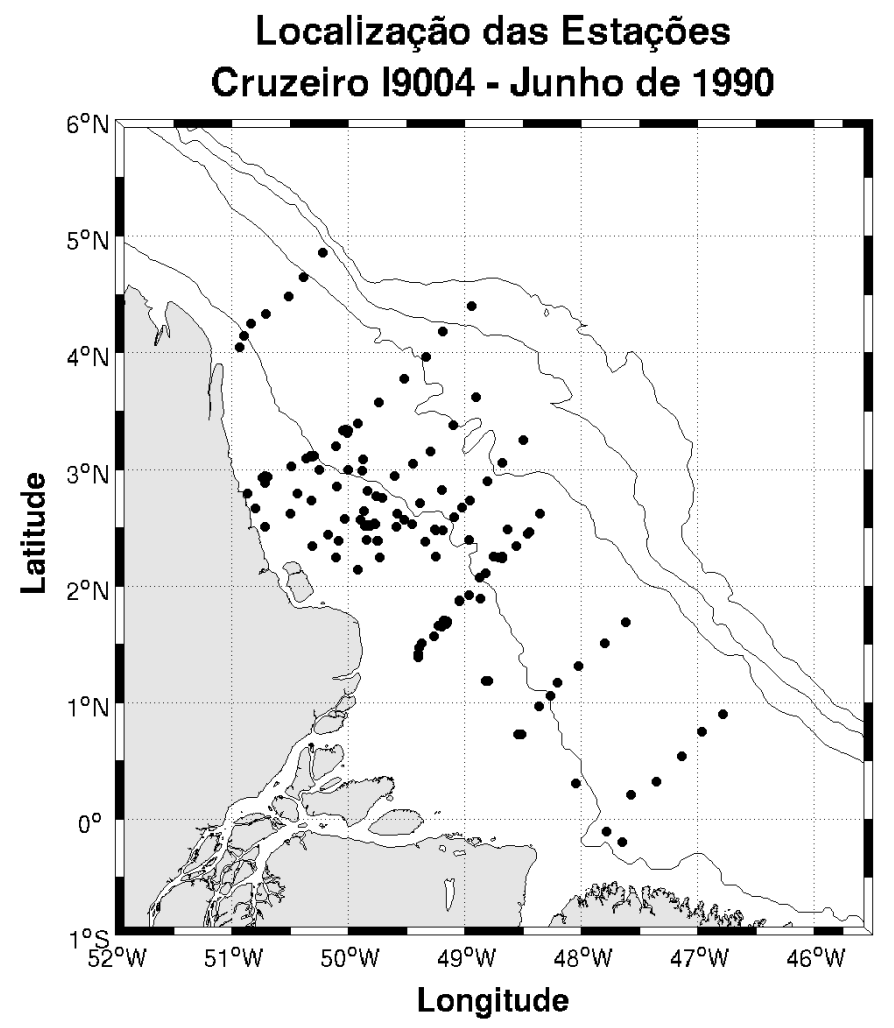

Figura 8: Localização das estações do cruzeiro hidrográfico I9004 realizado em junho de 1990 durante o projeto AMASSedS. As linhas isobatimétricas representam as profundidades de $20 \mathrm{~m}$, $100 \mathrm{~m}, 1000 \mathrm{~m}$ e $2000 \mathrm{~m}$. 


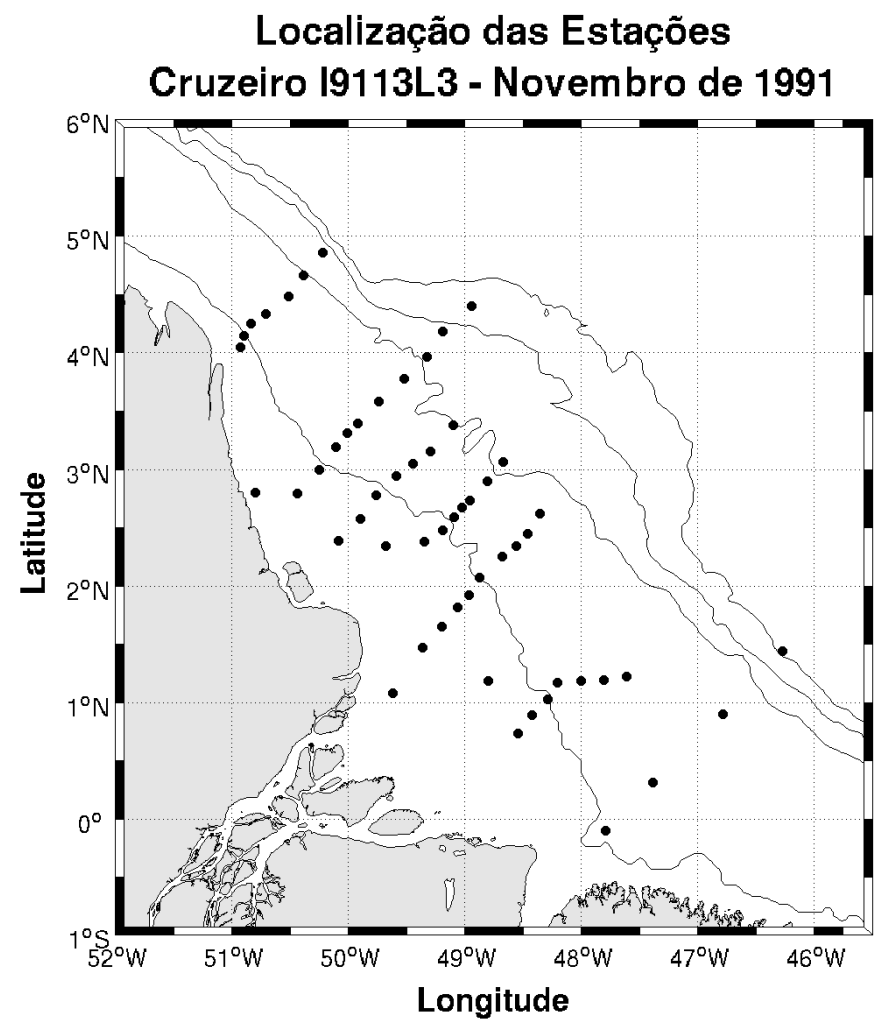

Figura 9: Localização das estações do cruzeiro hidrográfico I9113L3 realizado em novembro de 1991 durante o projeto AMASSedS. As linhas isobatimétricas representam as profundidades de $20 \mathrm{~m}, 100 \mathrm{~m}, 1000 \mathrm{~m}$ e $2000 \mathrm{~m}$. 


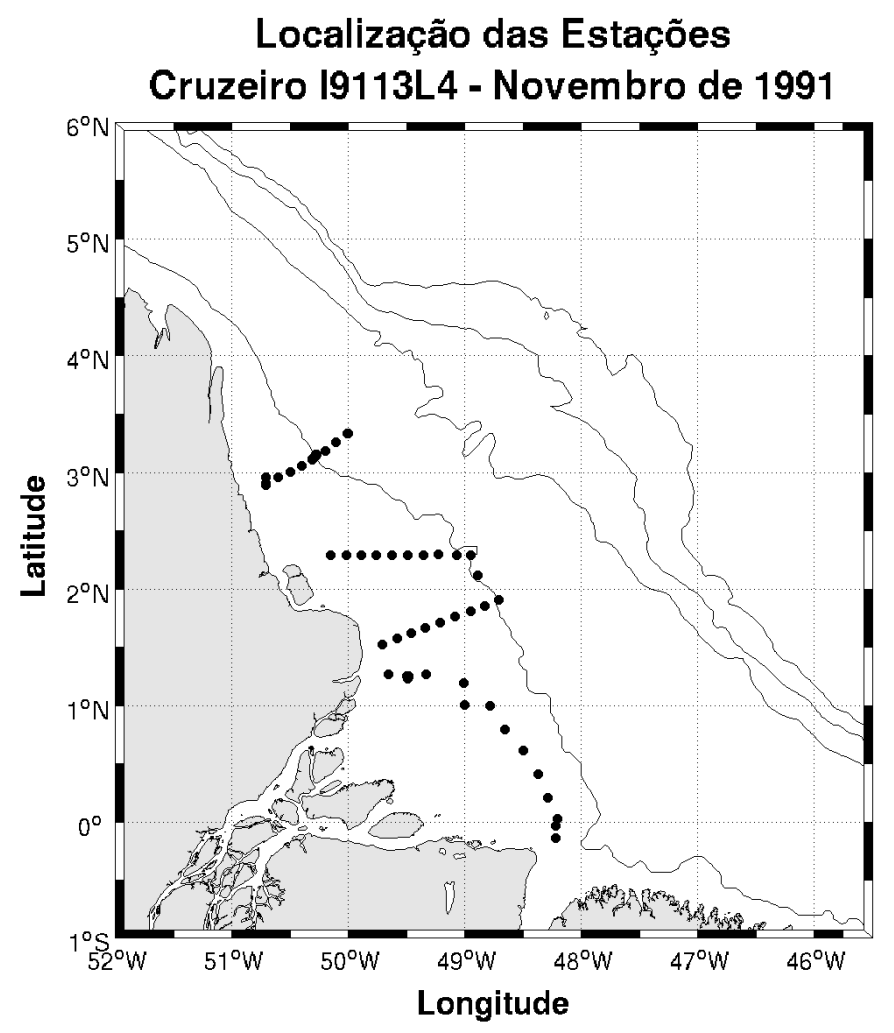

Figura 10: Localização das estações do cruzeiro hidrográfico I9113L4 realizado em novembro de 1991 durante o projeto AMASSedS. As linhas isobatimétricas representam as profundidades de $20 \mathrm{~m}, 100 \mathrm{~m}, 1000 \mathrm{~m}$ e $2000 \mathrm{~m}$.

A radial de fundeios teve como objetivo caracterizar a variabilidade temporal de parâmetros físicos na região da PCA e relacionar essa variabilidade com as forçantes físicas atuantes, como a CNB, a descarga do RA, os ventos alísios e a maré barotrópica. Também foi motivada pela busca de um melhor entendimento dos processos sedimentares e por tal razão foram posicionados na plataforma interna e média, região de maior taxa de acúmulo de sedimentos, e nas proximidades da quebra da plataforma. Os fundeios, chamados daqui em diante de F1, F2 e F3, foram posicionados a cerca de $300 \mathrm{~km}$ a noroeste da foz, em uma radial quase-perpendicular à topografia da PCA, nas isóbatas de $18 \mathrm{~m}$ (F1), $65 \mathrm{~m}$ (F2) e $103 \mathrm{~m}(\mathrm{~F} 3)$, nas coordenadas geográficas $3,075^{\circ} \mathrm{N}$ e 50,313 $\mathrm{W}$ (F1); 3,385 $\mathrm{N}$ e $49,940^{\circ} \mathrm{W}(\mathrm{F} 2)$; e $4,072^{\circ} \mathrm{N}$ e $49,623^{\circ} \mathrm{W}(\mathrm{F} 3)$ (Figura 11). As linhas de fundeio permaneceram por aproximadamente 4 meses - fevereiro a junho de 1990 - 
obtendo dados de corrente, temperatura atmosférica e da água, condutividade, vento e ondas de superfície (ALESSI et al., 1992).

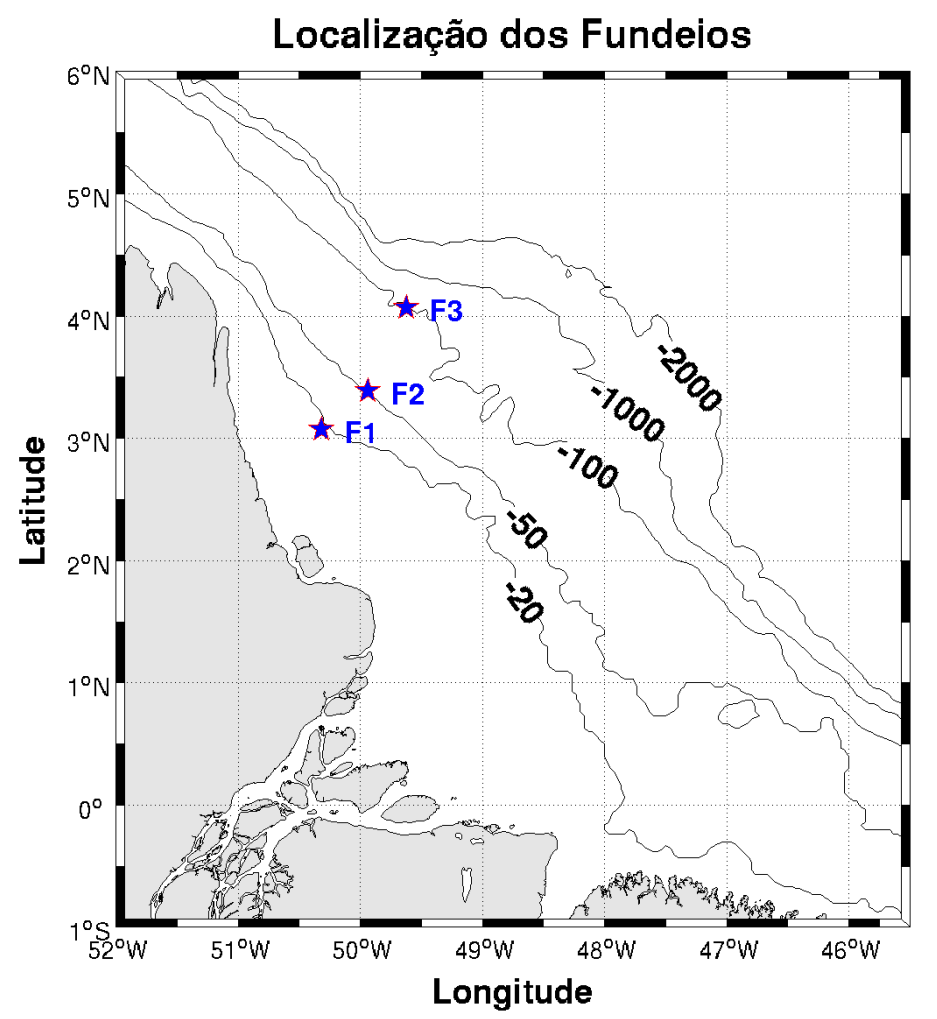

Figura 11: Localização dos Fundeios F1 (Plataforma interna), F2 (Plataforma média) e F3 (Plataforma externa) mantidos de fevereiro a junho de 1990 durante o projeto AMASSedS.

F1 foi projetado para uma coluna d'água de $20 \mathrm{~m}$ de forma a coletar dados de superfície e subsuperfície. Em superfície uma bóia foi instalada com um sensor para coletar dados de ondas de gravidade (Datawell waverider). Em subsuperfície, foi instalado a 3 $\mathrm{m}$ de profundidade um condutivímetro da marca SeaBird, acoplado a um correntômetro (VACMs - Vector Averaging Current Meters), que também mediu a temperatura da água. Todos os sensores foram programados para coletar dados a cada 7,5 min (ALESSI et al., 1992).

F2 foi projetado para uma coluna d'água de 65 metros de profundidade, contendo uma bóia de superfície com um sensor instalado para medir a intensidade e direção dos 
ventos (VAWR - Vector Averaging Wind Recorder). A temperatura e condutividade a $1 \mathrm{~m}$ de profundidade também foram medidas por sensores conectados à bóia de superfície. Em subsuperfície, foram instalados 3 correntômetros VACM com condutivímetros SeaBird acoplados, nas profundidades de $3 \mathrm{~m}, 32 \mathrm{~m}$ e $54 \mathrm{~m}$. Todos os sensores foram programados para coletar dados a cada 7,5 min (ALESSI et al., 1992).

Ambos os fundeios, F1 e F2, se conectavam, cada um, a uma linha secundária menor, coletando dados de corrente e condutividade. No ponto F1 a linha anexa tinha, a $16 \mathrm{~m}$ de profundidade, um condutivímetro acoplado a um correntômetro. O ponto anexo ao F2 continha 2 condutivímetros, cada um acoplado a um correntômetro que mediam a velocidade escalar nas profundidades de 62 m e 64 m (ALESSI et al., 1992). Este último, a 64 m, não será usado ao longo do trabalho.

F3, projetado para uma profundidade de $103 \mathrm{~m}$, foi delineado como um fundeio de subsuperfície, contendo 4 correntômetros, sendo 3 da marca SD2000, pertencentes ao IO-USP (Instituto Oceanográfico da Universidade de São Paulo), e um InterOcean S4, que além de correntes mediu a pressão. A disposição dos equipamentos neste ponto foi: correntômetros SD2000 instalados nas profundidades de 30 m, 61 m e 93 m e o correntômetro S4 instalado a $32 \mathrm{~m}$. Os dados de velocidade do correntógrafo a $61 \mathrm{~m}$ deste fundeio apresentaram erros e foram descartados. Ainda para este ponto, os correntógrafos a 30 m e a 32 m foram instalados para comparação dos equipamentos, de marcas diferentes (MIRANDA et al., 1990), já que os SD2000 não haviam sido testados em locais de fortes correntes de contorno oeste (ALESSI et al., 1992). Por conta da semelhança entre os dados, o correntômetro a 30 m não foi utilizado nas análises deste trabalho.

Uma parte dos dados provenientes de F2 não pode ser analisada por consequência da soltura acidental da bóia de superfície. Por conta deste fato, apenas o período de 10 de fevereiro a 16 de abril, comum a todos os equipamentos que operaram corretamente, foi considerado neste trabalho. A Figura 12 mostra o período e os parâmetros coletados em cada fundeio. As séries temporais de todos os parâmetros foram mediadas a cada hora e, assim, os dados cobrem 1562 horas ou aproximadamente 65 dias. Os dados aqui analisados serão os de temperatura da água do mar, salinidade e dados correntográficos. 

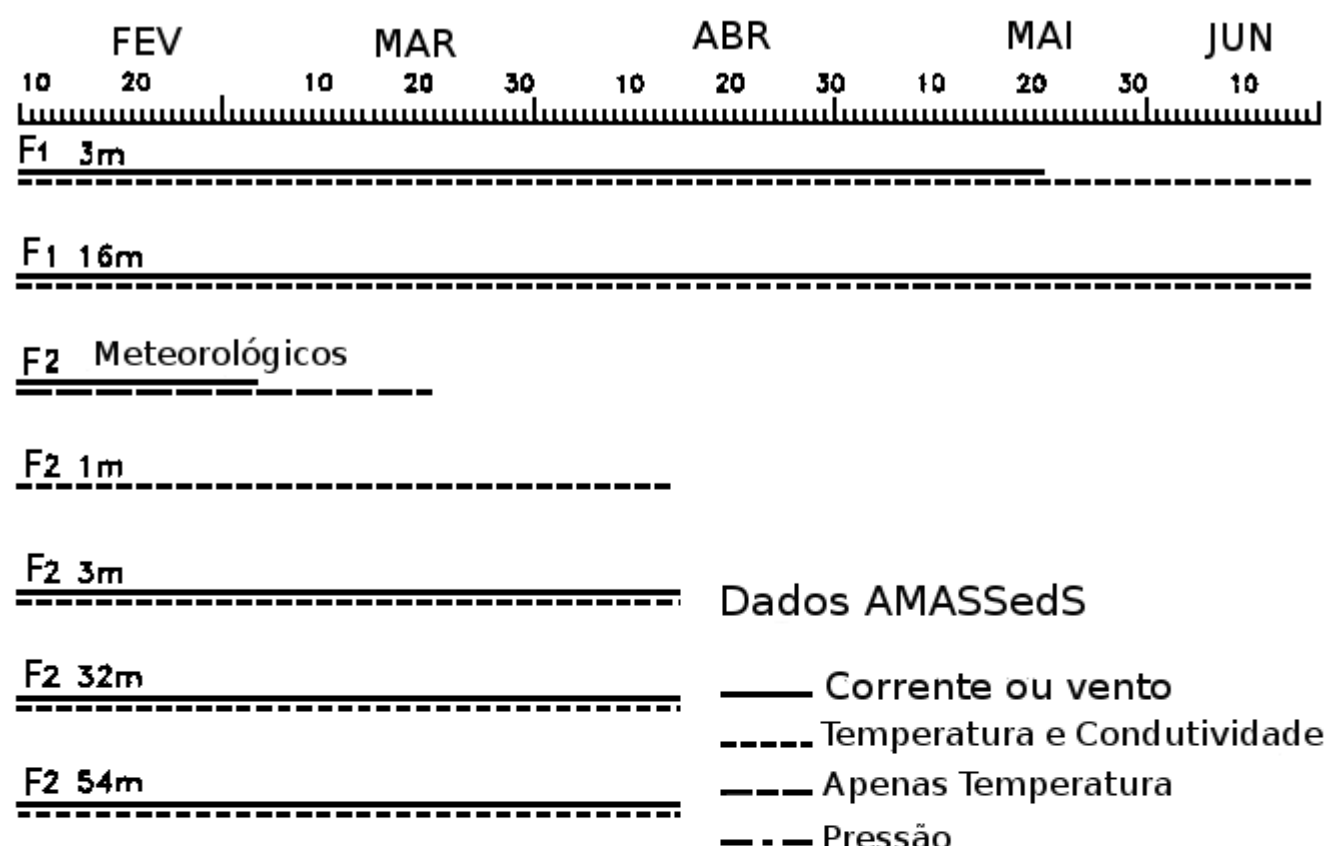

\section{Dados AMASSedS}

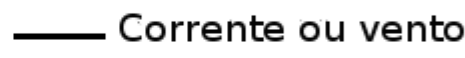

----- Temperatura e Condutividade

- - A penas Temperatura

- - - Pressão

F2 62m

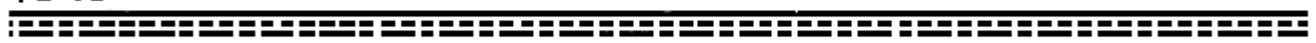

\section{F $30 \mathrm{~m}$}

\section{$\mathrm{F3} 32 \mathrm{~m}$}

\section{F3}

\section{F3 $93 \mathrm{~m}$}

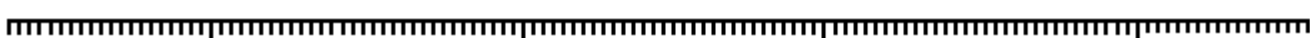

1020

FEV

20
MAR

$\begin{array}{cccccc}20 & 30 & 10 & 20 & 30 & 10 \\ \text { ABR } & & & \text { MAI } & & \text { JUN }\end{array}$

Figura 12: Período de funcionamento e parâmetros coletados para cada ponto amostrado nos fundeios AMASSedS. Modificado de Alessi et al. (1992).

Utilizaremos ainda os parâmetros da elipse de maré barotrópica provenientes dos resultados de Fontes (2000) e Fontes et al. (2008) como aproximação da corrente de maré barotrópica nos três pontos de fundeio supracitados. 


\section{Metodologia}

Apresentamos nesta Seção os métodos e técnicas utilizados para as análises dos dados apresentados na Seção anterior. Ressaltamos que os métodos aqui descritos não serão caracterizados em seus pormenores, sendo necessária a utilização de literatura específica, aqui referenciada, para o entendimento ideal e reprodução dos mesmos.

\subsection{Pré-processamento e análise dos dados termohalinos dos cruzeiros hidrográficos}

Visamos avaliar, a partir dos dados termohalinos, o potencial de geração de marés internas das principais componente de maré que influenciam a região da plataforma amazônica. Segundo Beardsley et al. (1995) e Fontes et al. (2008), a maré na região é essencialmente semi-diurna, com dominância da componente principal lunar $\mathrm{M}_{2}$. Sendo assim, os dados de temperatura e salinidade provenientes dos cruzeiros AMASSedS foram editados e analisados de forma a subsidiar as análises seguindo a rotina:

1. Remoção de picos espúrios e alisamento dos perfis verticais pela aplicação de janela móvel do tipo Blackman;

2. Estimativa da densidade usando a Equação Internacional de Estado da Água do Mar - EOS-80 (UNESCO, 1981) através de rotinas para o Software MatLab;

3. Estimativa da frequência de Brünt Väisälä;

4. Cálculo da inclinação do fundo em cada estação dos cruzeiros;

5. Estimativa da inclinação das características das ondas internas seguindo o proposto por Baines (1982);

6. Comparação da inclinação do fundo com a inclinação das características das ondas internas e estimativa da criticidade naquele ponto e;

7. Cálculo do comprimento de onda teórico das marés internas em cada estação. 
A remoção de dados espúrios consitiu na identificação e remoção de valores irreais ou fora de um padrão pré-determinado. Trabalhamos com a janela de \pm três desvios padrão. O segundo passo enumerado consistiu em filtrar os dados a partir de uma janela móvel, com o cálculo dos valores de temperatura e salinidade em cada metro da coluna d'água, substituindo os valores antigos por uma média ponderada entre os dados contidos no interior da janela. A janela móvel Blackman, aplicada aos perfis verticais de temperatura e salinidade, é uma função matemática onde, fora do intervalo determinado pela largura da janela, os pesos tendem a zero rapidamente. Os pesos da janela Blackman $(W)$ são definidos pela função:

$$
W(n)=a_{0}+a_{1}+a_{2} \cos \left(\frac{4 \pi n}{N}\right), 0 \leq n \leq N
$$

onde: $L=N+1$ é a largura da janela. Optou-se por uma largura da janela compatível com as profundidades das estações oceanográficas do projeto, algumas inferiores a $20 \mathrm{~m}$, e para não comprometer a resolução da pluma em maiores profundidades. Dessa forma, foram escolhidos os valores de $\mathrm{L}=5(\mathrm{~N}=4)$. A Figura 13 mostra o filtro utilizado. 


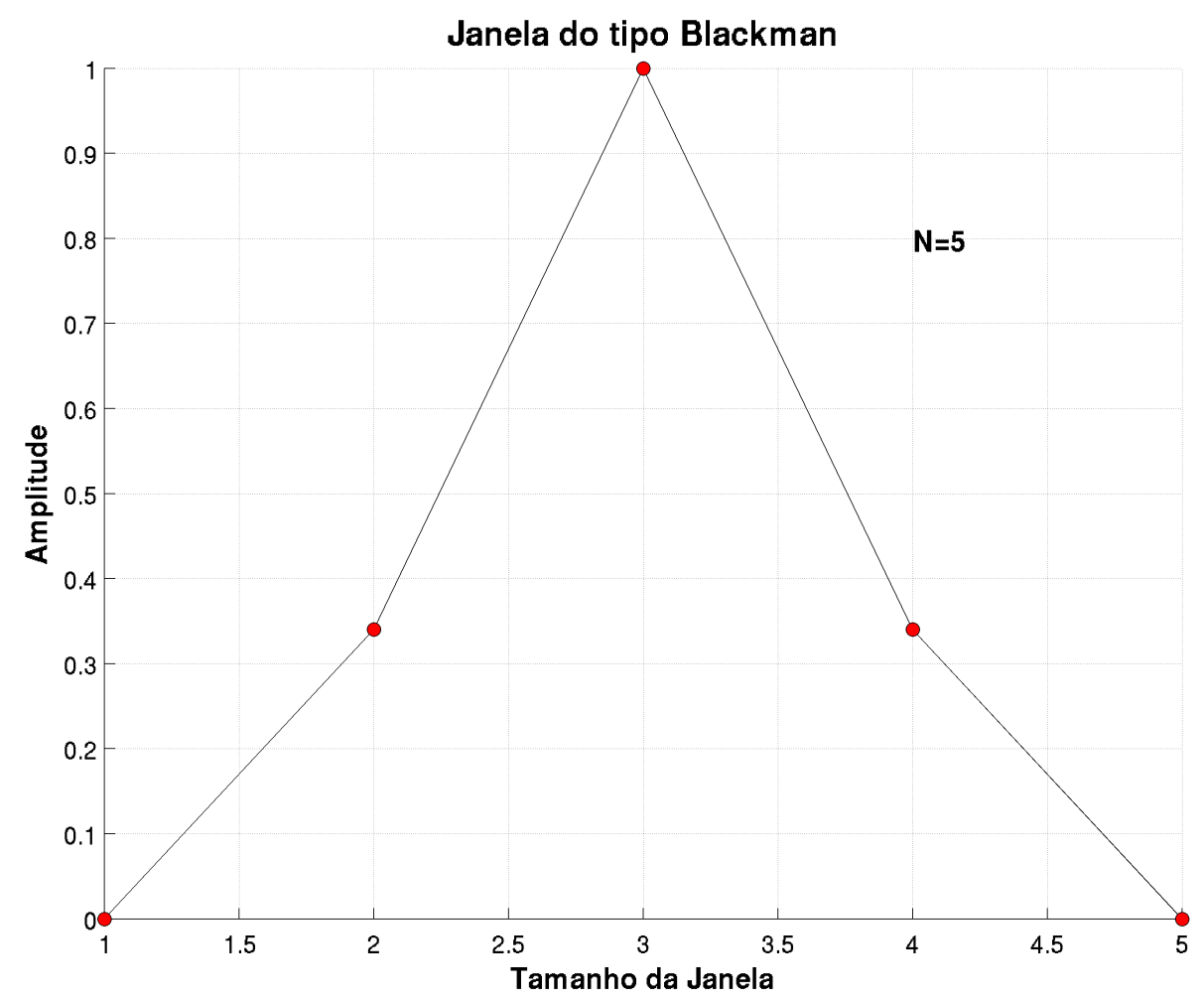

Figura 13: Filtro Blackman. Janela utilizada para filtragem dos dados.

O filtro foi aplicado em todos os perfis verticais de temperatura e salinidade. A Figura 14 mostra um exemplo da aplicação do filtro Blackman a um dos perfis verticais de temperatura do projeto AMASSedS. 

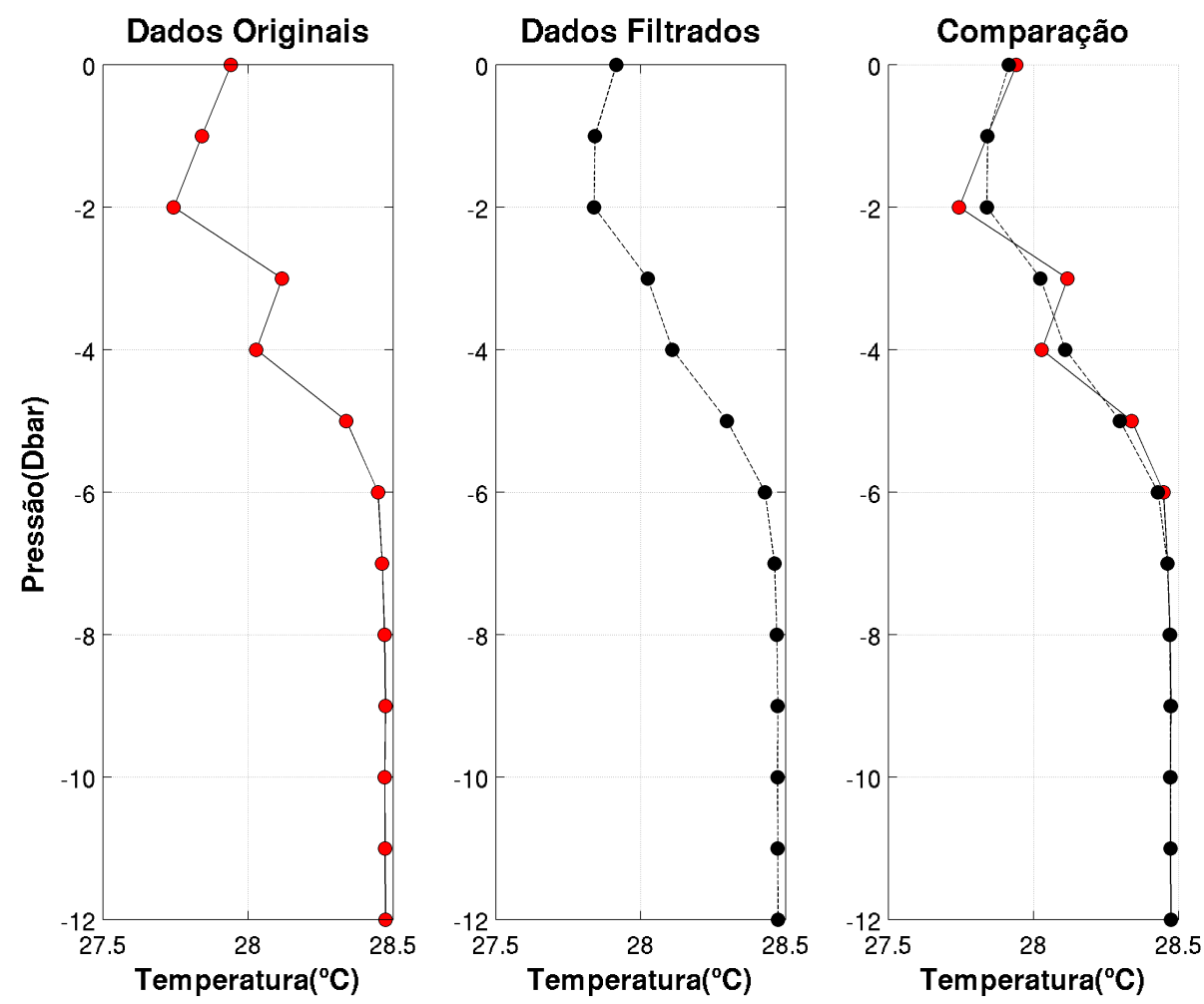

Figura 14: Comparação dos dados originais e filtrados de temperatura.

A Equação de Estado da Água do Mar, EOS-80 (UNESCO, 1981; UNESCO, 1983), foi aplicada aos dados de temperatura, salinidade e pressão para estimativa da densidade $\left(\rho, k g \cdot \mathrm{m}^{-3}\right)$ como função da salinidade prática (S,PSU), temperatura $\left(\mathrm{T},{ }^{\circ} \mathrm{C}\right) \mathrm{e}$ da pressão (P, Bars) através da seguinte relação:

$$
\rho(S, T, P)=\frac{\frac{\rho(S, T, 0)}{1-P}}{K(S, T, P)}
$$

onde $K(S, T, P)$ é um parâmetro associado à pressão relacionado a um decréscimo fracional de volume e $\rho(S, T, 0)$ é a densidade da água do mar à pressão oceânica zero.

A partir da densidade foi feita a estimativa da frequência de Brunt-Väisälä para todos os dados hidrográficos. Essa estimativa é baseada na equação:

$$
N=\sqrt{-\frac{g}{\bar{\rho}} \frac{\partial \rho}{\partial z}}
$$


onde $N$ é a frequência de Brunt-Väisälä, $g$ é a aceleração da gravidade, $\bar{\rho}$ é uma densidade de referência, $\rho$ é a densidade estimada e $z$ é direção vertical, com o eixo apontando no sentido oposto ao da aceleração da gravidade. A frequência de Brunt-Väisälä permite quantificar a estratificação vertical de densidade, identificando estações oceanográficas, assim como regiões na coluna d'água, com maior ou menor estratificação.

O passo seguinte foi calcular a inclinação da plataforma no local de cada estação seguindo a Equação 1.2. Esse cálculo foi feito nas radiais definidas nas Figuras 6 a 10, respectivamente para os 4 cruzeiros do projeto AMASSedS, nas amostragens definidas por radiais perpendiculares à costa. No caso da última estação das radiais, e para as estações fora de radiais, foram selecionados pontos, definidos manualmente, ao largo de cada uma dessas estações. Para tal, utilizamos a batimetria de Becker et al. (2009), cuja resolução espacial é de 30”.

Seguindo a ordem dos itens definidos no início desta Seção, foi feita a estimativa da inclinação (parâmetro c) das marés internas semi-diurnas referentes à componente principal lunar, $\mathrm{M}_{2}$, através da Equação $1.1 \mathrm{e}$, a avaliação do potencial de geração de marés internas (parâmetro $\alpha$ ) de cada estação, através da Equação 1.3. Para o cálculo dos parâmetros c e $\alpha$ utilizamos a parte inferior da coluna d'água, abaixo da picnoclina, com o $N$ estimado médio, já que marés internas são geradas próximo ao leito marinho (BAINES, 1982).

Esta limitação dos dados para o cálculo do parâmetro c seguiu os trabalhos de Curtin (1986) e Linhares (1995). O primeiro analisou dados hidrográficos na PCA e definiu as características das massas d'água para a plataforma num período de vazão máxima; Linhares (1995) analisou o mesmo conjunto de dados hidrográficos apresentado aqui para também caracterizar as massas d'água na região da PCA. Estabelecemos como limite para os dados os parâmetros indicados por Curtin (1986) (Tabela 1) e o limite de concentração máxima de 10\% da massa de água, Água do Rio, definido por Linhares (1995).

Uma característica importante das marés internas é o comprimento de onda. Esse parâmetro foi estimado teoricamente do primeiro modo baroclínico para as marés internas 
a partir da fórmula (PEREIRA et al., 2007):

$$
\lambda_{n}=\frac{N \cdot H \cdot T}{n \pi}
$$

onde $H$ é a profundidade local e $T$ é o período da onda. O índice $n$ representa o modo baroclínico ( $n=1$ para o primeiro modo). Neste estudo $T=12,4206$ horas.

Desta forma, a partir dos dados termohalinos pudemos obter uma estimativa da possibilidade de geração de marés internas na PCA e, quando houve geração, do comprimento teórico de tais ondas nos diferentes estágios da vazão do RA. 


\subsection{Pré-processamento e análise dos dados correntográficos e termo- halinos dos fundeios}

A análise dos dados de corrente visou identificar as frequências de oscilação mais energéticas nas componentes da velocidade baroclínica, bem como caracterizar a maré baroclínica das mesmas, com ênfase na componente semi-durna principal lunar, $\mathbf{M}_{2}$. Para tal, utilizamos as séries temporais de corrente, salinidade e temperatura dos fundeios AMASSedS. Tais séries, quando recebidas no início deste trabalho, já haviam sido editadas, interpoladas e corrigidas. Com a finalidade de ajustá-las às isóbatas locais, as séries vetoriais de velocidade observada sofreram rotação de $35^{\circ}$ para oeste no ponto $\mathrm{F} 1$; de $45^{\circ}$ para oeste no ponto $\mathrm{F} 2$ e de $50^{\circ}$ no ponto $\mathrm{F} 3$ (Tabela 2), sendo descritas ao longo do trabalho como componente quase-paralela às isobatas $(v>0$ para NO) $\mathrm{e}$ componente quase-perpendicular às isóbatas ( $u>0$ para NE, para o largo).

Tabela 2: Direção das componentes escalares $u$ e $v$, considerando o Norte como $\mathbf{0}^{\circ} / 360^{\circ}$.

\begin{tabular}{cccc}
\hline \multicolumn{4}{c}{ Novas direções após rotação } \\
\hline & $\mathrm{F} 1$ & $\mathrm{~F} 2$ & $\mathrm{~F} 3$ \\
\cline { 2 - 4 }$u$ & $35^{\circ}$ & $45^{\circ}$ & $50^{\circ}$ \\
$v$ & $325^{\circ}$ & $315^{\circ}$ & $310^{\circ}$ \\
\hline
\end{tabular}

Para avaliar a variabilidade baroclínica das séries de corrente, foi necessário separar a componente barotrópica da baroclínica, uma vez que a velocidade observada pode ser considerada a soma entre estes modos da forma:

$$
\overrightarrow{V_{O}}=\overrightarrow{V_{B}}+\overrightarrow{V^{\prime}}
$$

onde $\vec{V}_{O}$ é a velocidade observada; $\vec{V}_{B}$ é a velocidade barotrópica e $\vec{V}^{\prime}$ é a velocidade baroclínica. 
Uma das formas de se inferir a componente barotrópica da velocidade é tomando esta como a média das velocidades na coluna d'água. Dos três fundeios utilizados neste trabalho, dois possuem apenas 2 níveis de coleta e, por isso essa metodologia não pode ser empregada (EDWARDS e SEIM, 2008). Necessitamos ainda de uma metodologia para separar a maré barotrópica e a maré interna forçada por aquela. Tivemos então que separar, em cada série, sinais de mesma frequência, o que, segundo Lerczak et al. (2003), é tarefa muito difícil caso não se observe diferença de fase acentuada na coluna d'água, de aproximadamente $180^{\circ}$. Visto isso, utilizamos os resultados da simulação numérica barotrópica da hidrodinâmica local forçada pela maré $\mathrm{M}_{2}$ e condições de vento e vazão de um rio realísticas de Fontes (2000) e Fontes et al. (2008). Utilizamos as seguintes características da elipse da maré $\mathrm{M}_{2}$ : semi-eixo maior, semi-eixo menor, inclinação e fase. Com esses valores, reconstruimos a componente barotrópica da velocidade seguindo os passos de Godin (1988).

Uma vez que objetivamos avaliar apenas a componente $\mathrm{M}_{2}$, uma aproximação da maré semi-diurna como principal componente barotrópica é razoável. A ausência da componente de maré principal solar, $\mathrm{S}_{2}$, é uma fonte de erros inegável, uma vez que a variablididade das correntes associada à marés de sizígia e quadratura é importante. Entretanto, com amplitudes de aproximadamente $80 \%$ menores que a componente $\mathrm{M}_{2}$ e, por conta da ausência de dados disponíveis para suprir essa componente, consideramos apenas a componente $\mathrm{M}_{2}$ (BEARDSLEY et al., 1995).

A velocidade baroclínica $\left(\vec{V}^{\prime}\right)$, então, foi definida como a diferença entre a velocidade observada e o modo barotrópico:

$$
\overrightarrow{V^{\prime}}=\overrightarrow{V_{O}}-\overrightarrow{V_{B}}
$$

Equações análogas às últimas equações vetoriais foram aplicadas a cada uma das componentes horizontais da velocidade ( $u$ e $v$ ). As Figuras 15, 16 e 17 mostram as séries vetoriais correntográficas observadas e a componente barotrópica para os fundeios F1, F2 e F3. 


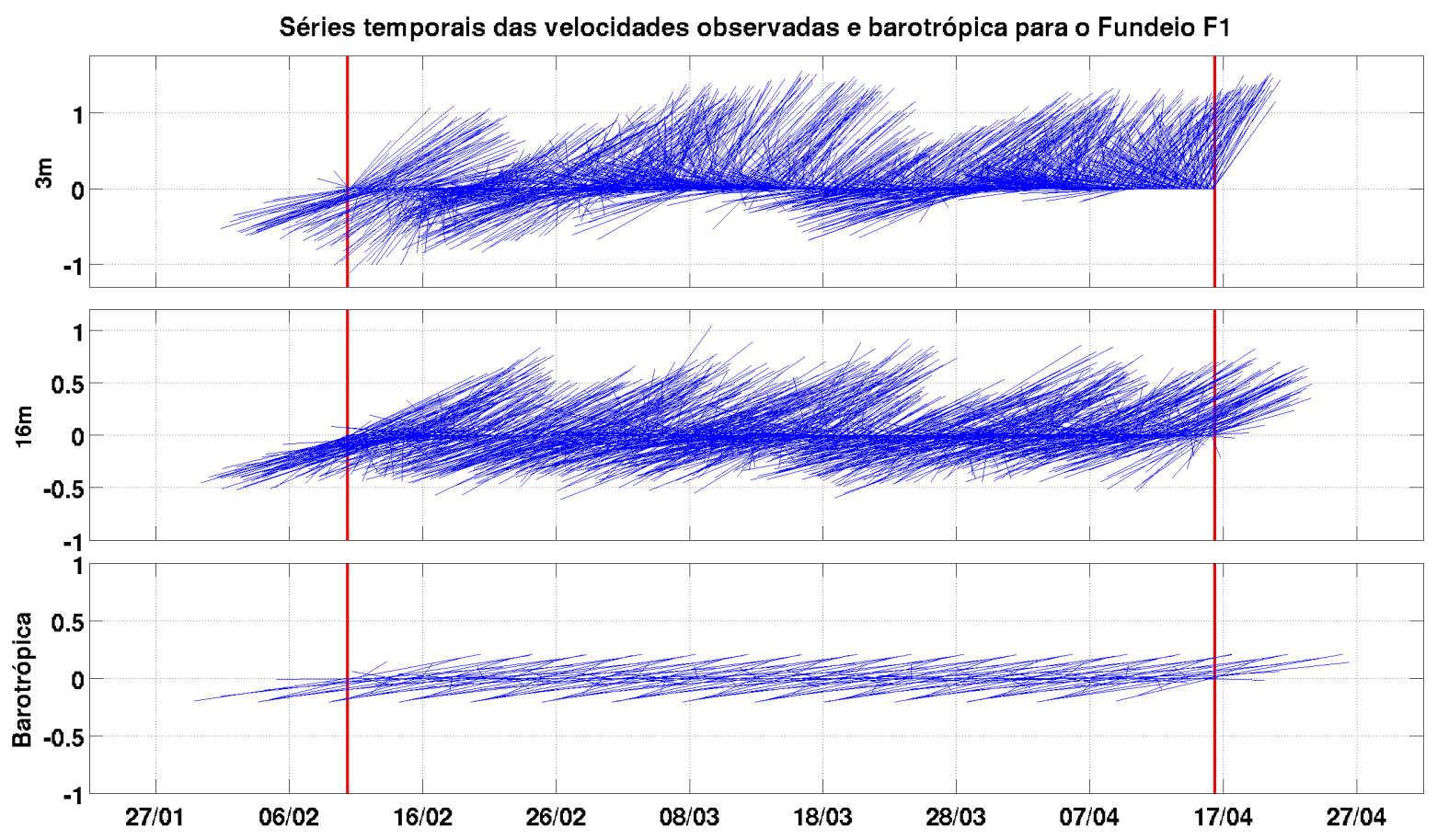

Figura 15: Série temporal dos vetores de velocidades observada e barotrópica - Fundeio F1, a 3 $\mathrm{m}$ de profundidade (quadro superior), a $16 \mathrm{~m}$ de profundidade (quadro intermediário) e a corrente barotrópica (terceiro quadro). Os vetores sofreram rotação de $55^{\circ}$ para Oeste para alinhar o eixo das ordenadas às isóbatas local. O período analisado cobre o intervalo de $\sim 65$ dias, de 10/Fev de 1990 a 16/Abr de 1990. As linhas verticais vermelhas marcam o início e o fim do período amostrado.

Nota-se, para o ponto F1 (Figura 15), que há uma direção preferencial das correntes para norte, com variações constantes de sentido. As correntes apresentam variações pequenas entre os sensores à 3 e a 16 m. Segundo Geyer et al. (1996), as correntes observadas são dominadas pela maré barotrópica com variação acentuada entre os períodos de sizígia e quadratura. A velocidade barotrópica corresponde, nesta Dissertação, à componente $\mathrm{M}_{2}$ da maré barotrópica obtida por Fontes et al. (2008). 


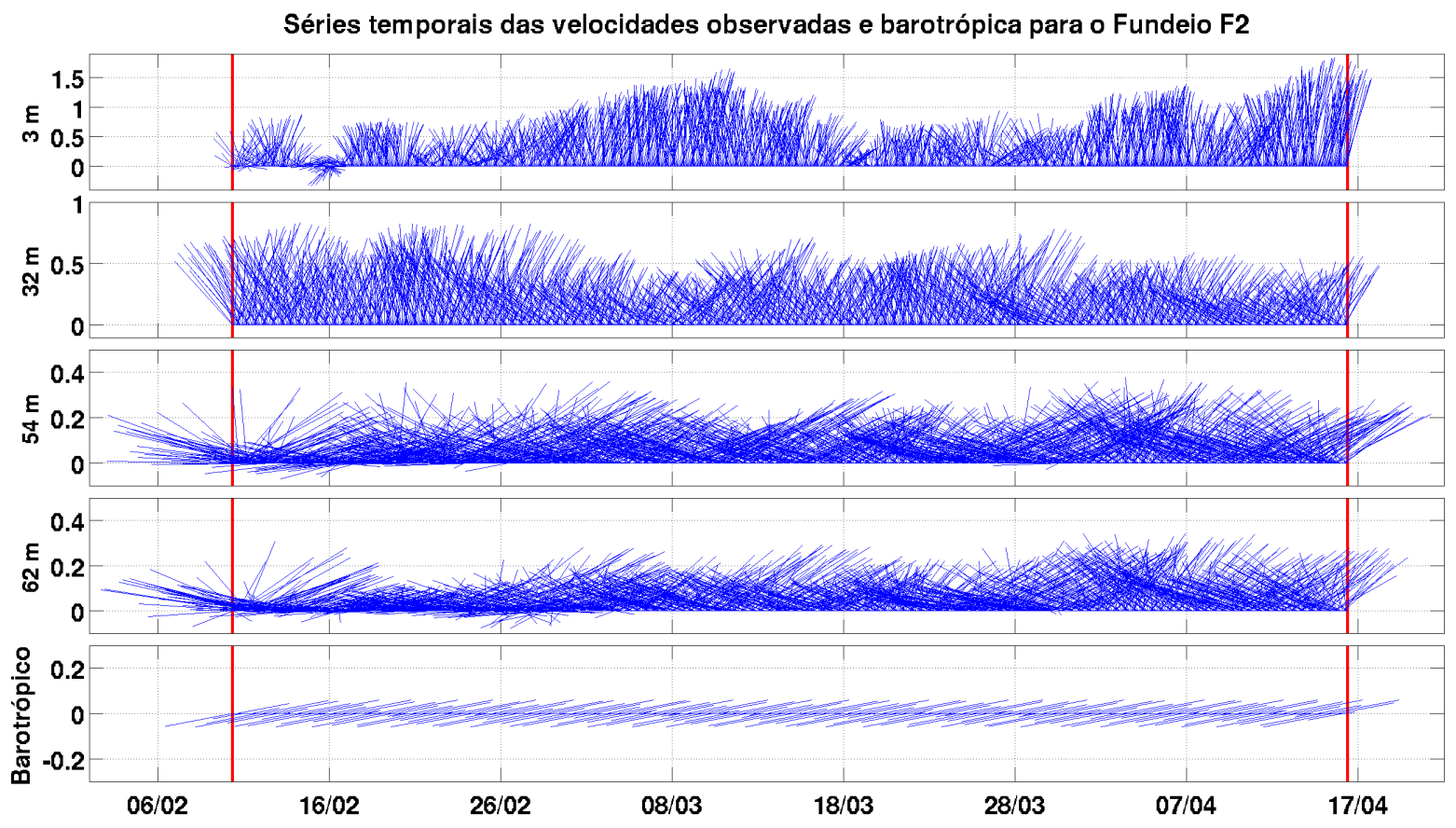

Figura 16: Série temporal dos vetores de velocidades observada e barotrópica - Fundeio F2, a $3 \mathrm{~m}$ (quadro superior), $32 \mathrm{~m}$ (segundo quadro), $54 \mathrm{~m}$ (terceiro quadro), $62 \mathrm{~m}$ de profundidade (quarto quadro) e corrente barotrópica (quinto quadro). Os vetores sofreram rotação de $45^{\circ}$ para Oeste para alinhar o eixo das ordenadas às isóbatas local. O período analisado cobre o intervalo de $\sim 65$ dias, de 10/Fev de 1990 a 16/Abr de 1990. As linhas verticais vermelhas marcam o início e o fim do período amostrado.

Para o F2 (Figura 16), podemos observar a direção preferencial das correntes para noroeste, oscilando entre oeste e norte, forçada pelos ventos alíseos predominantes (GEYER et al., 1996), com raras ocasiões de correntes para sudeste nas profundidades de $3 \mathrm{~m}, 54 \mathrm{~m}$ e $62 \mathrm{~m}$. Nota-se a diminuição da intensidade de correntes com o aumento da profundidade, de velocidades superiores a $1,5 \mathrm{~ms}^{-1}$ na superfície a menos de $0,4 \mathrm{~ms}^{-1}$ próximo ao fundo. A corrente barotrópica possui intensidade de corrente inferior a 0,7 $\mathrm{ms}^{-1}$ e direção preferencial semelhante à das correntes observadas, oscilando, também, entre as direções oeste e norte. 

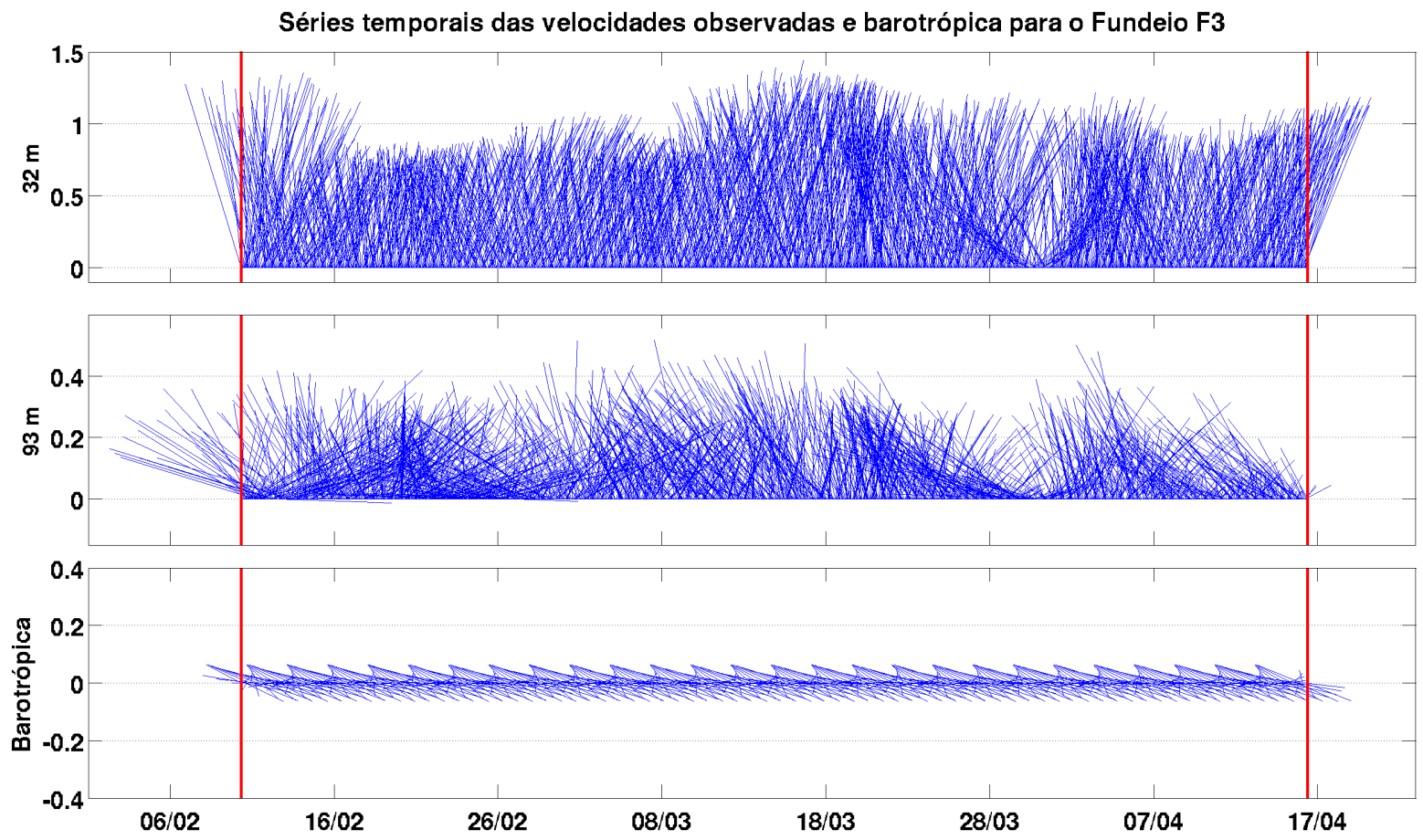

Figura 17: Série temporal dos vetores de velocidades observada e barotrópica - Fundeio F3, a 32 m (quadro superior), $93 \mathrm{~m}$ de profundidade (quadro intermediário) e a corrente barotrópica(quadro inferior). Os vetores sofreram rotação de $45^{\circ}$ para Oeste para alinhar o eixo das ordenadas às isóbatas local. O período analisado cobre o intervalo de $\sim 65$ dias, de 10/Fev de 1990 a 16/Abr de 1990. As linhas verticais vermelhas marcam o início e o fim do período amostrado.

O ponto F3 (Figura 17), apresenta velocidades com direção preferencial para NO com oscilações em torno dessa direção, entre oeste e norte. A intensidade de correntes a $32 \mathrm{~m}$ oscilou em torno de $1 \mathrm{~ms}^{-1}$, diminuindo para menos de $0,5 \mathrm{~ms}^{-1}$ a $93 \mathrm{~m}$ de profundidade, apresentando oscilações mais bruscas da direção a 93 m entre as direções oeste e norte.

\subsubsection{Análise Espectral}

A análise espectral é utilizada para particionar a variância de uma dada série temporal em função da frequência. Com o conjunto de dados disponível, a contribuição de uma dada frequência é mensurada em termos de densidade de potência espectral, o que 
por sua vez pode ser considerada energia por unidade de tempo (EMERY e THOMSON, 2004). Ou seja, os resultados da análise espectral nos dão uma idéia da energia contida em cada banda de frequência.

Investigamos espectralmente cada série de tempo utilizando o periodograma de Welch (WELCH, 1967). Resumidamente, o método de Welch separa a série temporal em segmentos de tamanho definido e aplica uma função janela em cada um dos segmentos, filtrando-os. Após isso, a transformada de Fourier é aplicada nos segmentos, permitindo sobreposição dos mesmos. Nesta Dissertação, o periodograma de Welch foi aplicado seguindo a rotina:

- Segmentos de 389 amostras ou aproximadamente 16 dias;

- Filtro hanning e;

- Sobreposição de $50 \%$ dos segmentos.

\subsubsection{Análise Harmônica de Marés}

De acordo com Emery e Thomson (2004), a utilização da análise harmônica para a caracterização da maré data de décadas, quiçá, séculos atrás e possui uma fórmula dita definitiva desde o trabalho de Foreman (1977a) e Foreman (1977b) . Neste trabalho utilizamos as rotinas de Pawlowicz et al. (2002), que são baseadas nos trabalhos de Foreman (1977a) e Foreman (1977b) para avaliar os parâmetros da maré local, em específico a componente semi-diurna principal lunar, $\mathrm{M}_{2}$.

As séries de velocidade foram analisadas harmonicamente para avaliar o papel das marés barotrópica e interna na dinâmica local. Para tal, começamos por transformar as componentes de velocidade em velocidade complexa na forma:

$$
V=u+i v
$$

onde $i=\sqrt{-1}$, em todas as séries temporais. Primeiramente analisamos as séries observadas completas para avaliar a rotina de Pawlowicz et al. (2002), comparando os 
resultados com as observações de Beardsley et al. (1995) (não apresentado). Os resultados foram idênticos. Após essa verificação, empregamos a mesma rotina nos dados barotrópicos e baroclínicos obtidos a partir da metodologia descrita na Seção 5.2.

Como já dito na introdução desta Dissertação (Seção 1), uma das características mais marcantes das marés internas é a sua intermitência, ou seja, o fato de não ocorrerem em intervalos regulares de forma determinística, como a maré barotrópica. Assim, para tentar capturar a intermitência, aplicamos a técnica da análise harmônica em janelas de 16 dias, tempo suficiente para que seja possível separar as componentes $\mathrm{M}_{2}$ e $\mathrm{S}_{2}$. As janelas possuem intervalo de um dia com sobreposição de 93,75 \%. Isto quer dizer que aplicamos a técnica na janela do dia 1 ao 16, do dia 2 ao 17 e assim sucessivamente, produzindo 50 análises harmônicas e séries temporais para cada um dos 4 parâmetros da elipse de maré, aos moldes do trabalho de Kurapov et al. (2003) e Osborne et al. (2011).

\subsubsection{Funções Empíricas Ortogonais - FOE}

Chama-se Funções Empíricas Ortogonais (FOE) à técnica para comprimir a variabilidade de um conjunto de séries temporais simultâneas e particionar sua variância. É utilizada muitas vezes na análise de variáveis escalares, como temperatura, salinidade ou componentes de velocidade. O método das FOE fornece uma descrição compacta da variabilidade temporal e espacial da série temporal de dados em termos de funções ortogonais, ou modos estatísticos, dando uma ideia dos padrões espaciais, variações temporais dos mesmos e, ainda, da importância de cada um desses padrões. Pode-se ter tantos modos/padrões quantos forem os pontos de medições, sendo comumente chamadas de modos de oscilação ou modos estatísticos (EMERY e THOMSON, 2004; BJORNSSON e VENEGAS, 1997). Geralmente, os modos estatísticos mais baixos (primeiro e segundo modo) possuem as maiores escalas espaciais e representam os modos de variabilidade estatística mais energéticos, diminuindo a energia e aumentando a complexidade quanto maior for o modo.

Diferentemente de modos dinâmicos, não há nesta análise nenhum tipo de consideração física anterior à aplicação do método, sendo este estritamente estatístico 
e, para ressaltar o fato de que as análises são baseadas a partir do próprio conjunto de dados, o método é "empírico". As FOE têm como propriedade, como já diz o nome, a ortogonalidade, ou seja, cada modo é independente do outro. Caso multipliquemos um modo pelo outro o resultado deve ser zero.

A análise FOE é tanto melhor quanto maior for o número de pontos de observação. Assim, como os fundeios F1 e F3 possuem apenas dois pontos de observação na coluna d'água, este método foi aplicado apenas no fundeio F2, que possui 4 pontos, resultando em 4 modos de oscilação. As FOE foram aplicadas a F2 seguindo a rotina de Bjornsson e Venegas (1997) da seguinte forma:

- Arranjamos as séries temporais do ponto F2 em uma matriz "F"(nome genérico), distribuindo nas colunas as séries temporais em cada profundidade. Assim, as linhas representam a evolução temporal de cada ponto observado (colunas da matriz F);

- Retiramos a média e a tendência de cada coluna de forma que cada coluna tenha média igual a zero;

- Calculamos a matriz de covariância "R"da matriz "F"da forma:

$$
R=F^{\prime} F
$$

- Em seguida resolvemos o problema de autovalor

$$
R C=C A
$$

onde A é a matriz diagonal que contém os autovalores $\left(\lambda_{i}\right)$ e cada coluna da matriz C corresponde aos autovetores $\left(C_{i}\right)$; para cada autovalor existe um autovetor correspondende. Cada um desses autovetores pode ser considerado um mapa. Neste método os autovetores estão ordenados de acordo com o tamanho do autovalor (variância). Dessa forma o primeiro modo está relacionado com o maior autovalor, o segundo modo com o segundo maior autovalor e assim sucessivamente. 
- Para sabermos como cada modo evolui no tempo, plotamo-los como mapas, multiplicando cada modo pela matriz F, obtendo assim o que é chamado de Componentes Principais ou Coeficientes de Expansão.

Ressaltamos aqui que os modos estatísticos não têm necessariamente nenhuma relação com os modos dinâmicos, físicos. Sendo assim, a interpretação dos modos deve ser cautelosa, podendo levar a conclusões errôneas. Pode haver casos que um único processo físico pode contaminar mais de um modo estatístico ao mesmo tempo, mesmo respeitando a ortogonalidade, assim como mais de um processo pode contribuir para a variância de um único modo (DOMMENGET e LATIF, 2002; EMERY e THOMSON, 2004).

Nesta Dissertação aplicamos o método das FOE para as componentes u e v da velocidade nas séries temporais do ponto F2 com o intuito de separar o modo barotrópico dos modos baroclínicos e, a partir do modo baroclínico, encontrar e caracterizar as marés internas. Entretanto, desde que nas análises da velocidade quase-paralela às isóbatas (v) não foi possível reconhecer com clareza os processos físicos dominantes nos modos, seus resultados não serão apresentados.

\subsubsection{Correlação}

A correlação entre duas séries temporais estima o grau de dependência linear existente entre as mesmas, com possibilidade de deslocamento no tempo $\tau$, sendo esta última variável o "atraso" ou "lag". A correlação pode ser calculada com a própria série, no que é chamado de auto-correlação ou com outra série, chamada de correlação cruzada. A auto-correlação e as correlações cruzadas entre as séries de velocidade analisadas nesta Dissertação podem ser encontradas no trabalho de Linhares (1995). Além disso estimamos nesta Dissertação o coeficiente de correlação cruzada que é (EMERY e THOMSON, 2004):

$$
\rho_{x y}(\tau) \equiv \frac{\frac{1}{N-k} \sum_{i=1}^{N-k}\left[y_{i}-\bar{y}\right]\left[x_{i+k}-\bar{x}\right]}{\sigma_{x} \sigma_{y}}
$$


onde $x_{i}$ e $y_{i}$ são as séries temporais a serem correlacionadas; $\bar{x}$ e $\bar{y}$ são as médias das séries, $\sigma_{x}$ e $\sigma_{y}$ são os desvios padrão das séries; $\mathrm{N}$ é o comprimento da série temporal e k é o incremento de tempo. O coeficiente de correlação cruzada varia entre -1 e 1 . Nesses limites, as séries são totalmente correlacionadas; caso o valor seja zero, não há correlação entre as séries.

Para se ter um índice de confiabilidade do método, estimamos valores limite seguindo a fórmula de Percival e Walden (1993):

$$
e= \pm \frac{2}{\sqrt{N}}
$$

Os valores de correlação entre $\pm e$ correspondem a um sinal similar à ruído branco, ou seja, um sinal randômico com a energia distribuida igualmente em todas as frequências. Consideraremos valores entre os limite $\pm e$ como "ausência de correlação".

Neste trabalho buscamos a correlação da velocidade baroclínica encontrada com as anomalias de salinidade. A correlação com atrasos negativos, que correspondem à salinidade liderando a velocidade, para as escalas temporais e espacias de interesse, não possuem significado físico. Assim, apenas a correlação com atraso positivo será considerada e apresentada neste trabalho. 


\section{Resultados e Discussão}

Primeiramente apresentamos os resultados das metodologias de análise propostas para os dados hidrográficos obtidos via cruzeiros e, em seguida, apresentamos os resultados obtidos das análises dos dados correntográficos e termohalinos provenientes dos fundeios.

\subsection{Cruzeiros hidrográficos}

Os dados dos cruzeiros foram utilizados neste trabalho com o propósito de mapear os locais com potencial de geração de marés internas na PCA, nas quatro condições de vazão do RA. Mostraremos os resultados obtidos a partir da metodologia proposta na Seção 5.1 seguindo a seguinte ordem: Vazão decrescente - cruzeiro I8909; Vazão crescente - cruzeiro I9002; Vazão máxima - cruzeiro I9004 e Vazão mínima - cruzeiros I9113L3 e I9113L4.

As Figuras 18 a 22, mostram as estações hidrográficas onde a geração de marés internas para a componente $\mathrm{M}_{2}$ é, teoricamente, possível, juntamente com a ordem de grandeza do comprimento de onda teórico dessas ondas. 


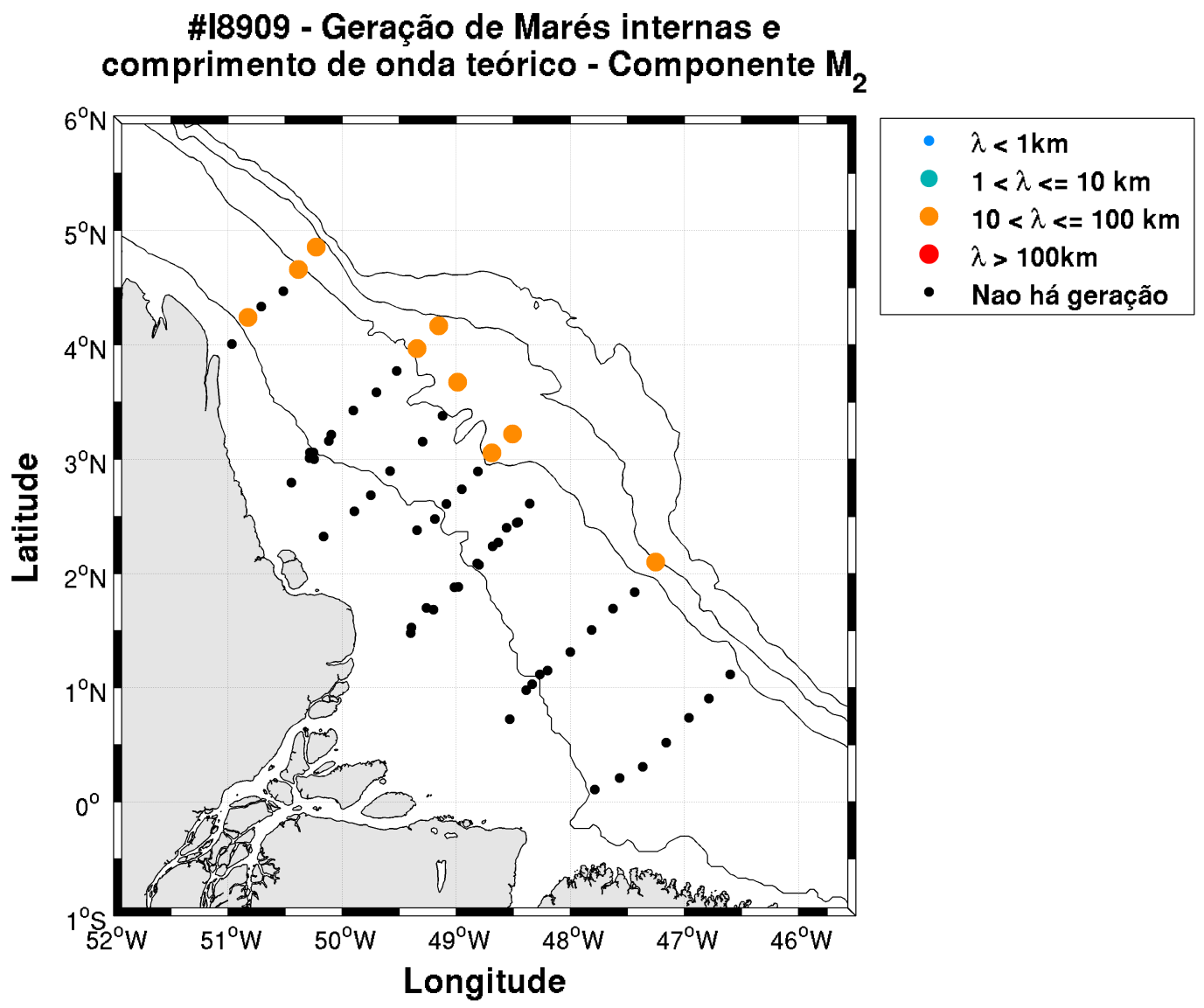

Figura 18: Possíveis locais geradores de maré interna para a componente $\mathrm{M}_{2}$ durante o cruzeiro I8909, agosto de 1989, período de vazão descrescente do Rio Amazonas. A legenda mostra a ordem de grandeza dos comprimentos de onda calculados para o primeiro modo baroclínico. As linhas pretas representam as isóbatas de 20 m, 100 m, 1000 m e 2000 m. 


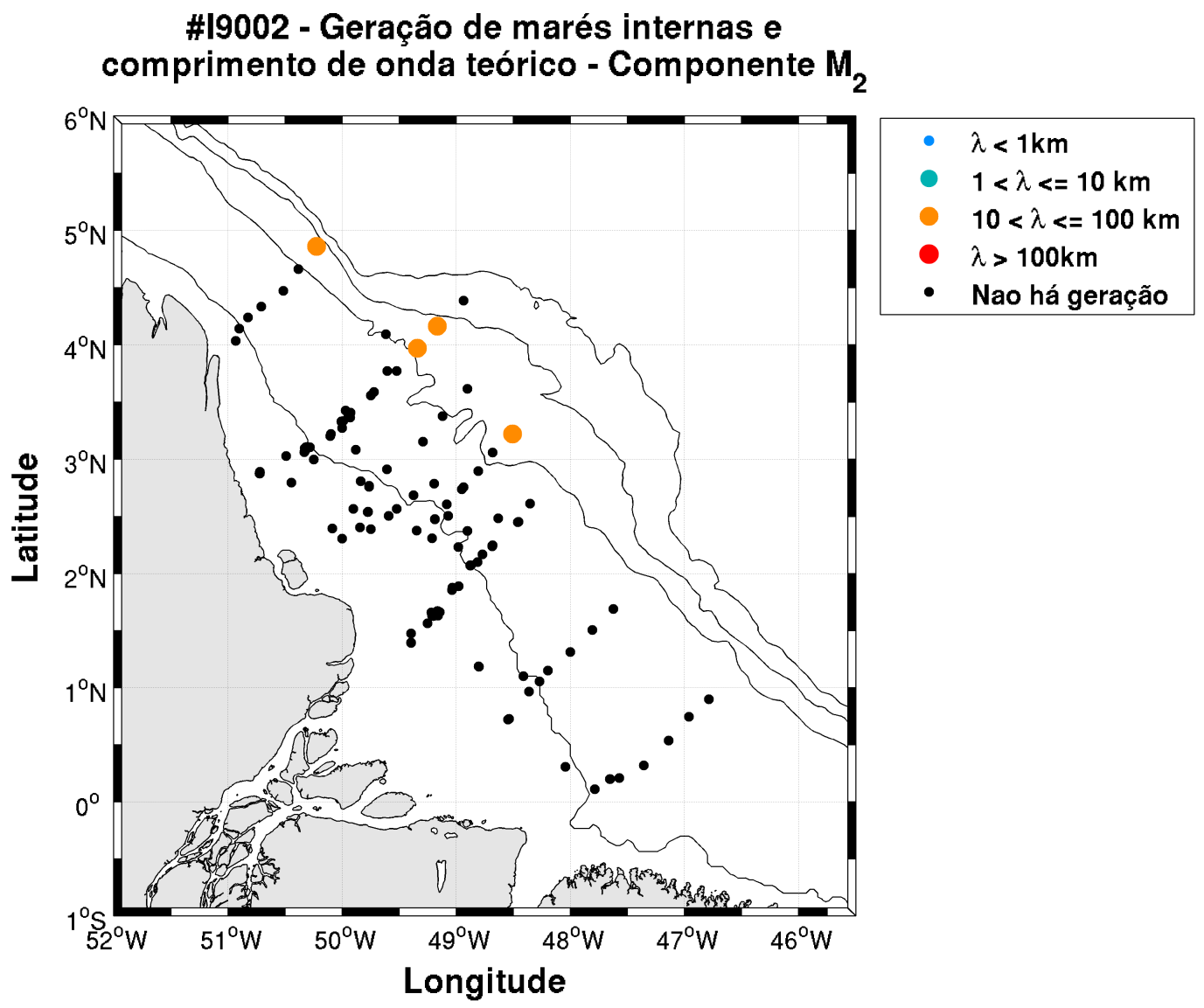

Figura 19: Possíveis locais geradores de maré interna para a componente $\mathrm{M}_{2}$ durante o cruzeiro I9002, março de 1990, período de vazão crescente do Rio Amazonas. A legenda mostra a ordem de grandeza dos comprimentos de onda calculados para o primeiro modo baroclínico. As linhas pretas representam as isóbatas de $20 \mathrm{~m}, 100 \mathrm{~m}, 1000 \mathrm{~m}$ e $2000 \mathrm{~m}$. 


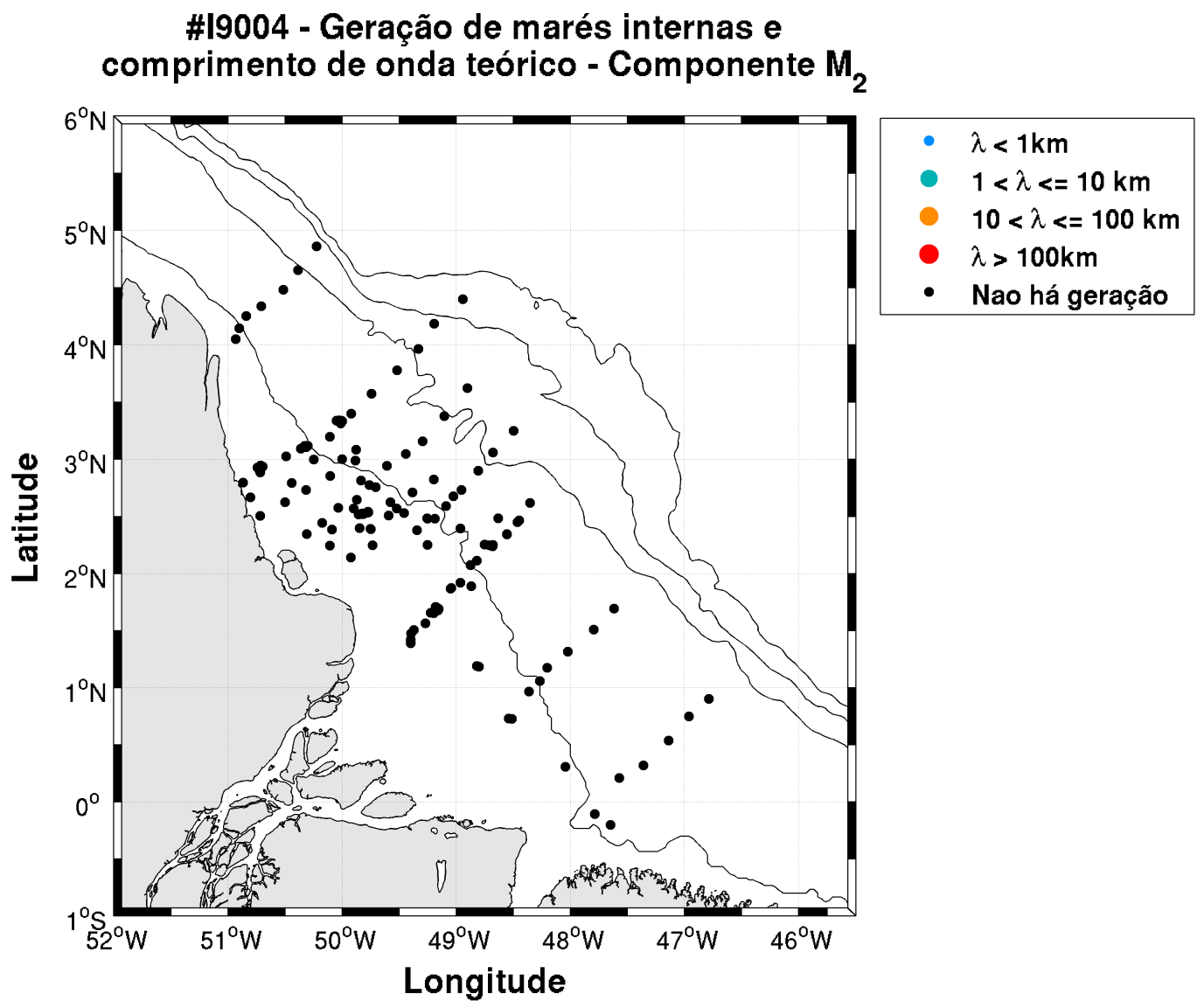

Figura 20: Possíveis locais geradores de maré interna para a componente $\mathrm{M}_{2}$ durante o cruzeiro I904, maio a junho de 1990, período de vazão máxima do Rio Amazonas. A legenda mostra a ordem de grandeza dos comprimentos de onda calculados para o primeiro modo baroclínico. As linhas pretas representam as isóbatas de 20 m, 100 m, 1000 m e 2000 m. 


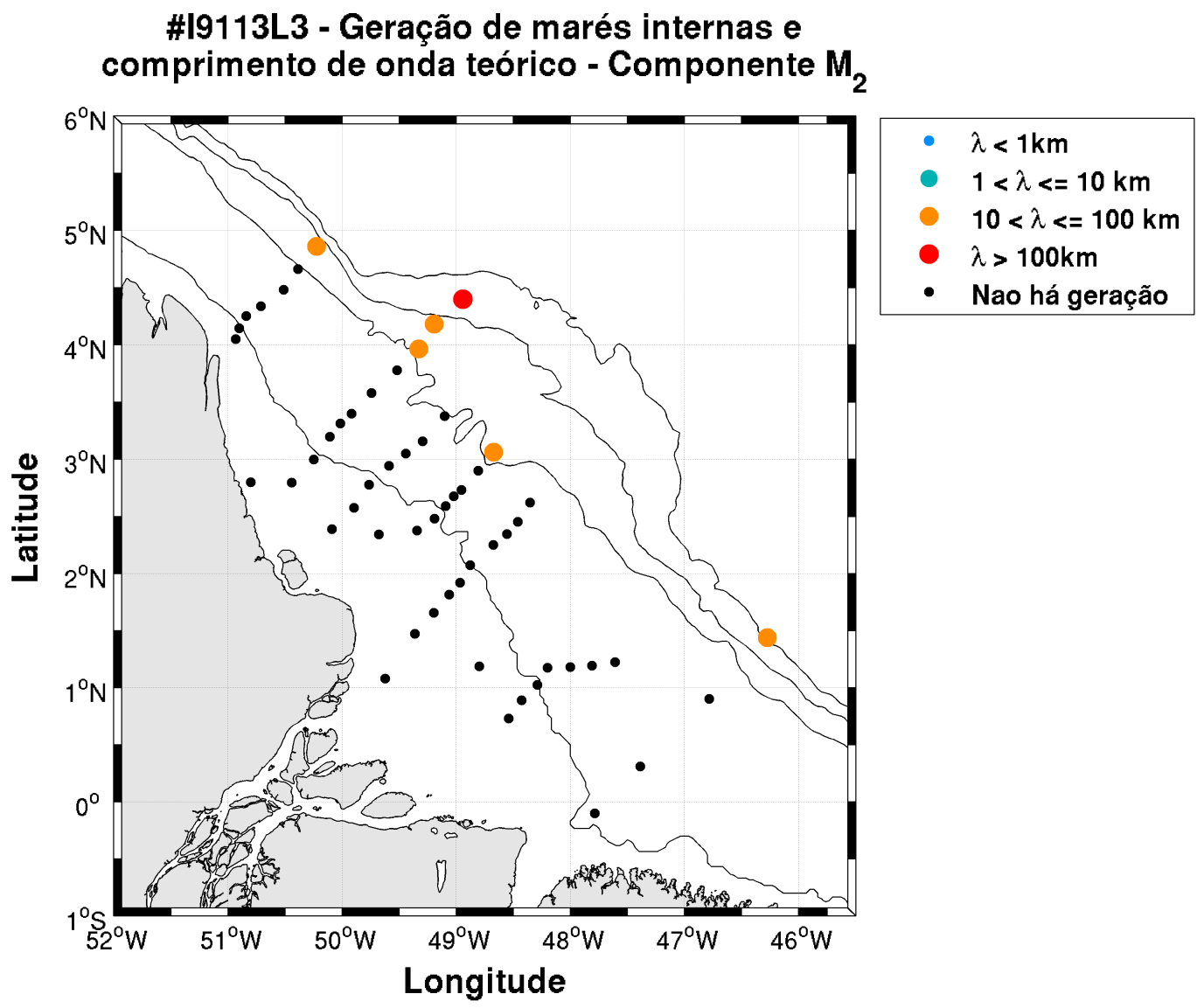

Figura 21: Possíveis locais geradores de maré interna para a componente $\mathrm{M}_{2}$ durante o cruzeiro I113L3, primeira pernada, na primeira quinzena de novembro de 1991, período de vazão mínima do Rio Amazonas. A legenda mostra a ordem de grandeza dos comprimentos de onda calculados para o primeiro modo baroclínico. As linhas pretas representam as isóbatas de 20 m, 100 m, 1000 m e $2000 \mathrm{~m}$. 


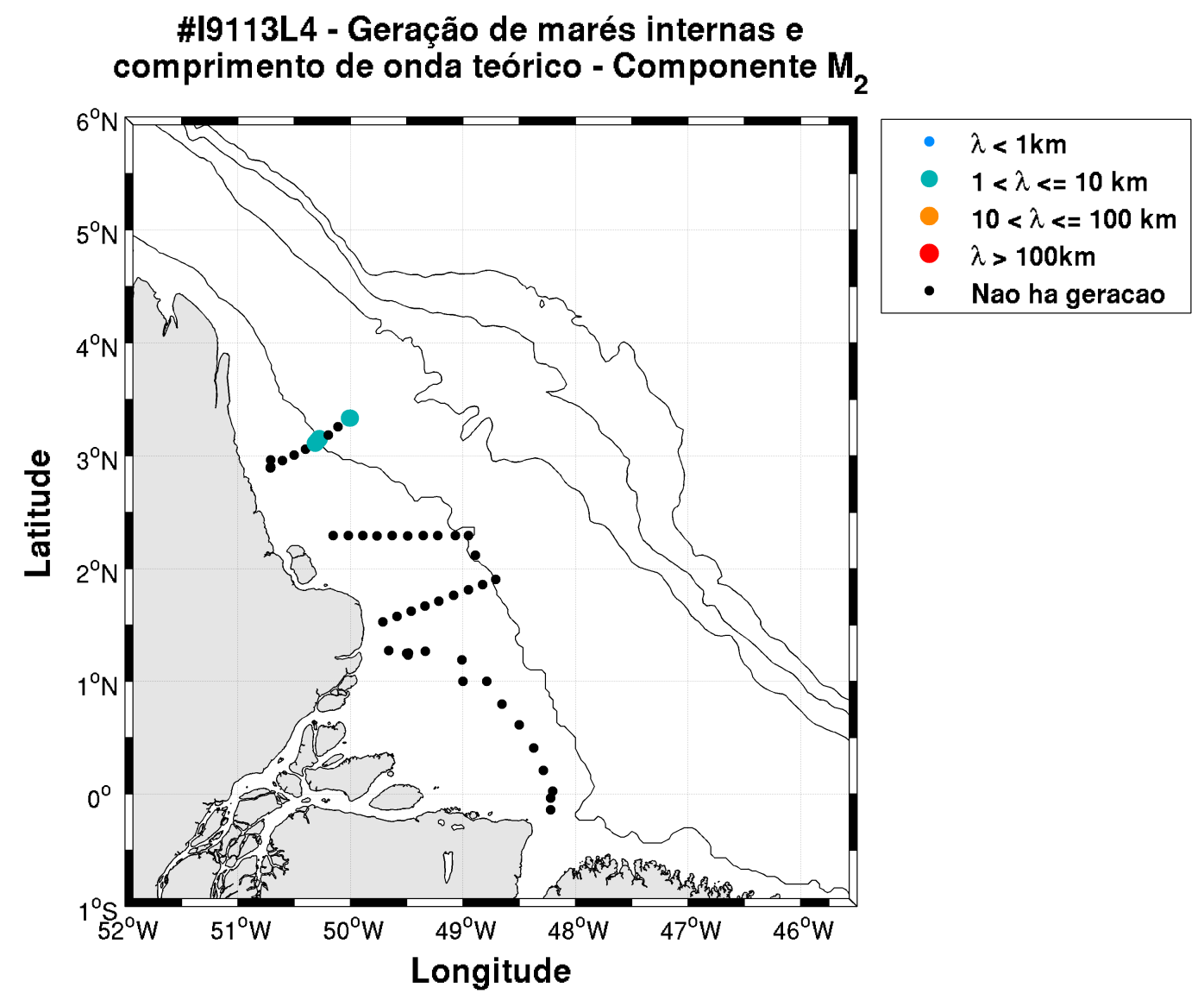

Figura 22: Possíveis locais geradores de maré interna para a componente $\mathrm{M}_{2}$ durante o cruzeiro I9113L4, segunda pernada, na segunda quinzena de novembro de 1991, período de vazão mínima do Rio Amazonas. A legenda mostra a ordem de grandeza dos comprimentos de onda calculados para o primeiro modo baroclínico. As linhas pretas representam as isóbatas de 20 m, 100 m, 1000 m e $2000 \mathrm{~m}$.

Nota-se, nos 4 períodos analisados (Figuras 18 a 22), que há um viés para a geração de marés internas nas estações próximas à quebra da plataforma continental. Esse é um resultado esperado, uma vez que a quebra de plataforma e o talude continental representam locais potencias para a geração em consequência da inclinação do fundo. Observa-se ainda a influência da época do ano, aliada à variabilidade da vazão do RA na estratificação de densidade da PCA e, consequentemente, na geração das marés internas. Para os períodos de transição, de vazão decrescente (agosto) ou crescente (fevereiro- 
março) (Figuras 18 e 19), a distribuição de pontos de possível geração é semelhante, com preferência para as regiões próximas ao talude. O comprimento de onda teórico das ondas nesses cruzeiros, agosto e fevereiro, é, em média, da ordem de $\mathrm{O}\left(10^{5}\right) \mathrm{m}$. Nesse período não há, potencialmente, na região interna e média da plataforma, geração de marés internas.

O período de vazão máxima (junho) (Figura 20), não apresentou nenhum ponto com potencial para geração de marés internas. Tal fato pode ser explicado pela influência da pluma do rio reduzindo a estratificação nas estações sobre a plataforma. Neste cruzeiro observamos a influência da pluma em algumas estações localizadas em isóbatas superiores a 100 m (não apresentado) numa faixa vertical de aproximadamente 15 m, com variação de salinidade de mais de 5 PSU e variação de densidade de $4 \mathrm{~kg} \mathrm{~m}^{-3}$.

Já para o período de vazão mínima (novembro), a primeira pernada, cruzeiro I9113L3 (Figura 21), apresenta possível geração de marés internas apenas nas regiões de quebra de plataforma e talude continental. Nas estações onde há potencial para geração, os comprimentos de onda próximo à quebra de plataforma possuem ordem de grandeza semelhante ao encontrado para os períodos de vazão intermediária e, na estação mais afastada da quebra, próximo à isóbata de 2000 m, o comprimento de onda teórico tem ordem de grandeza de $\mathrm{O}\left(10^{6}\right) \mathrm{m}$. A segunda pernada do cruzeiro hidrográfico em período de vazão mínima (Figura 22), teve estações hidrográficas até a isóbata de $40 \mathrm{~m}$ e foi o único cruzeiro a apresentar possibilidade de geração de marés internas na plataforma, em estações próximas à isóbata de $20 \mathrm{~m}$. Com a vazão em seu momento mínimo, a pluma do rio se restringe à parte costeira da PCA, diferentemente do observado para as outras épocas do ano (LENTZ e LIMEBURNER, 1995). A estação que indicou possibilidade de geração fez parte de uma série de estações ancoradas com 24 lançamentos horários de CTD. Estimamos valor médio para $N$, abaixo da picnoclina de, $\sim 0,05 \mathrm{~s}^{-1}$, que é grande quando comparado a trabalhos correlatos, como o de Holloway et al. (2001) (valor médio de $0,01 \mathrm{~s}^{-1}$ ) para a plataforma noroeste australiana. Dessa forma, seguindo a equação para a inclinação da característica da onda interna (Equação 1.1), a mesma é muito pequena, da ordem de $10^{-3}$ graus em relação à horizontal. Ao compararmos com a 
inclinação de fundo (Equação 1.3), que nessa região também é da ordem de $10^{-3}$, chegamos a valores críticos e supercríticos para a geração de marés internas. Uma explicação para esse resultado é o fato que, mesmo com a vazão mínima, o rio ainda descarrega cerca de $80 \times 10^{3} \mathrm{~m}^{3} \mathrm{~s}^{-1}$ de água na PCA. Nessa região de mistura da pluma com águas da plataforma, ainda há um gradiente de densidade alto, o que aumenta a frequência de estratificação e, como a frequência de estratificação é inversamente proporcional à inclinação da característica, quanto maior $N^{2}$, menor é a inclinação das características, favorecendo, teoricamente, a geração de ondas internas. Ao analisarmos a Figura 22, nos deparamos com locais de geração próximos aos pontos de ocorrência de sólitons propagando para o largo, apresentados por Jackson e Apel (2004).

Os resultados obtidos para os cruzeiros AMASSedS, no que tange à geração de marés internas, sugerem que a existência dessas ondas é possível e que a variabilidade da vazão do Rio Amazonas influencia diretamente sua geração na Plataforma Continental Amazônica e adjacências, como a quebra de plataforma e o talude continental. Indicam, ainda, que em casos de vazão mínima, há possibilidade de geração em regiões mais costeiras da plataforma. 


\subsection{Fundeios}

Apresentamos aqui os resultados obtidos pela aplicação da metodologia proposta na Seção 5.2.

\subsubsection{Análise gráfica das séries de correntes}

\section{Análise das componentes escalares u e v}

Analisando as componentes quase-perpendicular à costa $u$, e quase-paralela à costa $v$, separadamente (Figuras 23 a 28), podemos observar a dominância das oscilações de maré na primeira e a influência marcante das forçantes submaregráficas na segunda, embora esta última também possua energia notável na banda maregráfica. Essas componentes da velocidade foram decompostas aos moldes das Equações 5.2.1 e 5.2.2 em barotrópica e baroclínica, sendo também apresentadas nas Figuras 23 a 28. 
Analisando as Figuras 23 e 24 nota-se, ainda, para ambas as componentes $u$ e $v$, no ponto F1, a dominância das marés nas variabilidades das profundidades amostradas, nas frequências diurnas e subdiurnas, além de sinais significativos no período quinzenal, referentes à modulação de sizígia e quadratura. A amplitude da velocidade $u$ observada variou entre $\pm 1,5 \mathrm{~ms}^{-1}( \pm 1,5=-1,5 \mathrm{a}+1,5)$ durante a maré de sizígia e entre $\pm 1,0$ $\mathrm{ms}^{-1}$ durante a maré de quadratura, tanto a 3 quanto a $16 \mathrm{~m}$ de profundidade. Já para a velocidade $v$, a $3 \mathrm{~m}$, a corrente observada possui velocidades positivas com intensidade em torno de $1,5 \mathrm{~ms}^{-1}$ durante a sizígia e amplitude de aproximadamente $\pm 0,5 \mathrm{~ms}^{-1}$ durante a quadratura. À $16 \mathrm{~m}$ a corrente paralela é menos intensa oscilando entre $\pm 0,5 \mathrm{~ms}^{-1}$ durante a sizígia e entre $\pm 0,3 \mathrm{~ms}^{-1}$ durante a quadratura. A componente baroclínica da corrente $u$ apresenta pacotes de velocidades mais altas, de até $\approx \pm 1,4 \mathrm{~ms}^{-1}$ um pouco após a sizígia e $\pm 0,5 \mathrm{~ms}^{-1} \operatorname{logo}$ após o período de quadratura para ambas as profundidades analisadas. A componente baroclínica $v$ possui velocidade preferencialmente positivas a 3 m e com mesma ordem de grandeza da velocidade observada. A $16 \mathrm{~m}$ a velocidade possui menor intensidade que a $3 \mathrm{~m}$, com modulação mais correspondente à maré. A Tabela 3 mostra alguns momentos estatísticos para o ponto F1. Nesta tabela nota-se a dominância do fluxo perpendicular às isóbatas, evidenciado pela variância da série. Percebe-se a pouca influência do modo barotrópico na direção quase-paralela à costa, uma vez que a velocidade $v$ baroclínica é semelhante à observada. 


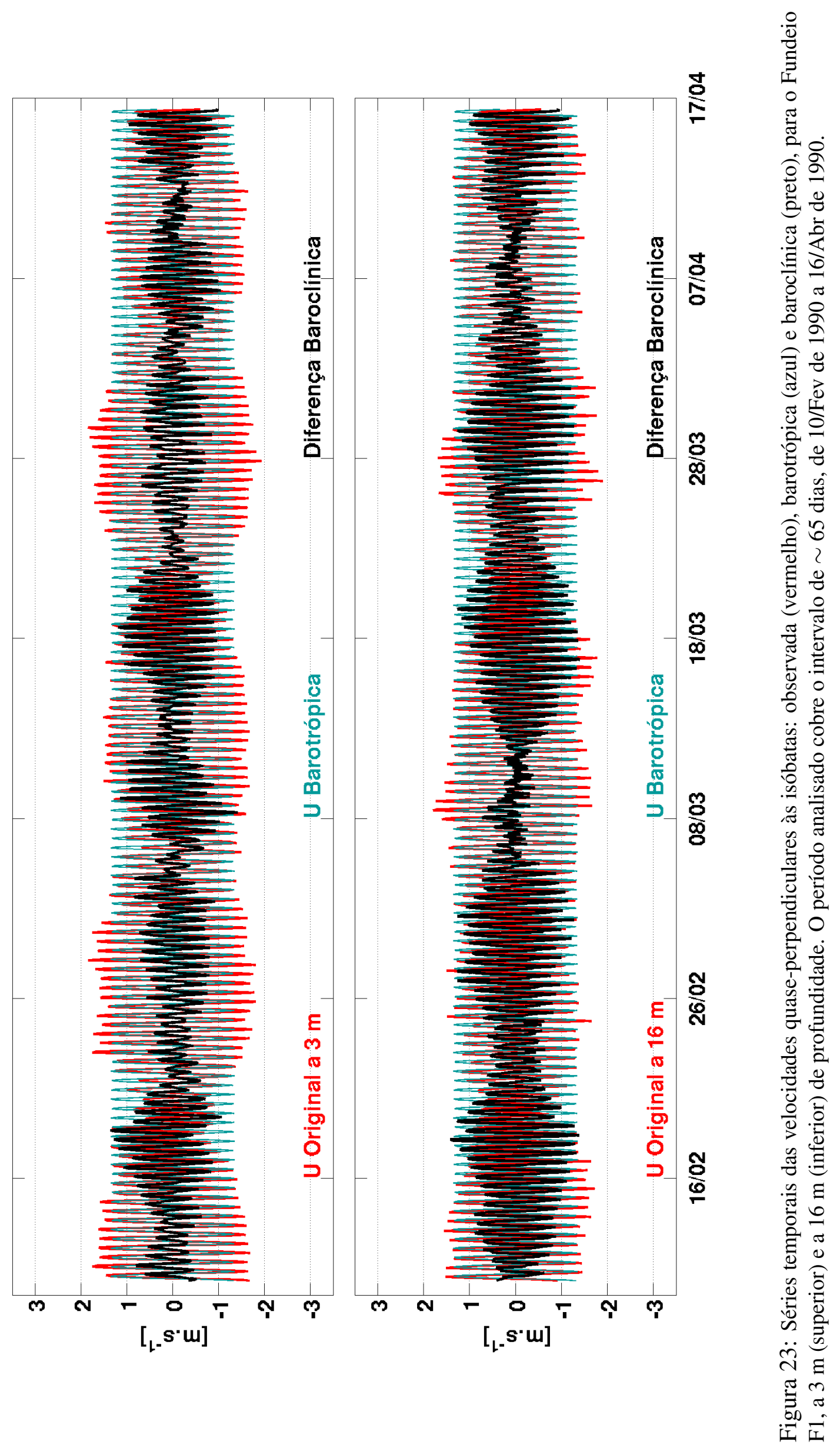




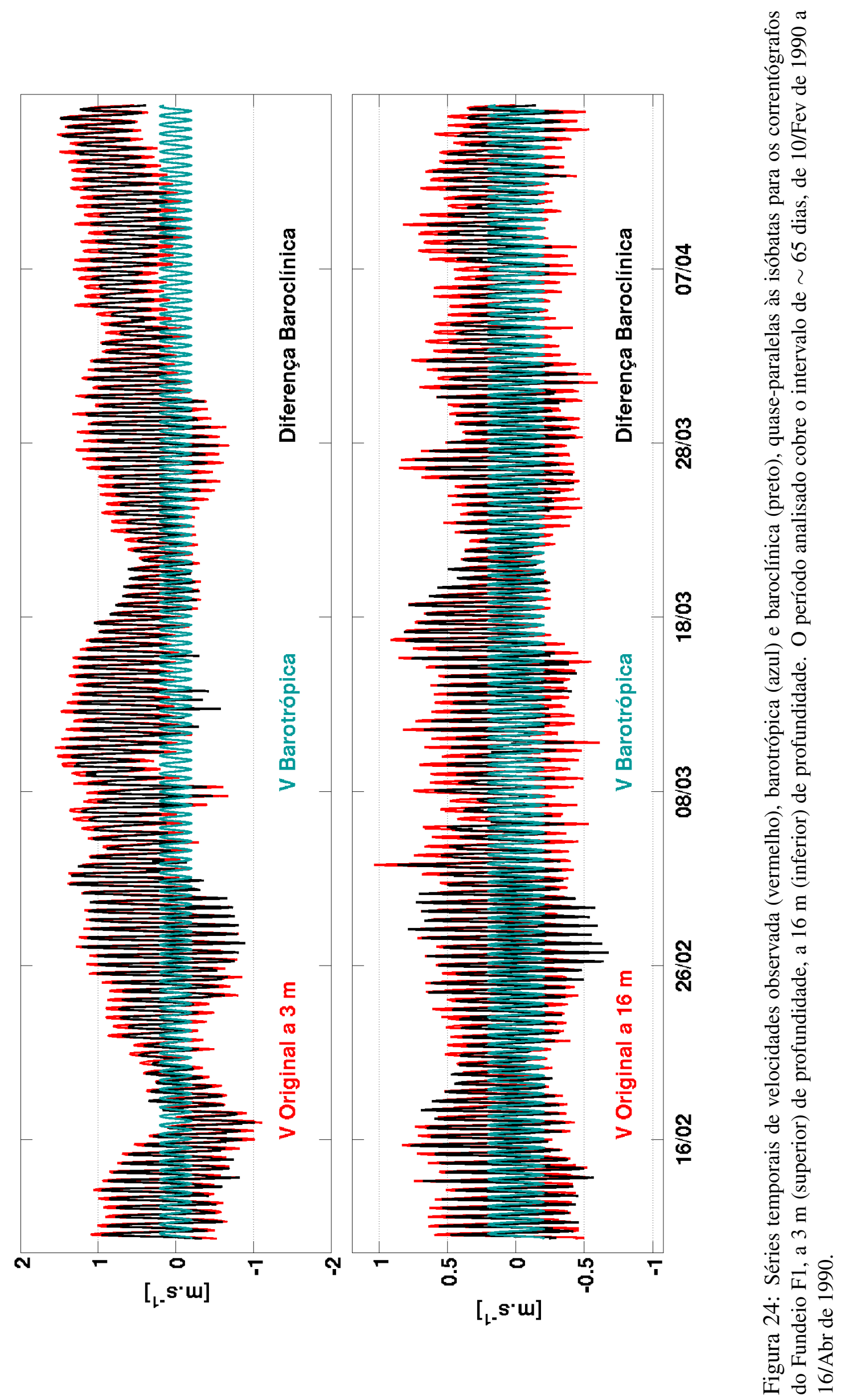


Tabela 3: Estatística básica para o Fundeio F1. $u$ é a componente da velocidade quase-perpendicular às isóbatas e $v$ é a componente da velocidade quase-paralela às isóbatas.

\section{Máximo Mínimo Média Desvio Padrão Variância}

$$
\left(m s^{-\mathbf{1}}\right) \quad\left(m s^{-\mathbf{1}}\right) \quad\left(m s^{-\mathbf{1}}\right) \quad\left(m s^{-\mathbf{1}}\right) \quad\left(m^{2} s^{-2}\right)
$$

Série de velocidades observadas

\begin{tabular}{llllll}
\hline$u-3 \mathbf{~ m}$ & 1,85 & $-1,93$ & $-0,04$ & 1,01 & 1,02 \\
$u-\mathbf{1 6} \mathbf{~ m}$ & 1,79 & $-1,90$ & $-0,01$ & 0,89 & 0,8 \\
\hline$v-3 \mathbf{~ m}$ & 1,56 & $-1,11$ & 0,38 & 0,58 & 0,34 \\
$v-\mathbf{1 6} \mathbf{~ m}$ & 1,04 & $-0,61$ & 0,08 & 0,36 & 0,13 \\
\hline
\end{tabular}

Série de velocidades barotrópicas (FONTES et al., 2008)

\begin{tabular}{llllll}
\hline$u$ & 1,35 & $-1,35$ & 0,00 & 0,95 & 0,91 \\
$v$ & 0,21 & $-0,21$ & 0,00 & 0,15 & 0,02 \\
\hline
\end{tabular}

Série de velocidades baroclínicas

\begin{tabular}{llllll}
\hline$u-3 \mathbf{~ m}$ & 1,36 & $-1,41$ & 0,04 & 0,44 & 0,20 \\
$u-\mathbf{- 1 6} \mathbf{~ m}$ & 1,42 & $-1,40$ & $-0,02$ & 0,57 & 0,33 \\
\hline$v-3 \mathbf{~ m}$ & 1,48 & $-1,02$ & 0,38 & 0,51 & 0,26 \\
$v-\mathbf{1 6} \mathbf{~ m}$ & 0,86 & $-0,68$ & $-0,08$ & 0,28 & 0,08 \\
\hline \hline
\end{tabular}

As correntes perpendiculares às isóbatas, no ponto F2, observadas a $3 \mathrm{~m}$ (Figura 25) apresentam amplitudes entre $\pm 0,5 \mathrm{~ms}^{-1}$, com alguns valores superiores a $\pm 1 \mathrm{~ms}^{-1}$, na maioria dos casos positivos e em épocas de maré de sizígia. Em épocas de quadratura as correntes possuem intensidade menor, com amplitudes próximas $\pm 0,3 \mathrm{~ms}^{-1}$. Nesta mesma profundidade a componente paralela às isóbatas (Figura 26), apresenta velocidades preferencialmente positivas com variações em períodos diurnos e semi-diurnos somadas a oscilações de baixa frequência, não sendo possível visualização clara de variações entre sizígia e quadratura. 


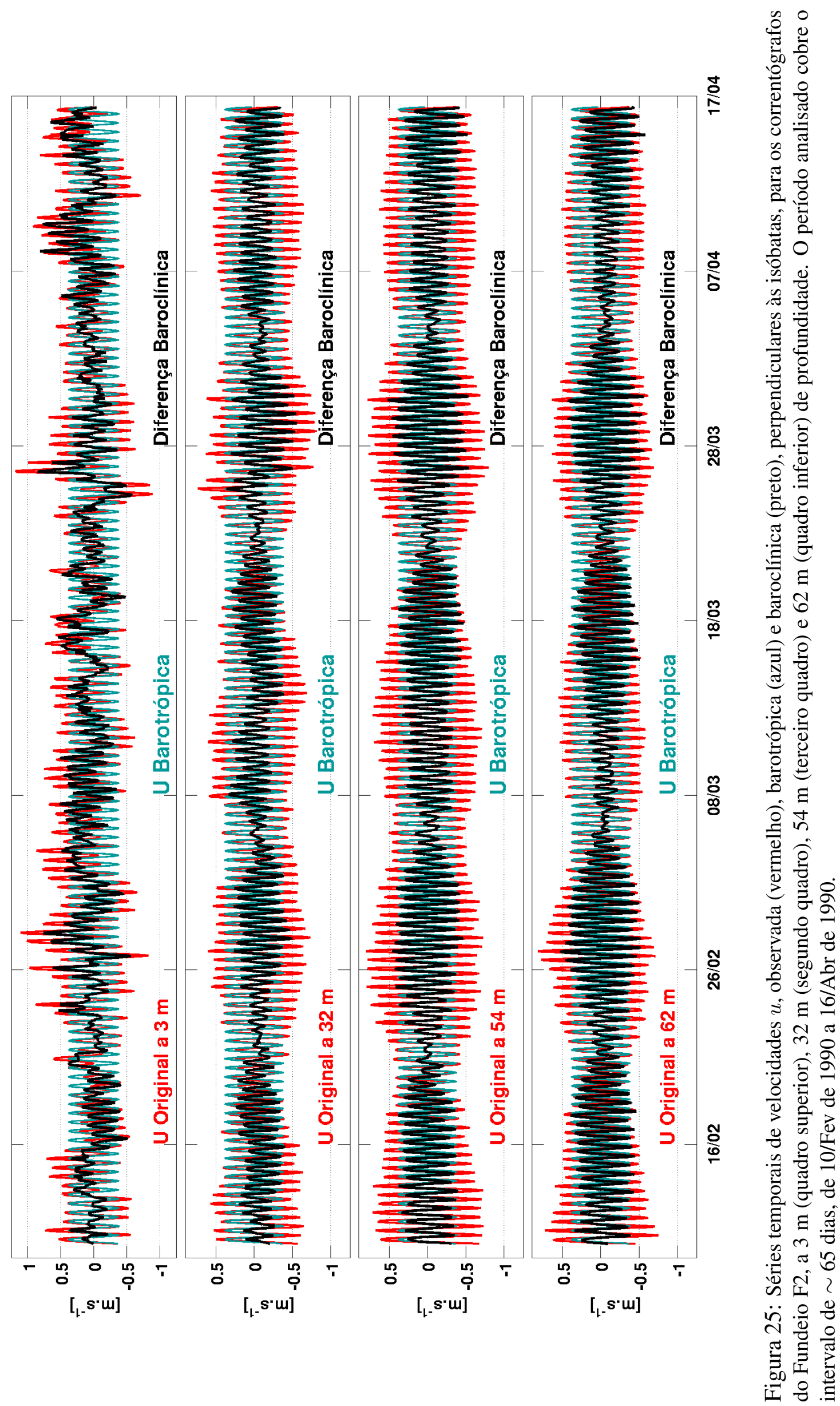


A 32 m no ponto F2 (Figuras 25 e 26), a amplitude da velocidade observada $u$ varia entre de $\pm 0,5 \mathrm{~ms}^{-1}$ durante a sizígia e $\pm 0,3 \mathrm{~ms}^{-1}$ durante a quadratura, enquanto que a velocidade $v$ varia entre 0 e $0,7 \mathrm{~ms}^{-1}$, influenciada pela maré semi-diurna sobreposta a oscilações com escalas temporais maiores. A $54 \mathrm{~m}$, a corrente $u$ é pouco mais intensa do que a observada a $32 \mathrm{~m}$, com amplitudes de $\pm 0,7 \mathrm{~ms}^{-1}$ durante a sizígia e $\pm 0,4 \mathrm{~ms}^{-1}$ durante a quadratura. As componentes $v$ a $54 \mathrm{~m}$ e $62 \mathrm{~m}$ apresentam séries similares, com pequenas variações positivas entre 0 e $0,3 \mathrm{~ms}^{-1}$. Já a $62 \mathrm{~m}$ de profundidade a velocidade $u$ apresenta-se pouco menos intensa que a $54 \mathrm{~m}$, tendo valores de aproximadamente \pm 0,6 $\mathrm{ms}^{-1}$ em sizígia e $\pm 0,3 \mathrm{~ms}^{-1}$ em quadratura. Para as componentes barotrópicas deste ponto (Figuras 25 e 26), a velocidade varia entre $\pm 0,6 \mathrm{~ms}^{-1} \mathrm{e} \pm 0,3 \mathrm{~ms}^{-1}$, com dominância das oscilações maregráficas e variações entre as épocas de sizígia e de quadratura. A componente barotrópica $v$ apresenta variações regulares com a maré, com valores positivos oscilando entre $0,05 \mathrm{~ms}^{-1}$ e $0,55 \mathrm{~ms}^{-1}$. Neste ponto $\mathrm{F} 2$, a componente baroclínica da velocidade $u$, a $3 \mathrm{~m}$, apresenta valores próximos a $\pm 0,3 \mathrm{~ms}^{-1}$, com modulação condizente com épocas de sizígia e quadratura e alguns picos de até $0,6 \mathrm{~ms}^{-1}$. A velocidade $v$ baroclínica a $3 \mathrm{~m}$ apresenta-se com mesma ordem de grandeza que a barotrópica, sendo por vezes mais intensa e, ainda, com variações similares à corrente $v$ observada. A $32 \mathrm{~m}$, a corrente $u$ apresenta valores entre $\pm 0,1 \mathrm{~ms}^{-1}$, com alguns picos um pouco maiores que $\pm 0,2 \mathrm{~ms}^{-1}$. Nesta profundidade, $v$ baroclínica está com fase oposta à $v$ barotrópica, e com intensidade menor. A $54 \mathrm{~m}$ e $62 \mathrm{~m}$, a corrente perpendicular baroclínica está modulada pela maré, apresentando variações entre sizígia e quadratura regulares e intensidades um pouco maiores no correntômetro mais profundo, ambas entre $\pm 0,2 \mathrm{~ms}^{-1}$. A 54 e a $62 \mathrm{~m}$ as correntes paralelas às isóbatas têm comportamento similar, com velocidades sempre negativas entre 0 e $-0,5 \mathrm{~ms}^{-1}$. A Tabela 4 agrupa os primeiros momentos estatísticos das séries de velocidade observada, barotrópica e baroclínica para o ponto F2. Os valores de máximos, mínimos, média e desvio padrão, apresentam decaimento com a profundidade. A variância também decresce à medida que a profundidade aumenta. 


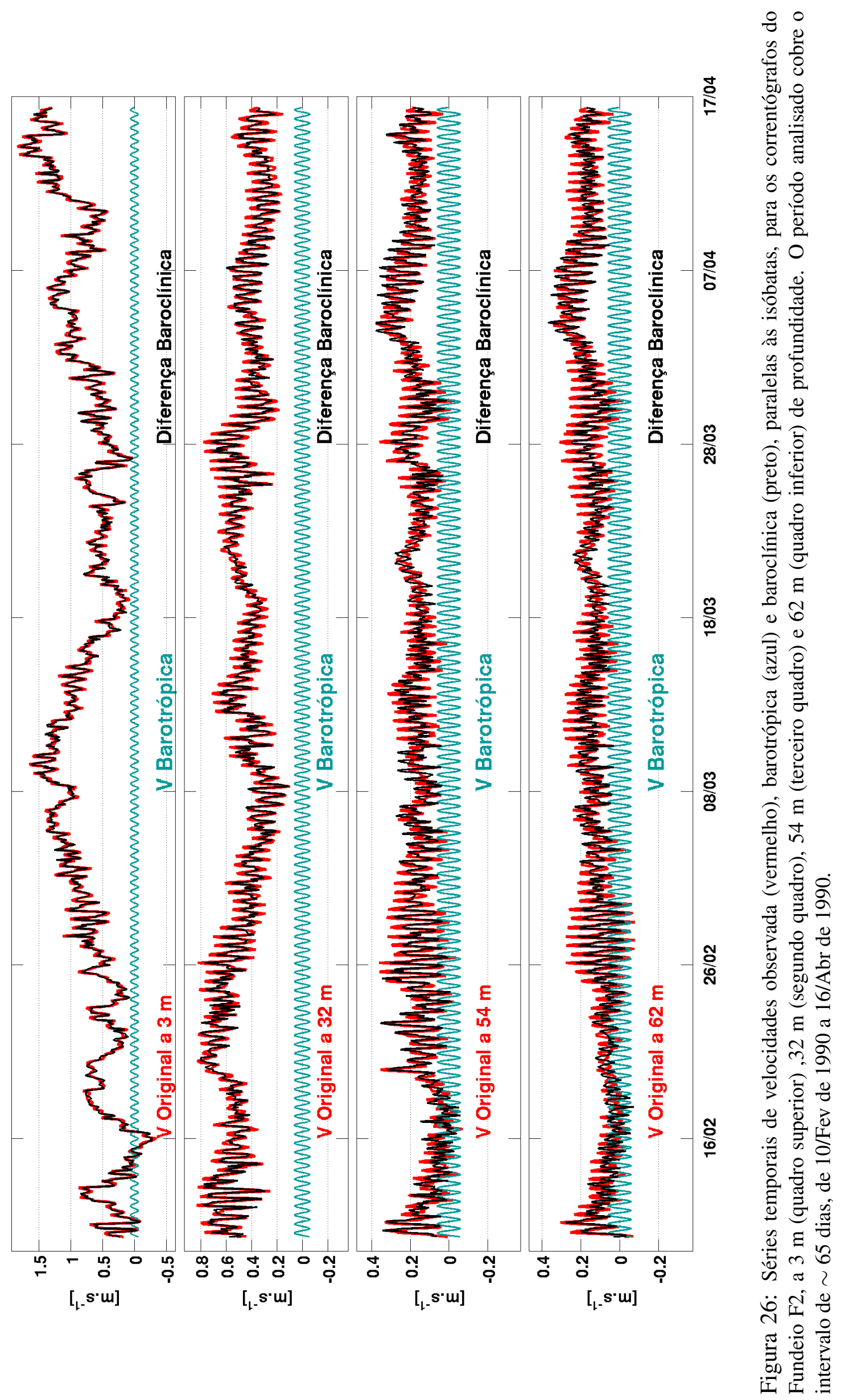


Tabela 4: Estatística básica para o Fundeio F2. $u$ é a componente da velocidade quase-perpendicular às isóbatas e $v$ é a componente da velocidade quase-paralela às isóbatas.

Máximo Mínimo Média Desvio Padrão Variância

$\left(m s^{1}\right) \quad\left(m s^{-1}\right) \quad\left(m s^{-1}\right) \quad\left(m s^{-1}\right) \quad\left(m^{2} s^{-2}\right)$

Série de velocidades observadas

\begin{tabular}{|c|c|c|c|c|c|}
\hline$u-3 \mathrm{~m}$ & 1,19 & $-0,89$ & 0,07 & 0,35 & 0,12 \\
\hline$u-32 \mathrm{~m}$ & 0,73 & $-0,81$ & $-0,06$ & 0,35 & 0,12 \\
\hline$u-54 \mathrm{~m}$ & 0,80 & $-0,79$ & $-0,03$ & 0,41 & 0,17 \\
\hline$u-62 \mathrm{~m}$ & 0,82 & $-0,75$ & $-0,05$ & 0,35 & 0,12 \\
\hline$v-3 \mathbf{~ m}$ & 1,84 & $-0,34$ & 0,74 & 0,41 & 0,16 \\
\hline$v-\mathbf{3 2} \mathbf{m}$ & 0,83 & 0,10 & 0,46 & 0,14 & 0,00 \\
\hline$v-54 \mathrm{~m}$ & 0,38 & $-0,07$ & 0,16 & 0,08 & 0,01 \\
\hline$v-62 \mathrm{~m}$ & 0,34 & $-0,08$ & 0,13 & 0,08 & 0,01 \\
\hline
\end{tabular}

Componentes da velocidade barotrópica (FONTES et al., 2008)

\begin{tabular}{llllll}
\hline$u$ & 0,39 & $-0,39$ & 0,00 & 0,27 & 0,07 \\
$v$ & 0,06 & $-0,06$ & 0,00 & 0,04 & 0,00 \\
\hline
\end{tabular}

Componentes da velocidade baroclínica

\begin{tabular}{|c|c|c|c|c|c|}
\hline$u-3 \mathrm{~m}$ & 0,85 & $-0,57$ & 0,07 & 0,21 & 0,04 \\
\hline$u-32 \mathrm{~m}$ & 0,36 & $-0,56$ & $-0,06$ & 0,16 & 0,03 \\
\hline$u-54 \mathrm{~m}$ & 0,52 & $-0,54$ & $-0,03$ & 0,22 & 0,05 \\
\hline$u-62 \mathrm{~m}$ & 0,53 & $-0,58$ & $-0,05$ & 0,21 & 0,04 \\
\hline$v-\mathbf{3} \mathbf{~ m}$ & 1,79 & $-0,28$ & 0,74 & 0,40 & 0,16 \\
\hline$v-32 \mathrm{~m}$ & 0,80 & $-0,11$ & 0,46 & 0,13 & 0,02 \\
\hline$v-54 \mathrm{~m}$ & 0,38 & $-0,06$ & 0,16 & 0,07 & 0,01 \\
\hline$v-62 \mathrm{~m}$ & 0,37 & $-0,07$ & 0,13 & 0,07 & 0,01 \\
\hline
\end{tabular}


O ponto F3 apresenta maior espaçamento vertical entre os correntômetros. Neste, as correntes perpendiculares às isóbatas (Figura 27) decaem com os quase 60 metros que separam os níveis de observação. A velocidade da corrente perpendicular a $32 \mathrm{~m}$, durante a sizígia, varia entre $\pm 0,5 \mathrm{~ms}^{-1}$, enquanto que a $93 \mathrm{~m}$ a corrente possui valores entre $\pm 0,4$ $\mathrm{ms}^{-1}$. Já em condições de quadratura as correntes a $32 \mathrm{~m}$ e a $93 \mathrm{~m}$ variam entre $\pm 0,2 \mathrm{~ms}^{-1}$. Neste ponto, a componente paralela da velocidade observada (Figura 28) apresenta, a 32 $\mathrm{m}$ profundidade, velocidades intensas sempre positivas, acima de $0,5 \mathrm{~ms}^{-1}$, com amplitude em torno de $1,0 \mathrm{~ms}^{-1}$. Nota-se a influência da maré semi-diurna sobreposta às oscilações de maior período. A $93 \mathrm{~m}$, a componente paralela apresenta velocidades sempre positivas, reguladas pela maré, com amplitude em torno de $0,2 \mathrm{~ms}^{-1}$. Ainda para o ponto $\mathrm{F} 3$ , as correntes baroclínicas $u$ e $v$ (Figuras 27 e 28) apresentam comportamento similar às correntes observadas a $32 \mathrm{~m}$, com amplitudes um pouco menores. A Tabela 5 mostra os primeiros momentos estatísticos para as séries de velocidade observada, barotrópica e baroclínica neste ponto. Os valores obtidos de variância, desvio padrão, média, mínimo e máximo decrescem com a profundidade. 


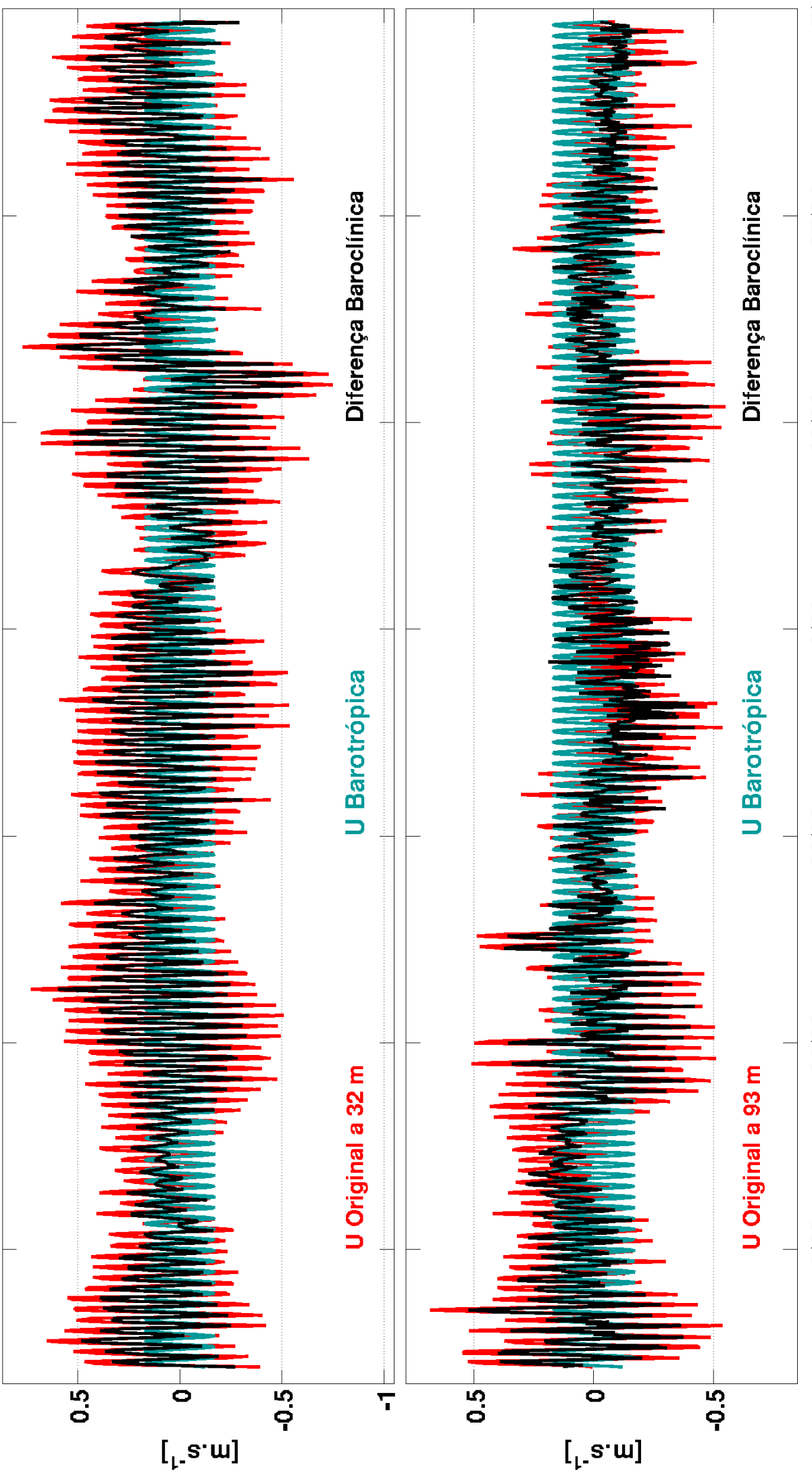

荡

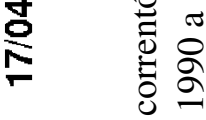

\% 용

ํํㄹ

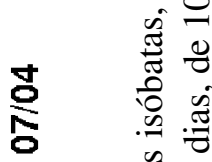

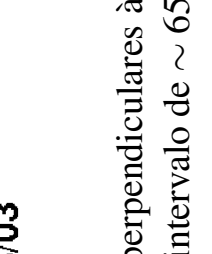

क्ष

$\hat{0} 0$
0
0

흥 응

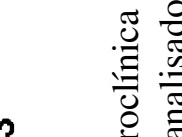

3 :

$\stackrel{0}{\circ} \div$

蛋

త్ర

离

\%

o

过

จ

\%

ชิ ลे

宽 0

흥

의

$\div$. 잏

흥

छ ํㅛ

के ले

这

$\ddot{\text { ป }} \cdot \frac{0}{8}$

콩

60, I 


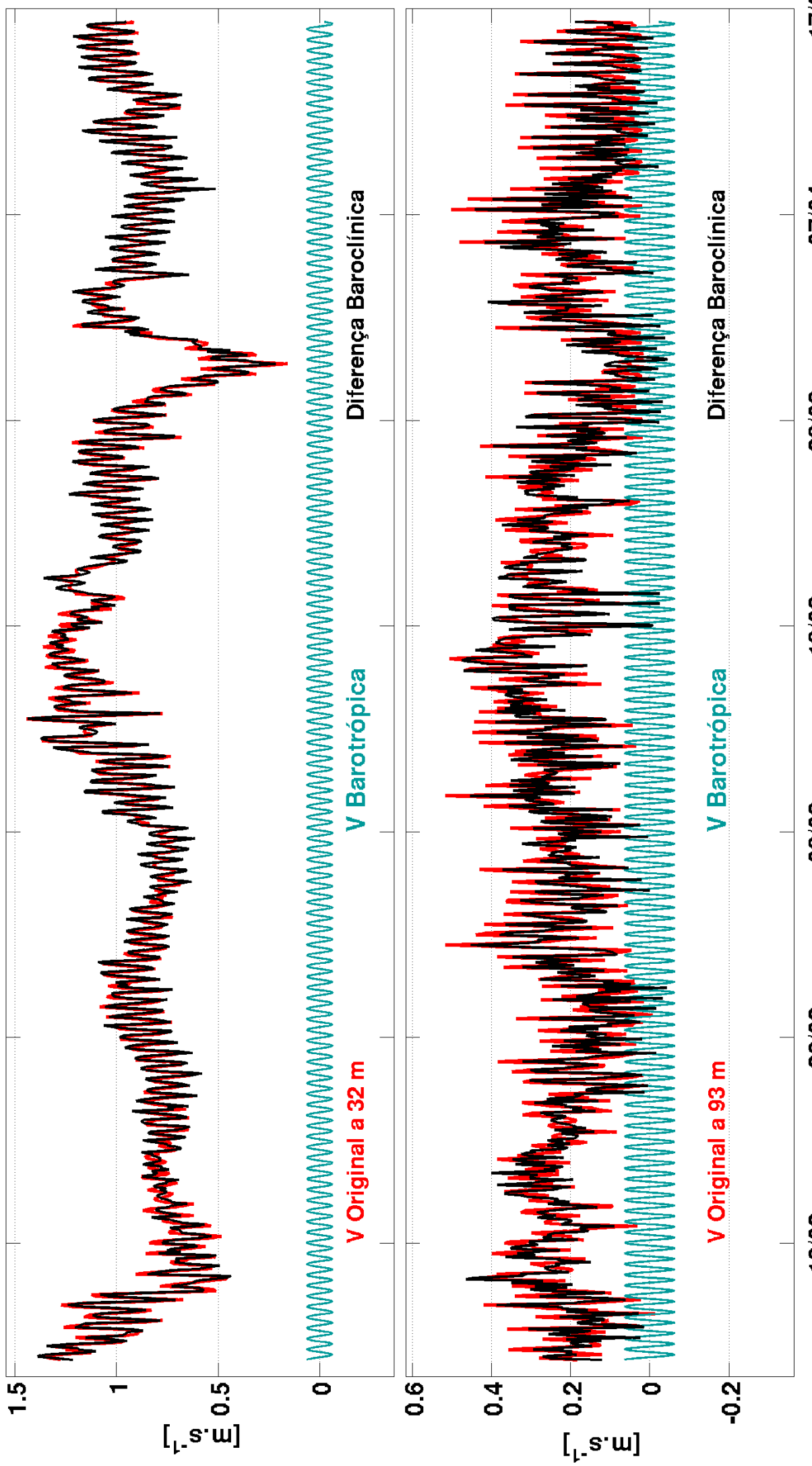

ष

융

용

:

뜛

\& $\quad \frac{8}{0}$

今 吾

용

휸 $\frac{0}{7}$

$8 \quad 2$

क्ष

है.

ซ 8

寻 웅

寻

\% ํํㅇ สำ

क 0

촗

ซึ 0

율

颉

\% )

各

뉼

중

ऽ

ง

कृ

त

잉

$\stackrel{\overrightarrow{0}}{>}$

ऽ

을 कू

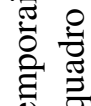

छ्च ह

$\approx \Xi$

है ले

$\ddot{\infty}$ ஸे

茟高 
Tabela 5: Estatística básica para o Fundeio F3. $u$ é a componente da velocidade quase-perpendicular às isóbatas e $v$ é a componente da velocidade quase-paralela às isóbatas.

\begin{tabular}{ccccc} 
Máximo & Mínimo & Média & Desvio Padrão & Variância \\
\hline$\left(m s^{-\mathbf{1}}\right)$ & $\left(m s^{-\mathbf{1}}\right)$ & $\left(m s^{-\mathbf{1}}\right)$ & $\left(m s^{-\mathbf{1}}\right)$ & $\left(\mathrm{m}^{2} \mathrm{~s}^{-2}\right)$ \\
\hline
\end{tabular}

Série de velocidades observadas

\begin{tabular}{llllll}
\hline$u$ - 32 m & 0,77 & $-0,75$ & 0,08 & 0,28 & 0,08 \\
$u$ - $93 \mathbf{~ m}$ & 0,68 & $-0,55$ & $-0,03$ & 0,19 & 0,04 \\
\hline$v$ - 32 $\mathbf{~ m}$ & 1,44 & 0,16 & 0,91 & 0,20 & 0,04 \\
$v$ - 93 m & 0,52 & $-0,01$ & 0,20 & 0,10 & 0,01 \\
\hline \hline
\end{tabular}

Série de velocidades barotrópicas (FONTES et al., 2008)

\begin{tabular}{llllll}
$u$ & 0,17 & $-0,17$ & 0,0 & 0,12 & 0,01 \\
\hline$v$ & 0,06 & $-0,06$ & 0,0 & 0,04 & 0,00
\end{tabular}

Série de velocidades baroclínicas

\begin{tabular}{llllll}
\hline$u$ - $32 \mathbf{~ m}$ & 0,60 & $-0,60$ & 0,08 & 0,19 & 0,04 \\
\hline$u$ - $93 \mathbf{~ m}$ & 0,52 & $-0,48$ & $-0,03$ & 0,13 & 0,02 \\
\hline$v$ - $32 \mathbf{~ m}$ & 1,44 & 0,22 & 0,91 & 0,20 & 0,04 \\
\hline$v$ - $93 \mathbf{~ m}$ & 0,47 & $-0,04$ & 0,20 & 0,10 & 0,01 \\
\hline \hline
\end{tabular}




\section{Análise dos vetores de corrente baroclínica}

Apresentamos nas Figuras 29 a 31 séries temporais dos vetores velocidade baroclínica para os 3 pontos amostrados na PCA. A descrição desta componente da velocidade necessita de um melhor embasamento para que sejam caracterizadas com rigor. Analisamos ainda, espectral e harmônicamente essas mesmas séries nas Seções 6.2.2 e 6.2.3.

No ponto F1 (Figura 29) a $3 \mathrm{~m}$, as correntes são visualmente difusas até o primeiro terço da série (26/02) e, a partir daí, mostram movimento preferencial para NO, influenciado pela maré. A 16 m, as correntes não apresentam direção preferencial de propagação, provavelmente por estar próximo à camada limite de fundo, sendo moduladas também pela maré.

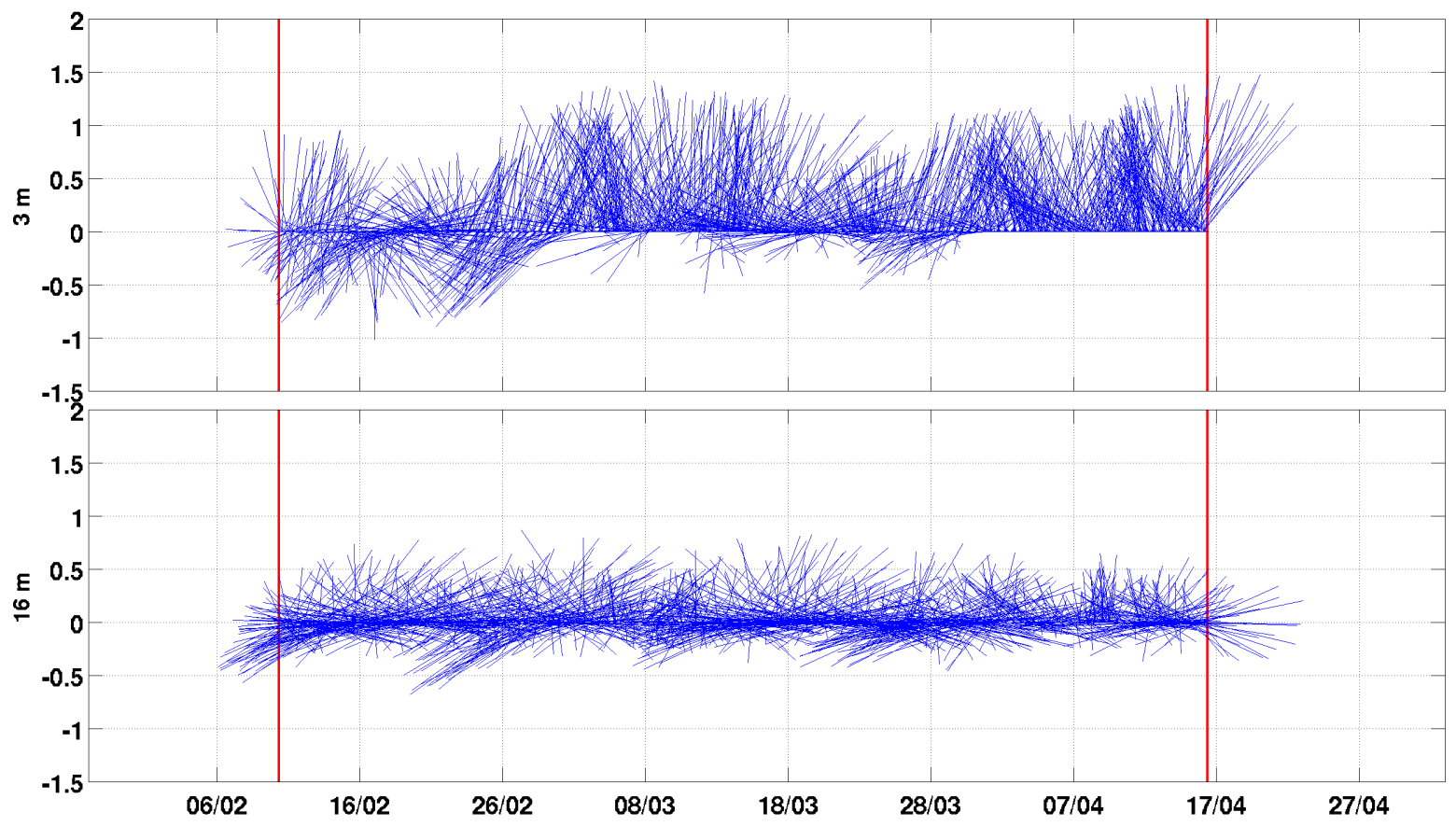

Figura 29: Série temporal dos vetores velocidade baroclínica para o Fundeio F1. O quadro superior mostra a série temporal a $3 \mathrm{~m}$ e o inferior a $16 \mathrm{~m}$. As correntes foram rotacionadas $55^{\circ}$ para Oeste, isto é, o eixo vertical aponta para $305^{\circ}$, deixando o mesmo quase paralelo à isóbata local. As linhas verticais vermelhas marcam o início e o fim do período amostrado

As correntes baroclínicas no ponto F2 (Figura 30) apresentam direções prefer- 
encias para NO nas duas primeiras profundidades, com intensidades raramente negativas e que decrescem com o aumento da profundidade. Nos dois pontos mais profundos, a velocidade apresenta maiores variações na direção e menores amplitudes do que nos dois pontos superiores, consequência da influência da camada limite de fundo. Em todas as profundidades as correntes são moduladas pela maré, sendo influenciadas por suas componentes com oscilações características de sizígia e quadratura.
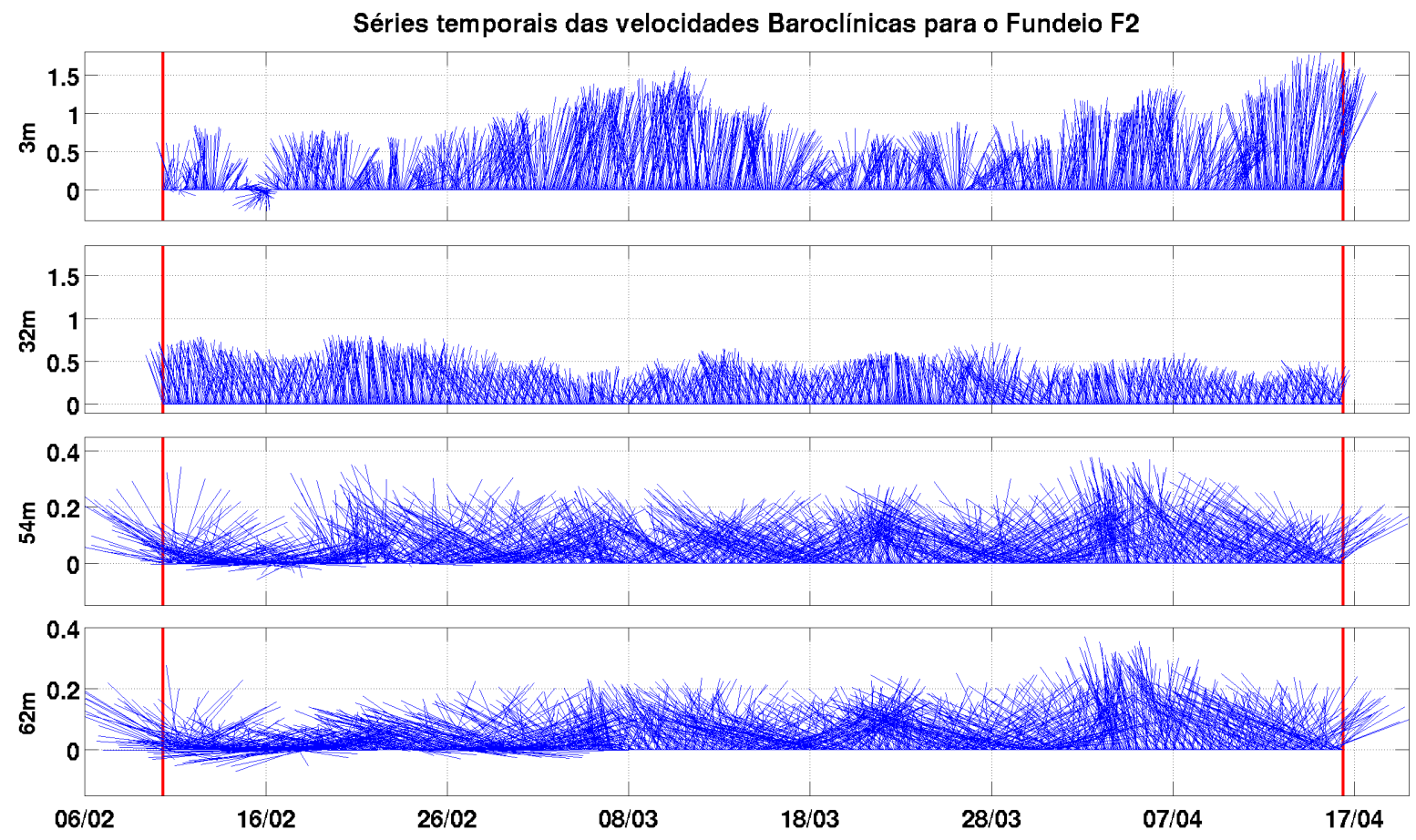

Figura 30: Série temporal dos vetores velocidade baroclínica para o Fundeio F2. Os quadros mostram as séries temporais, de cima para baixo a $3 \mathrm{~m}, 32 \mathrm{~m}, 54 \mathrm{~m}$ e a $62 \mathrm{~m}$. As correntes foram rotacionadas $45^{\circ}$ para Oeste, isto é, o eixo vertical aponta para $315^{\circ}$, deixando o mesmo quase paralelo à isóbata local. As linhas verticais vermelhas marcam o início e o fim do período amostrado.

As séries temporais de correntes baroclínicas no ponto F3 (Figura 31) mostram movimentos intensos preferencialmente para NO modulados pela maré e que decrescem com o aumento da profundidade. A $32 \mathrm{~m}$, as intensidades ultrapassam $1 \mathrm{~ms}^{-1}$, sendo sempre positivas e moduladas pela maré. Próximo ao fundo $(93 \mathrm{~m})$, as correntes são 
menos intensas, apresentando intensidades de até $0,5 \mathrm{~ms}^{-1}$ e, também, podemos verificar nelas a atuação da maré. Logo após o dia 28/03 nota-se mudança brusca na direção dos vetores, em ambas profundidades. Por afetar a velocidade, tanto a $32 \mathrm{~m}$ quanto a $93 \mathrm{~m}$, o fenômeno atuante cobriu mais de 70\% da coluna d'água. Por estar na borda da plataforma, este fenômeno pode estar ligado a algum meandro da CNB. Na Figura 28, percebem-se oscilações de baixa frequência com período aproximado de 30 dias, que pode também ser relacionado às oscilações da $\mathrm{CNB}$.
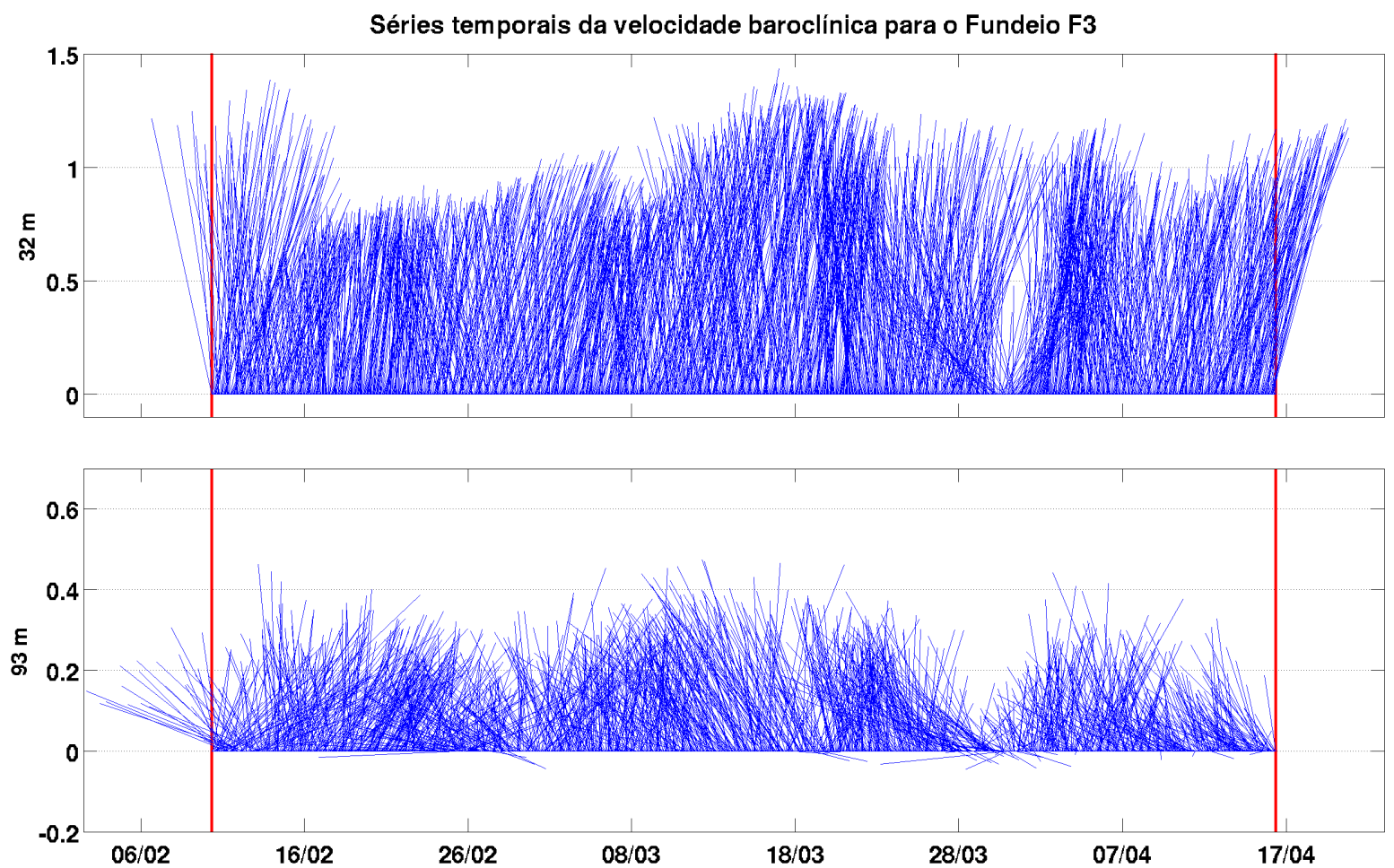

Figura 31: Série temporal dos vetores velocidade baroclínica para o Fundeio F3. Os quadros mostram as séries temporais, de cima para baixo a $32 \mathrm{~m}$ e a $93 \mathrm{~m}$. As correntes foram rotacionadas $45^{\circ}$ para Oeste, isto é, o eixo vertical aponta para $315^{\circ}$, deixando o mesmo quase paralelo à isóbata local. 


\subsubsection{Análise espectral das séries de corrente}

Estimamos a densidade espectral em cada série, para as componentes $u$ e $v$ da velocidade, para todas as profundidades amostradas nos fundeios (Figuras 32 a 39).

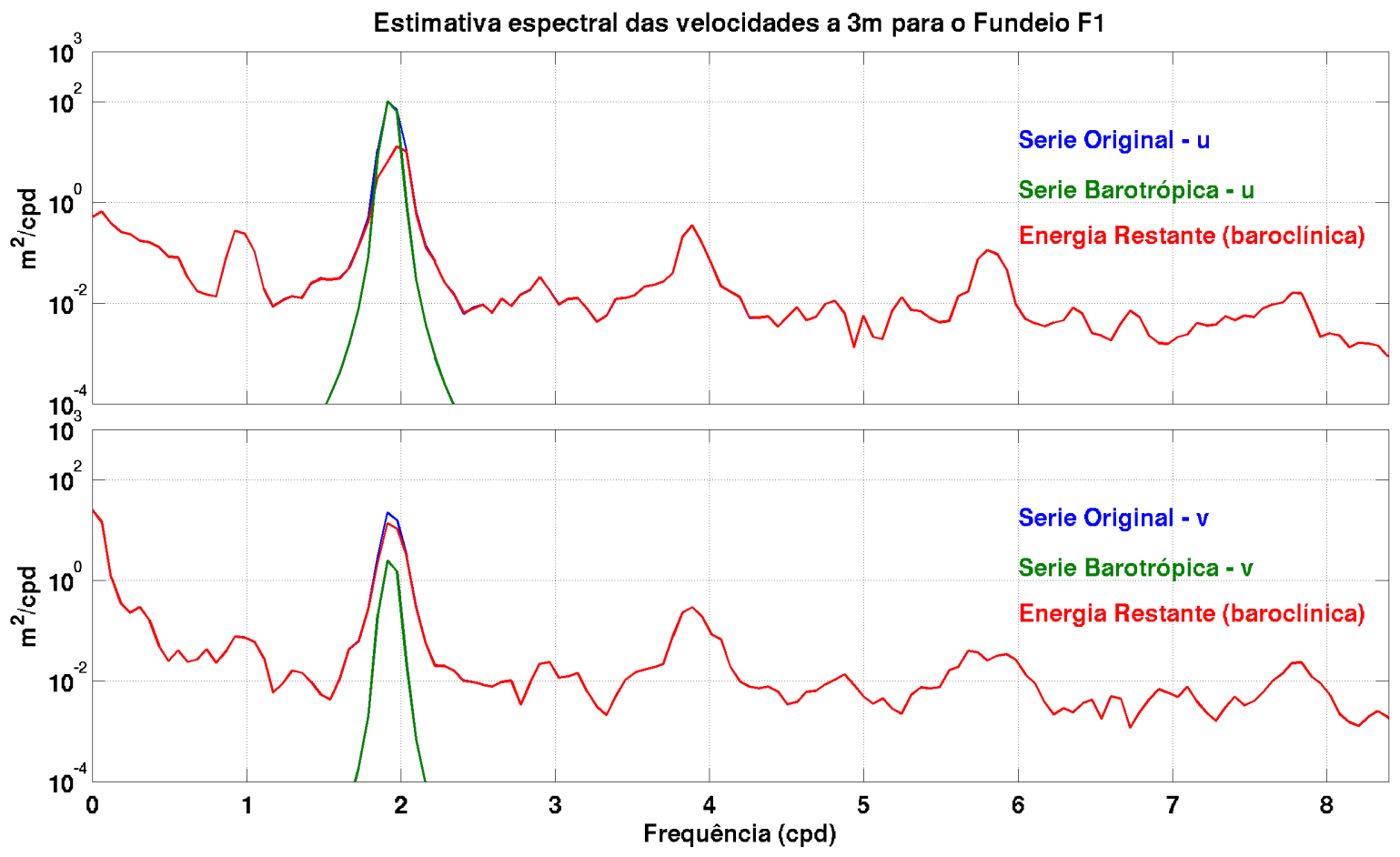

Figura 32: Estimativa de densidade espectral para as séries de velocidade medida(azul), barotrópica(verde) e baroclínica(vermelho) a $3 \mathrm{~m}$ de profundidade no Fundeio F1. O método utilizado, o periodograma de Welch, teve segmentos de 384 horas ( $\sim 16$ dias), com janela do tipo hanning e sobreposição de 50\% dos segmentos. Nos rótulos, cpd corresponde a ciclos por dia. 


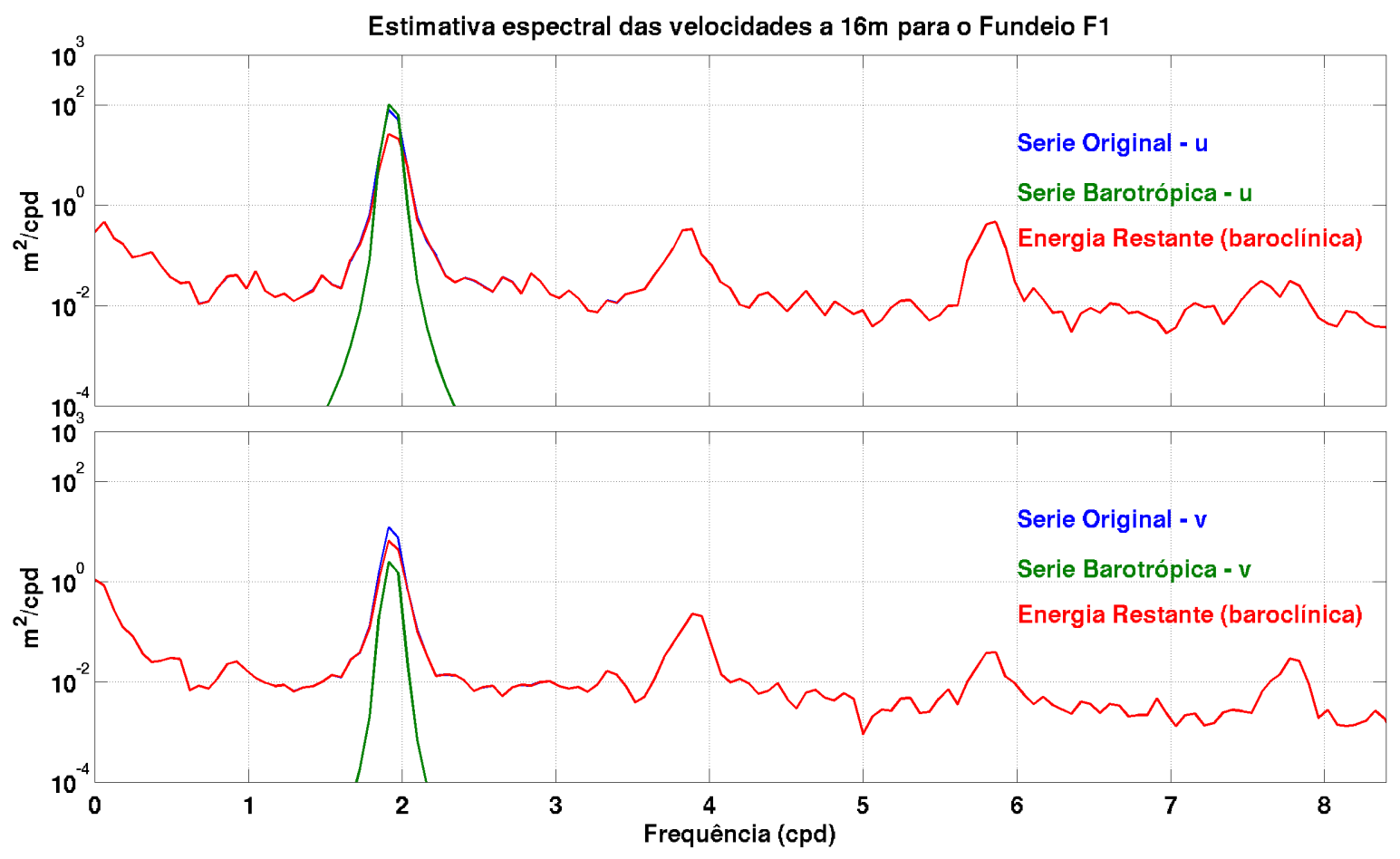

Figura 33: Estimativa de densidade espectral para as séries de velocidade medida(azul), barotrópica(verde) e baroclínica(vermelho) a 16 m de profundidade no Fundeio F1. O método utilizado, o periodograma de Welch, teve segmentos de 384 horas ( $\sim 16$ dias), com janela do tipo hanning e sobreposição de 50\% dos segmentos. Nos rótulos, cpd corresponde a ciclos por dia.

Para o fundeio F1 (Figuras 32 e 33), nota-se para a velocidade $u$, além do pico relativo às frequências semi-diurnas, picos menores nas frequências diurnas, quartodiurnas e sexto-diurnas. A energia baroclínica acompanha os picos de energia supracitados com ordem de grandeza menor, sendo iguais para as séries analisadas nas duas profundidades, $3 \mathrm{~m}$ e $16 \mathrm{~m}$, tanto para a velocidade $u$ quanto para $v$. Percebe-se que o pico na frequência semi-diurna é um pouco menor para a componente paralela do que para a perpendicular. Em baixas frequências há mais energia nas componentes paralelas do que nas perpendiculares. A distribuição de energia das séries, para ambas as componentes, é semelhante, sem diferenças marcantes em profundidade.

Para o fundeio F2 (Figuras 34 a 37), nota-se o decaimento da magnitude do espectro com o aumento da profundidade. Isso é perceptível comparando a magnitude do 
espectro da série barotrópica com as séries, original e baroclínica, na Figura 34, a 3 m e nas demais profundidades, a $32 \mathrm{~m}, 54 \mathrm{~m}$ e $62 \mathrm{~m}$ (Figuras 35, 36 e 37).

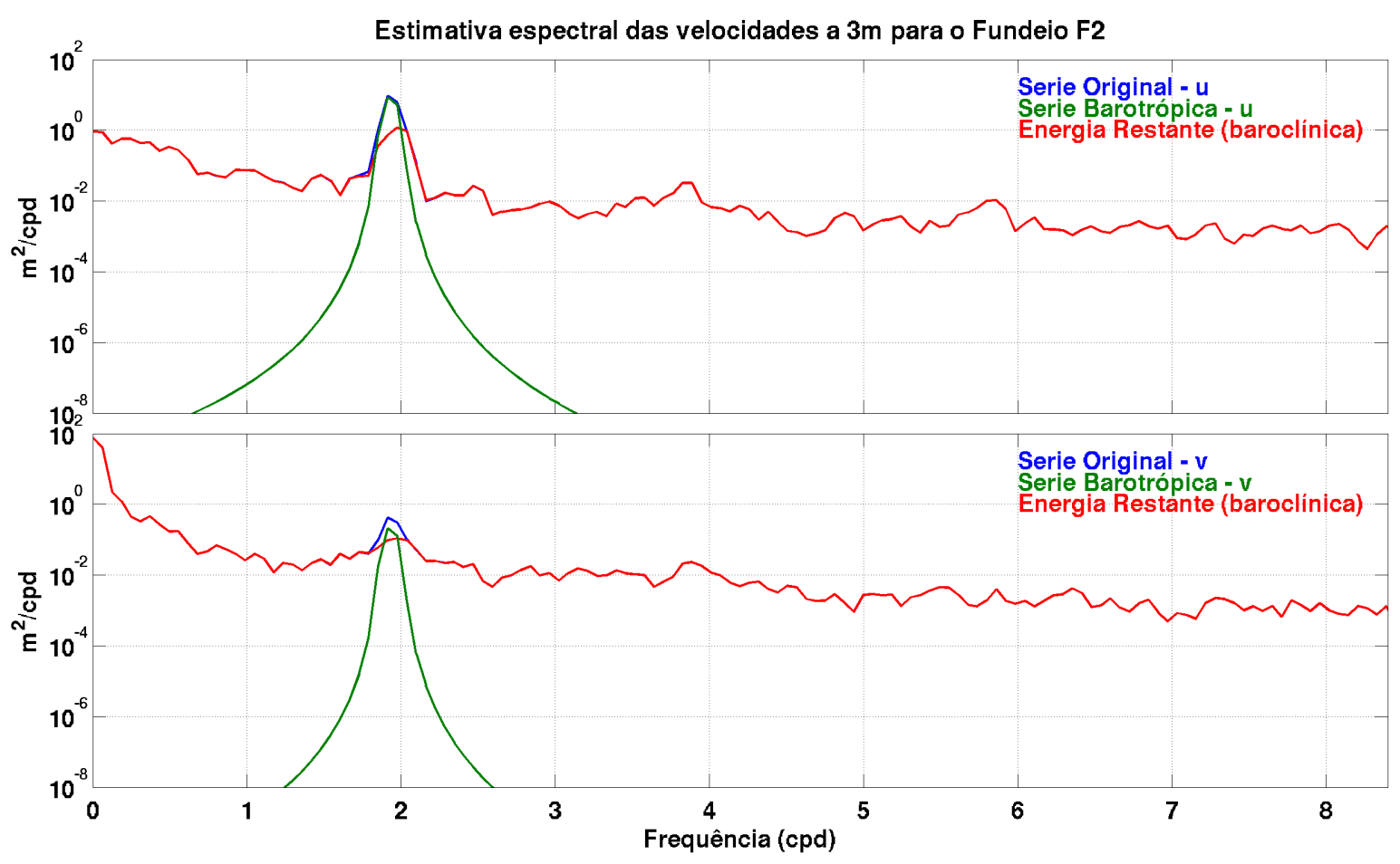

Figura 34: Estimativa de densidade espectral para as séries de velocidade medida (azul), barotrópica (verde) e baroclínica (vermelho) a $3 \mathrm{~m}$ de profundidade no Fundeio F2. O método utilizado, o periodograma de Welch, teve segmentos de 384 horas ( $\sim 16$ dias), com janela do tipo hanning e sobreposição de 50\% dos segmentos. Nos rótulos, cpd corresponde a ciclos por dia.

Como a energia barotrópica é semelhante para todas as profundidades, nota-se que a 3 m há mais energia nas séries originais e baroclínicas que nas demais profundidades. Além disso, para a velocidade $u$, nas Figuras 34 a 37, percebem-se picos de energia nas frequências semi-diurnas, diurnas e quarto diurnas. Para a velocidade $v$, nas profundidades maiores observam-se picos evidenciados nas frequências quarto-diurnas e sexto-diurnas e, a 3 m, nota-se energia em baixas frequências e na frequência semi-diurna.

A energia da velocidade $u$ baroclínica, nas frequências semi-diurnas, decresce com a profundidade de $3 \mathrm{~m}$ para $32 \mathrm{~m}$, aumentando em seguida com a profundidade, 
possuindo, a $3 \mathrm{~m}, 54 \mathrm{~m}$ e $62 \mathrm{~m}$, a mesma ordem de grandeza. A velocidade $v$ baroclínica, ao contrário do seu par $u$, apresenta decrescimento menor da energia com o aumento da profundidade, apresentando ainda, maior energia em baixas frequências.

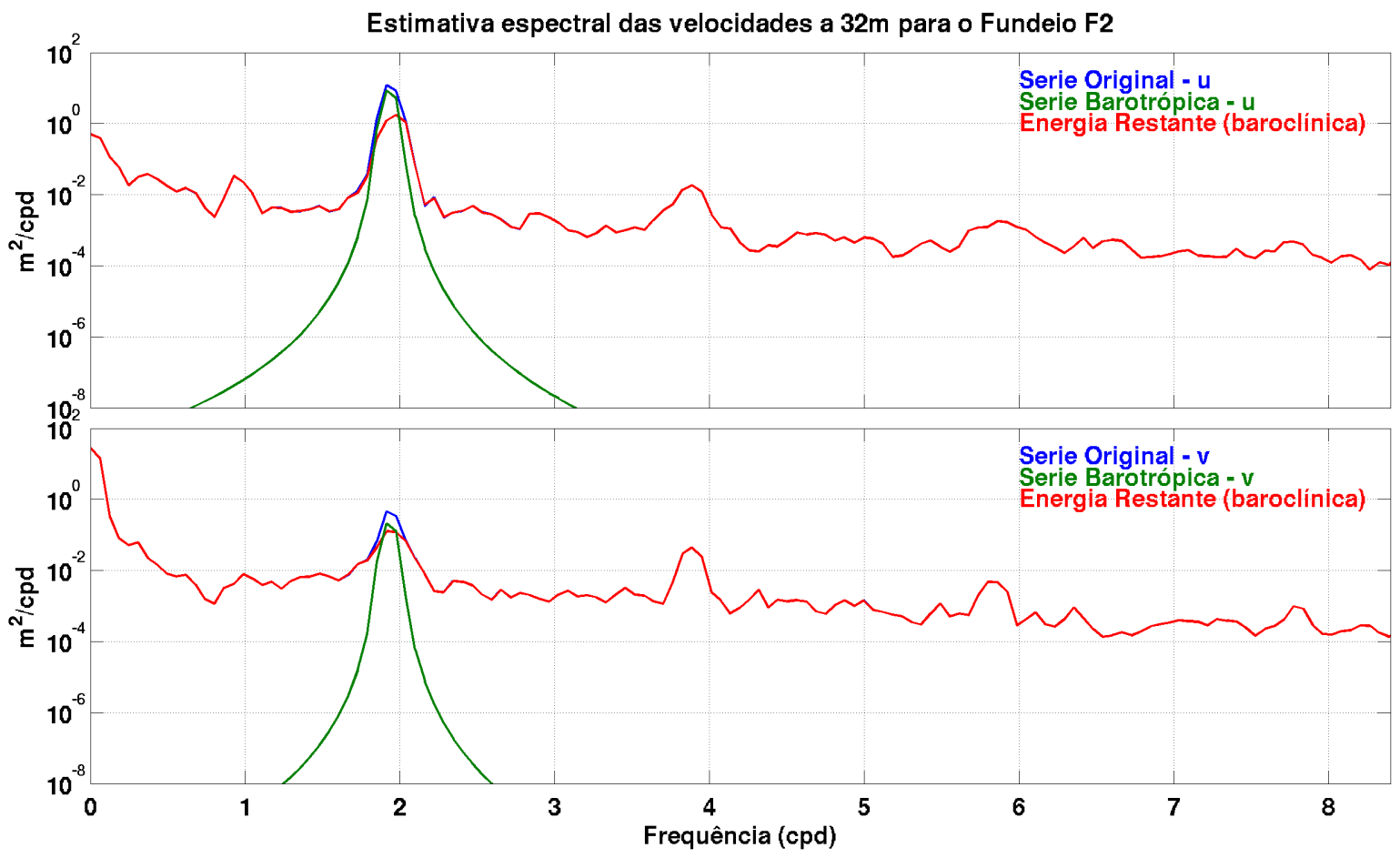

Figura 35: Estimativa de densidade espectral para as séries de velocidade medida (azul), barotrópica (verde) e baroclínica (vermelho) a $32 \mathrm{~m}$ de profundidade no Fundeio F2. O método utilizado, o periodograma de Welch, teve segmentos de 384 horas ( $\sim 16$ dias), com janela do tipo hanning e sobreposição de 50\% dos segmentos. Nos rótulos, cpd corresponde a ciclos por dia. 


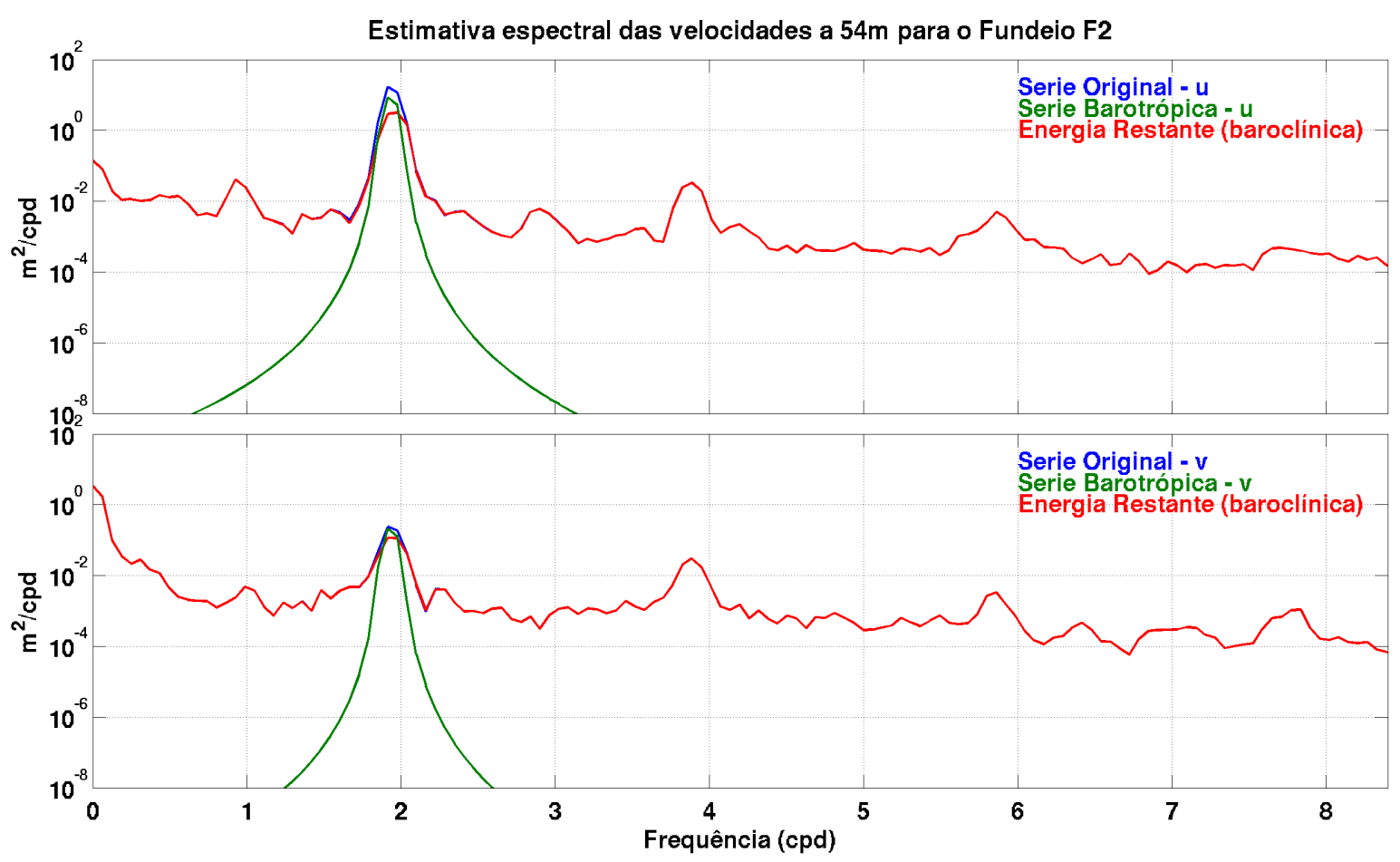

Figura 36: Estimativa de densidade espectral para as séries de velocidade medida (azul), barotrópica (verde) e baroclínica (vermelho) a $54 \mathrm{~m}$ de profundidade no Fundeio F2. O método utilizado, o periodograma de Welch, teve segmentos de 384 horas ( $\sim 16$ dias), com janela do tipo hanning e sobreposição de 50\% dos segmentos. Nos rótulos, cpd corresponde a ciclos por dia. 


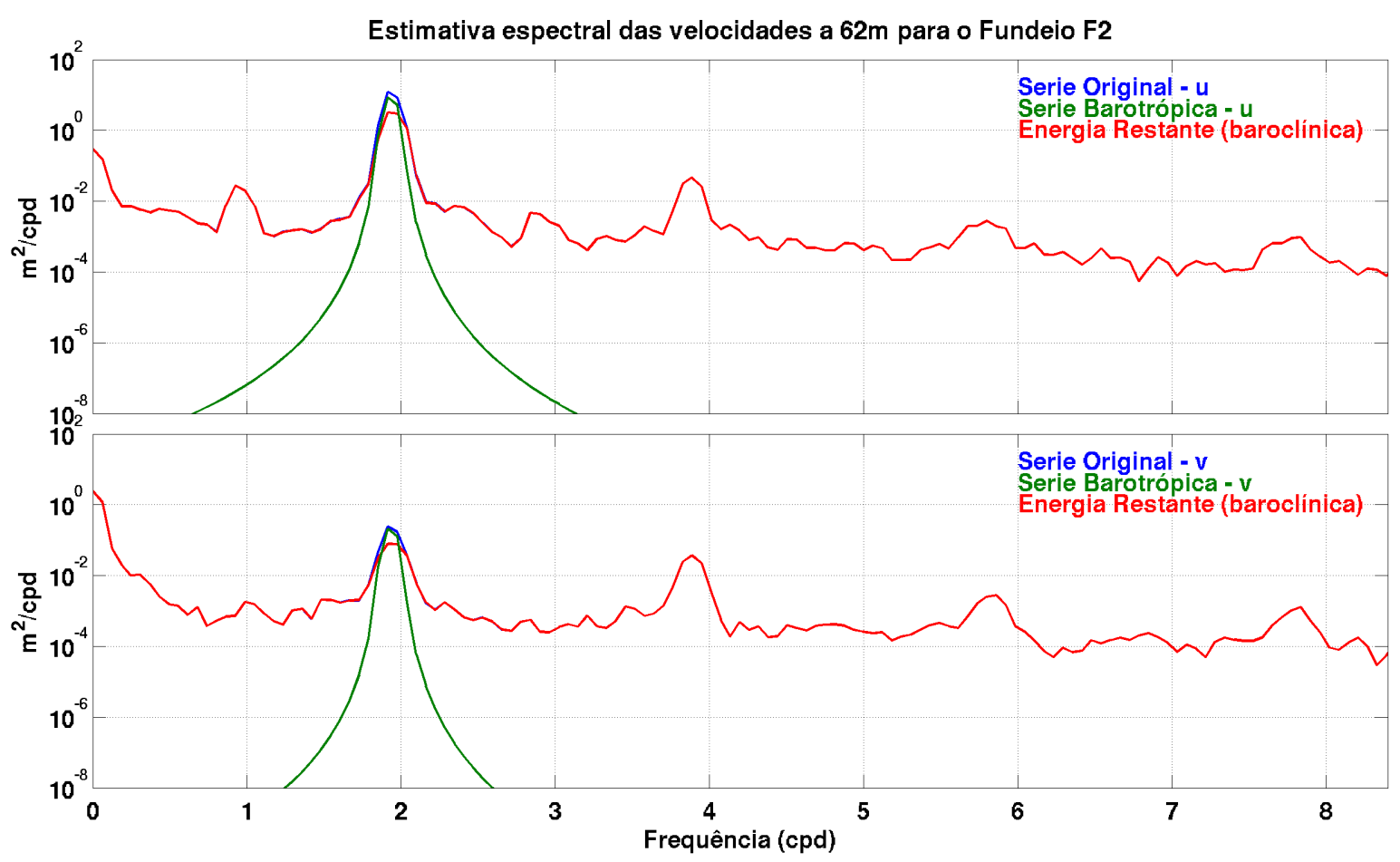

Figura 37: Estimativa de densidade espectral para as séries de velocidade medida (azul), barotrópica (verde) e baroclínica (vermelho) a $62 \mathrm{~m}$ de profundidade no Fundeio F1. O método utilizado, o periodograma de Welch, teve segmentos de 384 horas ( $\sim 16$ dias), com janela do tipo hanning e sobreposição de $50 \%$ dos segmentos. Nos rótulos, cpd corresponde a ciclos por dia.

Para o Fundeio F3 (Figuras 38 e 39), a análise do espectro para as séries originais não evidencia máximos de energia nas frequências diurnas e em frequências maiores que a semi-diurnas. A análise das séries originais para a velocidade $u$ mostra que há pequeno decréscimo da energia na escala semi-diurna entre as profundidades deste ponto. Ainda para a série original da velocidade $u$, em frequências mais baixas que a semi-diurna, há pequeno incremento de energia com a profundidade, enquanto que para frequências semidiurna e mais altas frequências há pequeno decréscimo com o aumento da profundidade. Para a velocidade $v$ original, a energia em frequências semi-diurnas e menores é maior a $32 \mathrm{~m}$ do que a $93 \mathrm{~m}$ enquanto que em frequências mais altas a energia decresce com o aumento da profundidade. Novamente, a frequência mais energétia é a semi-diurna. As séries baroclínicas nas duas profundidades analisadas, 32 m e 93 m são iguais, com picos, nas componentes paralela e perpendicular, na frequência semi-diurna. 


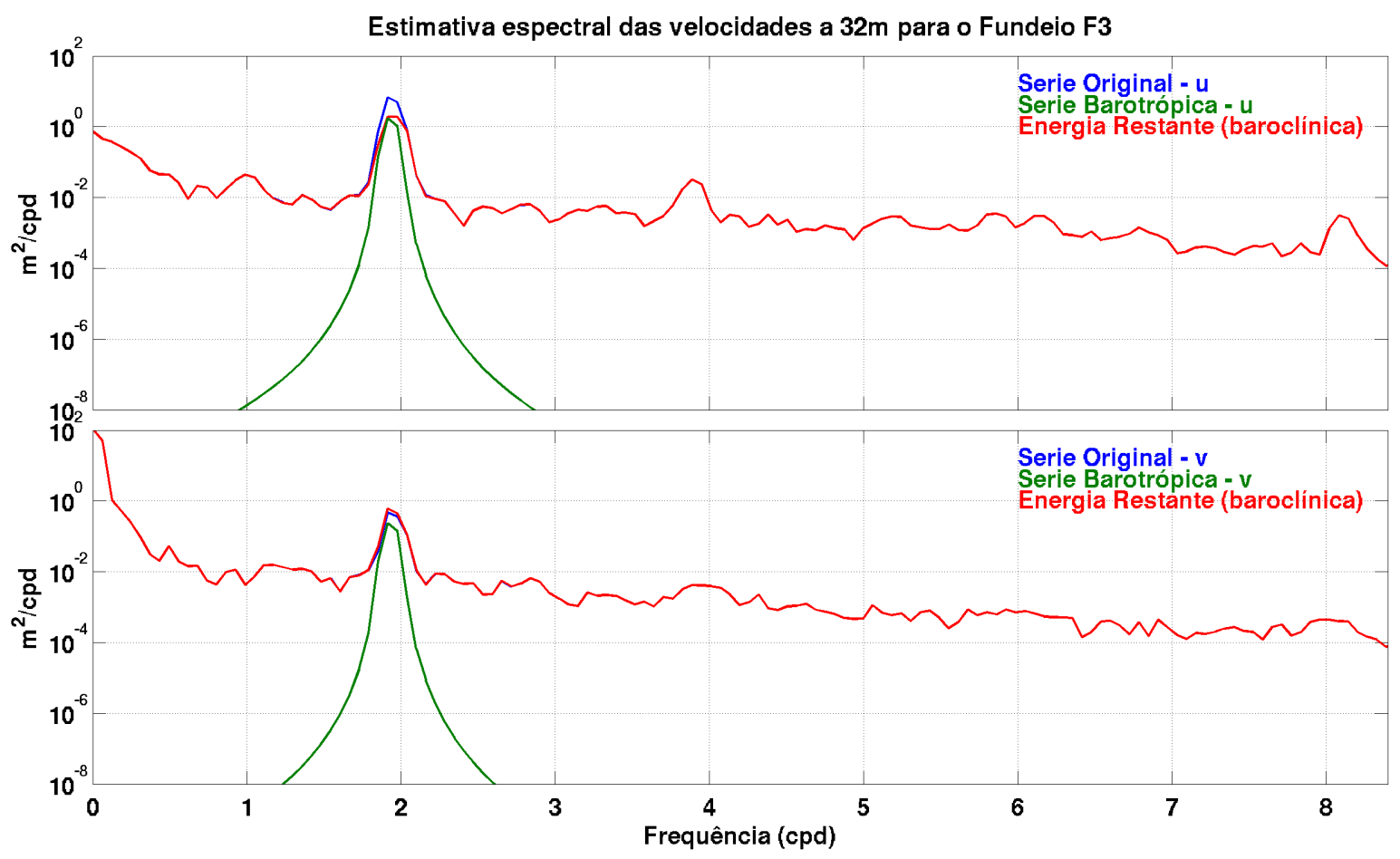

Figura 38: Estimativa de densidade espectral para as séries de velocidade medida (azul), barotrópica (verde) e baroclínica (vermelho) a $32 \mathrm{~m}$ de profundidade no Fundeio F3. O método utilizado, o periodograma de Welch, teve segmentos de 384 horas ( $\sim 16$ dias), com janela do tipo hanning e sobreposição de 50\% dos segmentos. Nos rótulos, cpd corresponde a ciclos por dia. 


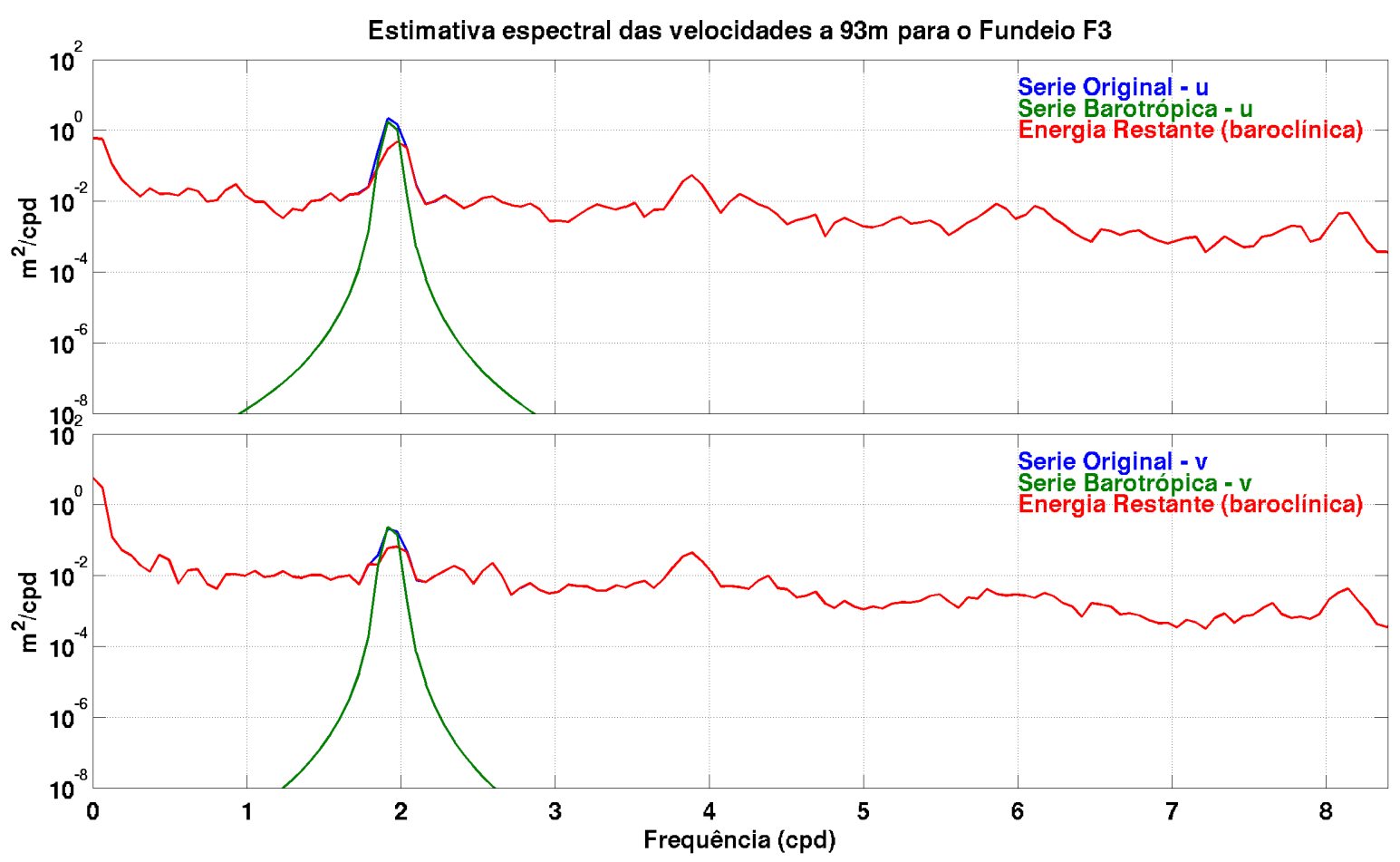

Figura 39: Estimativa de densidade espectral para as séries de velocidade medida (azul), barotrópica (verde) e baroclínica (vermelho) a 93 m de profundidade no Fundeio F3. O método utilizado, o periodograma de Welch, teve segmentos de 384 horas ( 16 dias), com janela do tipo hanning e sobreposição de 50\% dos segmentos. Nos rótulos, cpd corresponde a ciclos por dia.

A análise espectral das séries temporais obtidas nos fundeios, Figuras 32 a 39, indica que em todos os pontos a frequência semi-diurna possui mais energia, até duas ordens de grandeza maiores que as outras frequências. A análise da velocidade $u$, em geral, mostra energia na componente diurna, semi-diurna e quarto diurna, enquanto que a análise da velocidade $v$ indica, ainda, energias maiores do que as da outra componente em baixas frequências, em todos os pontos analisados. Na maioria dos casos, a velocidade $v$ não apresenta oscilações significativas nas frequências diurnas, mas tem picos nas frequências semi-diurnas e quarto-diurnas. A partir dos resultados, afirmamos que a frequência preferencial de atuação das correntes baroclínicas é a semi-diurna. 


\subsubsection{Análise Harmônica}

Aplicamos o método descrito na Seção 5.2.2 em todas as profundidades dos 3 fundeios.

As Figuras 40 a 50 mostram os resultados dessas análises para as componentes barotrópica e baroclínica. Estes resultados, em conjunto com a análise espectral feita na Seção 5.2.1, além dos trabalhos de Beardsley et al. (1995) e Geyer et al. (1996), indicam a dominância das componentes semi-diurnas, em especial a componente $\mathrm{M}_{2}$. Sumarizando as informações produzidas pela análise harmônica, montamos as Tabelas 6, 7 e 8 com os parâmetros das elipses da maré $\mathrm{M}_{2}$. Nessas Tabelas, apresentamos ainda informações acerca da inclinação e da fase associada, sendo cada um desses parâmetros acompanhados dos erros correspondentes.

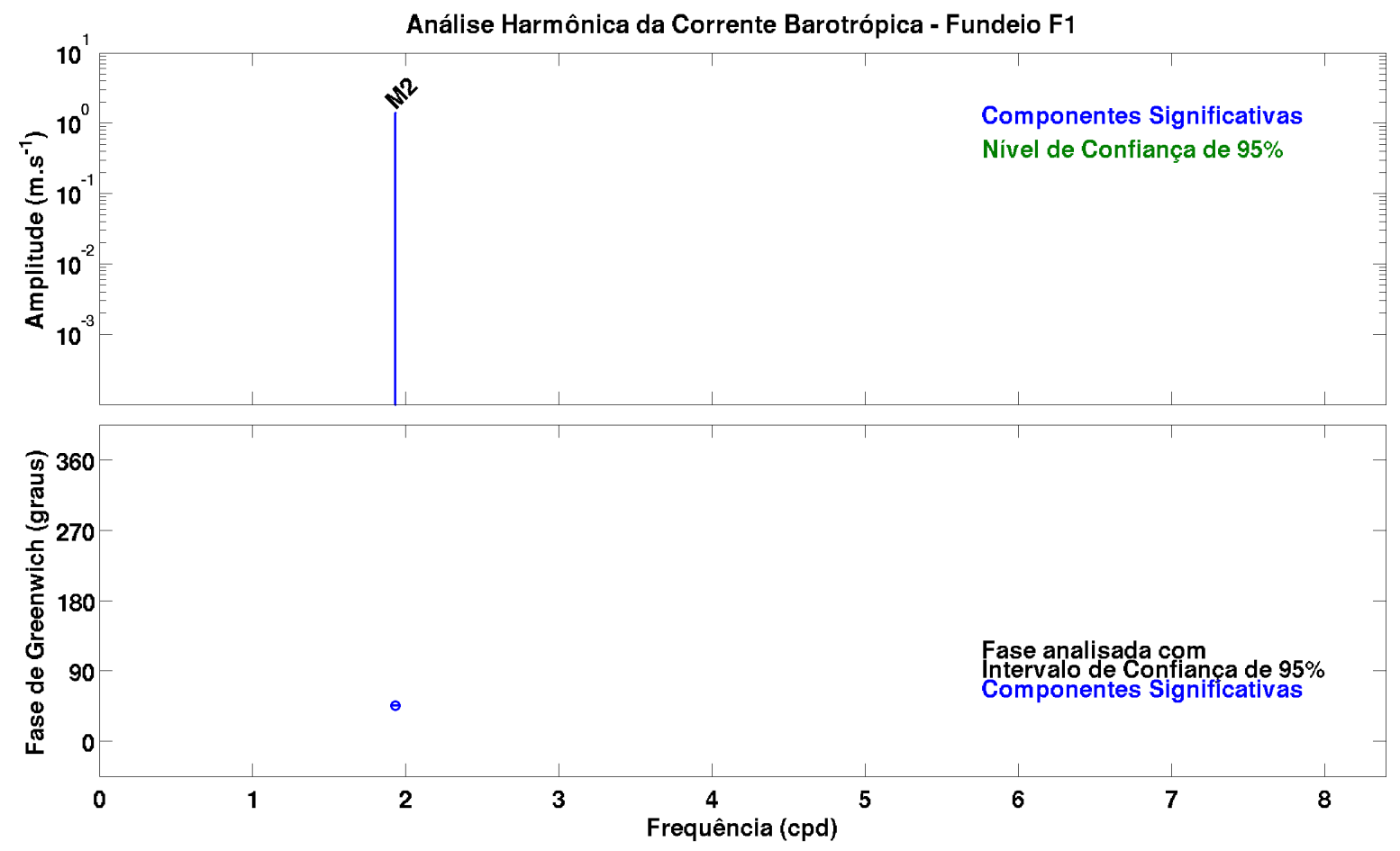

Figura 40: Resultado da análise harmônica da corrente barotrópica para o fundeio F1. O quadro superior apresenta as amplitudes das componentes harmônicas significativas da maré astronômica separadas por sua frequência, em ciclos por dia. O quadro inferior apresenta a fase em relação a Greenwich para as mesmas componentes harmônicas da maré astronômica do quadro superior. 


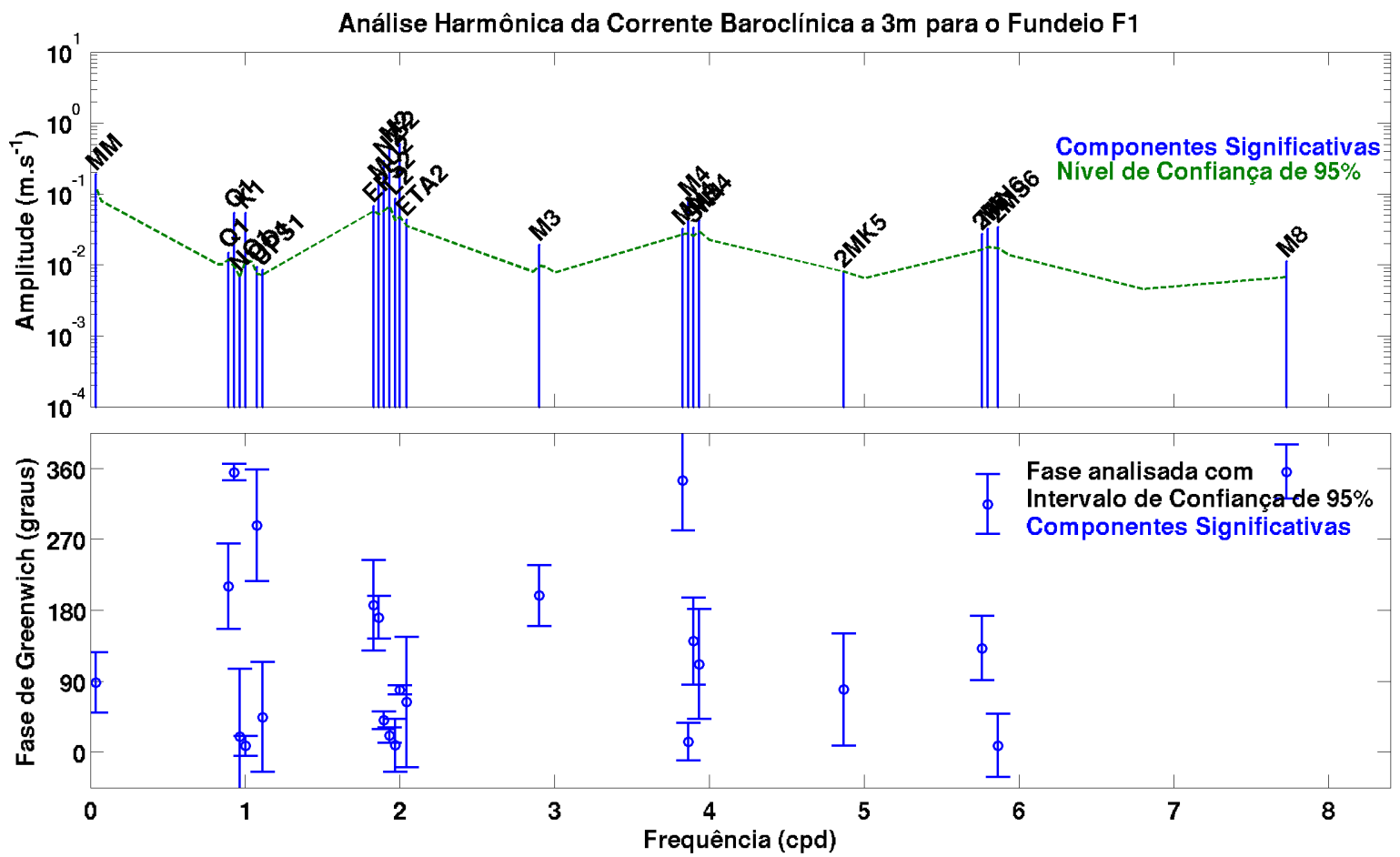

Figura 41: Resultado da análise harmônica da corrente baroclínica a $3 \mathrm{~m}$ para o fundeio F1. O quadro superior apresenta as amplitudes das componentes harmônicas significativas da maré astronômica separadas por sua frequência, em ciclos por dia. O quadro inferior apresenta a fase em relação a Greenwich para as mesmas componentes harmônicas da maré astronômica do quadro superior. 

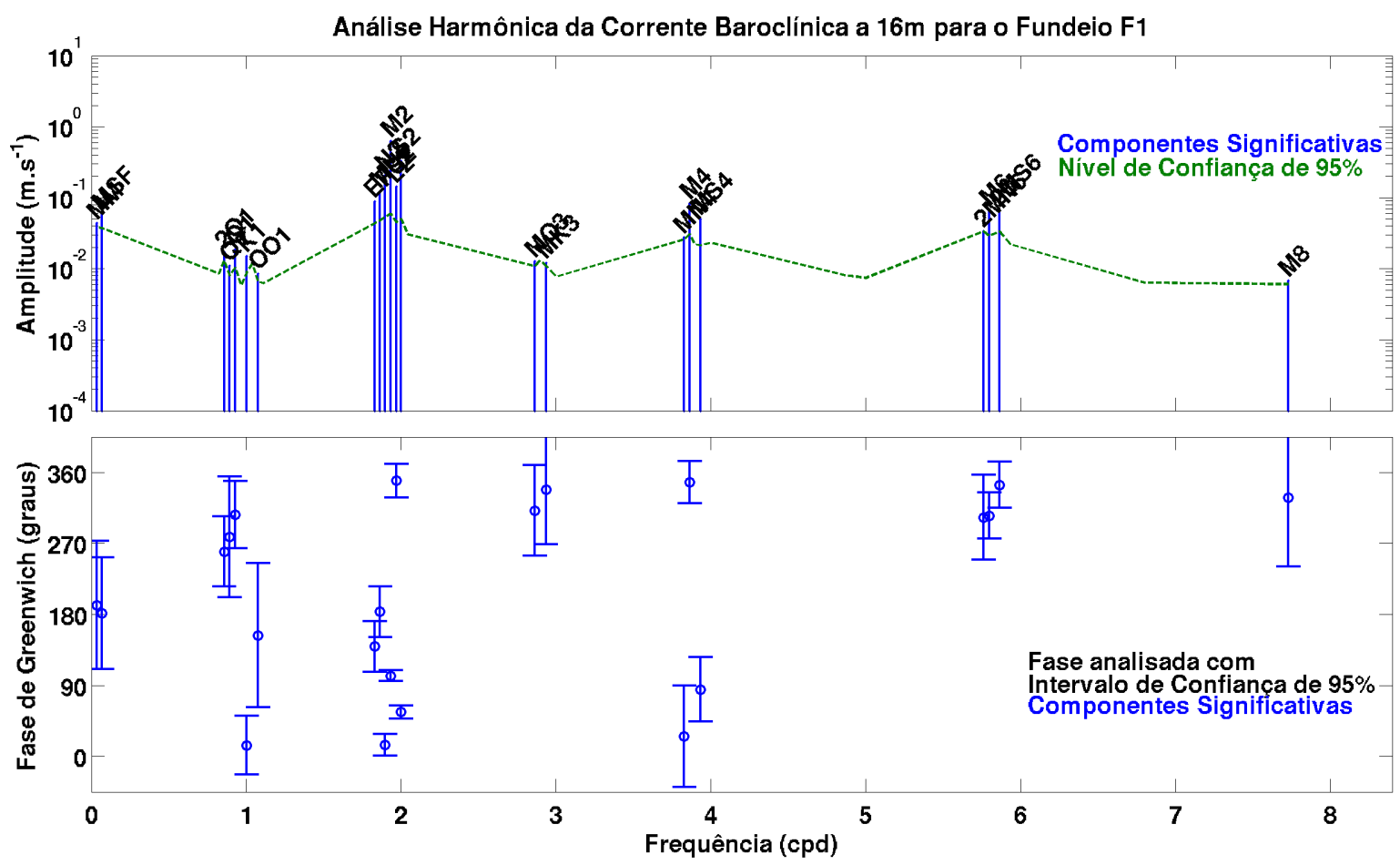

Figura 42: Resultado da análise harmônica da corrente baroclínica a 16 m para o fundeio F1. O quadro superior apresenta as amplitudes das componentes harmônicas significativas da maré astronômica separadas por sua frequência, em ciclos por dia. O quadro inferior apresenta a fase em relação a Greenwich para as mesmas componentes harmônicas da maré astronômica do quadro superior.

A análise harmônica para o ponto F1 (Figuras 40 a 42), indica a dominância da componente principal lunar, $\mathrm{M}_{2}$, tanto para a componente barotrópica quanto para as componente baroclínica. A amplitude da componente $\mathrm{M}_{2}$ barotrópica é aproximadamente quatro vezes maior que a segunda componente mais energética, a principal solar, $\mathrm{S}_{2}$. A componente baroclínica $\mathrm{M}_{2}$ apresenta diferenças entre as duas profundidades amostradas no ponto F1. A amplitude nesta componente, diferentemente da maré atuante nos dados observados, é maior a $16 \mathrm{~m}$. A fase e a inclinação desta componente apresentam diferença de aproximadamente $90^{\circ}$ entre as profundidades, o que também difere da maré observada, que possui diferenças bem menores entre as profundidades, como pode-se notar na Tabela 6. 
Tabela 6: Parâmetros das elipses das marés baroclínica e barotrópica para o fundeio F1. O semi-eixo maior, em ms ${ }^{-1}$, corresponde à coluna "Maior"; o semi-eixo menor, em ms ${ }^{-1}$, à coluna "Menor"; a inclinação, em graus, à coluna "Inc"e a fase em relação à Greenwich, em graus, à coluna "fase". As colunas "Erro"correspondem ao erro relativo de cada um dos parâmetros

Parâmetros da elipse de maré observada a 3 m e a 16 m

\begin{tabular}{lcccccccc}
\hline & Maior & Erro & Menor & Erro & Inc & Erro & Fase & Erro \\
$\mathrm{M}_{2} \mathbf{a} \mathbf{3} \mathbf{~ m}$ & 1,46 & 0,05 & $-0,01$ & 0,06 & 24,82 & 3,15 & 38,50 & 2,05 \\
$\mathrm{M}_{2} \mathbf{a} \mathbf{1 6} \mathbf{~ m}$ & 1,25 & 0,05 & 0,15 & 0,03 & 20,13 & 1,79 & 20,18 & 2,40 \\
\hline
\end{tabular}

Parâmetros da elipse de maré barotrópica (FONTES et al., 2008)

\begin{tabular}{lllllllll}
\hline $\mathrm{M}_{2}$ & 1,40 & 0,0 & 0,11 & 0,0 & 7,53 & 0,0 & 45,46 & 0,0
\end{tabular}

Parâmetros da elipse de maré baroclínica

\begin{tabular}{lllllllll}
\hline $\mathrm{M}_{2} \mathbf{a} \mathbf{3} \mathbf{~ m}$ & 0,47 & 0,07 & 0,16 & 0,05 & 89,98 & 7,26 & 21,28 & 9,57 \\
$\mathrm{M}_{2} \mathbf{a} \mathbf{1 6} \mathbf{~ m}$ & 0,63 & 0,06 & 0,31 & 0,03 & 179,65 & 5,30 & 102,35 & 7,07 \\
\hline \hline
\end{tabular}

A análise harmônica para o ponto F2 (Figuras 43 a 47 e a Tabela 7) mostra a dominância das componentes semi-diurnas, em especial a componente $\mathrm{M}_{2}$. Analisando a variação da amplitude da componente $\mathrm{M}_{2}$ baroclínica com a profundidade, nota-se aumento da amplitude de quase 6 vezes de $3 \mathrm{~m}$ para $32 \mathrm{~m} \mathrm{e}$, com diferença positiva de fase de aproximadamente $100^{\circ}$ (atraso de $\sim 4$ horas). De $32 \mathrm{~m}$ para $54 \mathrm{~m}$, há aumento da amplitude de quase 2 vezes e diferença de fase de $8^{\circ}$, da mesma ordem de grandeza do erro. De $54 \mathrm{~m}$ para $62 \mathrm{~m}$ não há variações significativas, exceto a diferença de fase em torno de $30^{\circ}$ (atraso de uma hora). Nos resultados apresentados, destacamos que os erros da componente $\mathrm{M}_{2}$ baroclínica a $3 \mathrm{~m}$ de profundidade. São grandes quando comparados aos parâmetros a que se referem, fato que não ocorre nas outras profundidades. Na profundidade de $3 \mathrm{~m}$, a componente $\mathrm{S}_{2}$ possui maior amplitude que a $\mathrm{M}_{2}$, muito provavelmente em razão da maré barotrópica considerada neste trabalho, composta apenas por esta última componente. 


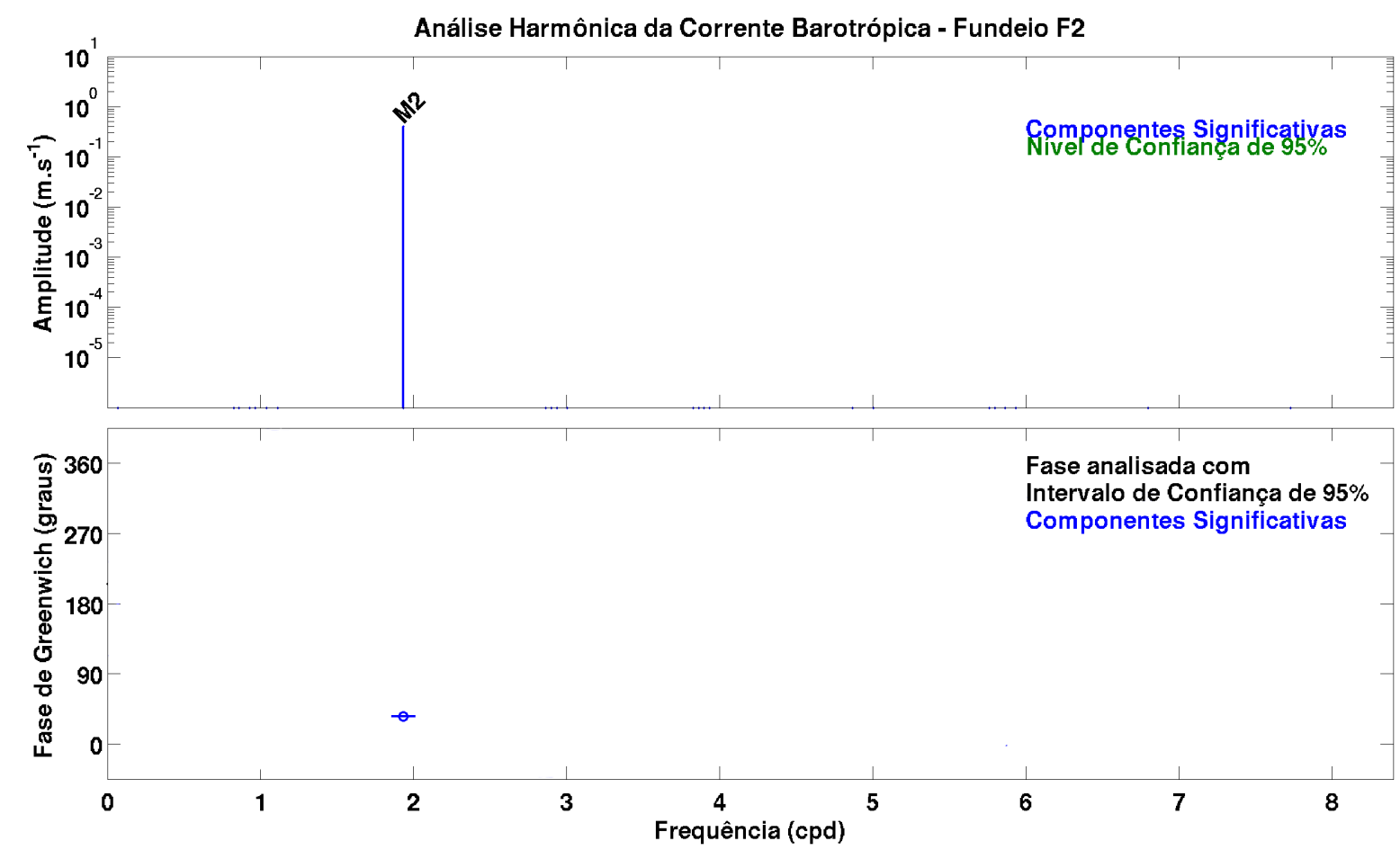

Figura 43: Resultado da análise harmônica da corrente barotrópica para o fundeio F2. O quadro superior apresenta as amplitudes das componentes harmônicas significativas da maré astronômica separadas por sua frequência, em ciclos por dia. O quadro inferior apresenta a fase em relação a Greenwich para as mesmas componentes harmônicas da maré astronômica do quadro superior. 


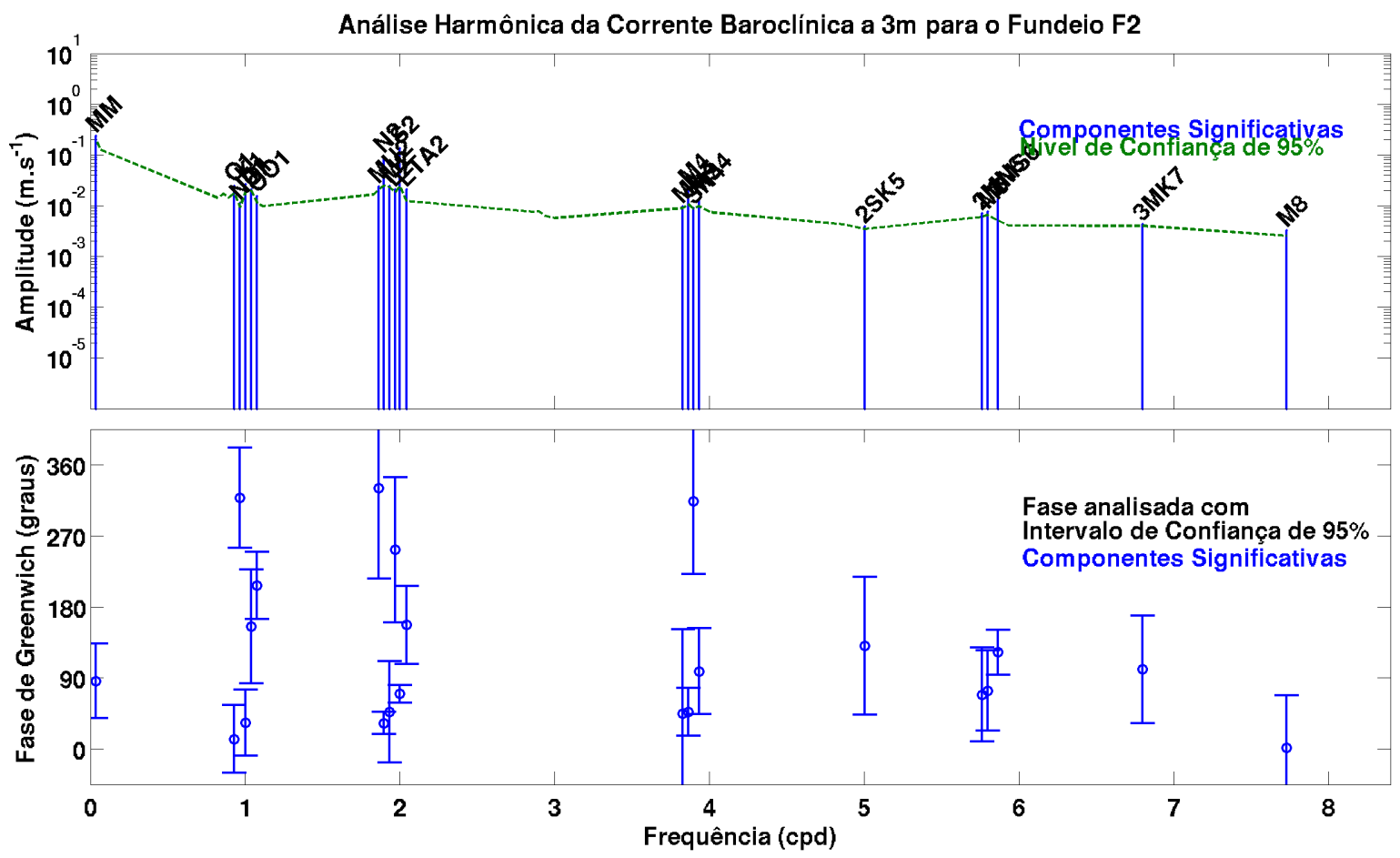

Figura 44: Resultado da análise harmônica da corrente baroclínica a $3 \mathrm{~m}$ para o fundeio F2. O quadro superior apresenta as amplitudes das componentes harmônicas significativas da maré astronômica separadas por sua frequência, em ciclos por dia.O quadro inferior apresenta a fase em relação a Greenwich para as mesmas componentes harmônicas da maré astronômica do quadro superior. 


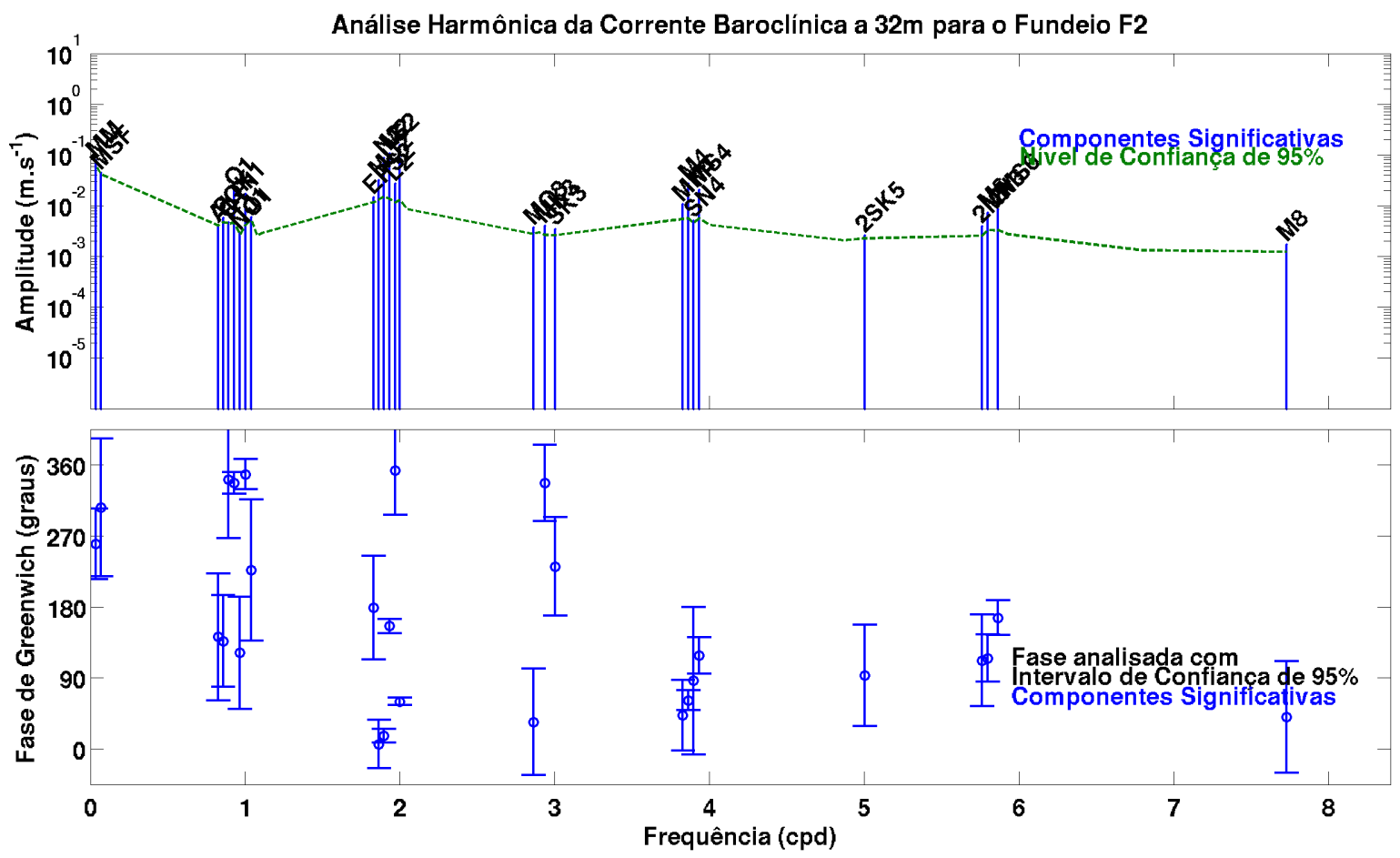

Figura 45: Resultado da análise harmônica da corrente baroclínica a $32 \mathrm{~m}$ para o fundeio F2. O quadro superior apresenta as amplitudes das componentes harmônicas significativas da maré astronômica separadas por sua frequência, em ciclos por dia.O quadro inferior apresenta a fase em relação a Greenwich para as mesmas componentes harmônicas da maré astronômica do quadro superior. 


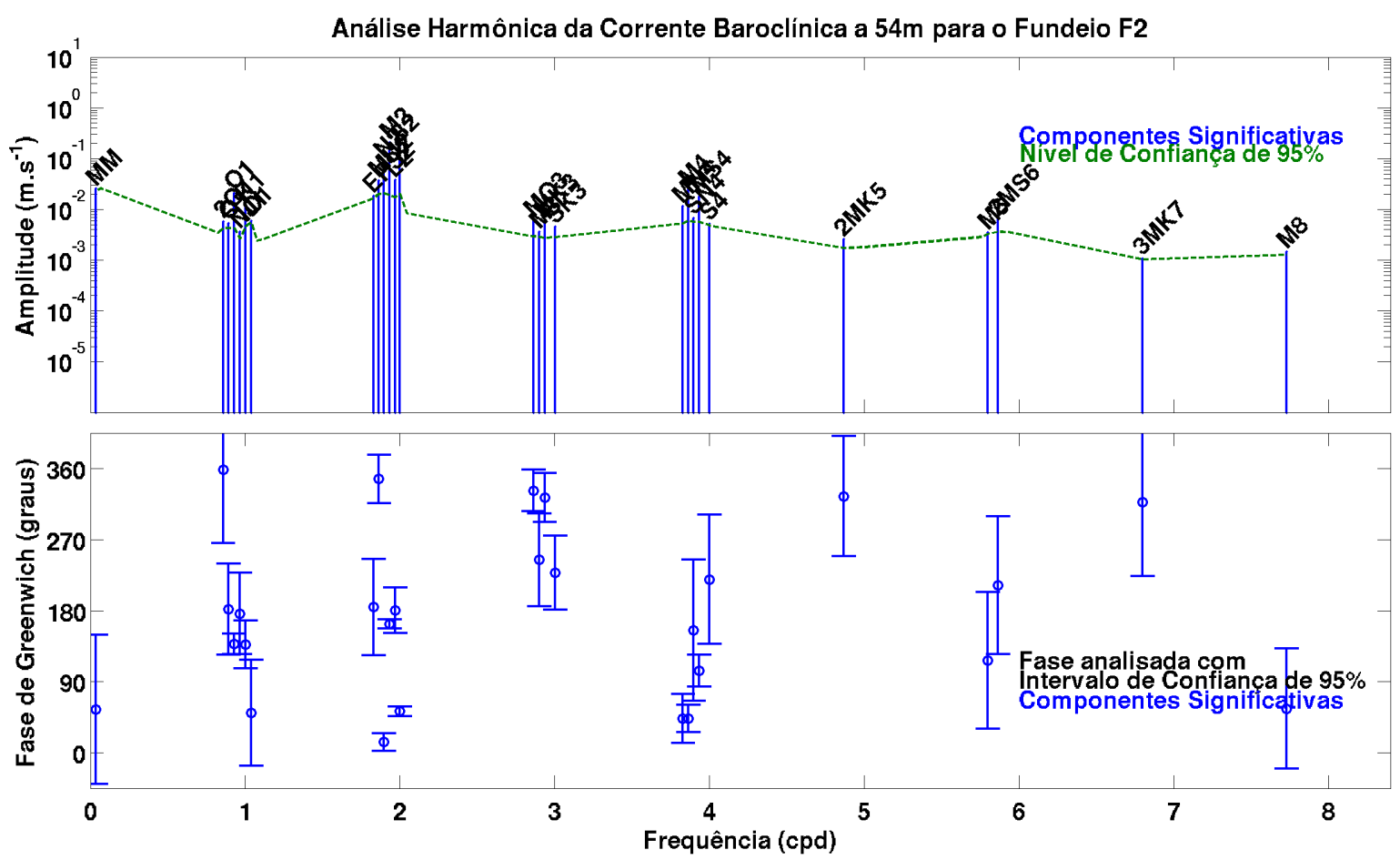

Figura 46: Resultado da análise harmônica da corrente baroclínica a 54 m para o fundeio F2. O quadro superior apresenta as amplitudes das componentes harmônicas significativas da maré astronômica separadas por sua frequência, em ciclos por dia. O quadro inferior apresenta a fase em relação a Greenwich para as mesmas componentes harmônicas da maré astronômica do quadro superior. 


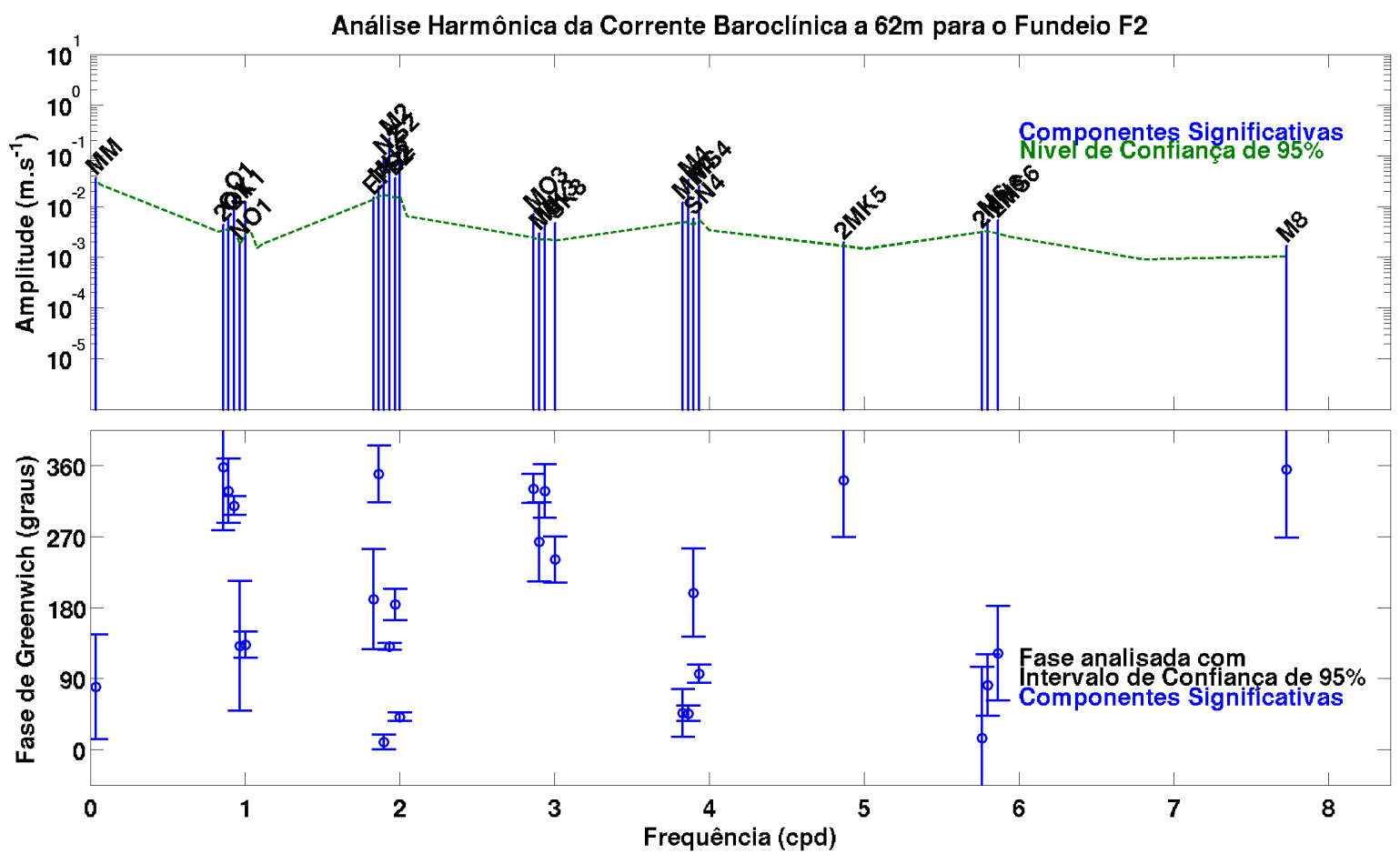

Figura 47: Resultado da análise harmônica da corrente baroclínica a 62 m para o fundeio F2. O quadro superior apresenta as amplitudes das componentes harmônicas significativas da maré astronômica separadas por sua frequência, em ciclos por dia. O quadro inferior apresenta a fase em relação a Greenwich para as mesmas componentes harmônicas da maré astronômica do quadro superior. 
Tabela 7: Parâmetros das elipses das as maré baroclínica e barotrópica para o fundeio F2. O semi-eixo maior, em $\mathrm{ms}^{-1}$, corresponde à coluna "Maior"; o semi-eixo menor, em ms ${ }^{-1}$, à coluna "Menor"; a inclinação, em graus, à coluna "Inc"e a fase em relação à Greenwich, em graus, à coluna "fase". As colunas "Erro"correspondem ao erro relativo de cada um dos parâmetros

Parâmetros da elipse da maré observada.

\begin{tabular}{lcccccccc}
\hline & Maior & Erro & Menor & Erro & Inc & Erro & Fase & Erro \\
\hline $\mathrm{M}_{2} \mathbf{a} \mathbf{3} \mathbf{~ m}$ & 0,41 & 0,02 & 0,01 & 0,03 & 11,86 & 3,66 & 35,53 & 3,04 \\
$\mathrm{M}_{2} \mathbf{a} \mathbf{3 2} \mathbf{~ m}$ & 0,47 & 0,01 & 0,05 & 0,02 & 9,38 & 2,03 & 25,42 & 1,40 \\
$\mathrm{M}_{2} \mathbf{a} \mathbf{5 4} \mathbf{~ m}$ & 0,55 & 0,02 & 0,05 & 0,01 & 3,88 & 1,23 & 18,52 & 2,02 \\
$\mathrm{M}_{2} \mathbf{a} \mathbf{6 2} \mathbf{~ m}$ & 0,47 & 0,01 & 0,05 & 0,01 & 4,68 & 1,09 & 8,19 & 1,88
\end{tabular}

Parâmetros da elipse de maré barotrópica (FONTES et al., 2008)

\begin{tabular}{lcccccccc}
\hline $\mathrm{M}_{2}$ & 0,43 & 0,0 & 0,00 & 0,0 & 11,7 & 0,0 & 35,65 & 0,0 \\
\hline \multicolumn{7}{l}{ Parâmetros da elipse de maré baroclínica } \\
\hline $\mathrm{M}_{2} \mathbf{a} 3 \mathbf{~ m}$ & 0,02 & 0,02 & 0,00 & 0,02 & 70,94 & 57,68 & 46,96 & 59,36 \\
$\mathrm{M}_{2} \mathbf{a} 32 \mathbf{~ m}$ & 0,12 & 0,01 & 0,04 & 0,01 & 170,25 & 9,77 & 155,65 & 8,24 \\
$\mathrm{M}_{2} \mathbf{a} \mathbf{5 4} \mathbf{~ m}$ & 0,21 & 0,02 & 0,01 & 0,01 & 170,23 & 3,39 & 163,17 & 5,42 \\
$\mathrm{M}_{2} \mathbf{a} \mathbf{6 2} \mathbf{~ m}$ & 0,22 & 0,01 & $-0,00$ & 0,01 & 173,13 & 1,93 & 130,34 & 4,13 \\
\hline \hline
\end{tabular}


No ponto F3 (Figuras 48 a 50), a componente harmônica $\mathrm{M}_{2}$, assim como nos pontos F1 e F2, domina a maré local, com amplitudes geralmente uma ordem de grandeza maiores, tanto para a série de velocidades barotrópicas quanto para as baroclínicas. As amplitudes das marés baroclínicas para esta componente (Tabela 8) possuem aproximadamente a metade da calculada para a maré barotrópica. Aquelas, possuem diferença de fase em profundidade de aproximadamente $180^{\circ}$. Essa análise sugere a existência de fluxo maregráfico baroclínico em camadas verticais, sobrepondo o fluxo barotrópico dominante para NO.

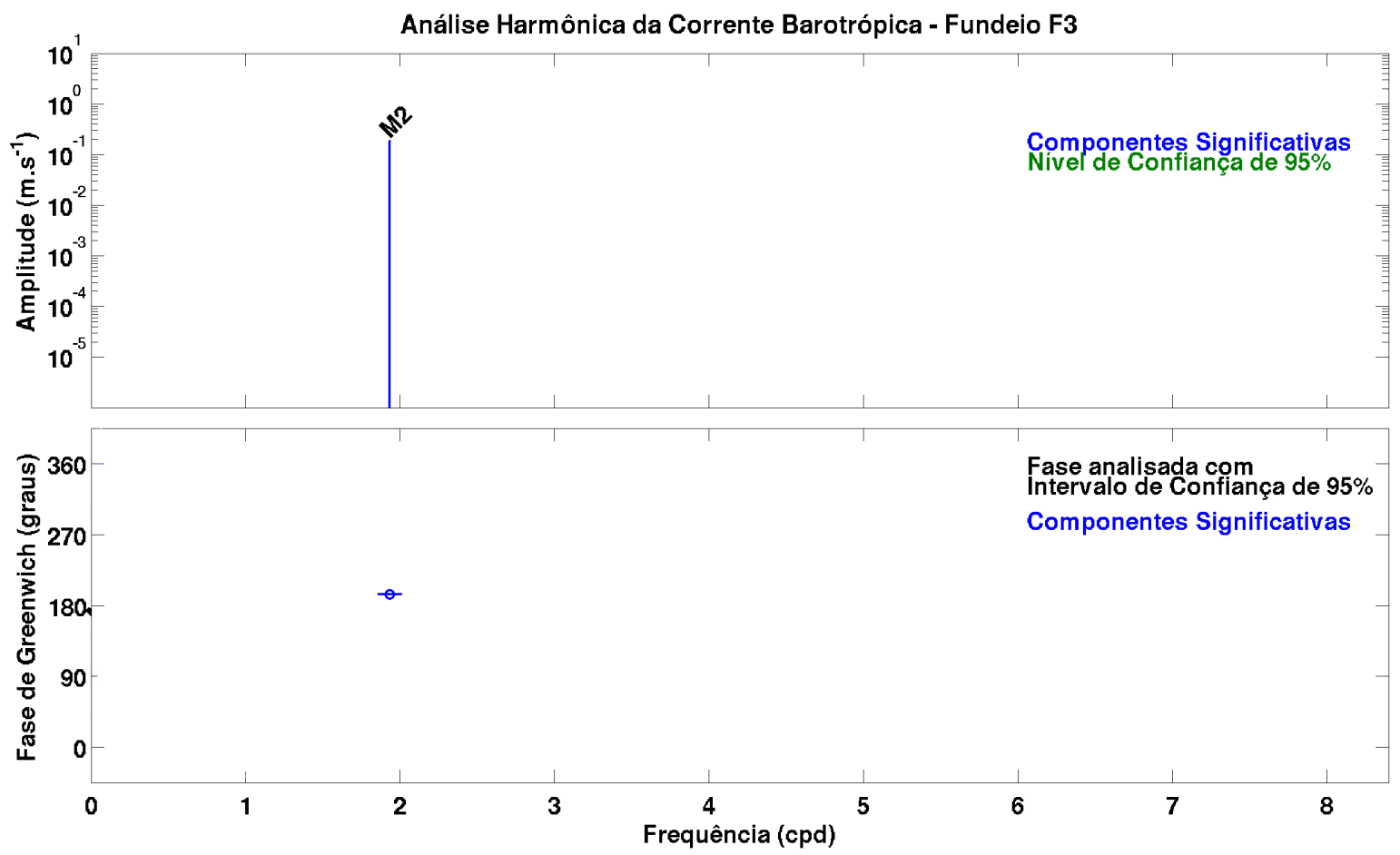

Figura 48: Resultado da análise harmônica da corrente barotrópica para o fundeio F3. O quadro superior apresenta as amplitudes das componentes harmônicas significativas da maré astronômica separadas por sua frequência, em ciclos por dia. O quadro inferior apresenta a fase em relação a Greenwich para as mesmas componentes harmônicas da maré astronômica do quadro superior. 


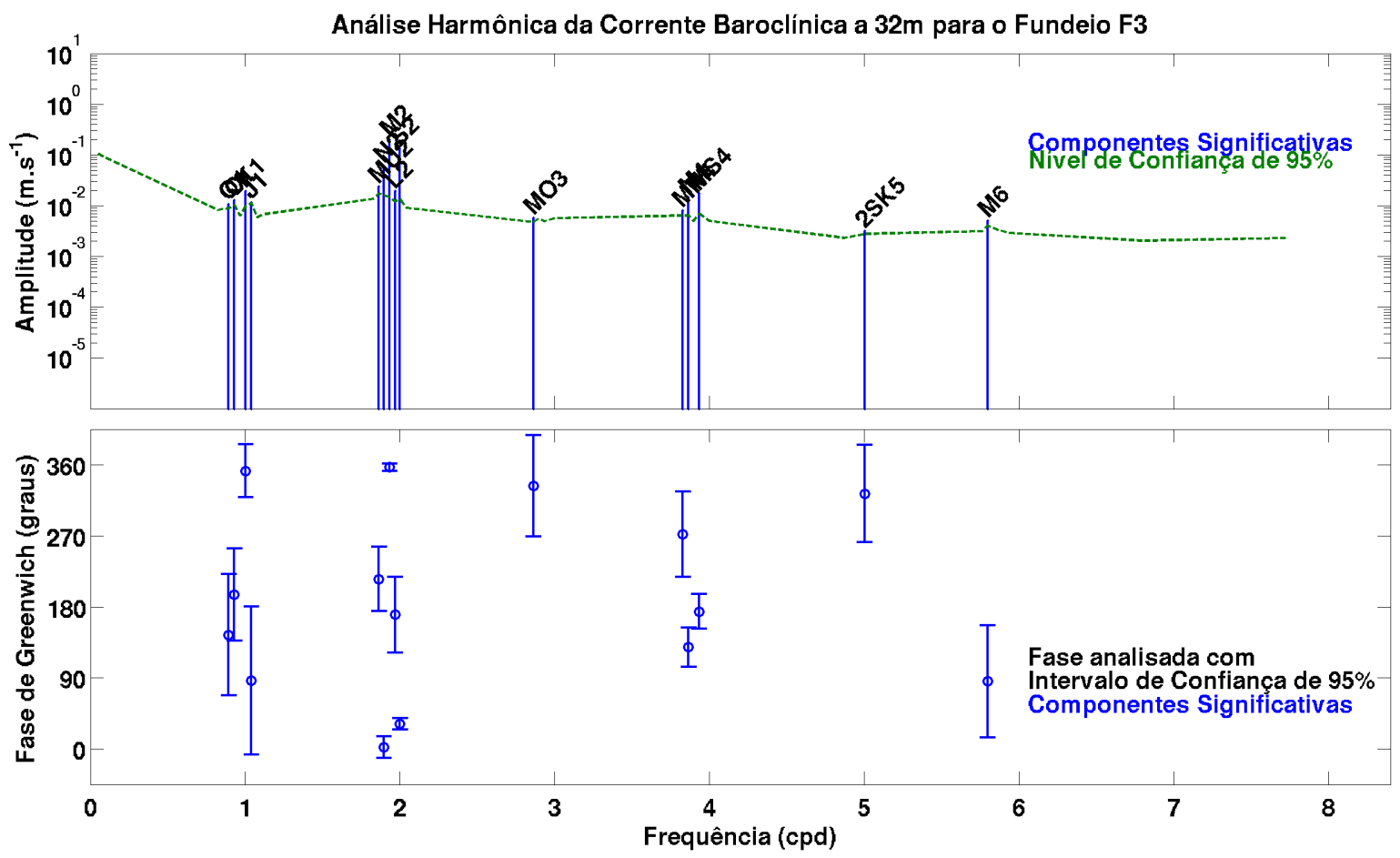

Figura 49: Resultado da análise harmônica da corrente baroclínica a 32 m para o fundeio F3. O quadro superior apresenta as amplitudes das componentes harmônicas significativas da maré astronômica separadas por sua frequência, em ciclos por dia. O quadro inferior apresenta a fase em relação a Greenwich para as mesmas componentes harmônicas da maré astronômica do quadro superior. 


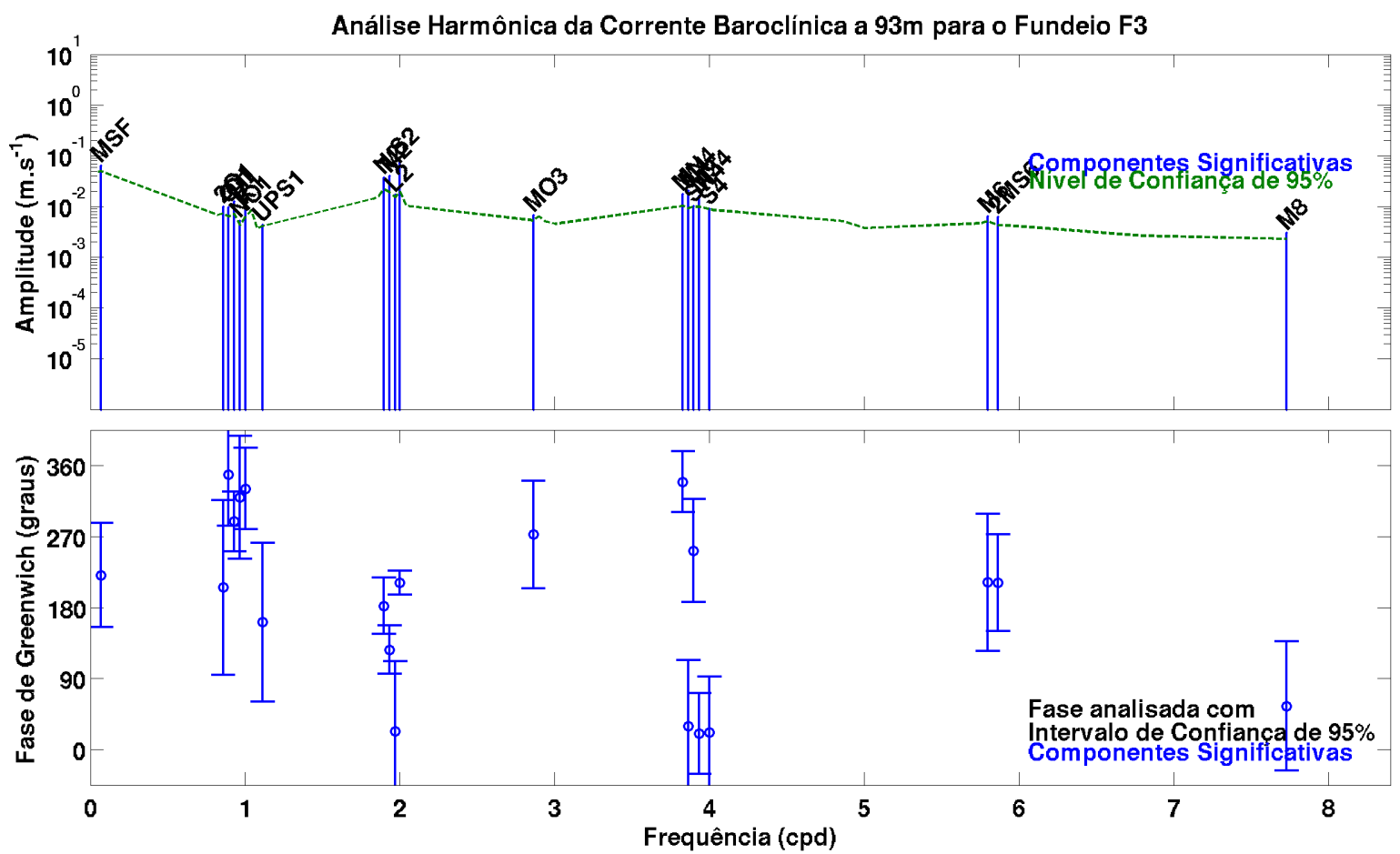

Figura 50: Resultado da análise harmônica da corrente baroclínica a 93 m para o fundeio F3. O quadro superior apresenta as amplitudes das componentes harmônicas significativas da maré astronômica separadas por sua frequência, em ciclos por dia. O quadro inferior apresenta a fase em relação a Greenwich para as mesmas componentes harmônicas da maré astronômica do quadro superior. 
Tabela 8: Parâmetros das elipses das marés baroclínica e barotrópica para o fundeio F3. O semi-eixo maior, em $\mathrm{ms}^{-1}$, corresponde à coluna "Maior"; o semi-eixo menor, em ms ${ }^{-1}$, à coluna "Menor"; a inclinação, em graus, à coluna "Inc"e a fase em relação à Greenwich, em graus, à coluna "fase". As colunas "Erro"correspondem ao erro relativo de cada um dos parâmetros

Parâmetros da elipse da maré observada

\begin{tabular}{ccccccccc}
\hline & Maior & Erro & Menor & Erro & Inc & Erro & Fase & Erro \\
\hline $\mathrm{M}_{2} \mathbf{a} 32 \mathbf{~ m}$ & 0,35 & 0,018 & $-0,07$ & 0,014 & 9,27 & 2,31 & 2,83 & 2,59 \\
$\mathrm{M}_{2}$ a 93 m & 0,20 & 0,023 & $-0,03$ & 0,017 & 164,61 & 4,83 & 184,2 & 5,87
\end{tabular}

Parâmetros da elipse de maré barotrópica (FONTES et al., 2008)

\begin{tabular}{lllllllll}
\hline $\mathrm{M}_{2}$ & 0,18 & 0,0 & $-0,04$ & 0,0 & 163,57 & 0,0 & 194,03 & 0,0 \\
\hline
\end{tabular}

Parâmetros da elipse de maré baroclínica

\begin{tabular}{rrrrrrrrr}
\hline $\mathrm{M}_{2} \mathbf{a} 32 \mathbf{~ m}$ & 0,2 & 0,016 & $-0,012$ & 0,012 & 30,75 & 3,89 & 356,90 & 4,6 \\
$\mathrm{M}_{2} \mathbf{a} \mathbf{9 3} \mathbf{~ m}$ & 0,04 & 0,019 & 0,005 & 0,017 & 143,71 & 23,41 & 126,37 & 30,55 \\
\hline \hline
\end{tabular}

Os resultados até aqui apresentados concordam com aqueles de Beardsley et al. (1995). As características das correntes de maré para os pontos analisados, em geral, refletem a dominância das componentes harmônicas semi-diurnas, tanto para as componentes barotrópicas quanto para as componentes baroclínicas. Observamos nas Figuras 40 a 50 a dominância da componente principal lunar, $\mathrm{M}_{2}$, tanto para a velocidade barotrópica quanto para a baroclínica, seguida da componente principal solar $\mathrm{S}_{2}$. As relativamente grandes amplitudes das componentes mensal lunar, $\mathrm{M}_{\mathrm{m}}$, e Luni-Solar quinzenal, $\mathrm{M}_{\mathrm{f}}($ Figuras 41 a 50), explicam, em parte, a energia observada nas baixas frequências para as componentes paralelas, $v$, nas análises espectrais (Figuras 34 a 37). Geyer et al. (1996) atribuiu a parcela da energia de baixas frequências a Ondas de Rossby Topográficas com períodos de 30-40 dias e Linhares (1995) adicionou a influência da CNB.

Para melhor visualizar as características das correntes de maré barotrópica e baroclínica, plotamos os hodógrafos do vetor velocidade durante um ciclo de maré. A Figura 51 ilustra as elipses da maré barotrópica para a componente $\mathrm{M}_{2}$ nas localidades 
dos fundeios F1, F2 e F3. Percebe-se a polarização, eixo maior normal às isóbatas, das elipses na direção perpendicular à costa. O comportamento das velocidades horizontais da maré baroclínica $\mathrm{M}_{2}$ nas diferentes profundidades pode ser observado na Figura 52. No ponto F1 há aumento da amplitude do semi-eixo maior com o aumento da profundidade e alteração da inclinação, quase-paralela às isóbatas em superfície para quaseperpendicular no fundo. Como já explicitado anteriormente, o ponto F2 apresenta aumento da amplitude em profundidade. Pode-se notar, em relação à inclinação, comportamento inverso ao observado no ponto F1. Em superfície, o semi-eixo maior da elipse encontra-se normal à isóbata, enquanto que nas profundidades abaixo o mesmo se encontra quase-paralelo. Já no ponto F3, localizado numa região onde há alterações abruptas na profundidade e isóbatas com curvas acentuadas, nota-se as elipses alinhadas à batimetria, quase-perpendicular a 32 m e quase-paralela a 93 m; a amplitude é praticamente a mesma nas duas profundidades amostradas. 


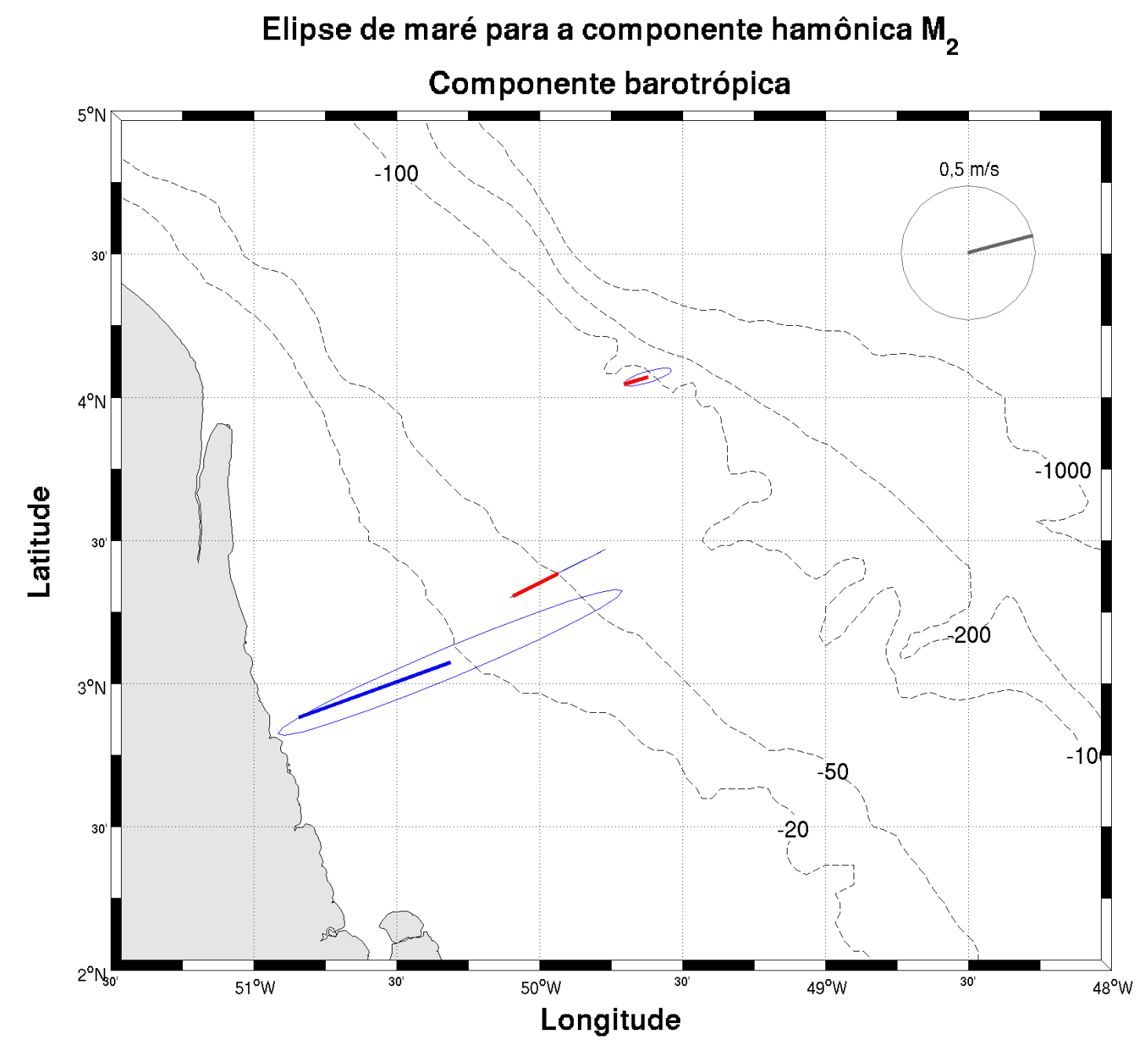

Figura 51: Elipses de maré barotrópica para a componente $M_{2}$ na localização do fundeios. A linha radial vermelha nas elipses indica rotação no sentido anti-horário e azul no sentido horário. As linhas isobatimétricas indicam as profundidades de $20 \mathrm{~m}, 50 \mathrm{~m}, 100 \mathrm{~m}, 200 \mathrm{~m}$ e $1000 \mathrm{~m}$. Baseado em Fontes et al. (2008) 


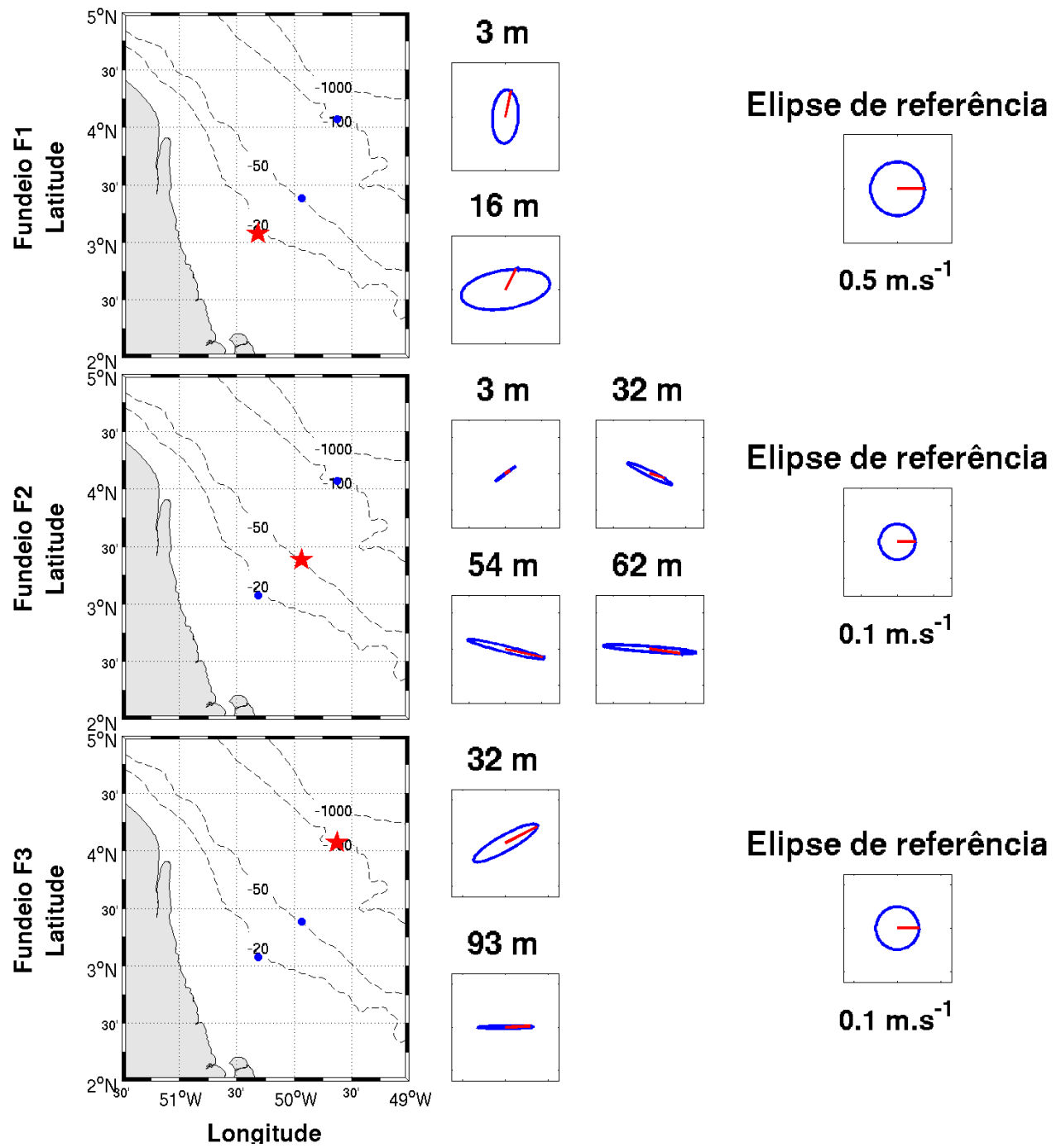

Figura 52: Elipses de maré baroclínica para a componente $\mathrm{M}_{2}$. Os quadros à esquerda mostram a PCA com a estrela vermelha indicando a posição do fundeio, de cima para baixo, F1, F2 e F3, respectivamente. As elipses da maré baroclínica correspondentes a cada ponto se encontram à direita do mapa. A linha radial vermelha nas elipses indica rotação no sentido anti-horário e azul no sentido horário. À direita das elipses está a elipse de refência para comparação de escalas.

Procuramos verificar a intermitência das marés baroclínicas e, para tal, fizemos a análise harmônica em janelas de 16 dias como já explicitado na Seção 5.2.2. Obtivemos então, séries temporais dos parâmetros das elipses, como consequência de 50 análises harmônicas, ilustradas na Figura 53. Para o ponto F1, verificamos que não há alterações temporais substanciais, apenas verificamos variações pequenas para os semi-eixos, que se igualam ao erro das análises e portanto não consideramos como significativas. 


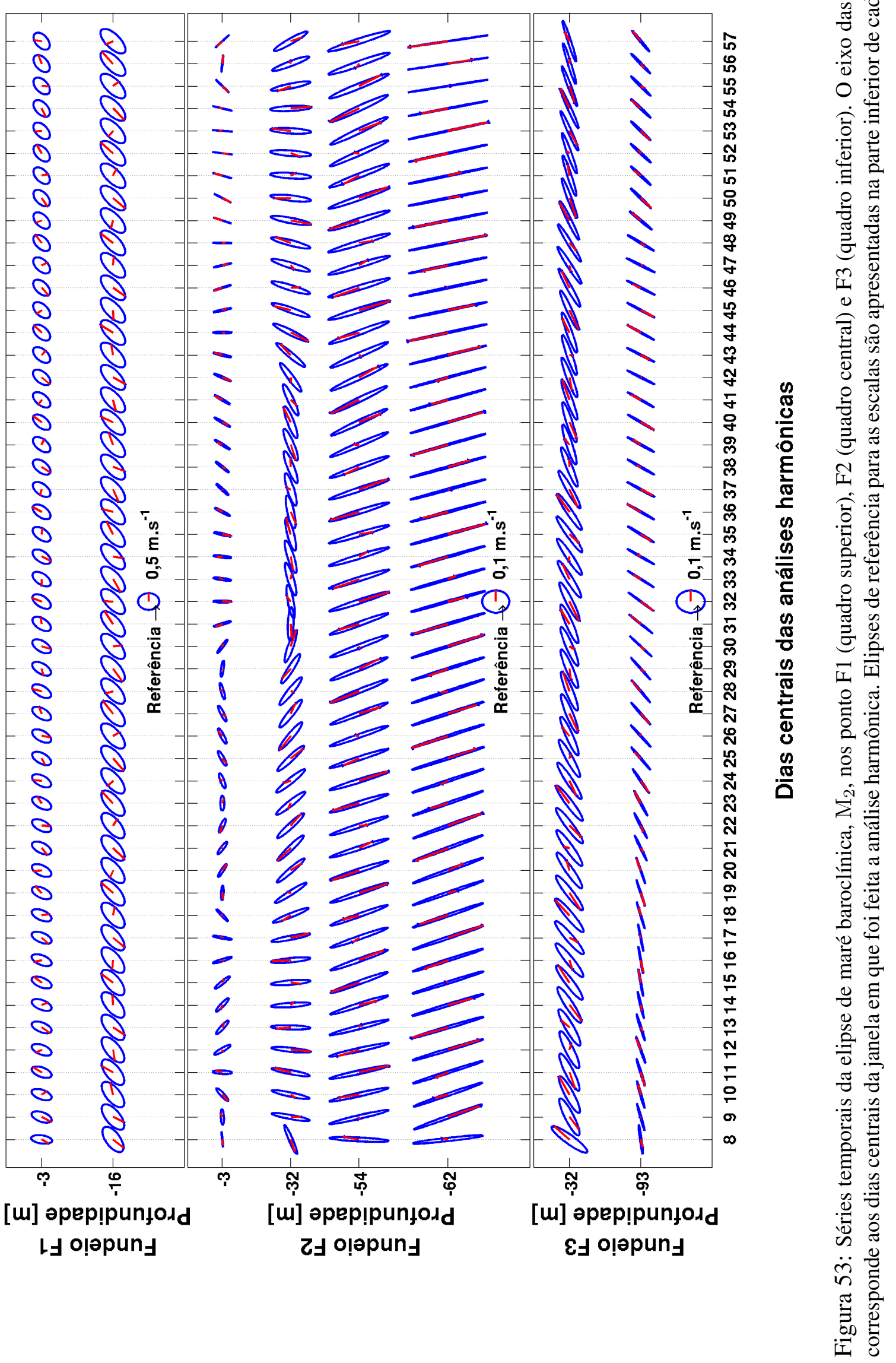


No ponto F2 há relativamente grandes variações temporais na inclinação para as duas profundidades mais rasas ( 3 e $32 \mathrm{~m}$ ), ficando ora quase-perpendiculares ora quaseparalelas à isóbata. As variações nos semi-eixos maiores são pequenas. Outro ponto marcante é o alinhamento paralelo à isóbata das elipses em maiores profundidades. A componente $\mathrm{M}_{2}$ baroclínica apresenta semi-eixo maior quase-normal àquele do que seria sua forçante, sugerindo que a maré interna não seria gerada na região, sendo advectada na direção do fluxo preponderante para NO.

No ponto F3 há variações temporais vísiveis na inclinação para ambas as profundidades. A $32 \mathrm{~m}$ a inclinação aumenta próximo à metade da série, ficando quase-paralela à isóbata, enquanto que o inverso é observado a $93 \mathrm{~m}$.

O que nota-se nessa última análise é que no ponto F1 as elipses são quase invariantes no tempo. No ponto F2, mesmo variando pouco, nas profundidades, de 54 e de $62 \mathrm{~m}$ os resultados diferem daqueles obtidos nos pontos F1 e F3. Já no ponto F3, houve variações opostas nas duas profundidades amostradas, embora a fase não apresente grandes mudanças entre os dois níveis. Não foi possível perceber variações temporais com escalas quinzenais referentes à modulação de sízigia e quadratura devido ao método utilizado, uma vez que cada uma das elipses representa esse período quinzenal. Feng et al. (1998), analisando dados de velocidade dos primeiros $300 \mathrm{~m}$ da coluna d'água em um fundeio de 1800 m no Oceano Pacífico Oeste, afirmam que correntes não maregráficas podem causar distorções espaciais e desvios de frequência nas correntes de maré baroclínica. Nossos resultados sugerem que oscilações de menor frequência, possivelmente associadas à variações da $\mathrm{CNB}$, influenciam as correntes baroclínicas de maré na plataforma média e externa. 


\subsubsection{Funções Empíricas Ortogonais - FOE}

Nossos resultados para concordam com os de Beardsley et al. (1995), que a velocidade $u$ é dominada pela maré semi-diurna. Além disso, Linhares (1995) e Geyer et al. (1996), afirmam que a componente barotrópica é predominante nesses movimentos perpendiculares à costa, enquanto que a parte baroclínica corresponderia a apenas $5 \%$ da energia barotrópica (BEARDSLEY et al., 1995).

Inicialmente, o método das FOE foi aplicado para as séries de 65 dias de velocidade, e obtivemos como resultado a influência da componente baroclínica semelhante ao proposto por Beardsley et al. (1995), de $\sim 5 \%$. Neste momento, é válida a pergunta de por que não filtrar a série com um filtro do tipo passa-alta, retirando os sinais de baixa frequência, repetindo posteriormente o método FOE. Neste trabalho, estamos estudando um processo físico altamente influenciável pelas características hidrográficas que, nesta região, são sensíveis à interferência dos sinais de menor frequência, como correntes geradas pelo vento e pela CNB. O trabalho de Pereira et al. (2007) ressalta a importância de analisar o campo baroclínico juntamente com o fluxo básico da região em questão, para que aquele seja caracterizado de forma correta.

As FOE, de modo geral, quando aplicadas a séries longas tendem a "filtrar"de certa forma parte dos sinais de mais alta frequência, deixando os sinais de períodos mais longos com importância relativa maior na variância dos modos estatísticos. Filtrar está entre aspas pelo fato de não se tratar de um filtro digital proposto pelo usuário. O que as FOE fazem é reorganizar os dados de acordo com sua regularidade, ou ao longo de direções preferenciais. O método encontra assim um novo conjunto base de vetores ortogonais que maximiza a projeção de cada mapa observado, neste caso, o observado em cada tempo $t$ ao longo da coluna d'água no fundeio. Visto isso, o que as FOE fazem é dar preferência aos sinais mais energéticos, o que, de acordo com o exposto na Seção 6.2.2 e nas Figuras 32 a 39 (energia grande nas baixas frequências), pode ser uma das causas para a baixa energia baroclínica encontrada.

Partindo deste pressuposto, dividimos as séries de velocidade, anomalia de salinidade e anomalia de temperatura provenientes do ponto F2 em sub-séries com aproxi- 
madamente 1/4 do mês lunar, separando a série original de 65 dias em 9 sub-séries de 7 dias, permitindo que haja repetições suficientes do fenômeno das marés para que seja possível avaliar tanto a a ocorrência de marés internas quanto sua intermitência. Aplicamos o método das FOE em cada uma dessas sub-séries que, então, foram comparadas com as anomalias de salinidade. Uma dificuldade desse procedimento é a impossibilidade de separação das componentes $\mathrm{M}_{2}$ e $\mathrm{S}_{2}$. Apesar de todos os resultados indicarem a dominância da componente $\mathrm{M}_{2}$, a influência da componente $\mathrm{S}_{2}$ é grande, causando modulações de sizígia e quadratura. Focaremos, então, nos resultados gerados pelas FOE na banda de frequências semi-diurnas.

As sub-séries correspondem aos seguintes períodos:

1. Sub-série 1 = SS-1 - de 10/02/1990 a 17/02/1990

2. Sub-série 2 = SS-2 - de 17/02/1990 a 24/02/1990

3. Sub-série 3 = SS-3 - de 24/02/1990 a 03/03/1990

4. Sub-série 4 = SS-4 - de 03/03/1990 a 10/03/1990

5. Sub-série $5=$ SS-5 - de 10/02/1990 a 17/03/1990

6. Sub-série 6 = SS-6 - de 17/03/1990 a 24/03/1990

7. Sub-série 7 = SS-7 - de 24/03/1990 a 31/03/1990

8. Sub-série $8=$ SS- 8 - de 31/03/1990 a 07/04/1990

9. Sub-série 9 = SS-9 - de 07/04/1990 a 14/04/1990

Ressaltamos que os resultados aqui apresentados diferem da abordagem anterior, nas Seções 5.2.2 e 5.2.1, e servem de comparação entre os métodos, uma vez que as correntes que consideraremos como barotrópica e baroclínica estão sendo inferidas a partir dos próprios dados. Sendo assim, apresentamos primeiramente as amplitudes dos dois primeiros modos estatísticos para a componente quase-perpendicular da velocidade, que somados correspondem a mais de $98 \%$ da variância. Apresentamos na Tabela 9 o 
percentual de variância explicada por cada modo estatístico e a soma dos dois primeiros modos.

Tabela 9: Percentual de variância explicada por cada modo estatístico para a componente quase-perpendicular de velocidade no ponto F2

\begin{tabular}{ccccccc}
\hline & $\mathbf{1}^{\mathbf{0}}$ Modo & $\mathbf{2}^{\mathbf{0}}$ Modo & $\mathbf{3}^{\mathbf{0}}$ Modo & $\mathbf{4}^{\mathbf{0}}$ Modo & $\mathbf{1}^{\mathbf{0}}+\mathbf{2}^{\mathbf{o}}$ & $\mathbf{3}^{\mathbf{0}}+\mathbf{4}^{\mathbf{0}}$ \\
& $(\boldsymbol{\%})$ & $(\boldsymbol{\%})$ & $(\boldsymbol{\%})$ & $(\boldsymbol{\%})$ & $(\boldsymbol{\%})$ & $(\boldsymbol{\%})$ \\
\hline Sub-série 1 & 94,48 & 4 & 0,93 & 0,59 & 98,48 & 1,52 \\
Sub-série 2 & 91,3 & 6,72 & 1,61 & 0,38 & 98,01 & 1,99 \\
Sub-série 3 & 92,75 & 5,55 & 1,46 & 0,24 & 98,30 & 1,7 \\
Sub-série 4 & 92,66 & 5,72 & 1,53 & 0,10 & 98,37 & 1,63 \\
Sub-série 5 & 91,10 & 7,27 & 1,49 & 0,14 & 98,37 & 1,63 \\
Sub-série 6 & 89,45 & 9,61 & 0,83 & 0,10 & 99,06 & 0,94 \\
Sub-série 7 & 90,86 & 7,04 & 1,98 & 0,12 & 97,90 & 2,1 \\
Sub-série 8 & 95,12 & 3,92 & 0,91 & 0,05 & 99,04 & 0,96 \\
Sub-série 9 & 90,13 & 8,73 & 1,09 & 0,05 & 98,86 & 1,14 \\
\hline \hline
\end{tabular}

Na Figura 54 nota-se que as amplitudes têm comportamento barotrópico para o primeiro modo estatístico e baroclínico para o segundo. Afirmamos que a divisão em sub-séries contribui de forma significativa para melhor avaliação da energia contida no $2^{\circ}$ modo estatístico, que apresenta variação do percentual de variância explicada de 3,92\% a 9,61\% (Tabela 9), quase o dobro do proposto por Beardsley et al. (1995), que previa que apenas 5\% da energia de maré barotrópica seria convertida em energia baroclínica. 

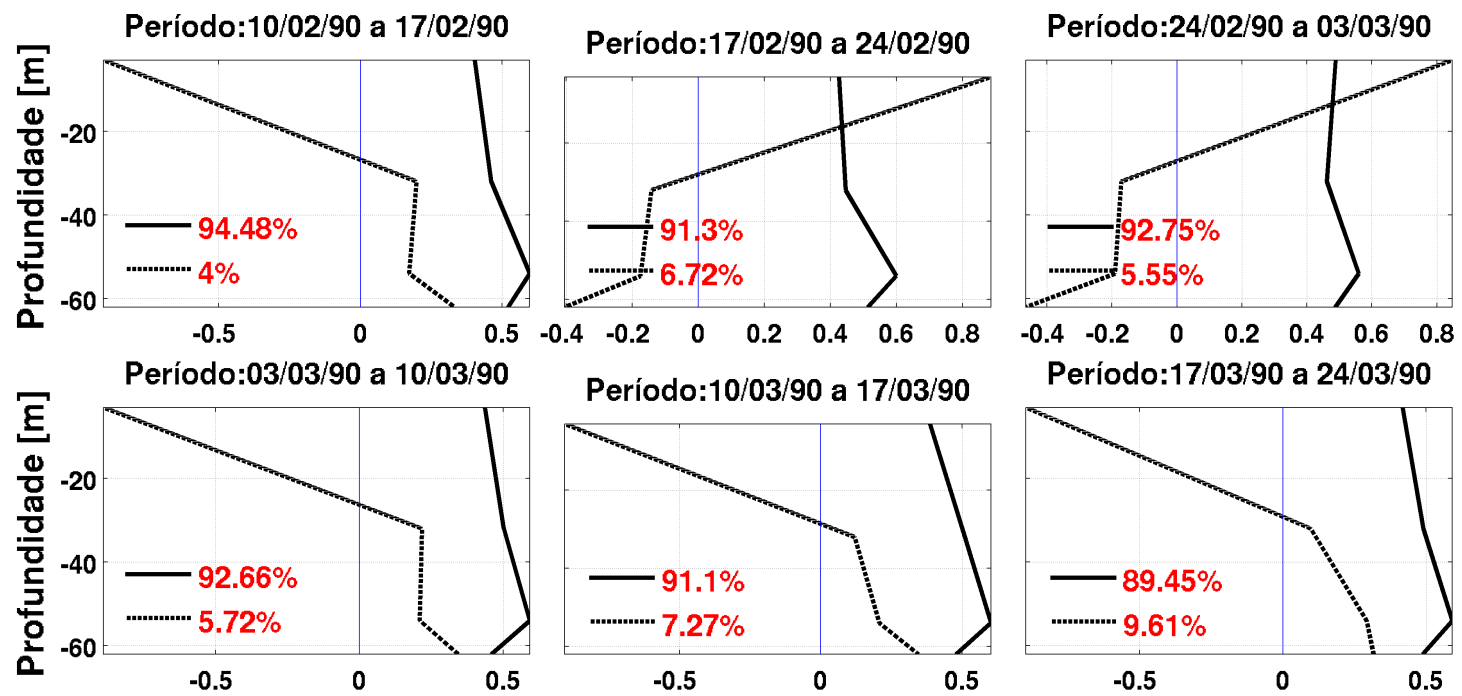

Período: $17 / 03 / 90$ a 24/03/90
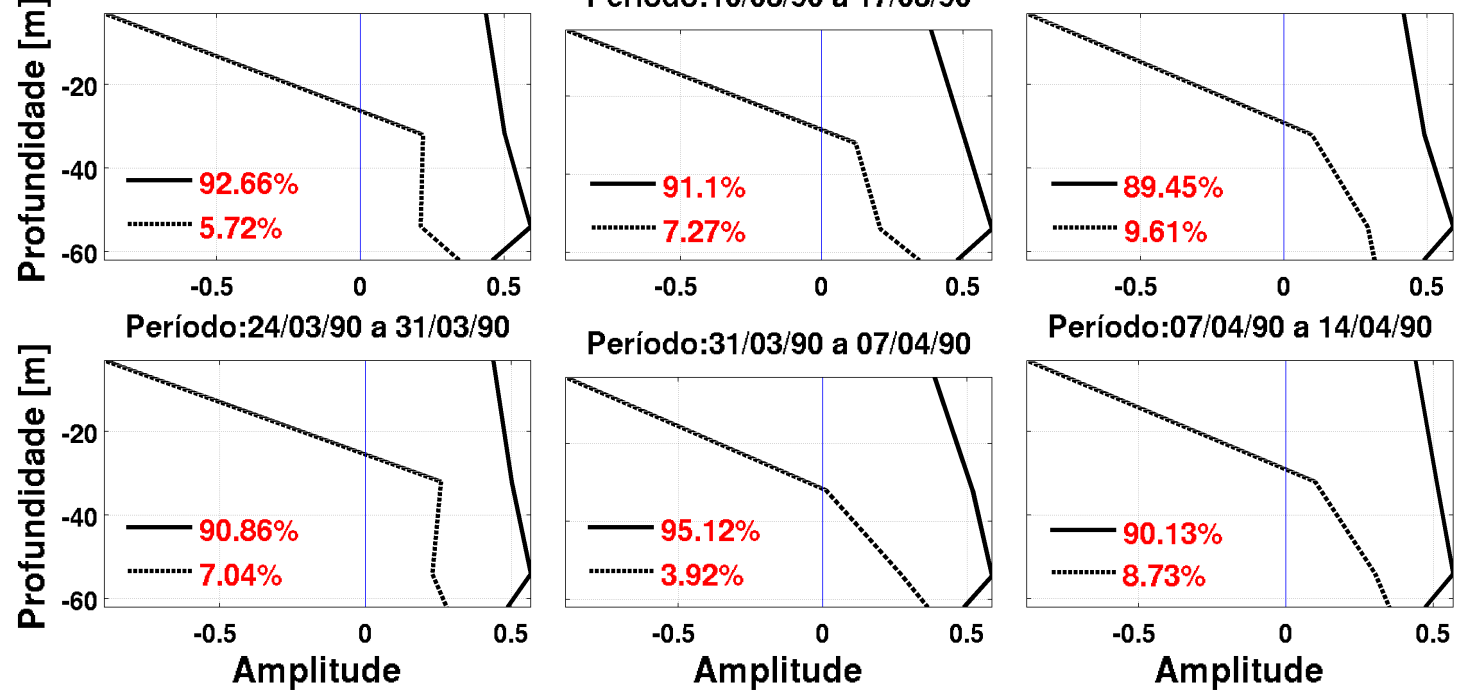

Figura 54: Amplitude dos modos estatísticos para a velocidade quase-perpendicular às isóbatas no ponto F2. A figura está organizada em 9 quadros de acordo com o período, crescente, indicado acima de cada quadro, em que foi aplicado o método das Funções Empíricas Ortogonais.

Para a componente quase-paralela (Figura 55) não se observa o mesmo comportamento das amplitudes resultantes para a velocidade $u$, e, por vezes, o modo mais energético é equivalente ao $1^{\circ}$ modo baroclínico. A maior importância da baroclinicidade para a componente quase-paralela à costa no ponto F2 pode ser inferida também da Figura 52, pois os hodógrafos das correntes de maré baroclínicas nos níveis mais profundos estão polarizados na direção quase-paralela à isóbata. Além disso, nessa direção desenvolvem-se corrente internas forçadas pelo vento, com variabilidade submaregráfica (GEYER et al., 1996; FONTES et al., 2008). Conforme mostrado por estes últimos autores, a tensão de cisalhamento dos ventos alísios é a principal responsável pela advecção para NO da pluma do RA, contribuindo para o sinal baroclínico das correntes na direção quase-paralela à isóbata da região altamente estratificada do ponto F2. 

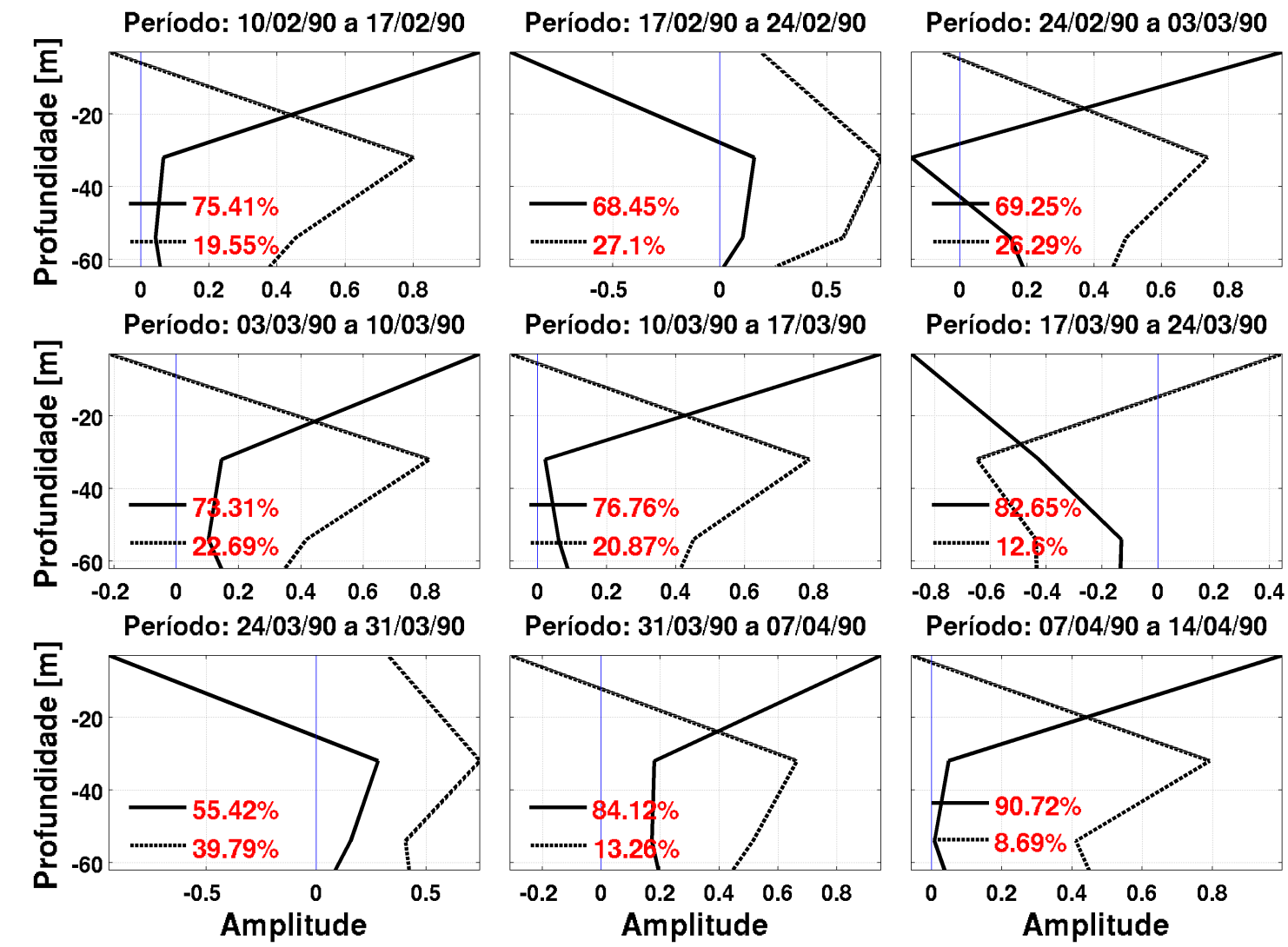

Figura 55: Amplitude dos modos estatísticos para a velocidade quase-paralela às isóbatas no ponto F2. A figura está organizada em 9 quadros de acordo com o período, crescente, indicado acima de cada quadro, em que foi aplicado o método das Funções Empíricas Ortogonais.

Para a componente $u$ da velocidade, consideramos como modo barotrópico o primeiro modo estatístico e como $1^{\mathrm{o}}$ modo baroclínico o segundo modo estatístico. Para tal, tomamos como base a evolução da fase da componente semi-diurna durante as nove sub-séries analisadas (Figura 56). Neste gráfico é possível separar com êxito o modo barotrópico do baroclínico. A figura mostra o $2^{\circ}$ modo estatístico da velocidade $u$ como equivalente ao existente em um fluido estratificado em duas camadas, uma em superfície (linha azul) e outra no resto da coluna d'água (linhas vermelha, verde e preta), com diferenças de fase de $\approx 180^{\circ}$. A Figura 56 mostra ainda a evolução da fase da salinidade na frequência semi-diurna. Nota-se que esta aparenta estar fora de fase com a velocidade baroclínica $u$ e em fase com a velocidade quase-paralela $v$ observada. 

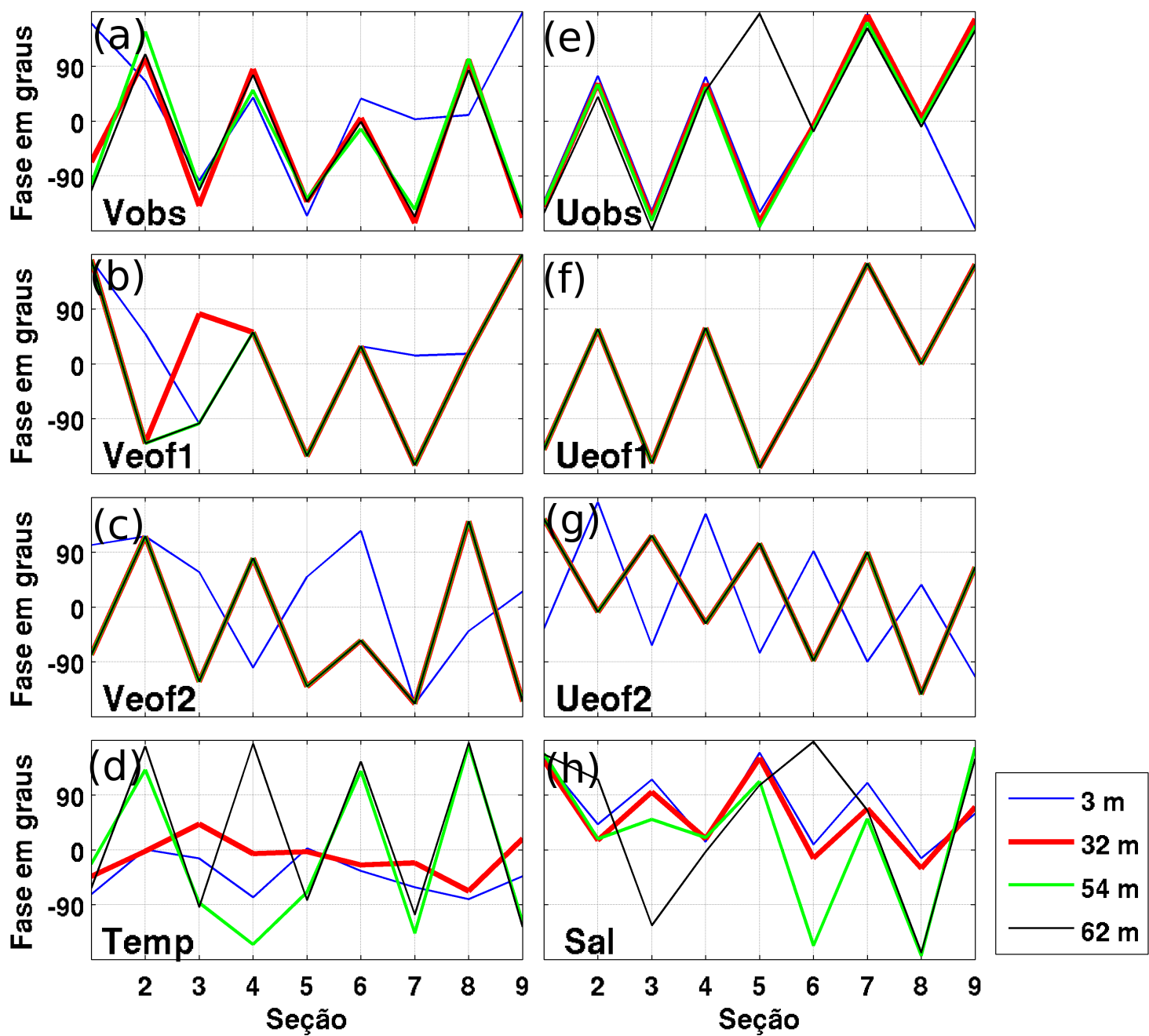

Figura 56: Evolução de fase da componente semi-diurna para as séries de velocidade, modos estatísticos, salinidade e temperatura. (a) representa a evolução de fase da velocidade quaseparalela às isóbatas observada (Vobs); (b) evolução da fase do $1^{\circ}$ modo estatístico da velocidade $v$ (Veof1); (c) evolução referente ao $2^{\circ}$ modo estatístico da velocidade $v$ (Veof2); (d) evolução de fase da Temperatura (Temp); (e) evolução de fase da velocidade quase-perpendicular às isóbatas (Uobs); (f) evolução de fase para o $1^{\circ}$ modo estatístico da velocidade $u$ (Ueof1); (g) evolução de fase do $2^{\circ}$ modo estatístico da velocidade $u$ (Ueof2) e, (h) evolução da fase da Salinidade (Sal), se encontra no $4^{\circ}$ quadro à direita. As linhas coloridas em azul, vermelho, verde e preto correspondem respectivamente às profundidades $3,32,54$ e $62 \mathrm{~m}$. 


\subsubsection{FOE - Reconstrução da velocidade}

As Figuras 57 a 65 mostram a reconstrução das séries temporais utilizando apenas o $1^{\circ}$ modo estatístico (quadro superior), apenas o $2^{\circ}$ modo ( $2^{\circ}$ quadro de cima para baixo), a velocidade $u$ observada ( $3^{\circ}$ quadro de cima para baixo) e a diferença entre o observado e a reconstrução da série utilizando os dois primeiros modos estatísticos (quadro inferior). Para que a diferença possa ser calculada, subtraímos a média temporal da velocidade observada $u$. Observamos diferenças entre as séries originais e as séries reconstruidas, provavelmente resultado também da não inclusão dos outros 2 modos superiores nas análises desta Dissertação. As Figuras 57 a 65, mostram que a componente baroclínica da velocidade pode ter intensidades relativamente altas, principalmente positivas e em superfície, com valores de até $0,5 \mathrm{~ms}^{-1}$. Nota-se que esses movimentos aparentam intermitência e possuem frequência próxima à semi-diurna. Nessas figuras, todas as subséries apresentam o primeiro modo estatístico com característcas barotrópicas, ou seja, velocidades oscilando sempre na mesma direção e com intensidade próxima em todas as profundidades.

A primeira sub-série (Figura 57) tem componente baroclínica com picos de velocidade a partir do dia 13/02 até a metade do dia 15/02, aparentemente com frequência semi-diurna e preferencialmente em superfície. Nota-se que mesmo quando a velocidade é nula, a modulação semi-diurna ainda é perceptível. A diferença entre as séries original e reconstruida é pequena. 


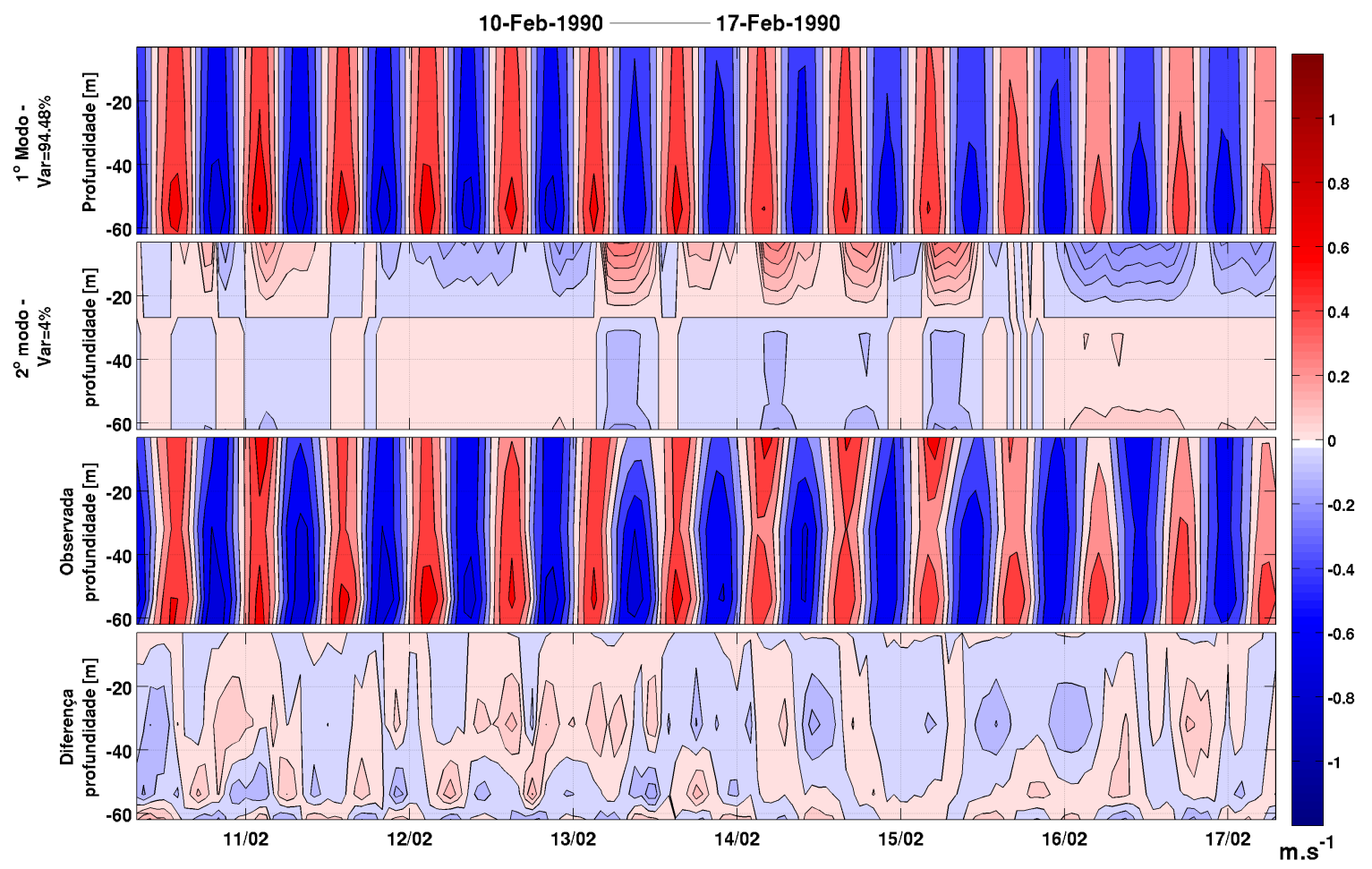

Figura 57: Comparação dos modos estatísticos com a velocidade quase-perpendicular observada para sub-série 1. O quadro superior representa a reconstrução da série de velocidade utilizando apenas o primeiro modo estatístico; o segundo quadro de cima para baixo representa a reconstrução da série utilizando apenas o segundo modo estatístico; o terceiro quadro é a velocidade observada quase-perpendicular e o último quadro representa a diferença entre a velocidade observada e a reconstruida a partir dos dois primeiros modos estatísticos. Interpolamos linearmente os dados para elaboração desta figura.

A segunda sub-série ( Figura 58) apresenta o $1^{\circ}$ modo baroclínico com oscilações em superfície de frequência semi-diurna fora de fase com a maré barotrópica da metade do dia 20/02 até o final da sub-série, quando ocorrem as maiores velocidades. Nota-se que, mesmo quando a velocidade é nula, a modulação semi-diurna na série ainda existe. A diferença entre as séries original e reconstruída tem, por vezes, a mesma ordem de grandeza da velocidade do $1^{\circ}$ modo baroclínico, indício de que mesmo contabilizando com menos de $2 \%$ da energia (ver Tabela 9), os modos estatísticos restantes podem ser importantes em alguns momentos. Ademais, a diferença entre a série reconstruída e a 
original aparenta estar relacionada também com a maré.

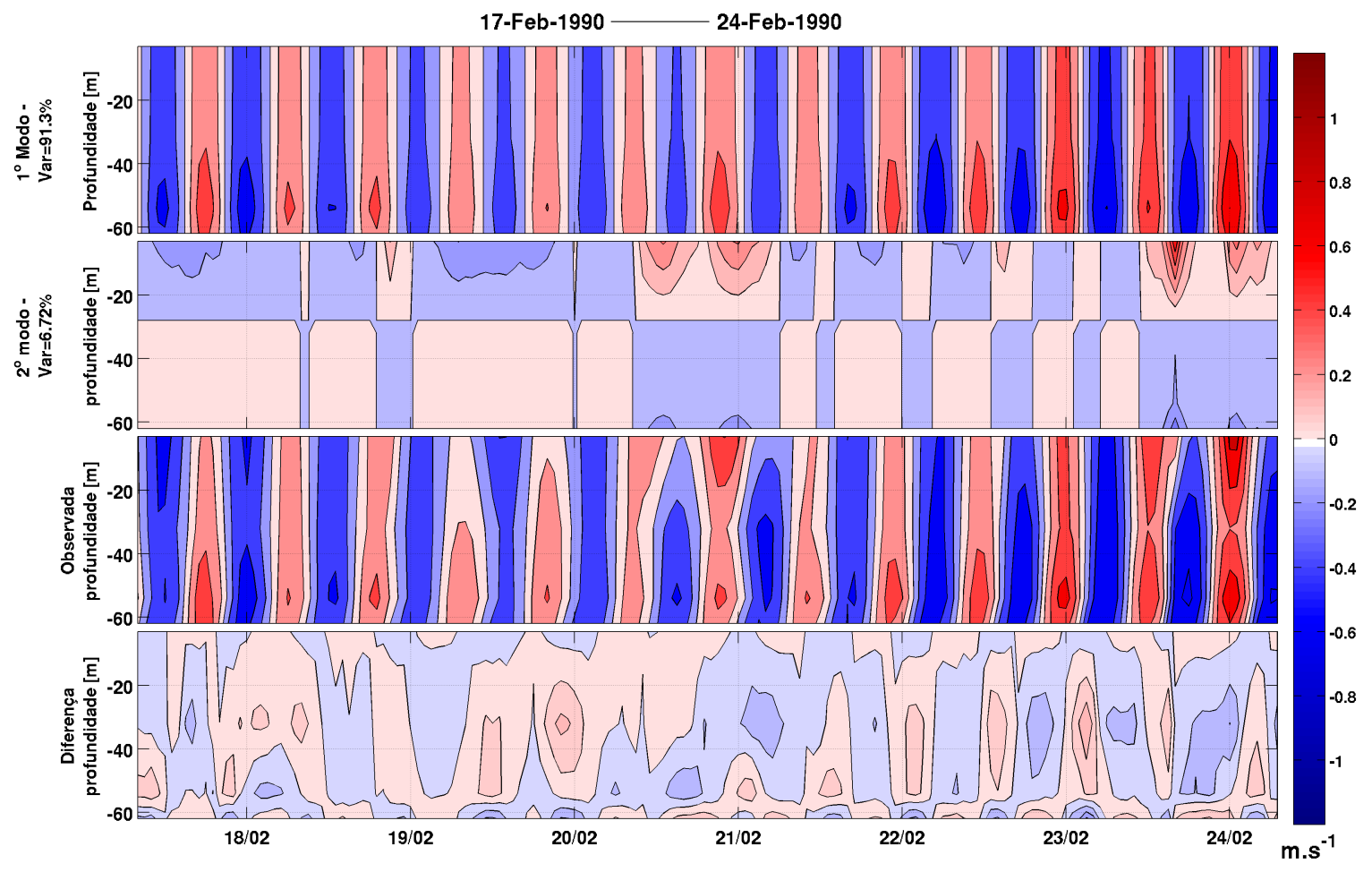

Figura 58: Comparação dos modos estatísticos com a velocidade quase-perpendicular observada para sub-série 2. O quadro superior representa a reconstrução da série de velocidade utilizando apenas o primeiro modo estatístico; o segundo quadro de cima para baixo representa a reconstrução da série utilizando apenas o segundo modo estatístico; o terceiro quadro é a velocidade observada quase-perpendicular e o último quadro representa a diferença entre a velocidade observada e a reconstruída a partir dos dois primeiros modos estatísticos. Interpolamos linearmente os dados para elaboração desta figura.

A terceira sub-série (Figura 59) possui componente baroclínica de $1^{\circ}$ modo com picos de velocidade ora em direção à costa, ora em direção ao largo. Nesses casos, apresenta variabilidade regular baroclínica com frequência semi-diurna, sempre fora de fase com relação ao primeiro modo estatístico ou barotrópico. A diferença entre as séries original e reconstruída, assim como na segunda sub-série, aparenta ter oscilações típicas de $2^{\circ}$ modo baroclínico, correspondentes às velocidade semi-diurnas com até $0,2 \mathrm{~ms}^{-1}$. 


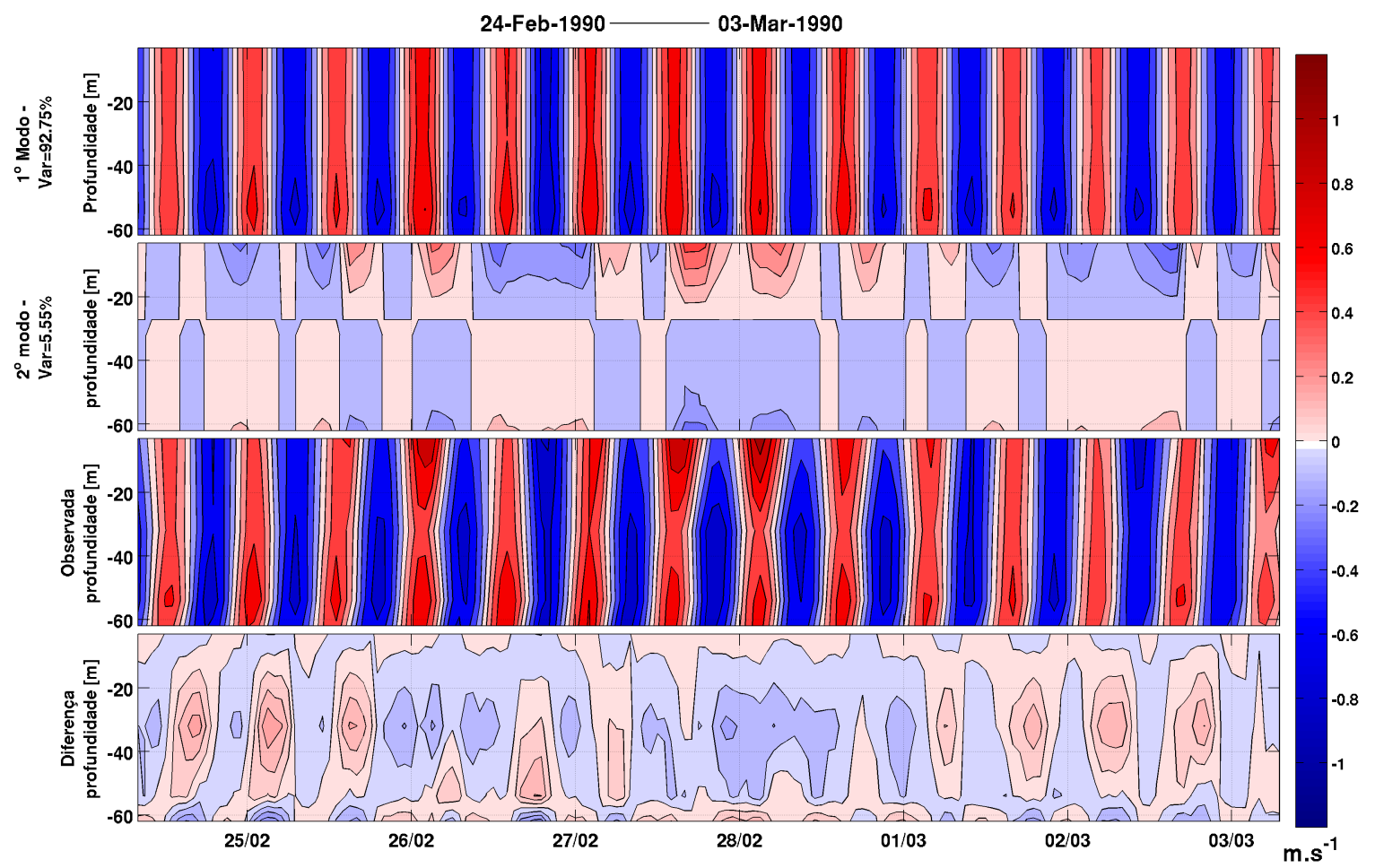

Figura 59: Comparação dos modos estatísticos com a velocidade quase-perpendicular observada para sub-série 3. O quadro superior representa a reconstrução da série de velocidade utilizando apenas o primeiro modo estatístico; o segundo quadro de cima para baixo representa a reconstrução da série utilizando apenas o segundo modo estatístico; o terceiro quadro é a velocidade observada quase-perpendicular e o último quadro representa a diferença entre a velocidade observada e a reconstruída a partir dos dois primeiros modos estatísticos. Interpolamos linearmente os dados para elaboração desta figura.

A quarta sub-série (Figura 60) é semelhante à terceira sub-série (Figura 59). O $1^{\mathrm{o}}$ modo baroclínico apresenta oscilações típicas bimodais, com frequência semi-diurna, pouco intensas e regulares durante toda a sub-série. A diferença entre as séries é pequena, com características típicas do $2^{\circ}$ modo baroclínico influenciado pela maré. 


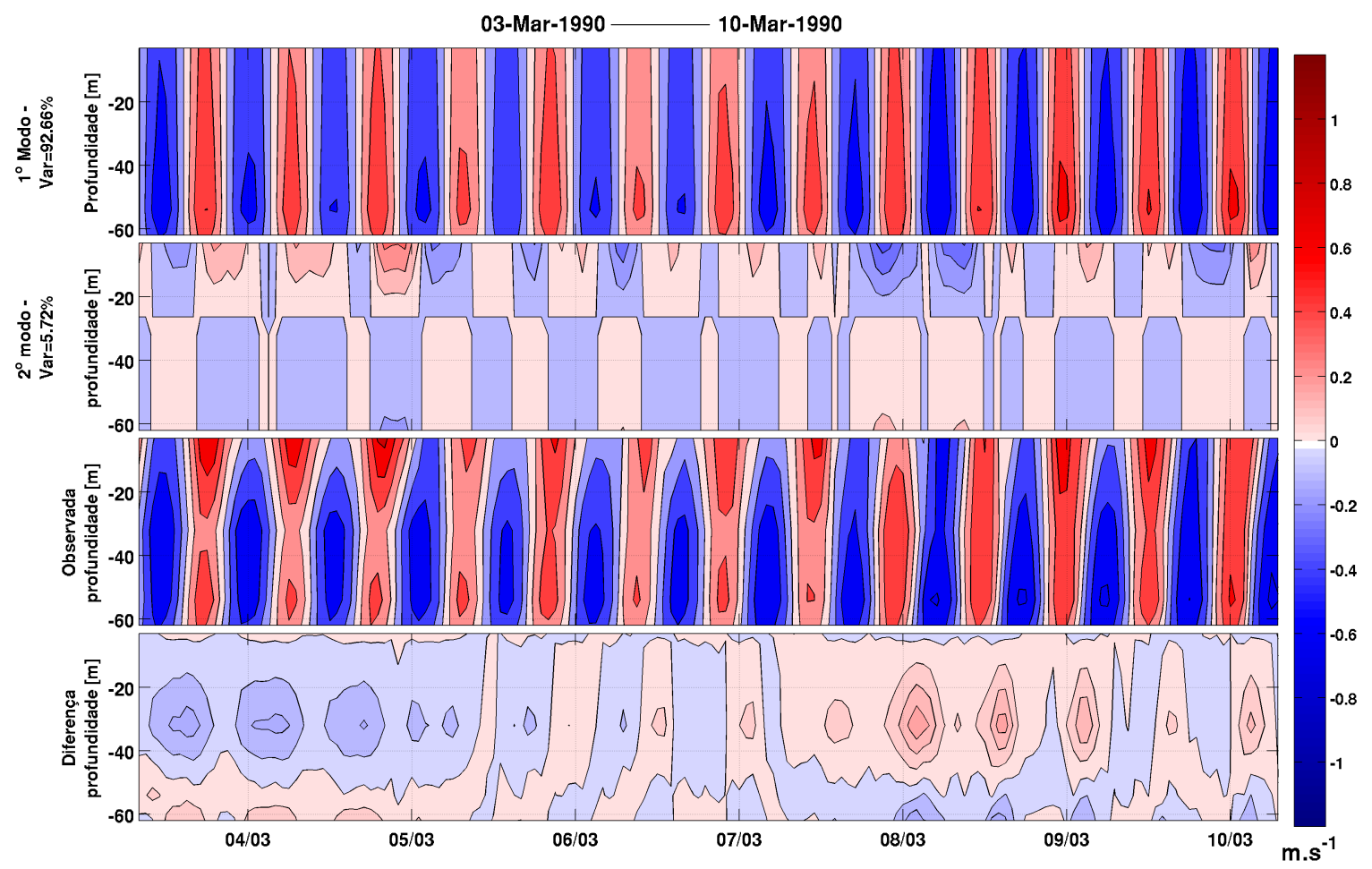

Figura 60: Comparação dos modos estatísticos com a velocidade quase-perpendicular observada para sub-série 4. O quadro superior representa a reconstrução da série de velocidade utilizando apenas o primeiro modo estatístico; o segundo quadro de cima para baixo representa a reconstrução da série utilizando apenas o segundo modo estatístico; o terceiro quadro é a velocidade observada quase-perpendicular e o último quadro representa a diferença entre a velocidade observada e a reconstruída a partir dos dois primeiros modos estatísticos. Interpolamos linearmente os dados para elaboração desta figura. 
A quinta sub-série (Figura 61) apresenta o $1^{\circ}$ modo baroclínico com oscilações em superfície semi-diurnas, principalmente do dia 13/03 ao dia 15/03, quando as velocidades positivas são um pouco mais intensas. A diferença entre as séries original e reconstruída é pequena e regular, possuindo sinal claro semi-diurno com características do $2^{\circ}$ modo baroclínico.

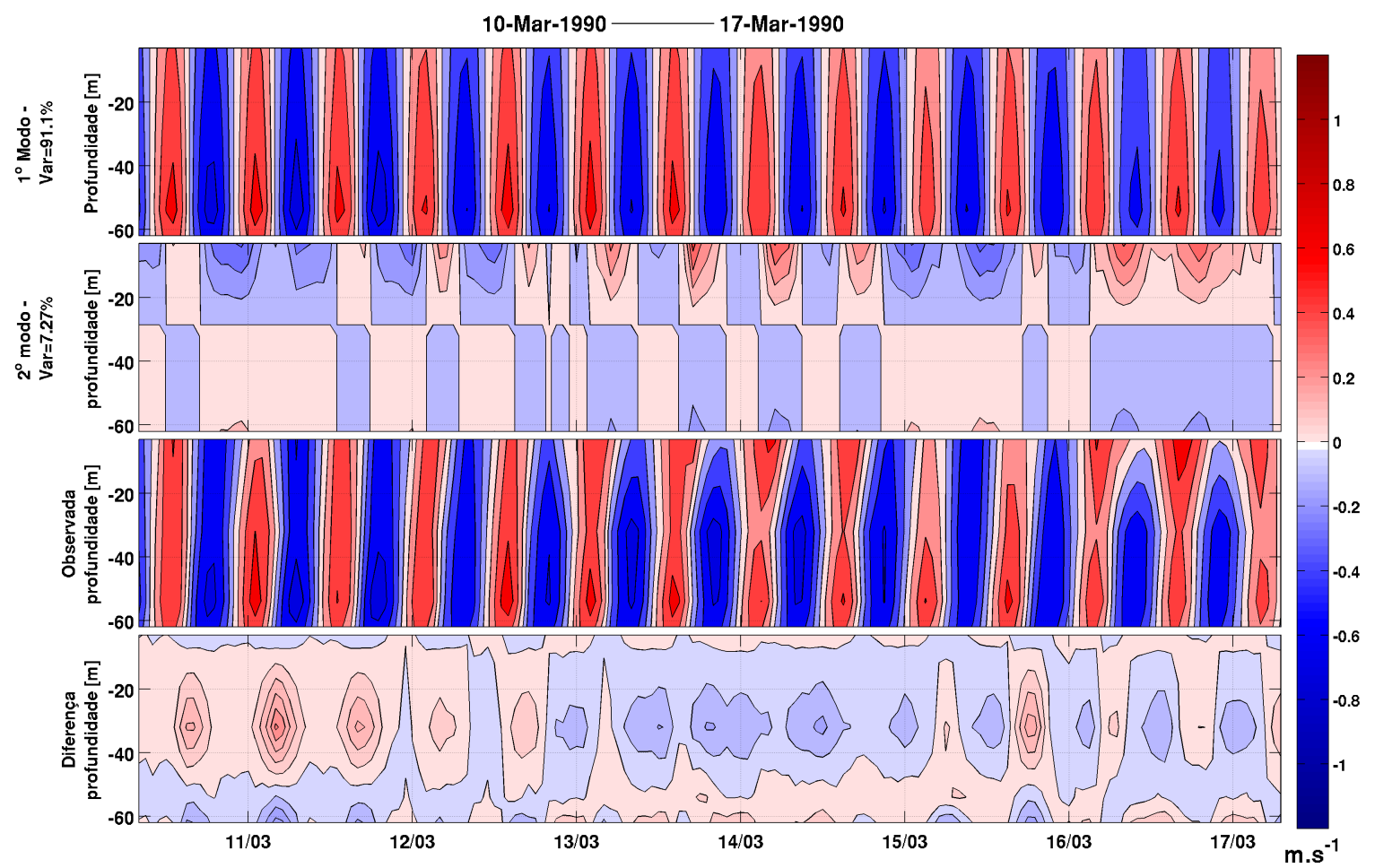

Figura 61: Comparação dos modos estatísticos com a velocidade quase-perpendicular observada para sub-série 5. O quadro superior representa a reconstrução da série de velocidade utilizando apenas o primeiro modo estatístico; o segundo quadro de cima para baixo representa a reconstrução da série utilizando apenas o segundo modo estatístico; o terceiro quadro é a velocidade observada quase-perpendicular e o último quadro representa a diferença entre a velocidade observada e a reconstruída a partir dos dois primeiros modos estatísticos. Interpolamos linearmente os dados para elaboração desta figura. 
A sexta sub-série (Figura 62) apresenta o maior percentual de variância explicada para o $2^{\circ}$ modo estatístico de todas as sub-séries, com 9,61\%. Entretanto apresenta velocidade baroclínica pouco intensa e com oscilações semi-diurnas claras a partir da metade do dia 21/03 até o final da série. A diferença entre as série original e reconstruída é a menor entre todas as sub-séries, com variações semi-diurnas e com padrão de oscilação vertical típico do $2^{\circ}$ modo baroclínico. Resultado esperado neste caso, já que a soma do $1^{\circ}$ e $2^{\circ}$ modos estatísticos explica $99 \%$ da variância.

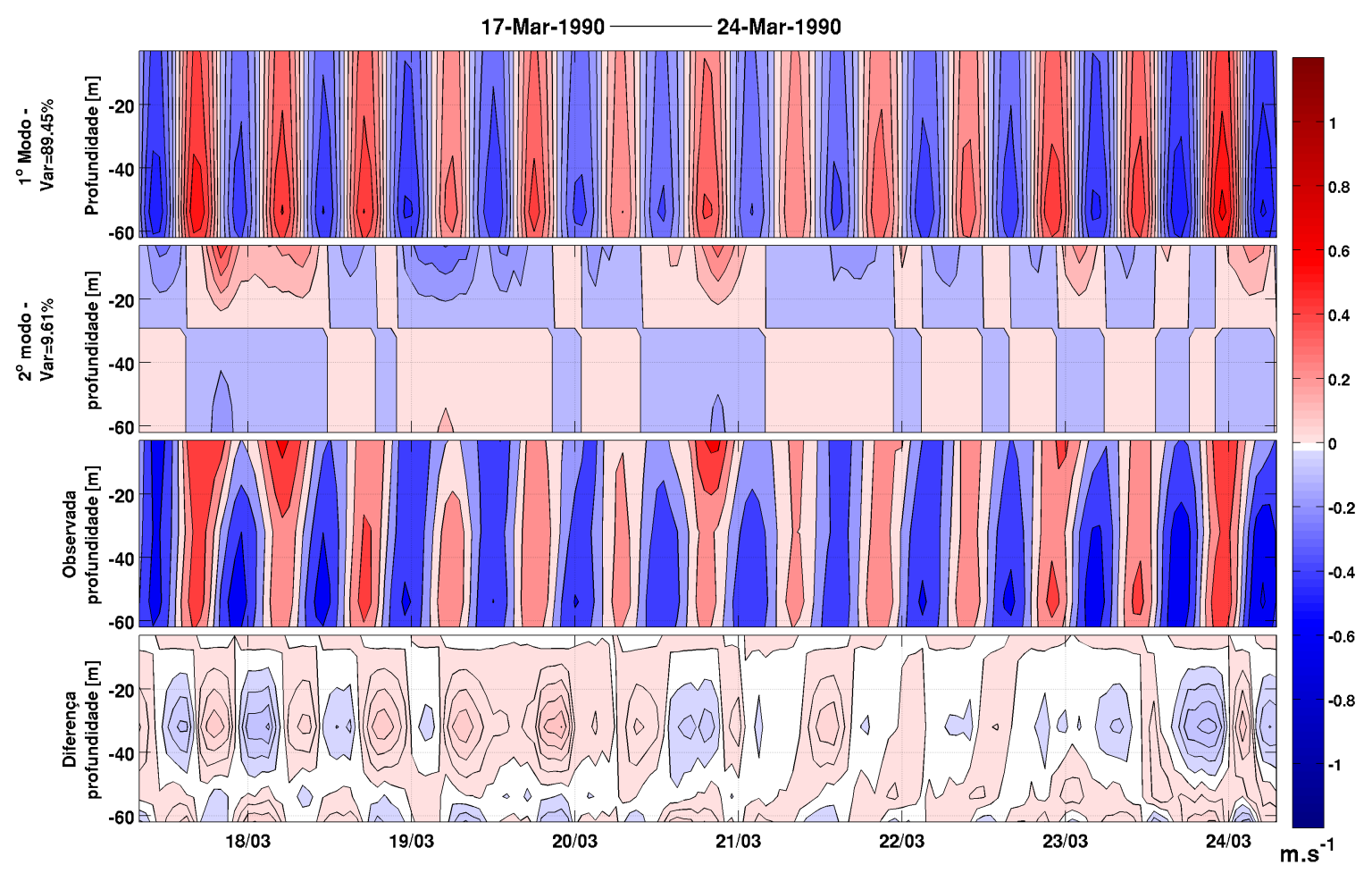

Figura 62: Comparação dos modos estatísticos com a velocidade quase-perpendicular observada para sub-série 6. O quadro superior representa a reconstrução da série de velocidade utilizando apenas o primeiro modo estatístico; o segundo quadro de cima para baixo representa a reconstrução da série utilizando apenas o segundo modo estatístico; o terceiro quadro é a velocidade observada quase-perpendicular e o último quadro representa a diferença entre a velocidade observada e a reconstruída a partir dos dois primeiros modos estatísticos. Interpolamos linearmente os dados para elaboração desta figura. 
A sétima sub-série (Figura 63) apresenta no $2^{\circ}$ modo estatístico movimentos baroclínicos com oscilações de frequências semi-diurnas a partir do dia 27/03, aparentemente até o final da série. A diferença entre as séries original e reconstruída é a maior entre as sub-séries, com sinal semi-diurno fraco e cujo modo de oscilação vertical correspondente ao $2^{\circ}$ modo baroclínico. A diferença grande está de acordo com o maior percentual de variância explicada pela soma do $3^{\circ}$ e $4^{\circ}$ modos estatísticos entre todas as sub-séries, com $2,1 \%$.

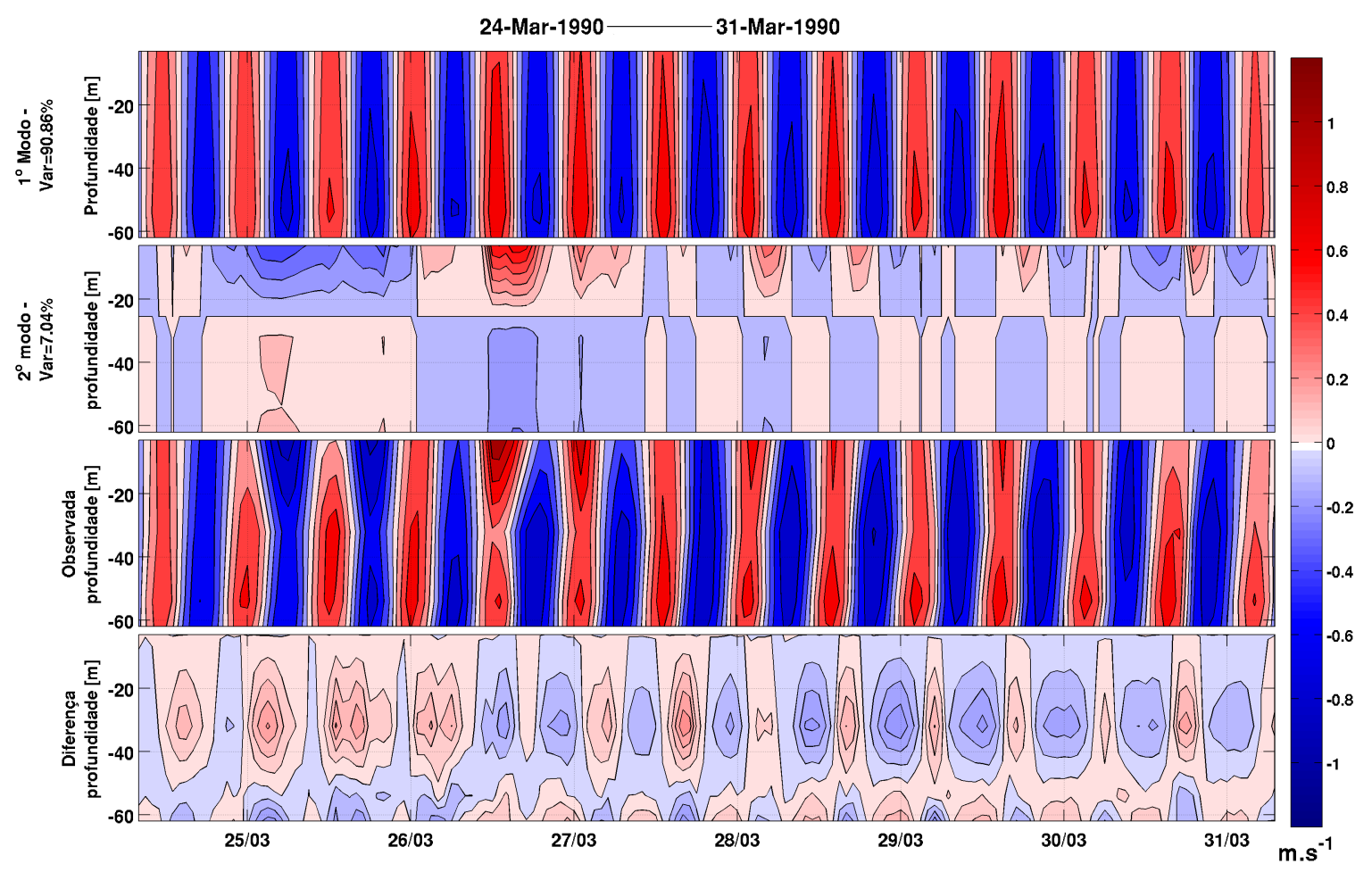

Figura 63: Comparação dos modos estatísticos com a velocidade quase-perpendicular observada para sub-série 7. O quadro superior representa a reconstrução da série de velocidade utilizando apenas o primeiro modo estatístico; o segundo quadro de cima para baixo representa a reconstrução da série utilizando apenas o segundo modo estatístico; o terceiro quadro é a velocidade observada quase-perpendicular e o último quadro representa a diferença entre a velocidade observada e a reconstruída a partir dos dois primeiros modos estatísticos. Interpolamos linearmente os dados para elaboração desta figura. 
A oitava sub-série (Figura 64) apresenta oscilações com frequências semi-diurnas intermitentes, ocorrendo do início da série até o dia 1/04 e da metade do dia 02/04 até a metade do dia 03/04. Da metade do dia 3 em diante, não há como, visualmente discernir em que frequência preferencial ocorrem as oscilações. A diferença entre as séries original e reconstruída é pequena, com sinal aparentemente semi-diurno fraco.

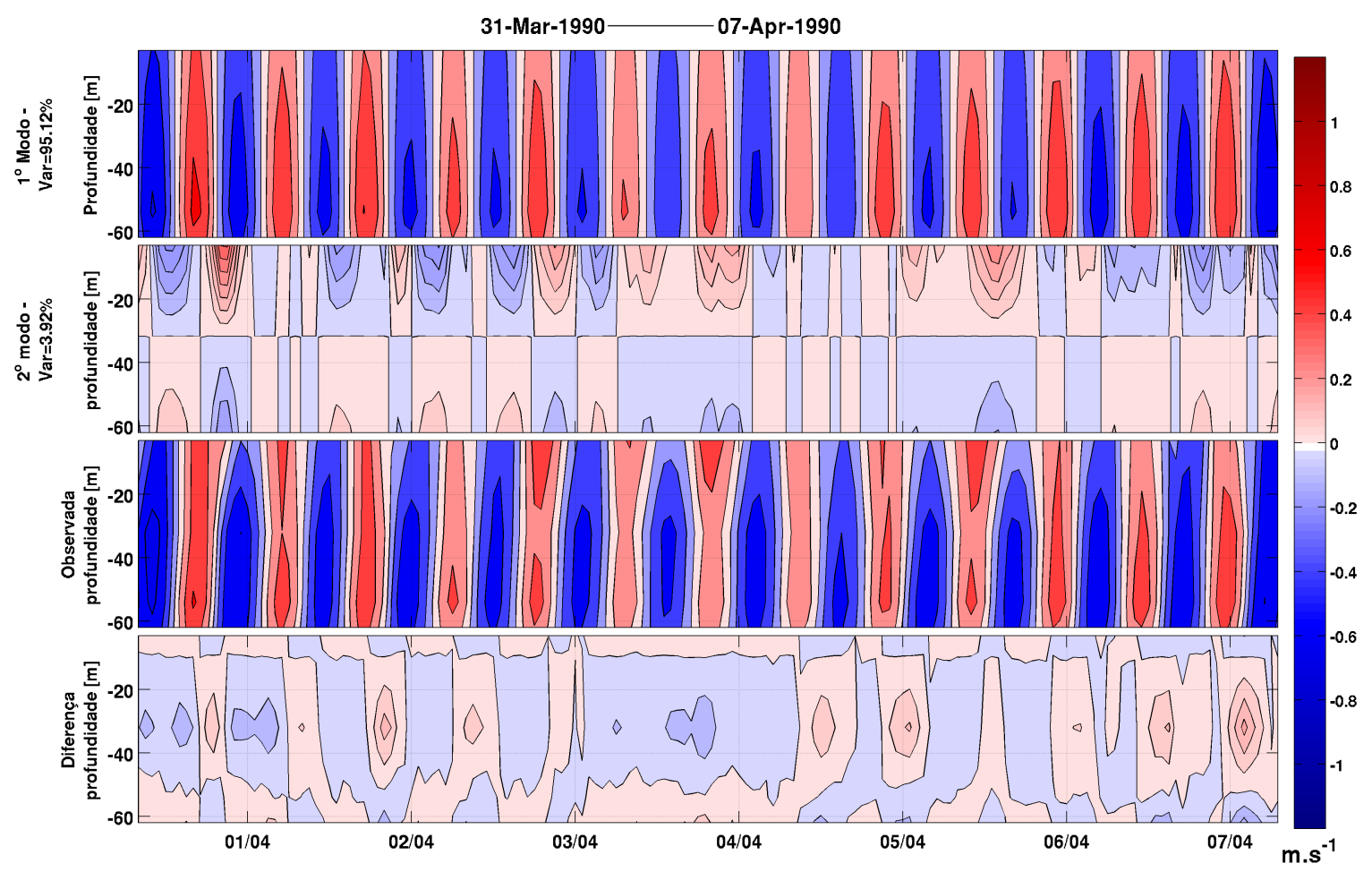

Figura 64: Comparação dos modos estatísticos com a velocidade quase-perpendicular observada para sub-série 8. O quadro superior representa a reconstrução da série de velocidade utilizando apenas o primeiro modo estatístico; o segundo quadro de cima para baixo representa a reconstrução da série utilizando apenas o segundo modo estatístico; o terceiro quadro é a velocidade observada quase-perpendicular e o último quadro representa a diferença entre a velocidade observada e a reconstruída a partir dos dois primeiros modos estatísticos. Interpolamos linearmente os dados para elaboração desta figura. 
Durante a primeira metade, até o dia 11/04, da nona sub-série (Figura 65) observamos movimentos baroclínicos intensos, com oscilações claramente semi-diurnas e positivas. A segunda metade da sub-série mostra velocidades negativas, também aparentemente semi-diurnas, que esvanece até o final da série. A diferença entre as séries original e reconstruída é pequena em relação à série baroclínica, com sinal semi-diurno fraco e cujo modo de oscilação vertical correspondente ao $2^{\circ}$ modo baroclínico.

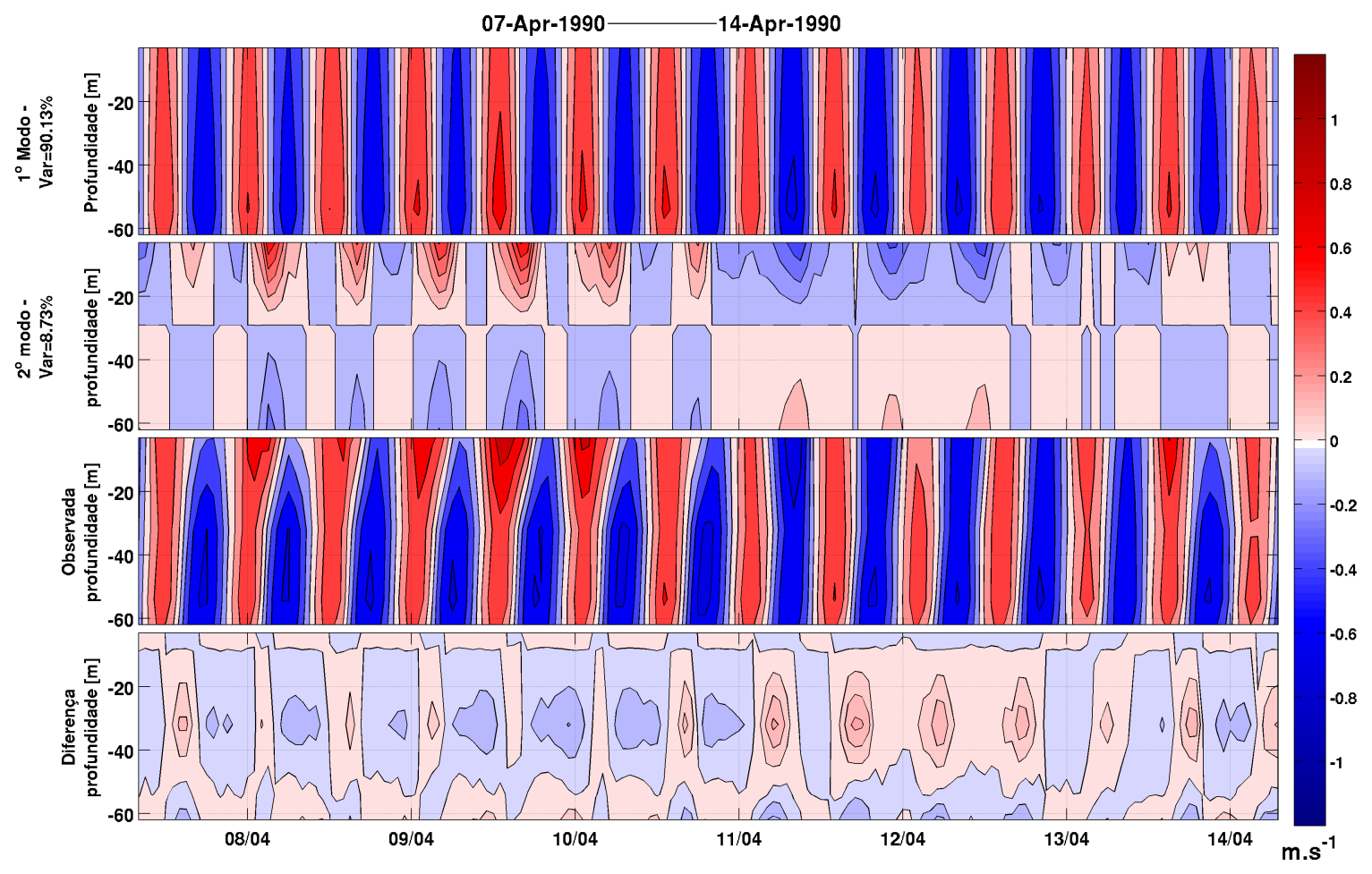

Figura 65: Comparação dos modos estatísticos com a velocidade quase-perpendicular observada para sub-série 9. O quadro superior representa a reconstrução da série de velocidade utilizando apenas o primeiro modo estatístico; o segundo quadro de cima para baixo representa a reconstrução da série utilizando apenas o segundo modo estatístico; o terceiro quadro é a velocidade observada quase-perpendicular e o último quadro representa a diferença entre a velocidade observada e a reconstruída a partir dos dois primeiros modos estatísticos. Interpolamos linearmente os dados para elaboração desta figura. 
A análise das Figuras 57 a 65 nos mostra que o modo baroclínico da componente quase-perpendicular develocidade é importante em determinados momentos, com movimentos por vezes intensos, e que apresentam variabilidades, principalmente em superfície, intermitentes e com frequência semi-diurna e, ainda, com clara diferença de fase em relação à maré barotrópica $\left(1^{\circ}\right.$ modo estatístico). De modo geral, os dois primeiros modos estatísticos explicam razoavelmente bem as oscilações observadas. Entretanto, o $3^{\circ}$ e $4^{\circ}$ modos estatísticos, apesar da pequena relevância percentual, haja vista a Tabela 9, aparentam ser importantes para a dinâmica local. A Tabela 10 mostra os máximos e mínimos para cada sub-série apresentada.

Tabela 10: Máximos e mínimos de velocidade para a componente quaseperpendicular, u, em ms $\mathrm{m}^{-1}$, observados a $3 \mathrm{~m}$.

\begin{tabular}{|c|c|c|c|c|c|c|c|c|}
\hline & \multicolumn{2}{|c|}{$1^{0}$ Modo } & \multicolumn{2}{|c|}{$2^{\circ}$ Modo } & \multicolumn{2}{|c|}{ Observado } & \multicolumn{2}{|c|}{ Diferença } \\
\hline & Máx & Mín & Máx & Mín & Máx & Mín & Máx & Mín \\
\hline SS-1 & 0,55 & $-0,49$ & 0,31 & $-0,24$ & 0,71 & $-0,59$ & 0,02 & $-0,02$ \\
\hline SS-2 & 0,57 & $-0,43$ & 0,58 & $-0,20$ & 0,87 & $-0,51$ & 0,03 & $-0,04$ \\
\hline SS-3 & 0,72 & $-0,67$ & 0,46 & $-0,33$ & 1,05 & $-0,89$ & 0,04 & $-0,05$ \\
\hline SS-4 & 0,50 & $-0,43$ & 0,33 & $-0,35$ & 0,70 & $-0,65$ & 0,01 & $-0,02$ \\
\hline SS-5 & 0,45 & $-0,46$ & 0,44 & $-0,34$ & 0,65 & $-0,71$ & 0,02 & $-0,04$ \\
\hline SS-6 & 0,45 & $-0,36$ & 0,47 & $-0,31$ & 0,59 & $-0,56$ & 0,02 & $-0,02$ \\
\hline SS-7 & 0,60 & $-0,57$ & 0,67 & $-0,39$ & 1,20 & $-0,88$ & 0,00 & $-0,01$ \\
\hline SS-8 & 0,44 & $-0,41$ & 0,36 & $-0,22$ & 0,52 & $-0,53$ & 0,03 & $-0,05$ \\
\hline SS-9 & 0,54 & $-0,50$ & 0,61 & $-0,39$ & 0,77 & $-0,86$ & 0,02 & $-0,04$ \\
\hline
\end{tabular}




\subsubsection{FOE - Influencia do $2^{\circ}$ modo estatístico na dinâmica de propriedades}

Visamos agora inferir a importância deste $1^{\circ}$ modo baroclínico na dinâmica de propriedades, tal qual a salinidade. Para inferir a importância do $1^{\circ}$ modo baroclínico na variabilidade da salinidade comparamos, nas Figuras 66 a 74, a velocidade $u$ observada, o $1^{\mathrm{o}}$ modo baroclínico da velocidade $u$ e a anomalia de salinidade. As comparações têm como objetivo verificar a influência da maré semi-diurna, assim como observado nas subséries 1 a 9 de correntes baroclínicas (Figuras 57 a 65), nas sub-séries de anomalia de salinidade.

A comparação da primeira sub-série de anomalia de salinidade com o $1^{\circ}$ modo baroclínico (Figura 66) mostra que, no período da metade do dia 13/02 à metade do dia 15/02, a anomalia de salinidade apresentou oscilação semi-diurna da mesma forma que a série de velocidade baroclínica. A anomalia de salinidade aparenta ter uma relação inversa com a série de velocidade, sendo negativa quando a velocidade é positiva e viceversa. A série de velocidade observada não apresenta, ao menos visualmente, relação com a anomalia de salinidade. 


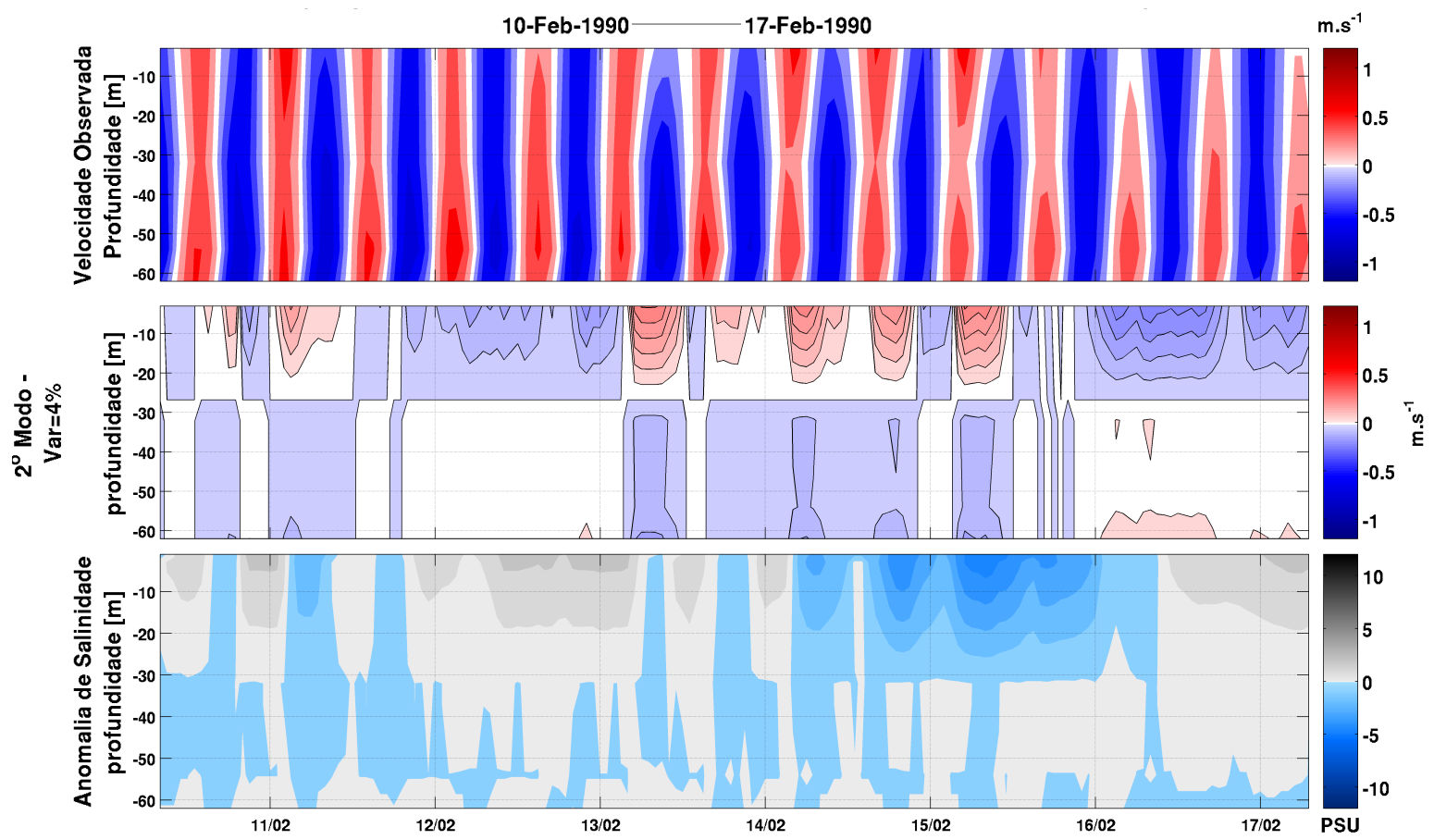

Figura 66: Comparação do $2^{\circ}$ modo estatístico com a anomalia de salinidade observada para a sub-série 1. O quadro superior é a velocidade quase-perpendicular observada subtraída de sua média; o segundo quadro representa a reconstrução da série de velocidade utilizando apenas o segundo modo estatístico; o terceiro quadro representa a anomalia de salinidade. Interpolamos linearmente os dados para elaboração desta figura.

A anomalia de salinidade calculada para a sub-série 2 (Figura 67) não apresenta oscilações semi-diurnas até a metade do dia 22/02, quando as oscilações estão, da mesma forma que na sub-série 1, inversamente relacionadas. A velocidade observada nesta subsérie também não apresenta qualquer relação aparente com a anomalia de salinidade. 

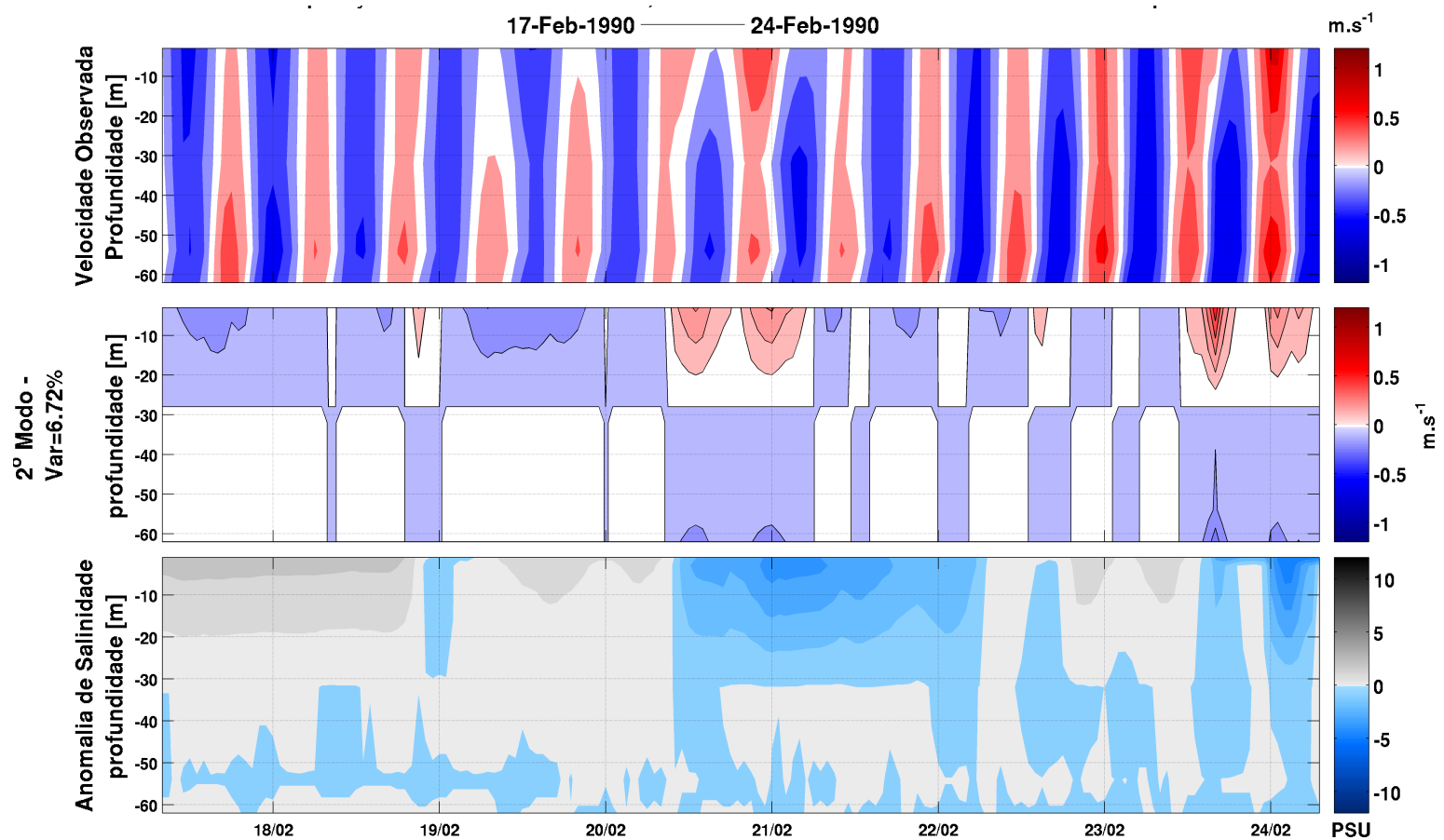

Figura 67: Comparação do $2^{\circ}$ modo estatístico com a anomalia de salinidade observada para a sub-série 2. O quadro superior é a velocidade quase-perpendicular observada subtraída de sua média; o segundo quadro representa a reconstrução da série de velocidade utilizando apenas o segundo modo estatístico; o terceiro quadro representa a anomalia de salinidade. Interpolamos linearmente os dados para elaboração desta figura.

Na sub-série 3 (Figura 68) nota-se que a anomalia de salinidade apresenta oscilações semi-diurnas durante todo o tempo. Comparando com o $1^{\circ}$ modo baroclínico, percebe-se que a salinidade, assim como o mencionado para a sub-série 1, está inversamente relacionada com a velocidade baroclínica. Novamente a velocidade observada não aparenta visualmente estar relacionada com a anomalia de salinidade. 

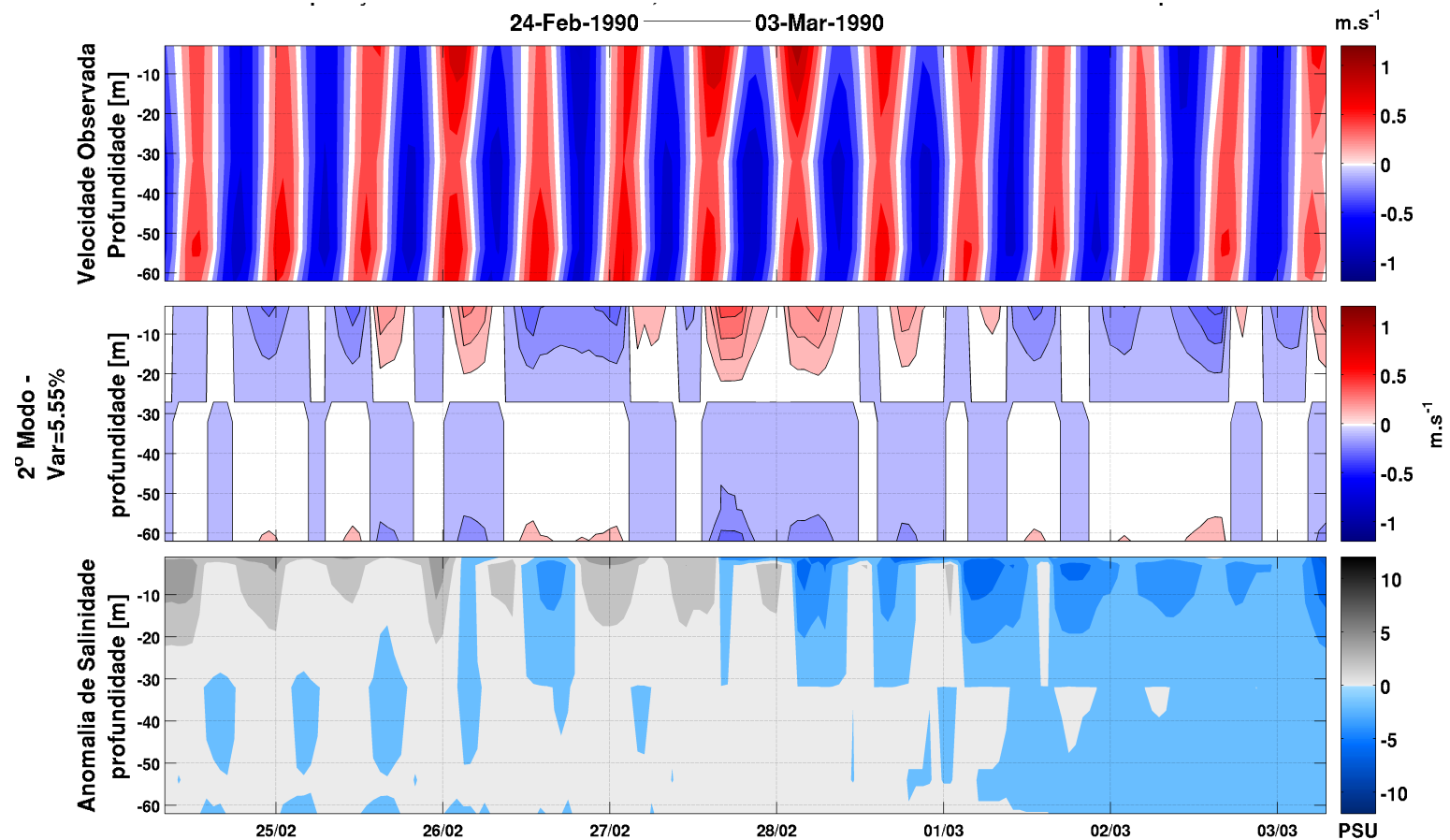

Figura 68: Comparação do $2^{\circ}$ modo estatístico com a anomalia de salinidade observada para a sub-série 3. O quadro superior é a velocidade quase-perpendicular observada subtraída de sua média; o segundo quadro representa a reconstrução da série de velocidade utilizando apenas o segundo modo estatístico; o terceiro quadro representa a anomalia de salinidade. Interpolamos linearmente os dados para elaboração desta figura.

Na sub-série 4 (Figura 69) não é possivel, ao menos visualmente, verificar qualquer oscilação clara de frequência semi-diurna na anomalia de salinidade. Outro processo físico pode ser dominante, regulando a distribuição da salinidade, ao menos nesta sub-série. O processo responsável por modificar a salinidade provavelmente tem escala temporal diferente da maregráfica. Adiantamos que, no cálculo da correlação cruzada, a sub-série de velocidade quase-paralela $v$ desta sub-série 4 apresentou altas correlações, sendo, possivelmente, responsável pelo comportamento desta sub-série de anomalia de salinidade. 


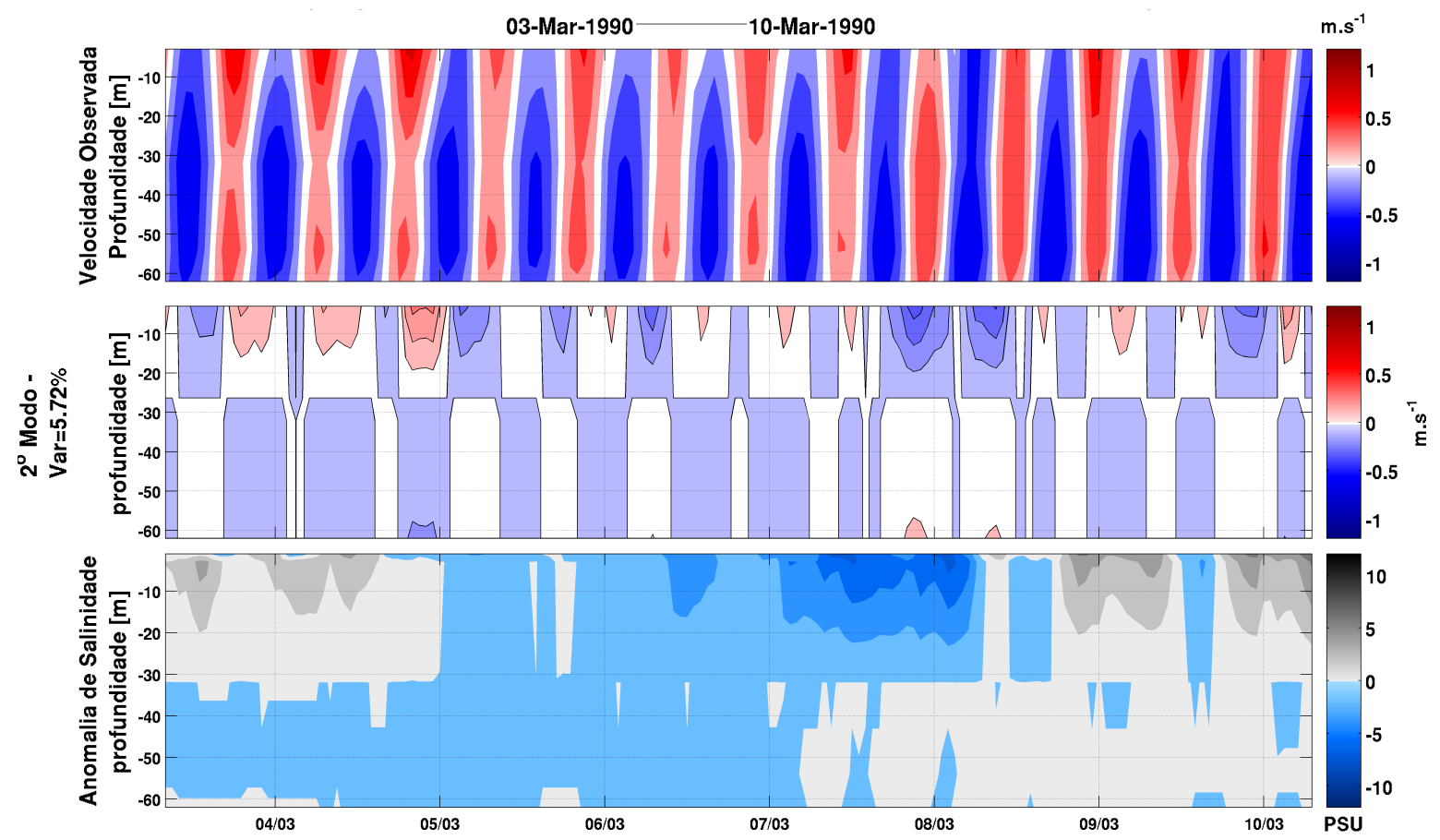

Figura 69: Comparação do $2^{\circ}$ modo estatístico com a anomalia de salinidade observada para a sub-série 4. O quadro superior é a velocidade quase-perpendicular observada subtraída de sua média; o segundo quadro representa a reconstrução da série de velocidade utilizando apenas o segundo modo estatístico; o terceiro quadro representa a anomalia de salinidade. Interpolamos linearmente os dados para elaboração desta figura.

A sub-série 5 (Figura 70) apresenta, a partir da metade do dia 13/03 até o final da série, oscilações próximas à superfície com frequência semi-diurna, semelhante ao proposto para a Figura 61. No período vicinal ao dia 15/03 podemos observar que a anomalia de salinidade é negativa ao mesmo tempo em que a velocidade baroclínica é positiva. No nível que a velocidade muda de sentido, a anomalia de salinidade, mesmo que não mude de sinal, tem a tendência de aumentar. Logo em seguida, entre os dias 15/03 e 16/03, percebe-se que a velocidade possui dois picos consecutivos de velocidade negativa, não chegando a mudar de sentido. Ainda assim, a anomalia de salinidade diminui, aparentemente respondendo às variações de velocidade baroclínica que possuem um sinal semi-diurno evidente. 

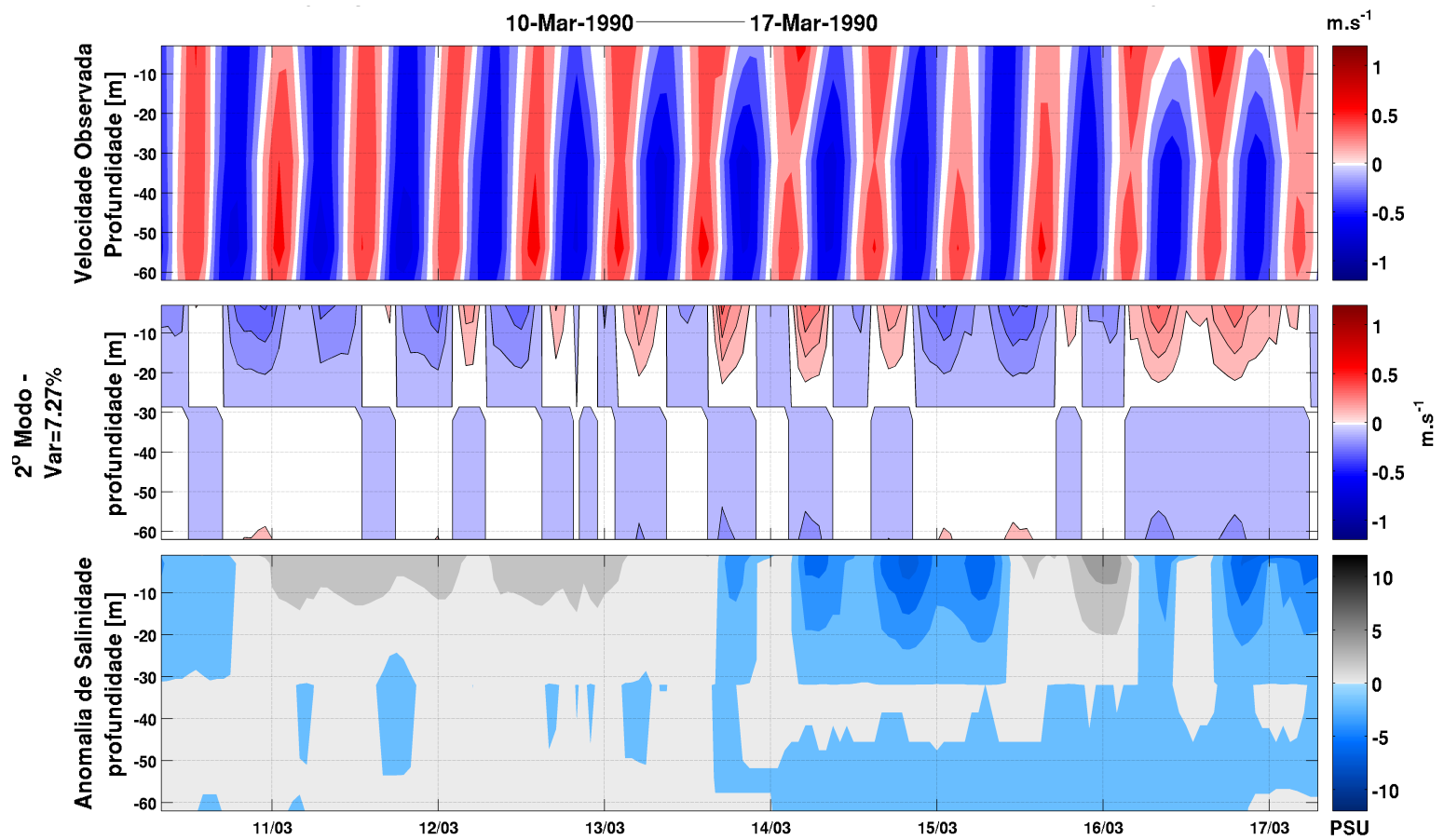

Figura 70: Comparação do $2^{\circ}$ modo estatístico com a anomalia de salinidade observada para a sub-série 5. O quadro superior é a velocidade quase-perpendicular observada subtraída de sua média; o segundo quadro representa a reconstrução da série de velocidade utilizando apenas o segundo modo estatístico; o terceiro quadro representa a anomalia de salinidade. Interpolamos linearmente os dados para elaboração desta figura.

Assim como para as sub-séries anteriores, a sexta sub-série de anomalia de salinidade (Figura 71) apresenta oscilações semi-diurnas perceptíveis a partir da metade do dia 21/03, até o final. Novamente, as oscilações da anomalia de salinidade aparentam, em alguns momentos, estar correlacionadas com as correntes baroclínicas semi-diurnas. 


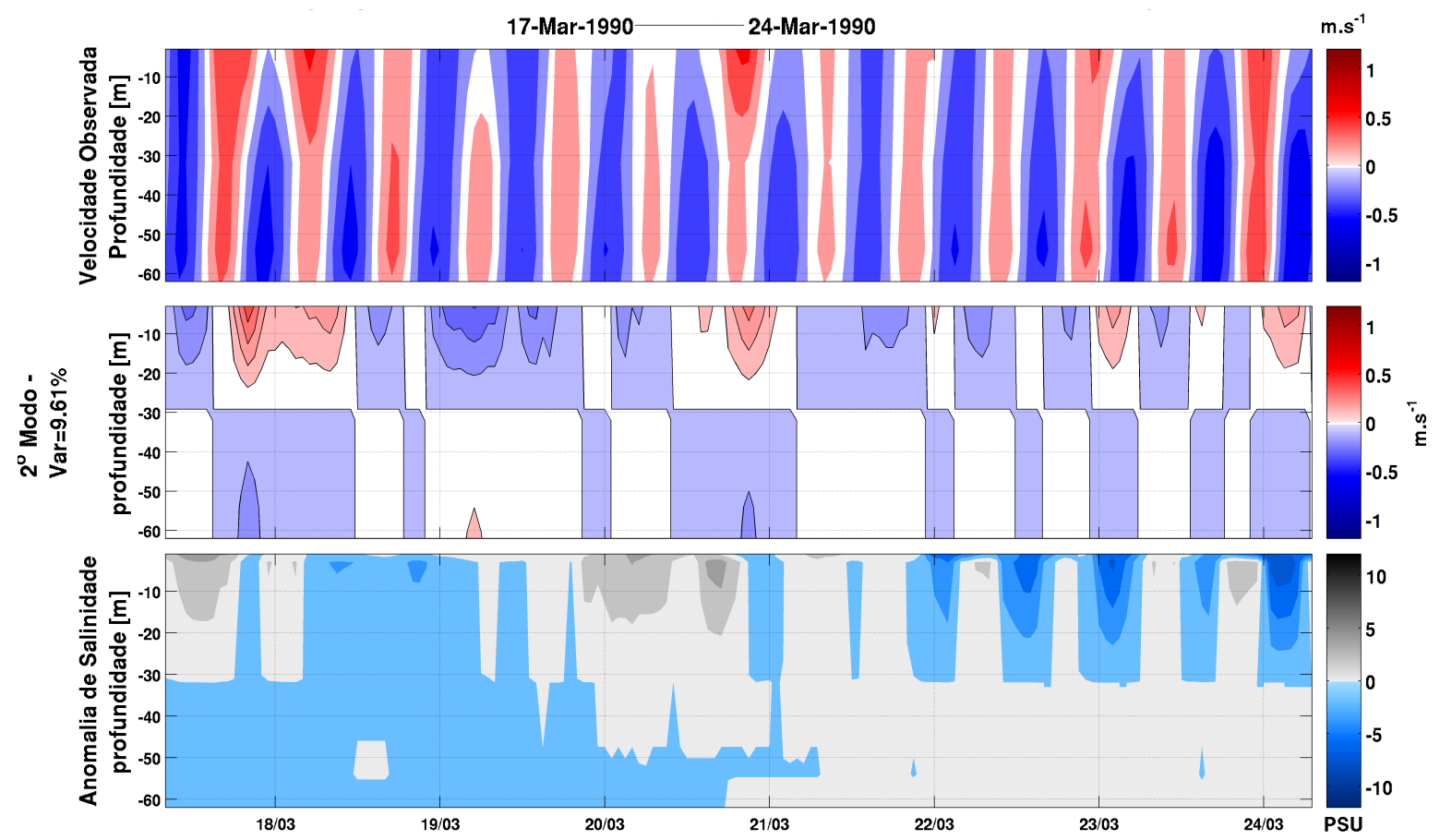

Figura 71: Comparação do $2^{\circ}$ modo estatístico com a anomalia de salinidade observada para a sub-série 6. O quadro superior é a velocidade quase-perpendicular observada subtraída de sua média; o segundo quadro representa a reconstrução da série de velocidade utilizando apenas o segundo modo estatístico; o terceiro quadro representa a anomalia de salinidade. Interpolamos linearmente os dados para elaboração desta figura.

Comparando as sub-séries de anomalia de salinidade e velocidades do $1^{\circ}$ modo baroclínico para o período da sub-série 7 (Figura 72), verifica-se no intervalo entre a metade do dia 26/03 até o dia 29/03 oscilações semi-diurnas. Antes do dia 26/03 e depois do dia 29/03, entretanto não há oscilações semi-diurnas claras. 


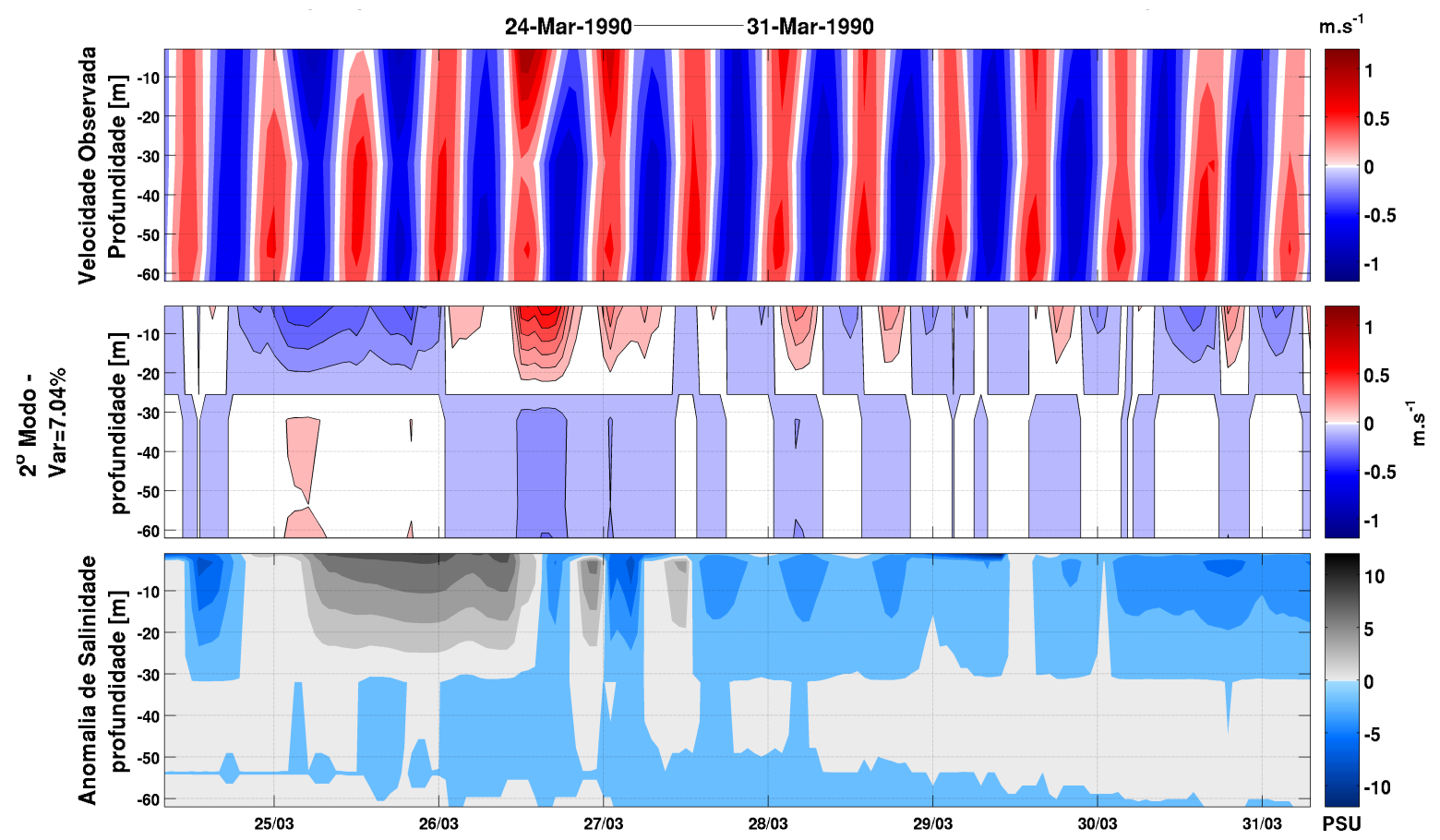

Figura 72: Comparação do $2^{\circ}$ modo estatístico com a anomalia de salinidade observada para a sub-série 7. O quadro superior é a velocidade quase-perpendicular observada subtraída de sua média; o segundo quadro representa a reconstrução da série de velocidade utilizando apenas o segundo modo estatístico; o terceiro quadro representa a anomalia de salinidade. Interpolamos linearmente os dados para elaboração desta figura.

A sub-série oito de anomalias de salinidade (Figura 73) não apresenta variação semi-diurna em superfície bem definida, como observado nas sub-séries anteriores (Figuras 66 a 72). Com excessão de alguns instantes, não há influência clara da velocidade baroclínica nesta sub-série. 


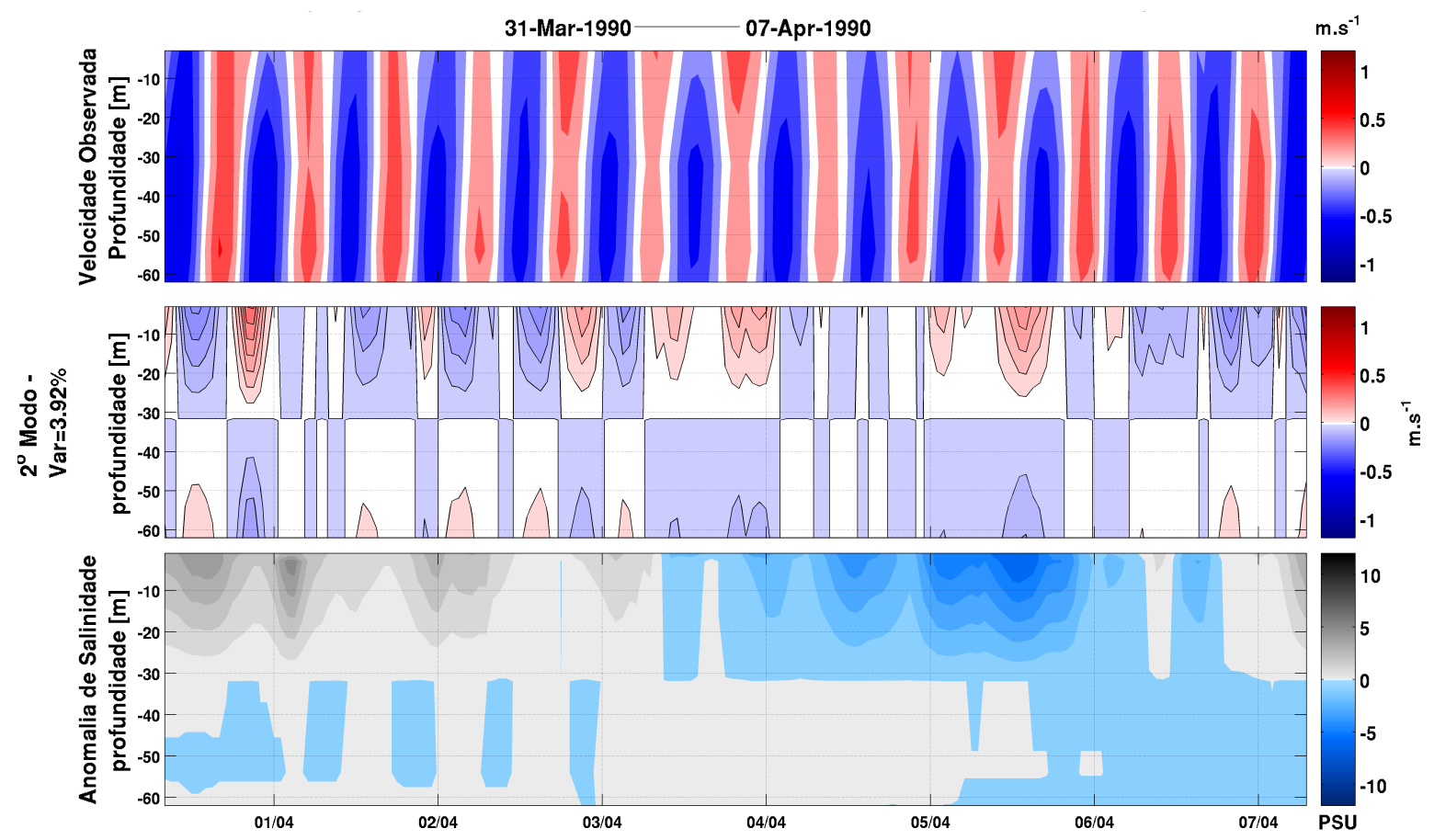

Figura 73: Comparação do $2^{\circ}$ modo estatístico com a anomalia de salinidade observada para a sub-série 8. O quadro superior é a velocidade quase-perpendicular observada subtraída de sua média; o segundo quadro representa a reconstrução da série de velocidade utilizando apenas o segundo modo estatístico; o terceiro quadro representa a anomalia de salinidade. Interpolamos linearmente os dados para elaboração desta figura.

A sub-série nove, como já observado na Figura 65, apresenta oscilações evidentes, na primeira metade da série, do dia 7/04 até o dia 11/04, relacionadas à maré semi-diurna na série de velocidade baroclínica. A anomalia de salinidade responde claramente à essas oscilações, indicando a importância da corrente baroclínica nesta série. 


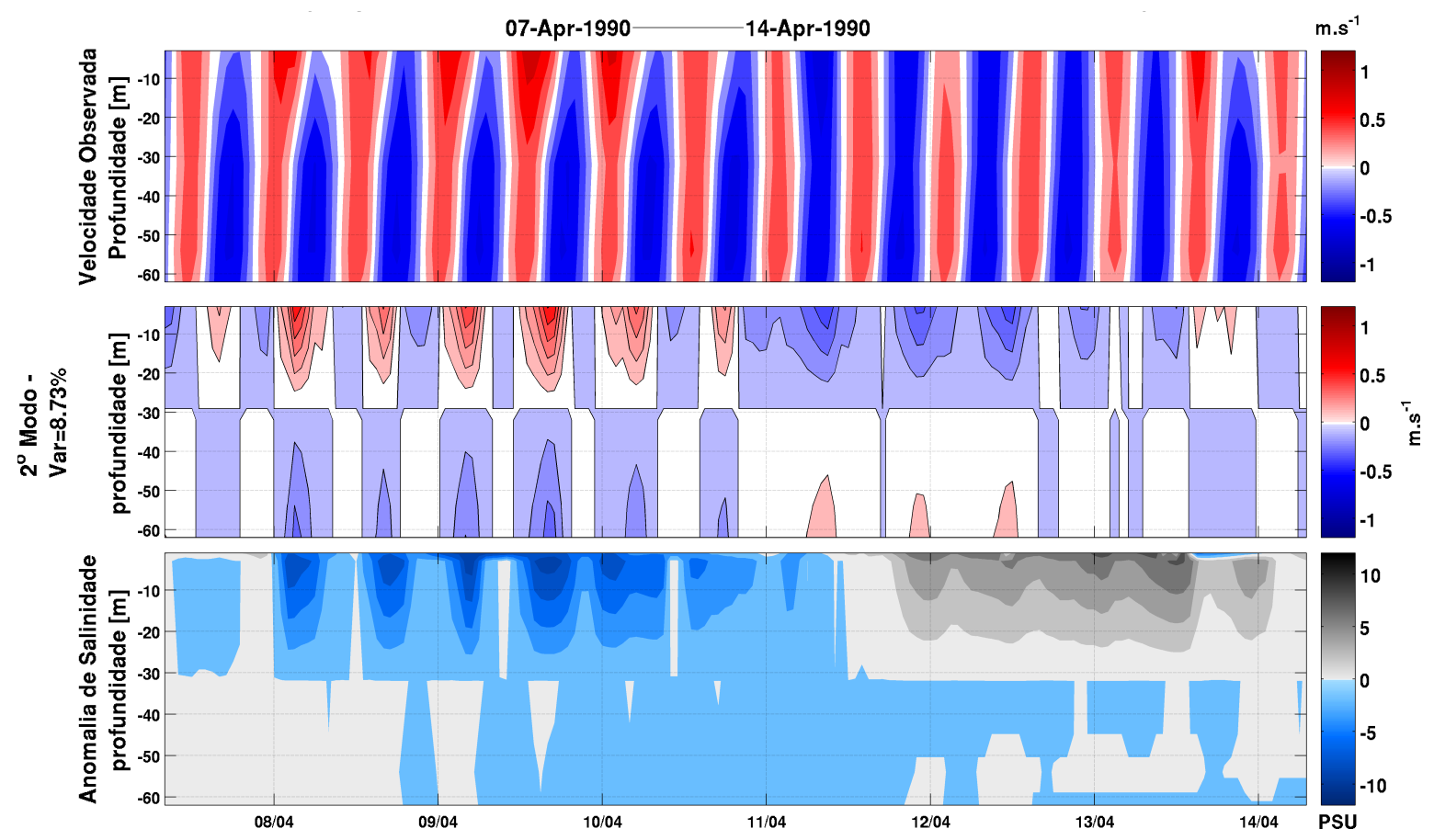

Figura 74: Comparação do $2^{\circ}$ modo estatístico com a anomalia de salinidade observada para a sub-série 9. O quadro superior é a velocidade quase-perpendicular observada subtraída de sua média; o segundo quadro representa a reconstrução da série de velocidade utilizando apenas o segundo modo estatístico; o terceiro quadro representa a anomalia de salinidade. Interpolamos linearmente os dados para elaboração desta figura.

Nas sub-séries de anomalia de salinidade analisadas, Figuras 66 a 74, nota-se, como é evidente principalmente na Figura 74, que a anomalia de salinidade está respondendo às variações do campo baroclínico em superfície. A relação entre a anomalia de salinidade e a velocidade baroclínica se dá numa relação inversa, isto é variações negativas de salinidade associam-se a velocidades positivas e variações positivas de salinidade a velocidades negativas. Ao analisarmos as direções definidas para as velocidades e a hidrodinâmica da PCA, temos que velocidades positivas representam transporte em direção ao largo, o que levaria águas da porção mais interna da PCA (menos salinas) para o largo. Em condições de velocidades negativas, verifica-se o oposto: águas mais salinas da borda da PCA seriam direcionadas para o interior da plataforma. A comparação das sub-séries 1 a 9 (Figuras 66 a 74) evidencia, ainda, que há oscilações semi-diurnas intermitentes em superfície. Ou seja, como sabido, diferentemente da maré astronômica, as marés internas não são determinísticas, fazendo com que a previsão deste processo seja 
muito difícil. 


\subsubsection{FOE - Correlação}

A partir dos resultados da última Seção 6.2.6, buscamos verificar o coeficiente de correlação existente entre a anomalia de salinidade e a velocidade baroclínica, visando os períodos em que marés internas ocorrem e avaliando sua intermitência. Para tal, foi calculada a correlação entre os dados à profundidade de $3 \mathrm{~m}$, que apresentaram maior variabilidade e, caso haja correlação, da fase. Caso a salinidade responda às marés internas, esperamos que a maior correlação esteja no atraso próximo a zero hora. Considerando que as marés internas são intermitentes, o cálculo da correlação entre as sub-séries completas não é adequado. Portanto, seguindo a metodologia proposta na Seção 5.2.4, calculamos a correlação entre as sub-séries em janelas de 2 dias. As Figuras 75 a 83 mostram a correlação entre a velocidade observada $u, 1^{\circ}$ modo baroclínico e velocidade observada $v$, com a anomalia de salinidade. A correlação está indicada no valor de cada instante; cada ponto corresponde ao valor da correlação para o intervalo de dois dias a partir daquele instante. As cores azul, vermelho, verde e preto diferenciam a correlação com atraso, respectivamente, de zero, uma, duas e três horas. As 2 linhas sólidas correspondem ao intervalo de confiança de $95 \%$ da correlação calculado a partir da Equação 5.2.7, e os valores entre esses limites, $\pm 0,2357$, representam séries não correlacionadas.

As correlações para a sub-série 1 (Figura 75) mostram que a anomalia de salinidade está altamente correlacionada positivamente com a velocidade quase-paralela à isóbata em lag zero durante praticamente toda sub-série. A componente baroclínica, a partir da metade do dia 13/02, apresenta alta correlação negativa com a anomalia de salinidade. Durante a maior parte da série, a correlação entre a velocidade observada quase-perpendicular $u$ e a anomalia de salinidade não é significativa. 


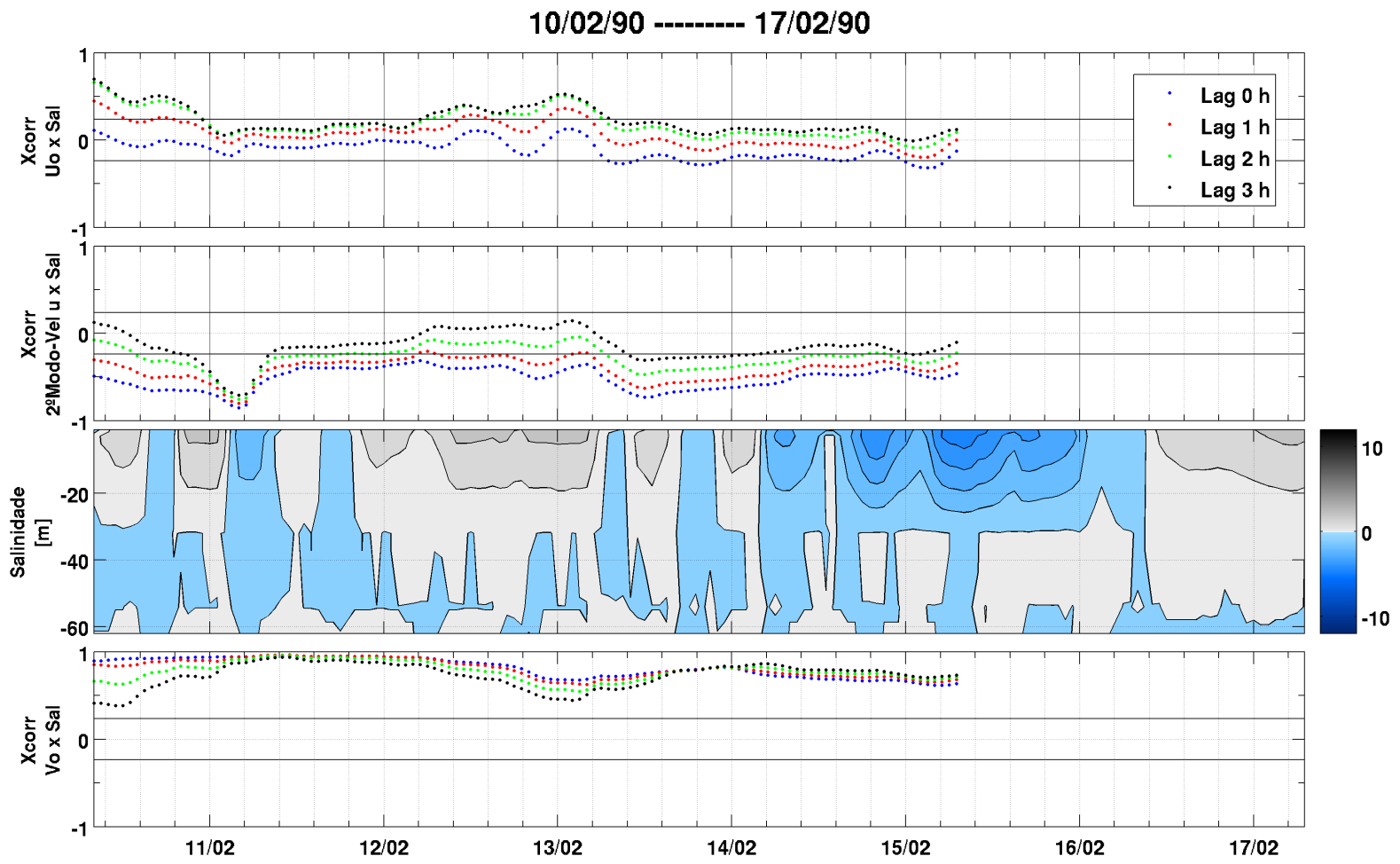

Figura 75: Correlações cruzadas calculadas para a sub-série 1 a $3 \mathrm{~m}$ de profundidade. Cada ponto representa o valor da correlação entre a janela de dois dias iniciada no instante que o ponto se encontra. Os quadros representam a correlação entre janelas de sub-séries de anomalia de salinidade e janelas das sub-séries de: velocidade observada $u$ (quadro superior); $1^{\circ}$ modo baroclínico da velocidade $u$ (segundo quadro de cima para baixo); velocidade observada $v$ (quarto quadro). O terceiro quadro representa a anomalia de salinidade para o período da sub-série. Os pontos azuis representam a correlação com atraso de 0 hora, vermelhos de uma hora, verdes de duas horas e pretos de 3 horas. As linhas sólidas representam o limite de confiabilidade das correlações. 
Verifica-se para a segunda sub-série (Figura 76) que a anomalia de salinidade possui alta correlação positiva com a velocidade quase-paralela à isóbata em todos os lags analisados. Isto pode ser interpretado como um sinal de que as baixas frequências são importantes. A componente baroclínica da velocidade apresenta correlação negativa com a salinidade na primeira metade da série e ao final da série; entretanto, a série de anomalia de salinidade não apresenta oscilações semi-diurnas claras na primeira metade da série. A correlação entre a velocidade observada quase-perpendicular, $u$, e a anomalia de salinidade novamente encontra-se no intervalo correspondente a séries não correlacionadas.

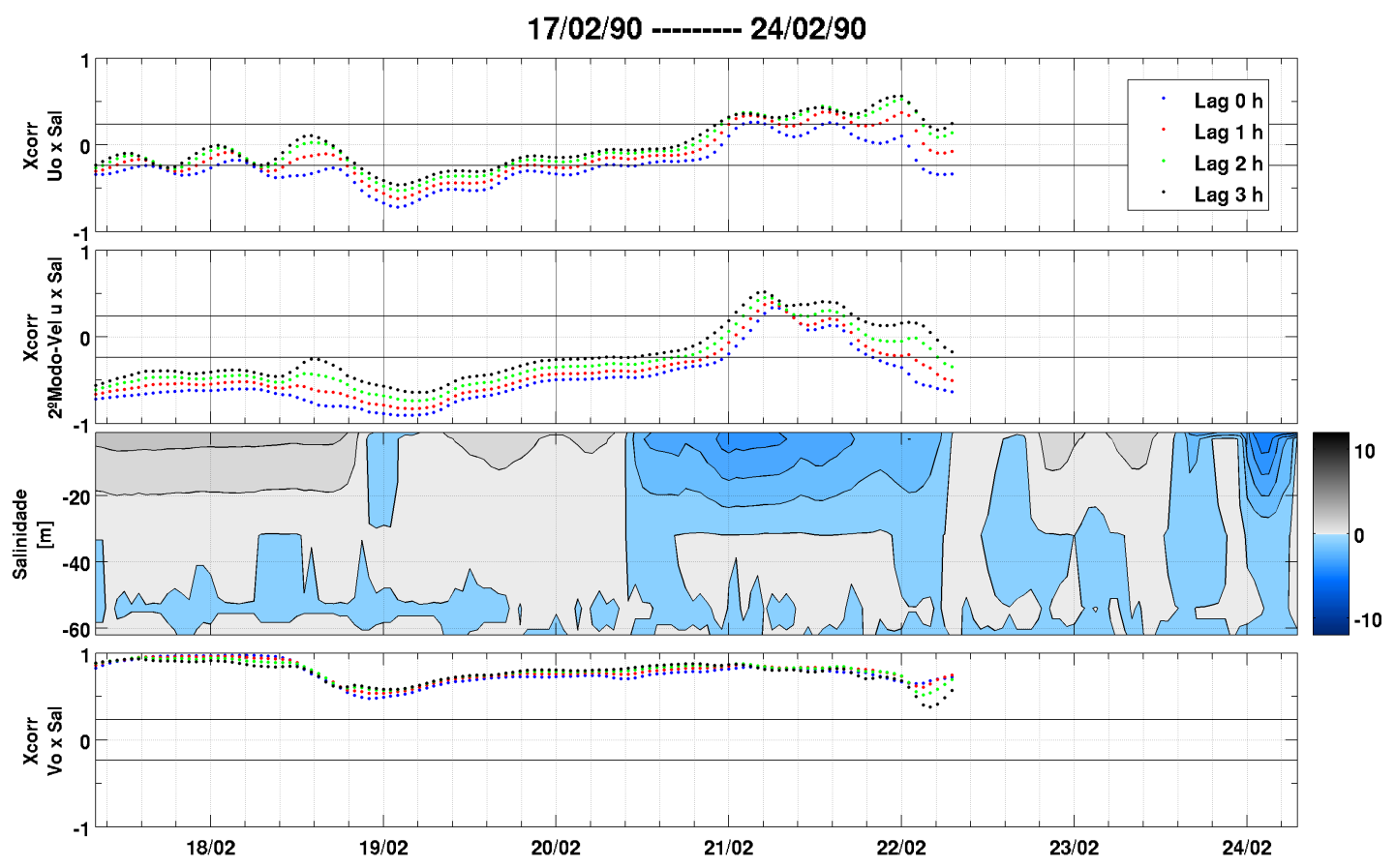

Figura 76: Correlações cruzadas calculadas para a sub-série 2 a $3 \mathrm{~m}$ de profundidade. cada ponto representa o valor da correlação entre a janela de dois dias iniciada na data onde o ponto se encontra. Os quadros representam a correlação entre janelas de sub-séries de anomalia de salinidade e janelas das sub-séries de: velocidade observada $u$ (quadro superior); $1^{\circ}$ modo baroclínico da velocidade $u$ (segundo quadro de cima para baixo); velocidade observada $v$ (quarto quadro). $\mathrm{O}$ terceiro quadro representa a anomalia de salinidade para o período da sub-série. Os pontos azuis representam a correlação com atraso de 0 hora, vermelhos de uma hora, verdes de duas horas e pretos de 3 horas. As linhas sólidas representam o limite de confiabilidade das correlações. 
As correlações calculadas para a sub-série três (Figura 77) mostram que a anomalia de salinidade está correlacionada, no início da série, com as velocidades observadas $u$ e $v$. A partir da metade do dia 27/02, a correlação entre a velocidade $v$ observada e a anomalia salinidade é alta e negativa, contrário ao que foi observado para as duas primeiras subséries. A componente baroclínica não mostra correlação significativa com a anomalia de salinidade. A velocidade observada $u$, em lag de 3 horas, apresenta correlação positiva com a anomalia de salinidade durante toda a série. Esta sub-série, segundo os resultados, não está relacionada às oscilações baroclínicas.

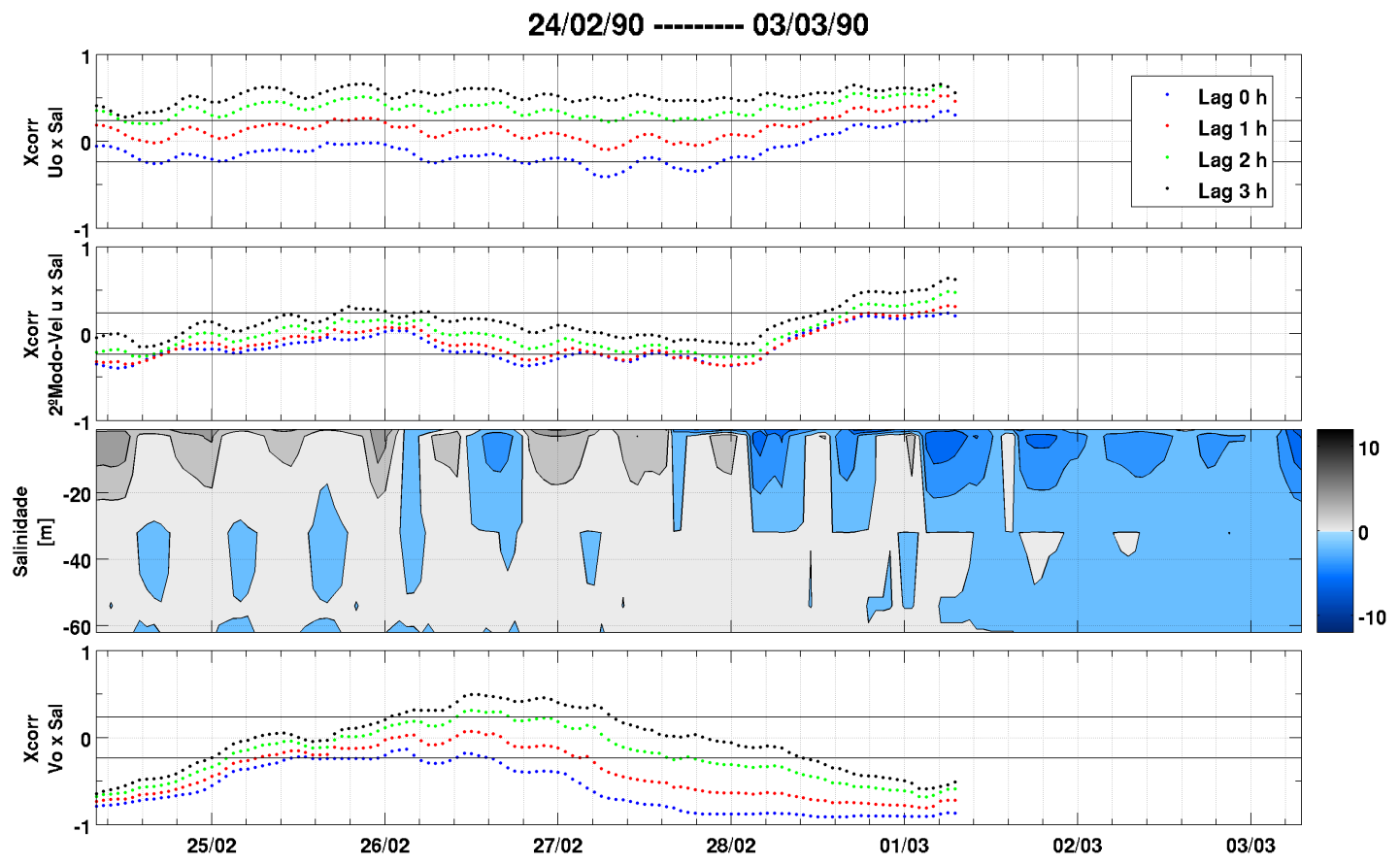

Figura 77: Correlações cruzadas calculadas para a sub-série 3 a $3 \mathrm{~m}$ de profundidade. cada ponto representa o valor da correlação entre a janela de dois dias iniciada na data onde o ponto se encontra. Os quadros representam a correlação entre janelas de sub-séries de anomalia de salinidade e janelas das sub-séries de: velocidade observada $u$ (quadro superior); $1^{\circ}$ modo baroclínico da velocidade $u$ (segundo quadro de cima para baixo); velocidade observada $v$ (quarto quadro). $\mathrm{O}$ terceiro quadro representa a anomalia de salinidade para o período da sub-série. Os pontos azuis representam a correlação com atraso de 0 hora, vermelhos de uma hora, verdes de duas horas e pretos de 3 horas. As linhas sólidas representam o limite de confiabilidade da correlação, onde os valores de correlação entre as linhas correspondem a séries não correlacionadas. 
A análise de correlação para as variáveis da quarta sub-série (Figura 78) mostra que, na primeira metade do período compreendido, a anomalia de salinidade está negativamente correlacionada com a velocidade quase-paralela. Na outra metade, a correlação é positiva com a mesma velocidade componente. As sub-séries de velocidade observada quase-perpendicular e a sub-série do $1^{\circ}$ modo baroclínico da mesma apresentaram correlações baixas ou ausência de correlação em lag zero com as anomalias de salinidade. Nota-se que na série de anomalias de salinidade não há, sinais claros semi-diurnos; logo, as oscilações de maior período devem ser importantes na evolução da salinidade.

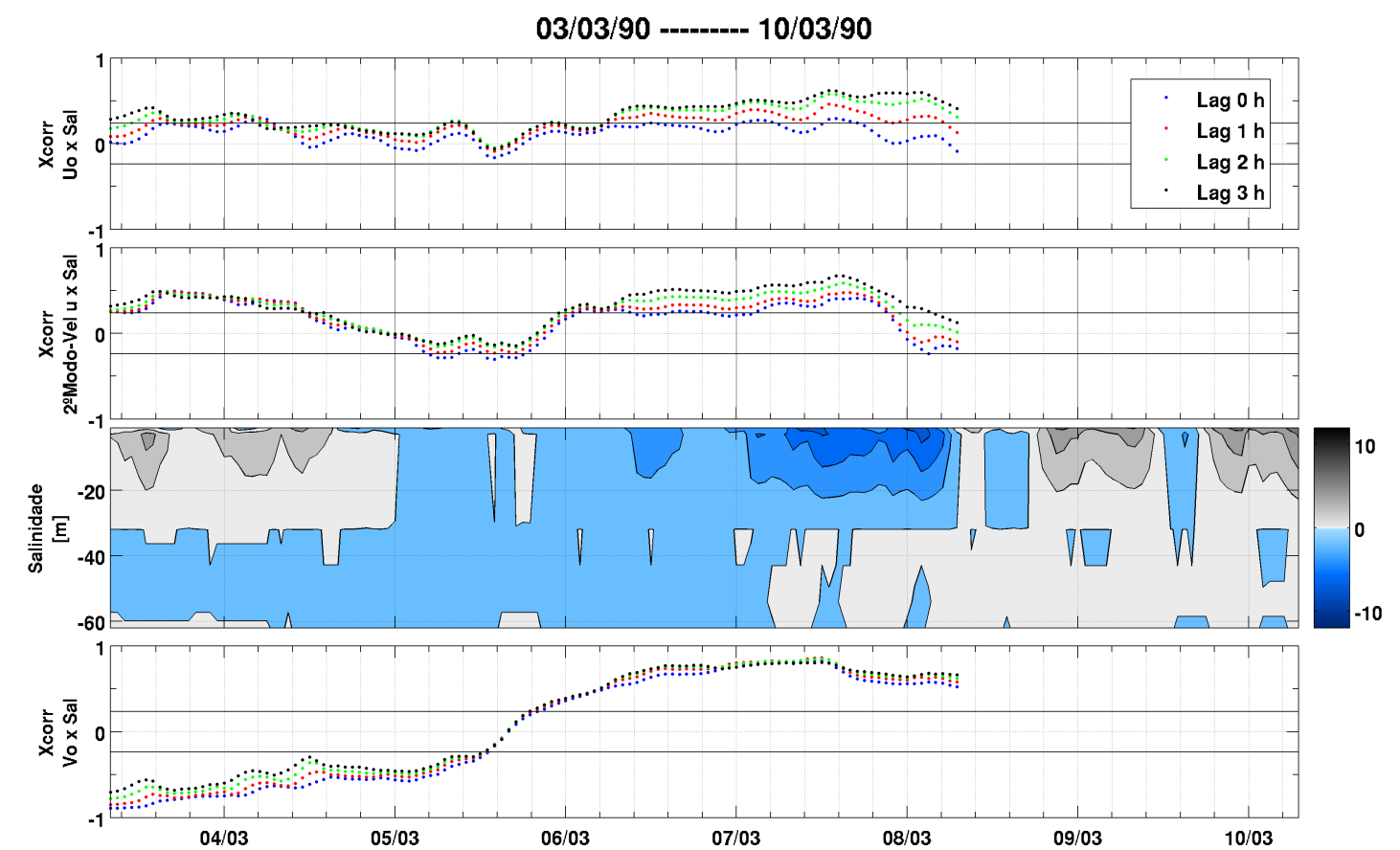

Figura 78: . Correlações cruzadas calculadas para a sub-série 4 a $3 \mathrm{~m}$ de profundidade. Cada ponto representa o valor da correlação entre a janela de dois dias iniciada na data onde o ponto se encontra. Os quadros representam a correlação entre janelas de sub-séries de anomalia de salinidade e janelas das sub-séries de: velocidade observada $u$ (quadro superior); $1^{\circ}$ modo baroclínico da velocidade $u$ (segundo quadro de cima para baixo); velocidade observada $v$ (quarto quadro). O terceiro quadro representa a anomalia de salinidade para o período da sub-série. Os pontos azuis representam a correlação com atraso de 0 hora, vermelhos de uma hora, verdes de duas horas e pretos de 3 horas. As linhas sólidas representam o limite de confiabilidade das correlações. 
Examinando a correlação entre a anomalia de salinidade e as demais variáveis da quinta sub-série (Figura 79) observamos que a correlação com a velocidade quaseparalela é alta para o início da série. Com o $1^{\circ}$ modo baroclínico notam-se alguns picos de correlação com a anomalia de salinidade. Como cada ponto corresponde ao valor da correlação calculado na janela de dois dias iniciada na data correspondente à posição deste ponto no eixo das abscissas, o pico observado próximo ao dia 13/03/1990 corresponde à correlação calculada desta data a até o dia 15/03, que apresenta certas oscilações visíveis semi-diurnas.

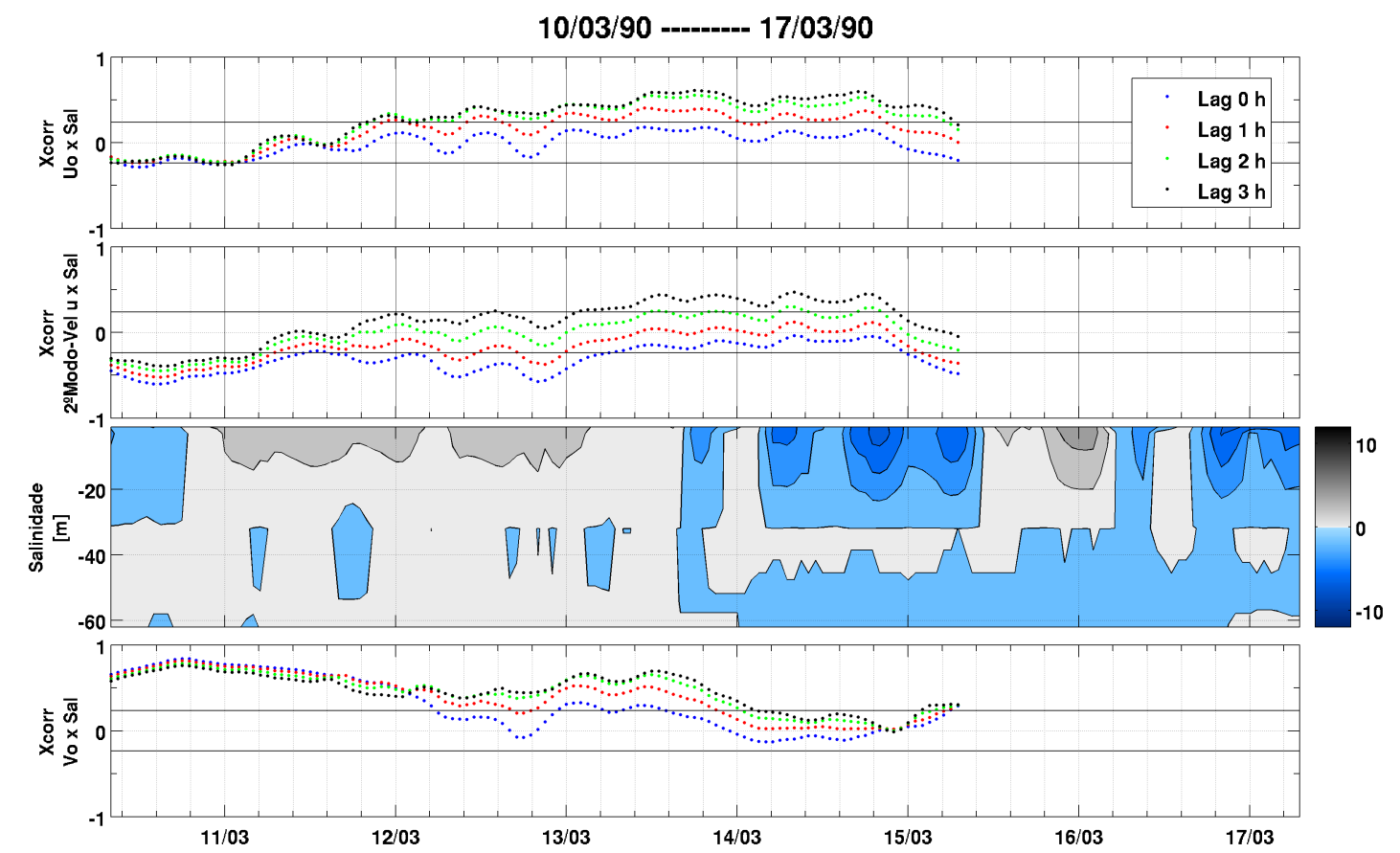

Figura 79: Correlações cruzadas calculadas para a sub-série 5 a $3 \mathrm{~m}$ de profundidade. Cada ponto representa o valor da correlação entre a janela de dois dias iniciada na data onde o ponto se encontra. Os quadros representam a correlação entre janelas de sub-séries de anomalia de salinidade e janelas das sub-séries de: velocidade observada $u$ (quadro superior); $1^{\circ}$ modo baroclínico da velocidade $u$ (segundo quadro de cima para baixo); velocidade observada $v$ (quarto quadro). O terceiro quadro representa a anomalia de salinidade para o período da sub-série. Os pontos azuis representam a correlação com atraso de 0 hora, vermelhos de uma hora, verdes de duas horas e pretos de 3 horas. As linhas sólidas representam o limite de confiabilidade das correlações. 
A análise da correlação cruzada para a sub-série seis (Figura 80) mostra alta correlação negativa entre a série do $1^{\circ}$ modo baroclínico e a anomalia de salinidade, a partir do dia 21/03 até o final da série, resultado consonante com o observado na análise comparativa da sub-série 6 (Figura 71). A velocidade observada $v$ apresenta correlação positiva com a anomalia de salinidade para o período anterior a este intervalo. A velocidade $u$ observada apresenta correlações positivas com a anomalia de salinidade, com atraso de 3 horas, no mesmo período em que há correlações significativas deste último com o $1^{\mathrm{o}}$ modo baroclínico.

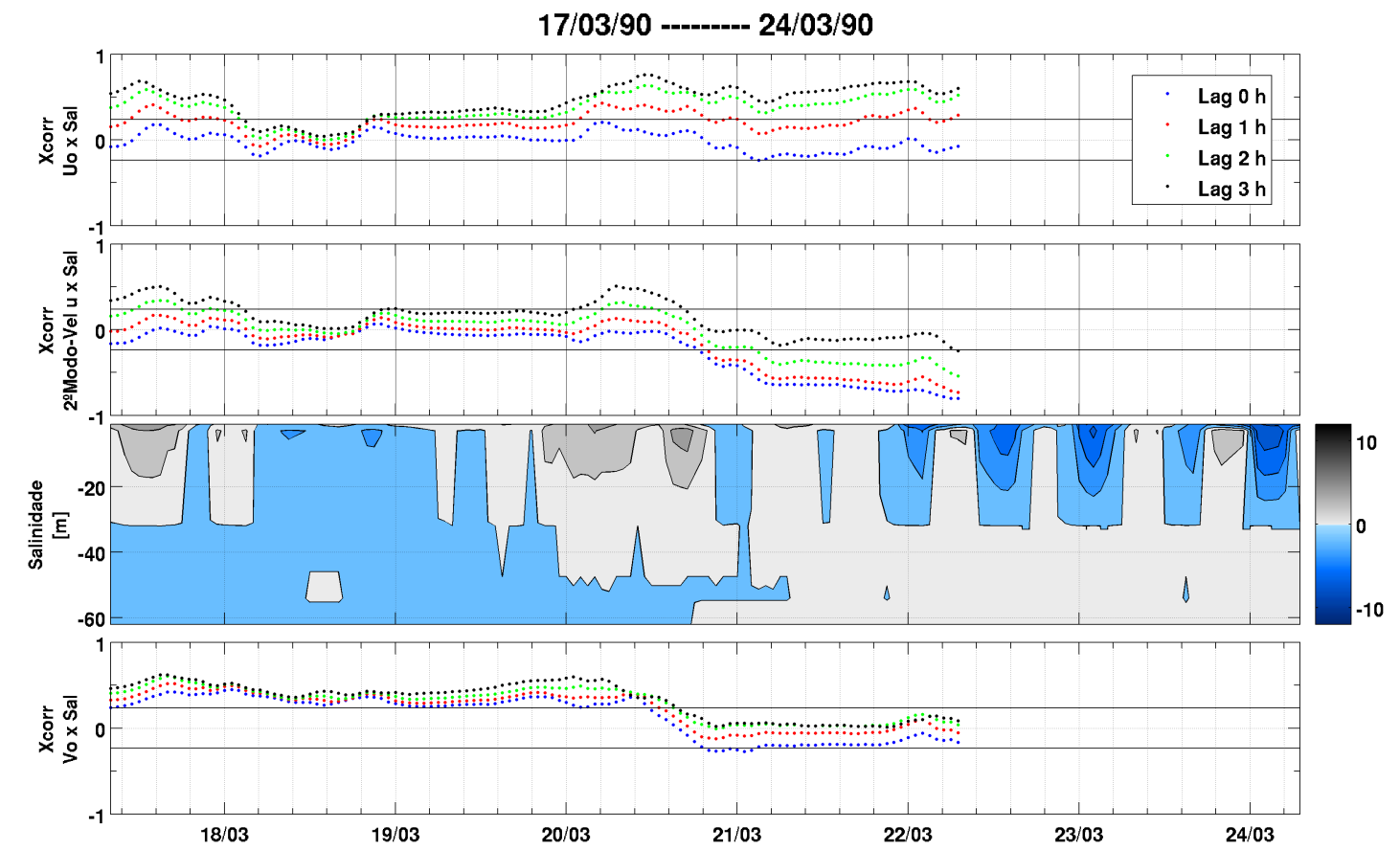

Figura 80: Correlações cruzadas calculadas para a sub-série 6 a $3 \mathrm{~m}$ de profundidade. Cada ponto representa o valor da correlação entre a janela de dois dias iniciada na data onde o ponto se encontra. Os quadros representam a correlação entre janelas de sub-séries de anomalia de salinidade e janelas das sub-séries de: velocidade observada $u$ (quadro superior); $1^{\circ}$ modo baroclínico da velocidade $u$ (segundo quadro de cima para baixo); velocidade observada $v$ (quarto quadro). O terceiro quadro representa a anomalia de salinidade para o período da sub-série. Os pontos azuis representam a correlação com atraso de 0 hora, vermelhos de uma hora, verdes de duas horas e pretos de 3 horas. As linhas sólidas representam o limite de confiabilidade das correlações. 
A correlação cruzada a 3 m, entre as sub-séries 7 (Figura 81) apresenta, entre $1^{\mathrm{o}}$ modo baroclínico e anomalia de salinidade correlação negativa, significativa apenas durante o período do dia 27/03 ao dia 30/03. Do início da série, do dia 24/03 ao dia 27/03 a velocidade observada $v$ possui alta correlação positiva com a anomalia de salinidade, mas a partir do dia 27/03 decai e não apresenta correlação significativa até o final da série, assim como as outras séries. A baixa correlação é um indício de outras frequências importantes, com períodos acima dos dois dias compreendidos pela janela utilizada.

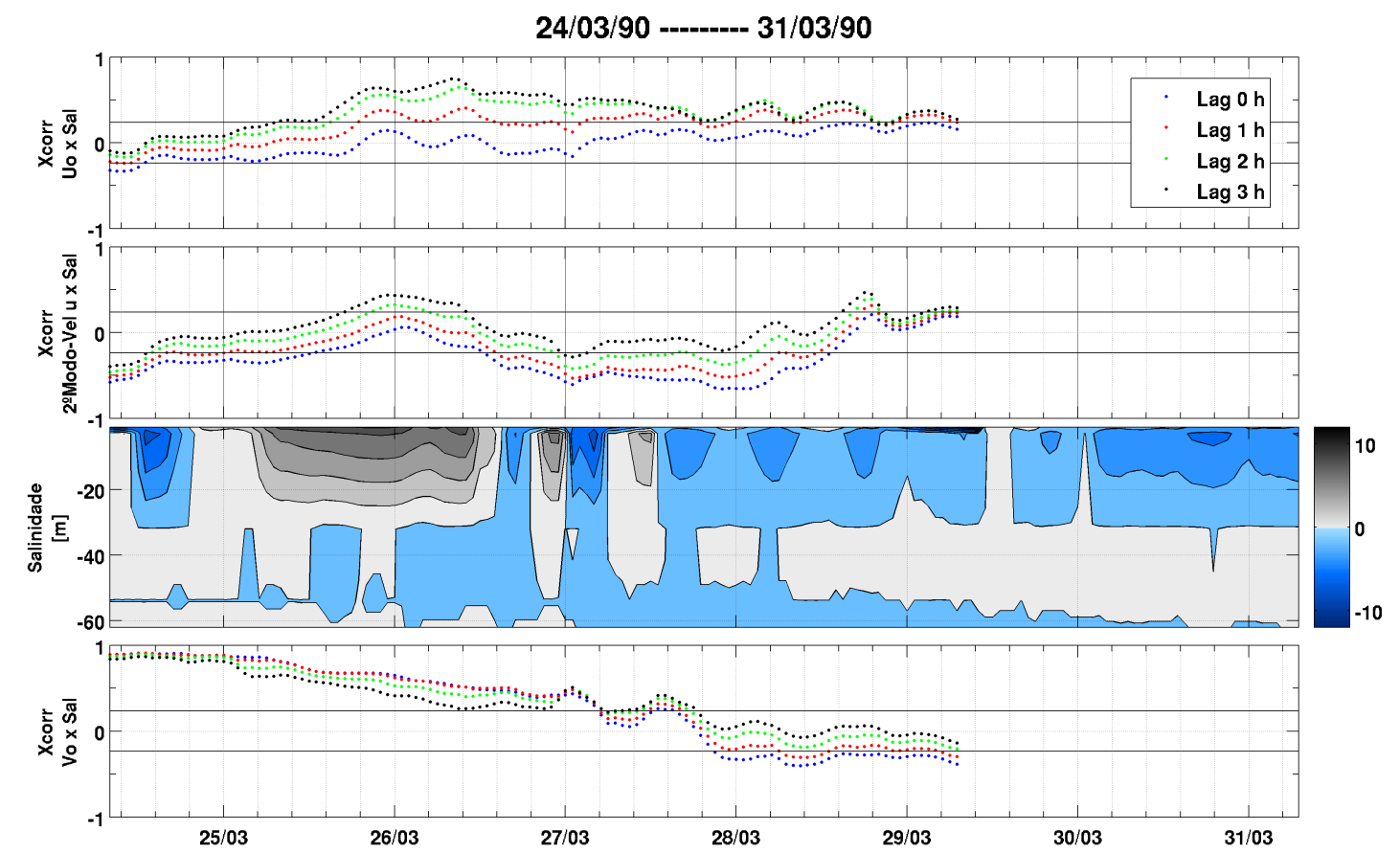

Figura 81: Correlações cruzadas calculadas para a sub-série 7 a $3 \mathrm{~m}$ de profundidade. Cada ponto representa o valor da correlação entre a janela de dois dias iniciada na data onde o ponto se encontra. Os quadros representam a correlação entre janelas de sub-séries de anomalia de salinidade e janelas das sub-séries de: velocidade observada $u$ (quadro superior); $1^{\circ}$ modo baroclínico da velocidade $u$ (segundo quadro de cima para baixo); velocidade observada $v$ (quarto quadro). O terceiro quadro representa a anomalia de salinidade para o período da sub-série. Os pontos azuis representam a correlação com atraso de 0 hora, vermelhos de uma hora, verdes de duas horas e pretos de 3 horas. As linhas sólidas representam o limite de confiabilidade das correlações. 
Correlacionando a anomalia de salinidade da sub-série 8 e as séries de velocidade observada $u, 1^{\mathrm{o}}$ modo baroclínico da velocidade $u$ e velocidade observada $v$ (Figura 82), nota-se, no início da série, uma correlação mais alta com a velocidade $v$ observada e, a partir da metade do dia 03/04 a correlação é alta, tanto para a componente baroclínica da velocidade $u$, quanto para a velocidade quase-paralela à isóbata. Não se verificam diferenças claras entre os atrasos para a correlação com o $1^{\circ}$ modo baroclínico, o que sugere ou uma onda estacionária ou que a correlação se deve às oscilações de períodos mais longos; quando, em 3 horas, ocorreriam pequenas mudanças no campo de velocidade baroclínica.

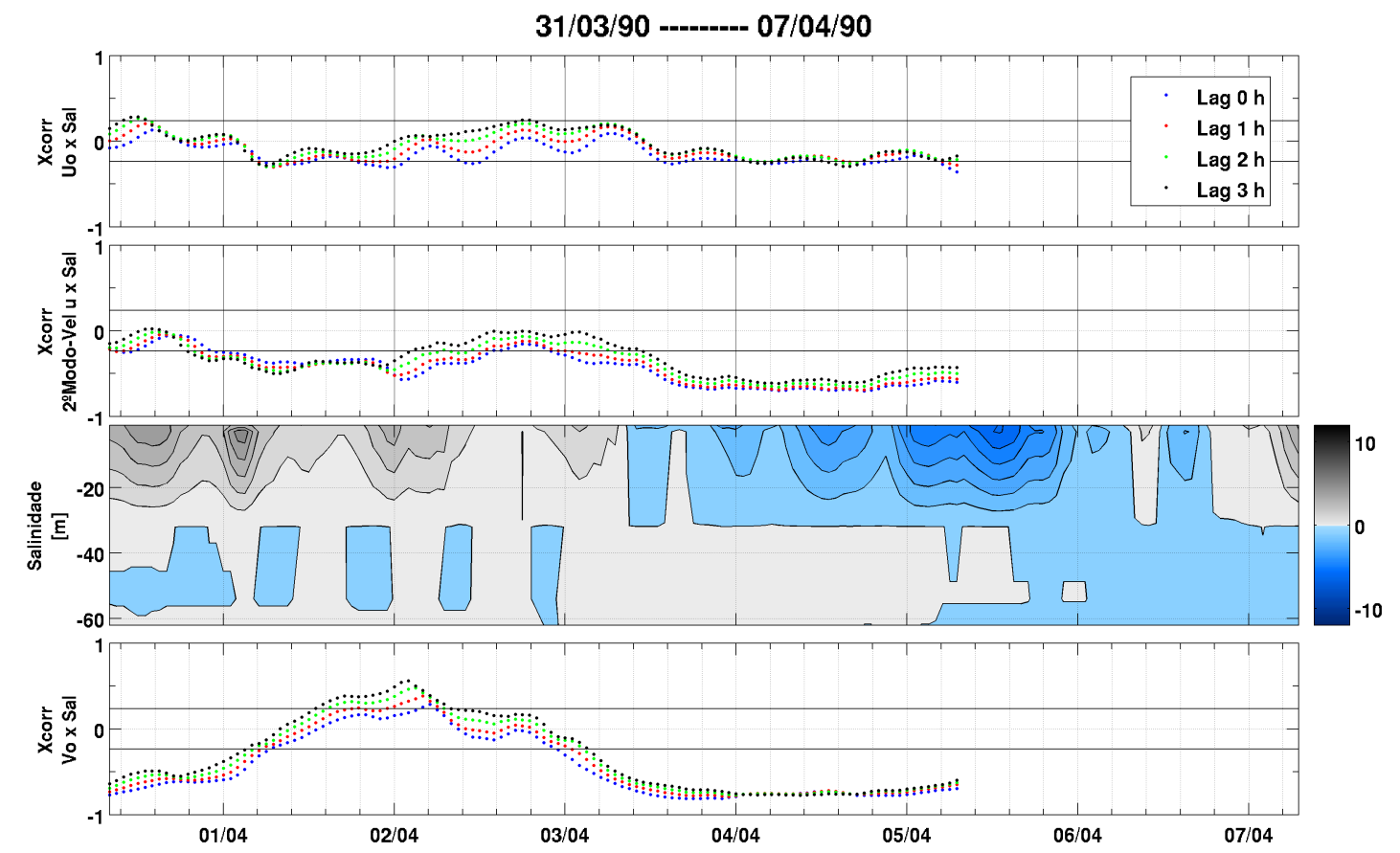

Figura 82: Correlações cruzadas calculadas para a sub-série 8 a $3 \mathrm{~m}$ de profundidade. Cada ponto representa o valor da correlação entre a janela de dois dias iniciada na data onde o ponto se encontra. Os quadros representam a correlação entre janelas de sub-séries de anomalia de salinidade e janelas das sub-séries de: velocidade observada $u$ (quadro superior); $1^{\circ}$ modo baroclínico da velocidade $u$ (segundo quadro de cima para baixo); velocidade observada $v$ (quarto quadro). O terceiro quadro representa a anomalia de salinidade para o período da sub-série. Os pontos azuis representam a correlação com atraso de 0 hora, vermelhos de uma hora, verdes de duas horas e pretos de 3 horas. As linhas sólidas representam o limite de confiabilidade das correlações. 
A correlação cruzada entre a anomalia de salinidade e as sub-séries de velocidade observada, $u$ e $v$, e $1^{\circ}$ modo baroclínico $u$, para o nono intervalo (Figura 83) apresenta correlações significativas no início da série para todas as componentes analisadas até a metade do dia 09/04, o que corresponde até o dia 11/04. Notam-se correlações de até $\approx$ 0,5 em lag de zero hora para a velocidade observada $u$, enquanto que as correlações entre a salinidade e o $1^{\circ}$ modo baroclínico ultrapassam 0,8 de correlação, também em lag de zero hora. A velocidade quase-paralela $v$ apresenta correlação positiva com a anomalia de salinidade em todos os lags analisados.

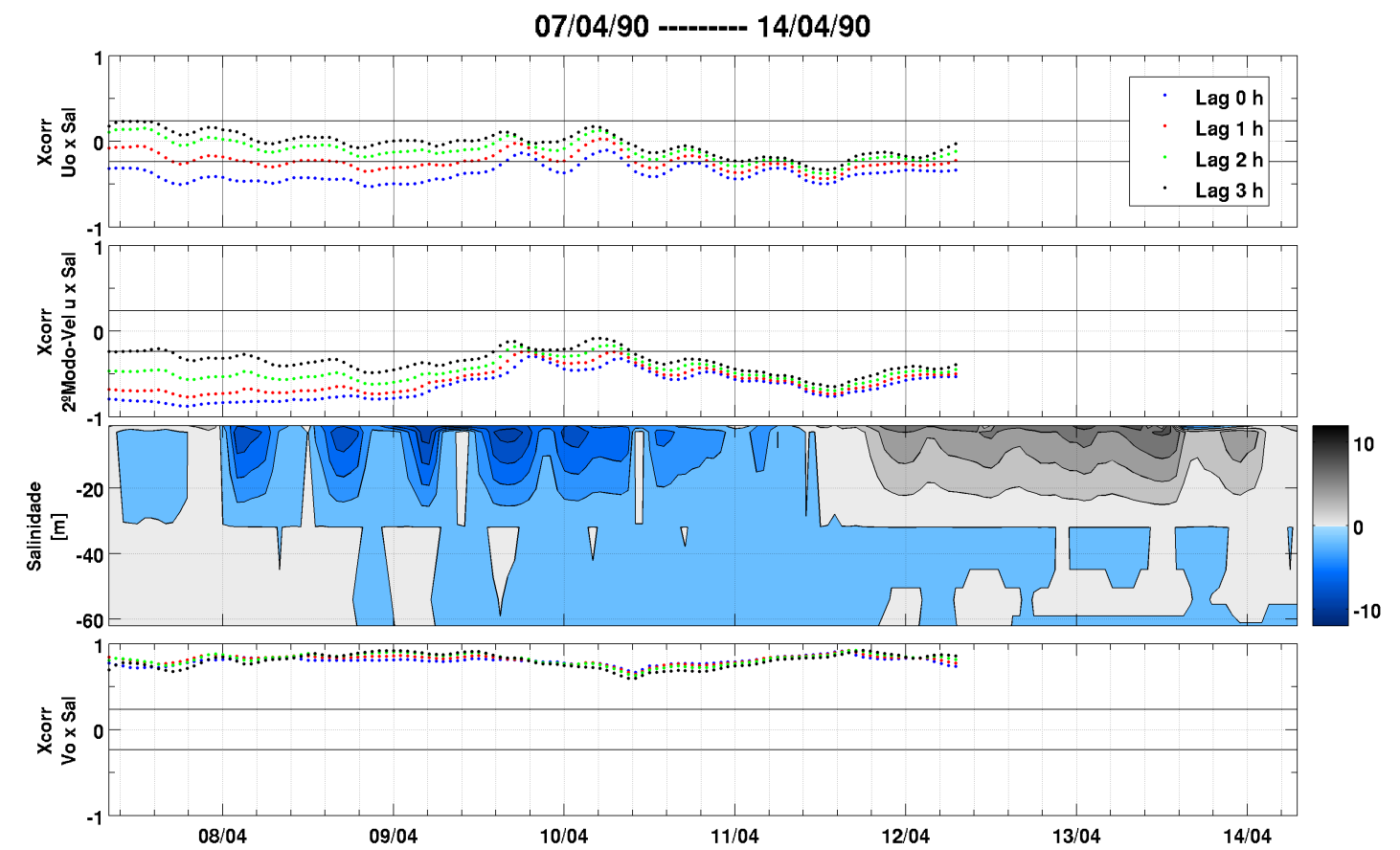

Figura 83: Correlações cruzadas calculadas para a sub-série 9 a $3 \mathrm{~m}$ de profundidade. Cada ponto representa o valor da correlação entre a janela de dois dias iniciada na data onde o ponto se encontra. Os quadros representam a correlação entre janelas de sub-séries de anomalia de salinidade e janelas das sub-séries de: velocidade observada $u$ (quadro superior); $1^{\circ}$ modo baroclínico da velocidade $u$ (segundo quadro de cima para baixo); velocidade observada $v$ (quarto quadro). O terceiro quadro representa a anomalia de salinidade para o período da sub-série. Os pontos azuis representam a correlação com atraso de 0 hora, vermelhos de uma hora, verdes de duas horas e pretos de 3 horas. As linhas sólidas representam o limite de confiabilidade das correlações. 
Até o momento avaliamos o método das FOE na separação da componente quaseperpendicular às isóbatas, $u$, da velocidade no ponto $\mathrm{F} 2 \mathrm{em}$ modos estatísticos e os consideramos correspondentes aos modos de oscilação, sendo o $1^{\circ}$ modo estatístico correspondente ao modo barotrópico e o $2^{\circ}$ modo estatístico correspondente ao $1^{\circ}$ modo baroclínico. A comparação das séries de velocidade reconstruidas a partir dos 2 primeiros modos estatísticos com a velocidade observada apresentou apenas pequenas diferenças e, quando comparamos os modos estatíscos com a anomalia de salinidade, evidenciamos a relação entre a salinidade e o que chamamos de $1^{\circ}$ modo baroclínico.

A análise de correlação cruzada entre as sub-séries 1 a 9 (Figuras 75 a 83) mostrou que a componente baroclínica da velocidade quase-perpendicular, $u$, visivelmente se relaciona com a salinidade, haja vista a última sub-série, de 07/04 a 14/04 (Figuras 74 e 83). Entretanto, aparenta ter importância igual ou menor, quando comparada à velocidade observada quase-paralela às isóbatas, $v$. Esta última, apresenta-se, como já mencionado anteriormente, altamente correlacionada com a anomalia de salinidade. A possível explicação reside na influência de processos de maior escala, tanto espacial quanto temporal, influenciando a salinidade na coluna d'água na região do ponto F2, todavia, não minimizam os resultados acerca da ocorrência de marés internas semidiurnas na região do ponto $\mathrm{F} 2$. 


\subsubsection{FOE - Densidade de potência espectral}

Busca-se neste trabalho a influência de marés internas de frequência semi-diurna e, para tentar avaliar a influência desta frequência na salinidade, foi calculada a densidade de potência espectral contida em cada frequência, para cada sub-séries de velocidades u e v, $1^{\circ}$ e $2^{\circ}$ modos estatísticos das velocidades u e v, bem como para a salinidade e para a temperatura (Figuras 84 a 88). Primeiramente, foram analisadas espectralmente as sub-séries 1 a 9 (Figura 84) de velocidade $u$ observada. Assim como nos resultados da Seção 6.2.2, o domínio visível da frequências semi-diurnas aparece também nas subséries. Nota-se, ainda, que a energia nas 4 profundidades é quase a mesma para esta banda de frequência, resultante da dominância da componente barotrópica. 

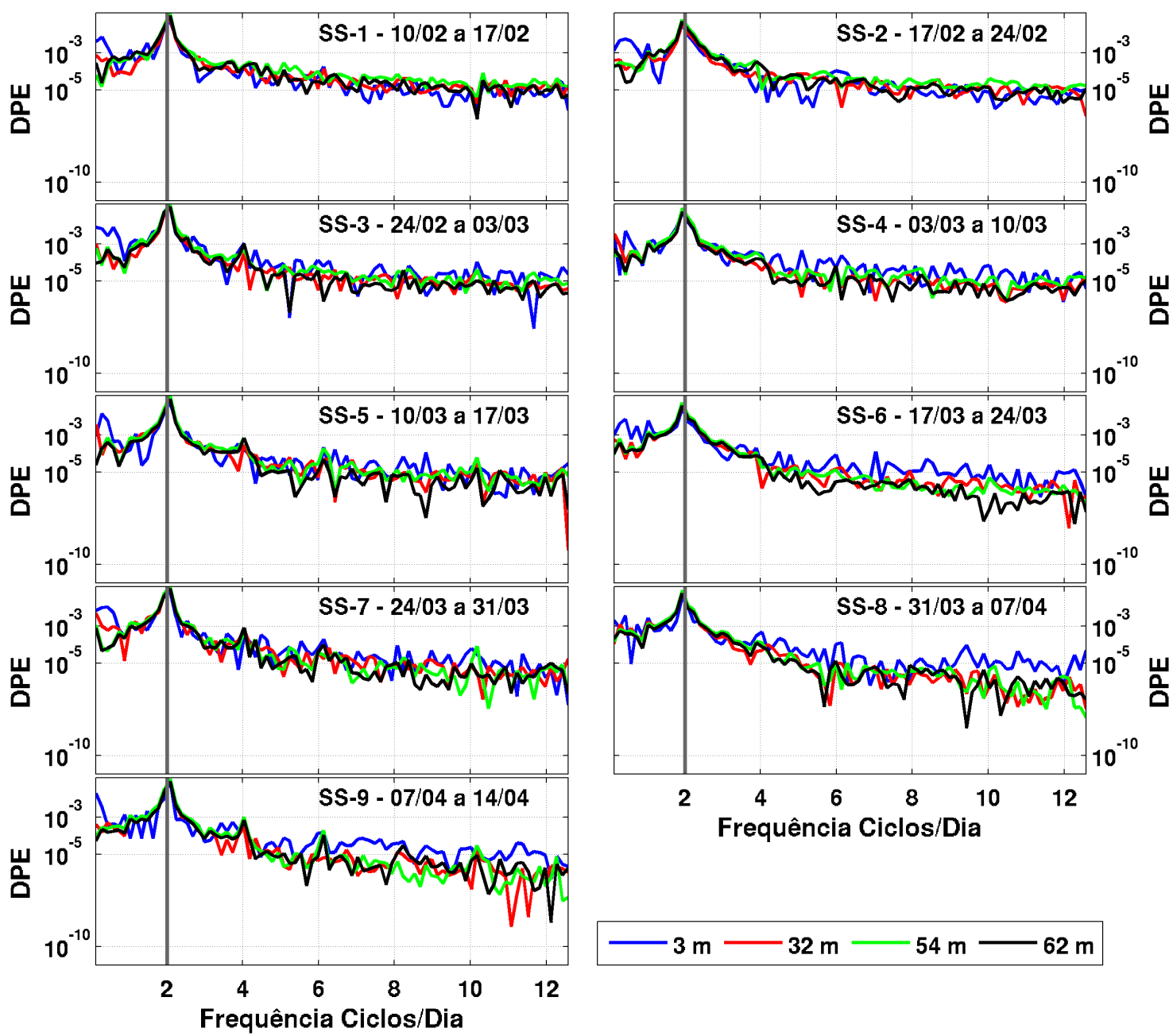

Figura 84: Densidade de Potência Espectral (DPE $\mathrm{em} \mathrm{m}^{2} / \mathrm{cpd}$ ) por frequência para a velocidade quase-perpendicular às isóbatas em todas as sub-séries (SS) no ponto F2. As linhas coloridas correspondem à análise espectral nas 4 profundidades deste ponto, 3, 32, 54 e 62 m, representadas respectivamente pelas cores, azul, vermelho, verde e preto. A linha vertical cinza marca a frequência semi-diurna.

Em seguida, foram analisadas as sub-séries para a velocidade observada $v$ (Figura 85). Esta componente da velocidade não apresenta sinal semi-diurno proeminente, como observado para a componente quase-perpendicular; ademais, nota-se que a energia é grande nas baixas frequências, principalmente a $3 \mathrm{~m}$ de profundidade (linha azul). Nesta profundidade ( $3 \mathrm{~m}$ ) a densidade espectral na frequências semi-diurna possui a mesma amplitude que as das frequências vizinhas. $\mathrm{O}$ mesmo não pode ser dito para o espectro a 62 
m (linha preta), que apresenta picos claros semi-diurnos e quarto-diurnos.
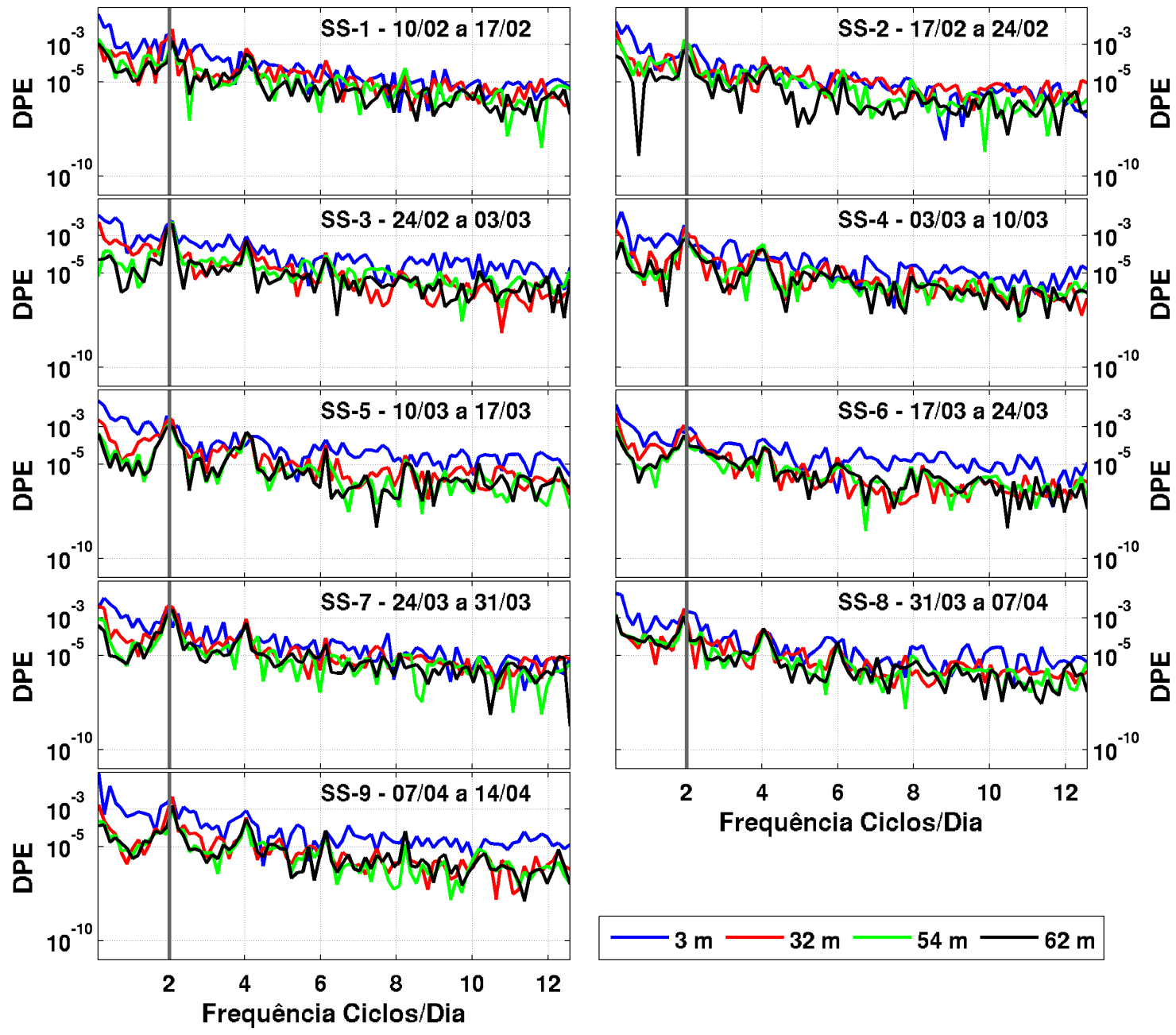

Figura 85: Densidade de Potência Espectral (DPE $\mathrm{em} \mathrm{m}^{2} / \mathrm{cpd}$ ) por frequência para a velocidade quase-paralela às isóbatas em todas as sub-séries no ponto F2. As linhas coloridas correspondem à análise espectral nas 4 profundidades deste ponto, 3, 32, 54 e $62 \mathrm{~m}$, representadas respectivamente pelas cores, azul, vermelho, verde e preto. A linha vertical cinza marca a frequência semi-diurna.

Com o intuito de avaliar se o $1^{\circ}$ modo estatístico corresponde ao modo barotrópico analisamos espectralmente esta componente (Figura 86). Esta análise mostra que a separação do sinal barotrópico, aparentemente, foi bem sucedida. Os espectros apresentam a mesma energia em todas as profundidades, com um pico distinto, proeminente (duas ordens de grandeza a mais), na banda de frequência semi-diurna. 

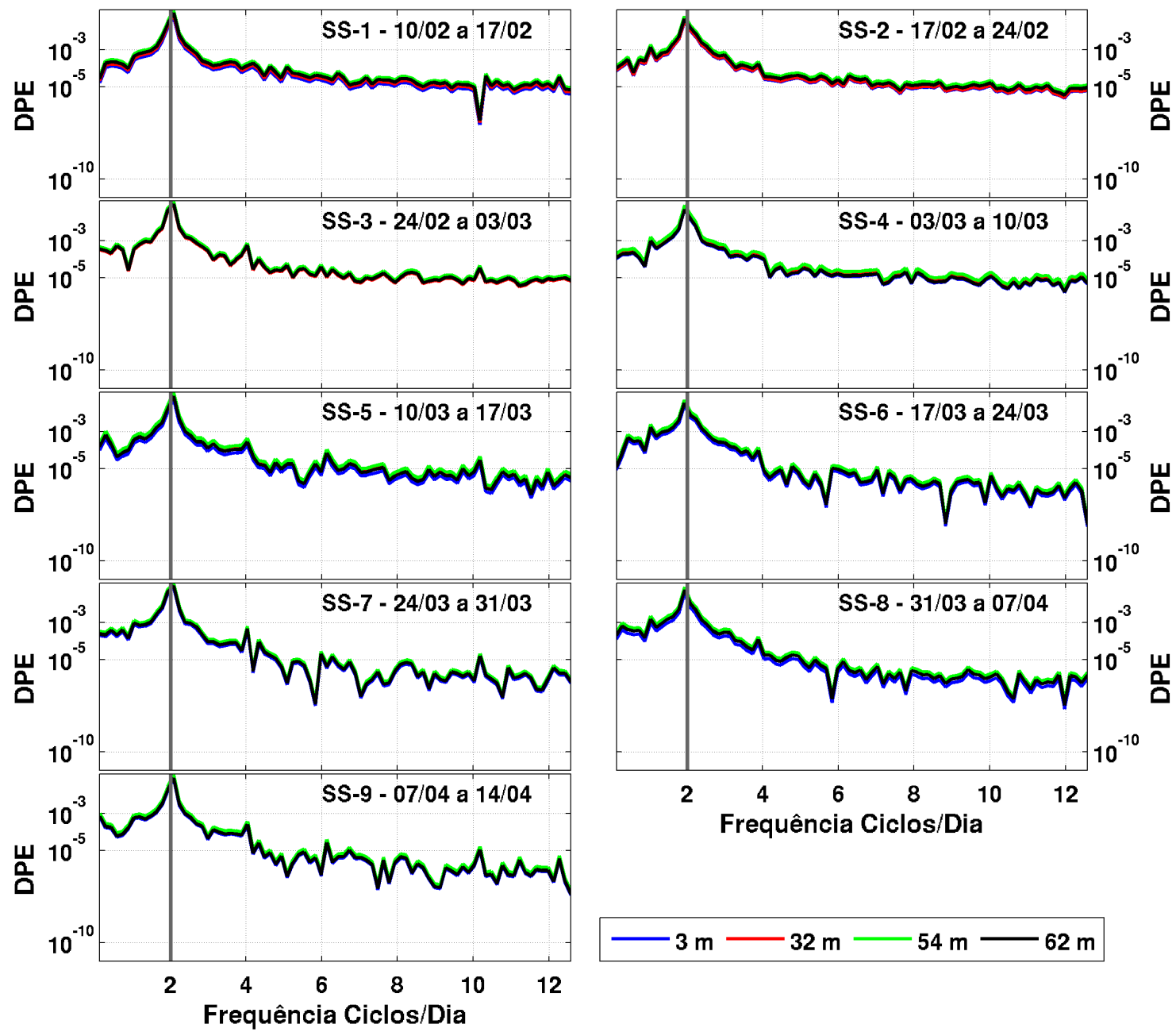

Figura 86: Densidade de Potência Espectral (DPE em $\mathrm{m}^{2} / \mathrm{cpd}$ ) por frequência para a $1^{\circ}$ modo estatístico da velocidade quase-perpendicular, $u$, em todas as sub-séries no ponto F2. As linhas coloridas correspondem à análise espectral nas 4 profundidades deste ponto, 3, 32, 54 e 62 m, representadas respectivamente pelas cores, azul, vermelho, verde e preto. A linha vertical cinza marca a frequência semi-diurna.

O espectro das sub-séries do $1^{\circ}$ modo baroclínico (Figura 87) mostra pico notável na frequência semi-diurna, principalmente a $3 \mathrm{~m}$ de profundidade (linhas azuis). A energia difere nas profundidades analisadas, o que é previsto, uma vez que a maior variabilidade das correntes deste modo está na superfície. A energia a $32 \mathrm{~m}$ (linhas vermelhas) apresenta, na maioria das séries, menor valor. O modo baroclínico exige pontos nodais, onde a velocidade seja próximo de zero ou zero. Acreditamos que devido ao número limitado de pontos de observação na coluna d'água, o método define esta profundidade como 
ponto nodal onde o sentido da velocidade mudaria.
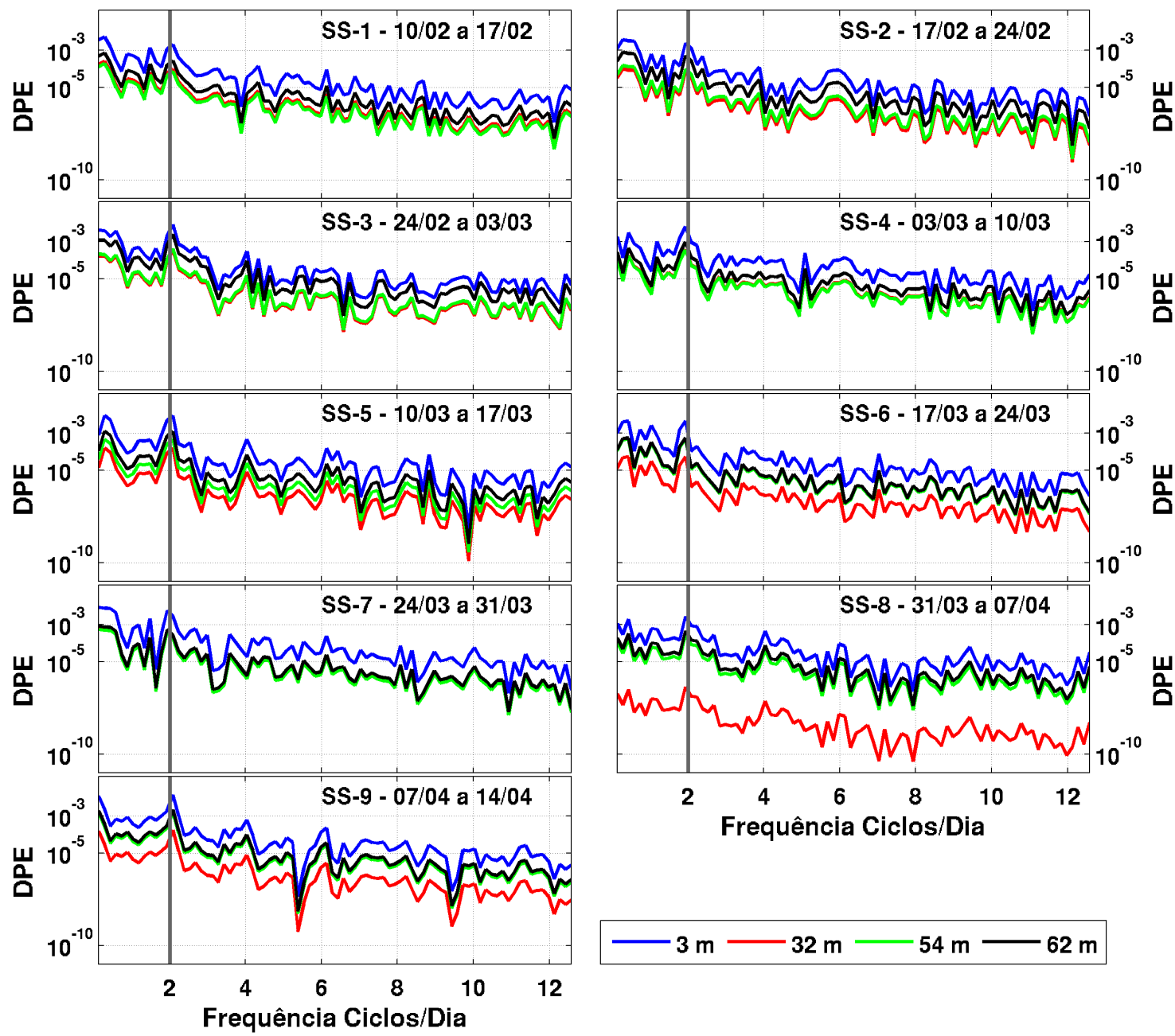

Figura 87: Densidade de Potência Espectral (DPE em $\mathrm{m}^{2} / \mathrm{cpd}$ ) por frequência para o $2^{\circ}$ modo estatístico da velocidade quase-perpendicular, $u$, em todas as sub-séries no ponto F2. As linhas coloridas correspondem à análise espectral nas 4 profundidades deste ponto, 3, 32, 54 e $62 \mathrm{~m}$, representadas respectivamente pelas cores, azul, vermelho, verde e preto. A linha vertical cinza marca a frequência semi-diurna

Calculamos ainda a densidade espectral nas diferentes frequências para as subséries de temperatura (Figura 88). Nota-se, como já observado por Linhares (1995) e Geyer et al. (1996), que a temperatura, em superfície, responde às variações diárias, relativas ao aquecimento e resfriamento causados pela insolação e, por isso, verifica-se o 
pico em frequências diurnas. Percebe-se ainda, principalmente a $62 \mathrm{~m}$ de profundidade, um pico nas frequências semi-diurnas, provavelmente em razão do atrito das correntes de maré com o fundo.
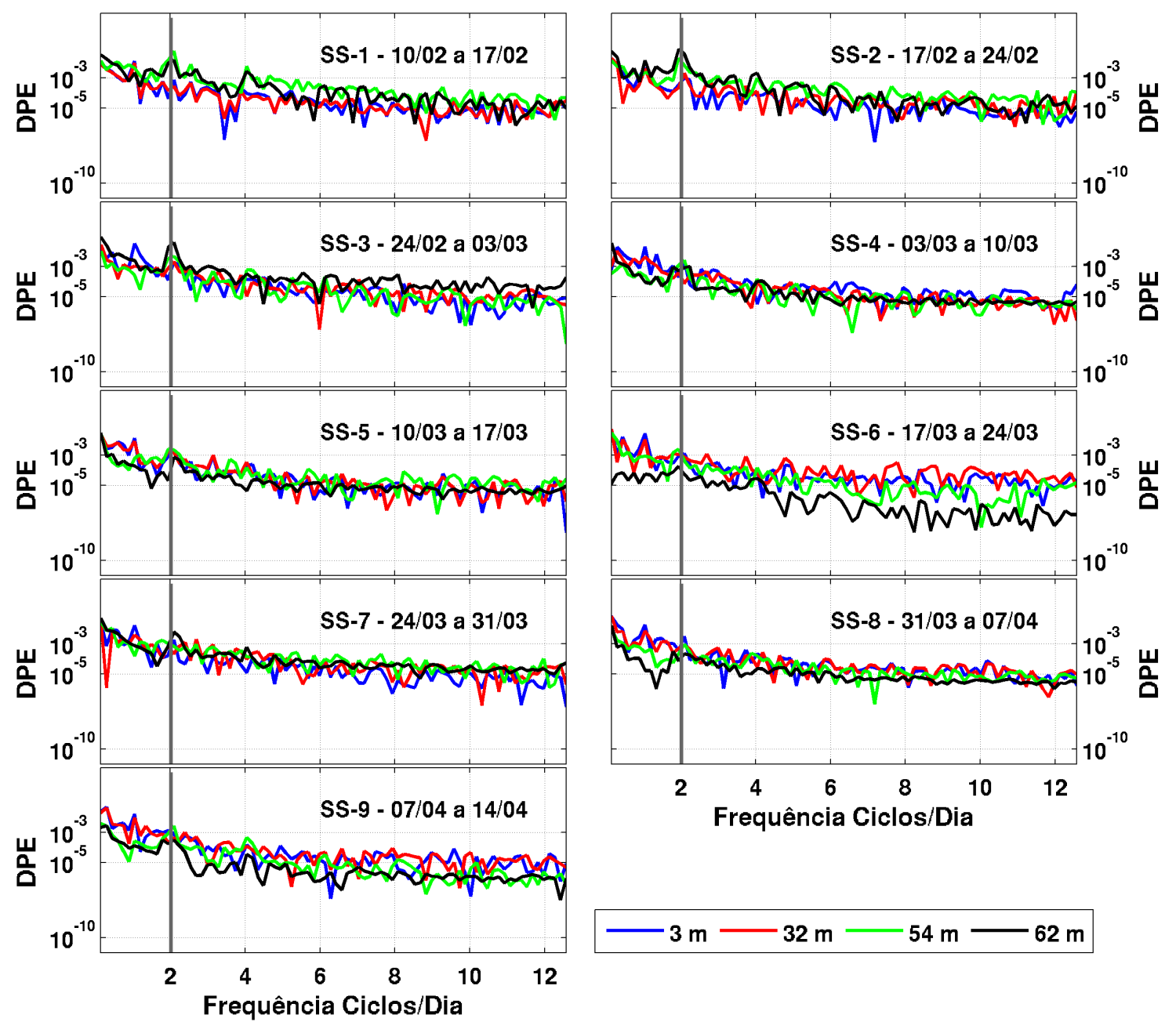

Figura 88: Densidade de Potência Espectral (DPE em $\mathrm{m}^{2} / \mathrm{cpd}$ ) por frequência para a Temperatura em todas as sub-séries no ponto F2. As linhas coloridas correspondem à análise espectral nas 4 profundidades deste ponto, 3, 32, 54 e $62 \mathrm{~m}$, representadas respectivamente pelas cores, azul, vermelho, verde e preto. A linha vertical cinza marca a frequência semi-diurna.

Por fim, analisamos espectralmente as sub-séries de anomalia de salinidade (Figura 89). Verifica-se a separação do espectro entre as profundidades mais rasas (3 e $32 \mathrm{~m}$, linhas azul e vermelha) e as mais profundas (54 e $62 \mathrm{~m}$, linhas verde e preta), em virtude das variações em superfície da pluma de baixa salinidade. Observam-se variações do 
espectro na frequência semi-diurna (linha vertical cinza) de acordo com a sub-série analisada. Acreditamos que tais variações de energia são consequência da intermitência das oscilações naquela frequência aliado à influência de oscilações em outras frequências, como as da velocidade observada $v$ de baixa frequência.
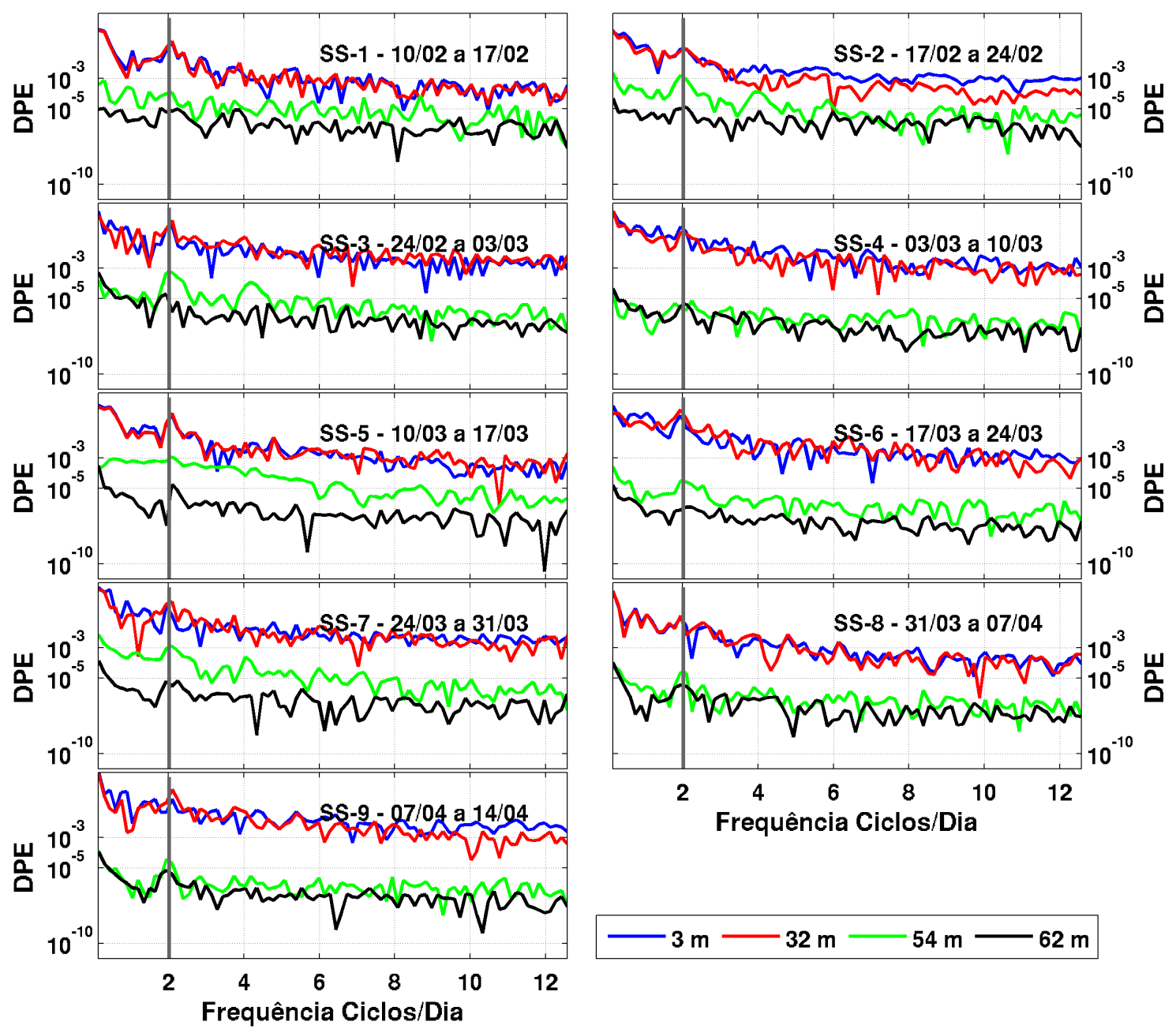

Figura 89: Densidade de Potência Espectral (DPE em $\mathrm{m}^{2} / \mathrm{cpd}$ ) por frequência para a salinidade em todas as sub-séries no ponto F2. As linhas coloridas correspondem à análise espectral nas 4 profundidades deste ponto, 3, 32, 54 e $62 \mathrm{~m}$, representadas respectivamente pelas cores, azul, vermelho, verde e preto. A linha vertical cinza marca a frequência semi-diurna.

Para avaliar o desenvolvimento progressivo das oscilações semi-diurnas, separamos os valores de densidade de potência espectral a $3 \mathrm{~m}$ de profundidade nesta frequência 
das 9 sub-séries para o $1^{\circ}$ modo baroclínico da velocidade $u$, para a anomalia de salinidade (Figura 90). A evolução da densidade espectral na frequência semi-diurna, para a anomalia de salinidade (linha vermelha) e $1^{\circ}$ modo baroclínico (linha azul), mostra que estas progridem em fase, podendo-se observar variações de até três ordens de grandeza, tanto para a salinidade quanto para o $1^{\circ}$ modo baroclínico. Foi comparado ainda, em conjunto com as grandezas supracitadas, a densidade espectral na frequência semi-diurna da velocidade observada $v$ (Figura 90), com o intuito de verificar a influência desta na anomalia de salinidade. Nota-se, na Figura 90 que o $1^{\circ}$ modo baroclínico possui mais energia na frequência estudada do que a velocidade observada $v$ e que esta, diferentemente daquele, possui tendência de crescimento/descrescimento diferente da observada para o espectro da salinidade. Desta forma, pode-se dizer que as grandes correlações obtidas entre a componente $v$ observada e a anomalia de salinidade devem-se, na maioria dos casos, à frequências diferentes da semi-diurna, principalmente às frequências menores.

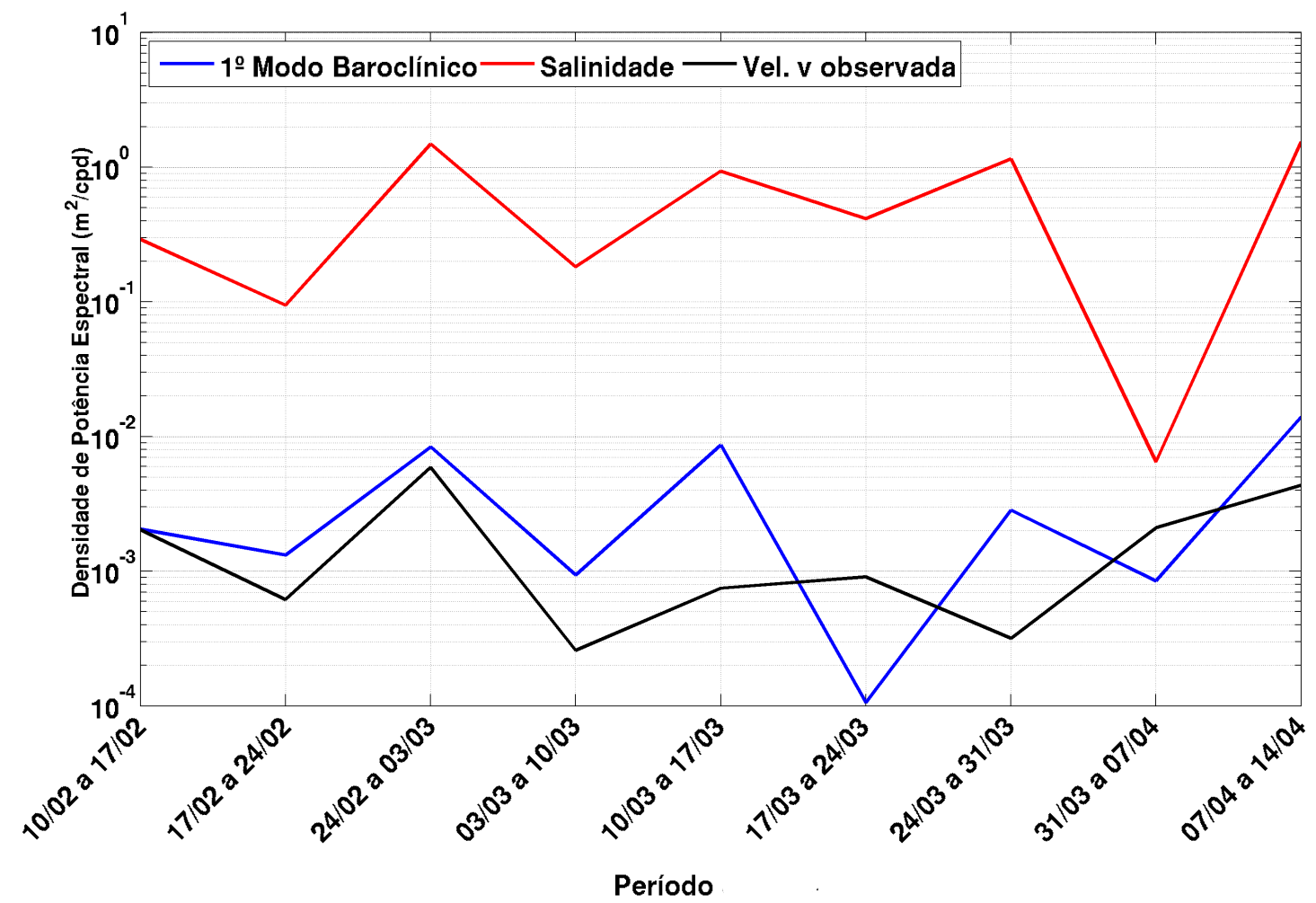

Figura 90: Evolução da densidade de potência espectral (PDE $\mathrm{em} \mathrm{m}^{2} / \mathrm{cpd}$ ) para a frequência semi-diurna para o $1^{\circ}$ modo baroclínico da velocidade quase-perpendicular, $u$ (Linha azul), 
anomalia de salinidade (Linha vermelha) e velocidade observada quase-paralela, $v$ (Linha preta), na profundidade de $3 \mathrm{~m}$. Cada ponto do eixo das abscissas (nove) representa o período da sub-série correspondente.

Os resultados obtidos pela aplicação das FOE nos possibilita julgar que este método foi capaz de separar o modo barotrópico do baroclínico; entretanto, apenas para a componente quase-perpendicular da velocidade. Baseamo-nos, para tal, na visão combinada de três análises apresentadas:

- $\mathrm{O} 1^{\circ}$ modo estatístico da velocidade $u$, apresenta a fase da componente $M_{2}$ igual em todas as profundidades, condizente com o modo barotrópico. No $2^{\circ}$ modo estatístico, as séries temporais a $3 \mathrm{~m}$ de profundidade apresentam diferença de fase de $180^{\circ}$ das demais profundidades $(32,54$ e $62 \mathrm{~m})$. Típico de um fluido baroclínico de $1^{\circ}$ modo, estratificado em duas camadas, com sentido oposto de propagação.

- A reconstrução das séries a partir dos modos estatísticos, nas Figuras 57 a 65: mostram para o $1^{\circ}$ modo estatístico características marcantes de um fluido barotrópico. O $2^{\circ}$ modo estatístico apresenta características de um fluido estratificado em duas camadas durante todo o período e, a diferença entre a série reconstruída e a original é pequena, mas apresenta, em algumas sub-séries, indícios de fluxos relativamente intensos em modos superiores.

- A partir da análise espectral das sub-séries de velocidade $u$ observada, $1^{\circ}$ e $2^{\circ}$ modos estatísticos (Figuras 84, 86 e 87), verifica-se que a energia é igual em todas as profundidades para o $1^{\circ}$ modo estatístico enquanto que a energia para o $2^{\circ}$ modo estatístico possui diferenças que, a julgar pela necessidade de um ponto nodal para que o $1^{\circ}$ modo baroclínico exista, a energia deve ser desigual.

A partir da separação do modo barotrópico do baroclínico, analisamos o $2^{\circ}$ modo estatístico como o primeiro modo baroclínico. Procuramos neste modo, sinais com frequência semi-diurnas relativos às marés internas. A análise dos gráficos dispostos nas 
Figuras 57 a 65 mostra o modo baroclínico como um fluxo, por vezes, intenso, capaz de chegar a até $0,67 \mathrm{~ms}^{-1}$ (Ver Tabela 10).

Acreditamos que este modo baroclínico, influenciado pelas marés internas semidiurnas, é capaz de causar alterações no campo de salinidade e, quando não há marés internas atuantes, a variação da salinidade obedece à influência das forçantes de baixas frequências. Com a análise da correlação (Figuras 75 a 83), buscou-se salientar exatamente a influência da intermitência das marés baroclínicas na anomalia de salinidade que, quando ocorrem, a correlação entre o modo baroclínico e a anomalia de salinidade aumenta em módulo, sendo esta negativa, comprovando o que se observa, na maioria dos casos, ao menos visualmente, nas Figuras 66 a 74.

Desta forma, obtêm-se evidências de que as marés internas semi-diurnas, na PCA, correspondem à um processo energético, intermitente, com consequências marcantes na anomalia de salinidade. 


\section{Considerações Finais}

\subsection{Sumário}

Neste trabalho buscamos mapear os locais onde a geração de marés internas semi-diurnas é possível, confirmar sua presença e caracterizá-las, via análise de dados observados, na Plataforma Continental Amazônica.

Separamos o conjunto de dados e os resultados de acordo com os objetivos específicos desta Dissertação, que são:

1. Mapear regiões propícias para geração de marés internas na PCA;

2. Caracterizar o comportamento destas ondas internas na região, identificando as frequências mais importantes e direções preferenciais de propagação, e

3. Verificar a intermitência de tais ondas, bem como os processos responsáveis por tal comportamento.

Concluímos o primeiro objetivo apresentando as Figuras 18 a 22 que mostram os possíveis locais de geração de marés internas. Nota-se claramente a influência da vazão do Rio Amazonas na geração de marés internas. Num período de máxima vazão (Figura 20), maio a junho de 1990, não há, potencialmente, geração de marés internas. Nas outras condições de vazão do RA, a quebra de plataforma e o talude continental apresentamse como locais preferenciais para a geração de tais ondas, resultado esperado, já que a inclinação de fundo nessas regiões é cerca de 2 ordens de grandeza maior que a inclinação da PCA. Entretanto, os períodos de vazão decrescente e mínima, em agosto de 1989 e em novembro de 1991 (Figuras 18 e 22), respectivamente, mostram, em poucas estações, a possibilidade de geração de marés internas semi-diurnas no interior da plataforma.

Tomando por base as simplificações feitas para avaliar o potencial de formação de marés internas, é difícil afirmar que a geração na região interna da PCA é realmente plausível. Contundo, Jackson e Apel (2004), analisando imagens de satélite, descrevem a passagem de onda interna solitária com propagação para o largo em região próxima de onde haveria possibilidade de geração (Figuras 2 e 3). Como já observado na Seção 1, 
essas ondas solitárias, ou sólitons, seriam formadas como consequência da atuação de processos não lineares em marés internas. A propagação para o largo é um indício da geração de tais ondas em áreas próximas ao local de observação.

A análise gráfica, espectral e harmônica das correntes observadas nos três fundeios, Seções 6.2.1, 6.2.2 e 6.2.3, nos possibilitou confirmar que o modo dominante é o modo barotrópico e que a maré semi-diurna principal lunar, $\mathrm{M}_{2}$, é a mais importante. Essas análises mostram que o modo baroclínico atua principalmente regulado por marés internas semi-diurnas com frequência igual à de sua forçante, a principal lunar, comportando-se de forma diferente tanto horizontalmente, na localização dos 3 fundeios, quanto verticalmente, nas profundidades analisadas. De acordo com as análises feitas nas Seções supracitadas, na plataforma interna, ponto do Fundeio F1, as marés internas de frequência $M_{2}$ se comportam como movimentos intensos, de até $43 \mathrm{~cm} / \mathrm{s}$ na direção quase-paralela à isóbata local a $3 \mathrm{~m}$ de profundidade. Já a $16 \mathrm{~m}$ de profundidade as marés internas apresentam correntes de $63 \mathrm{~cm} / \mathrm{s}$ com direção preferencial quase-perpendicular à isóbata local, como pode ser observado na Tabela 6 e nas Figuras 23, 29 e 52. A Figura 53 mostra que as elipses de maré interna não variam em direção preferencial ou amplitude com o tempo.

Para a plataforma média, ponto onde se localiza o Fundeio F2, as marés internas representam movimentos menos intensos que em F1, com velocidades menores do que 2 $\mathrm{cm} / \mathrm{s}$ a $3 \mathrm{~m}$ de profundidade, aumentando para $12 \mathrm{~cm} / \mathrm{s}$ a $32 \mathrm{~m}$ e, a 54 e $62 \mathrm{~m}$, a velocidade é quase a mesma, com valores próximos a $21 \mathrm{~cm} / \mathrm{s}$ (Figuras 25 e 30 e Tabela 7). As elipses de maré $\mathrm{M}_{2}$ baroclínica, Figura 52, mostram que a $3 \mathrm{~m}$ de profundidade o fluxo é quaseperpendicular e a $32 \mathrm{~m}, 54 \mathrm{~m}$ e $62 \mathrm{~m}$ é quase-paralelo, contrário ao observado no ponto F1. Na Figura 53 nota-se que as elipses a $3 \mathrm{~m}$ e $32 \mathrm{~m}$ apresentam variações intensas na inclinação com o passar do tempo. Entretanto, a $3 \mathrm{~m}$, o erro relativo à inclinação das elipses é alto, de quase $81 \%$. Já a 32 m, este erro é menor que 6\%. Nesta série temporal de elipses, nos correntógrafos mais profundos a 54 e a 62 m, o semi-eixo maior e a inclinação das elipses praticamente não variam com o tempo.

Na plataforma externa, representada pelo ponto F3, analisamos as marés baroclínicas 
em duas profundidades, a $32 \mathrm{~m}$ e $93 \mathrm{~m}$ (Figuras 27 e 31). De acordo com os resultados apresentados, as marés baroclínicas de frequência $\mathrm{M}_{2}$ nessa região próximo à quebra de plataforma apresentam correntes por vezes mais intensas que as correntes de maré barotrópica de mesma frequência (ver Tabela 8). A 32 m, as marés internas têm velocidades de corrente de até $35 \mathrm{~cm} / \mathrm{s}$ e estão quase-perpendiculares às isóbatas locais. A 93 m, próximo ao fundo, as correntes são, no máximo, $20 \mathrm{~cm} / \mathrm{s}$, quase-paralelas às isóbatas e fora de fase em $180^{\circ}$ com as correntes de maré $\mathrm{M}_{2}$ interna a $32 \mathrm{~m}$ (Figuras 52 e 53). Analisando o terceiro quadro da Figura 53, notam-se variações na inclinação das elipses durante a série, enquanto que a amplitude se mantém praticamente a mesma. Geyer et al. (1996) atribuem aos mesmos fundeios F2 e F3, oscilações referentes à ondas de Rossby topográficas com período de $690 \mathrm{~h}$ a $1000 \mathrm{~h}$, período condizente com as variações das elipses mostradas.

Nos três fundeios percebe-se que as velocidades apresentadas pelas correntes baroclínicas próximas ao fundo são superiores às observadas nos níveis mais rasos (Figuras 23 a 31; Tabelas 3 a 8). A metodologia utilizada para obter a corrente baroclínica emerge como uma causa possível para tal diferença observada. Fontes (2000) compara as elipses de maré $\mathrm{M}_{2}$ barotrópicas, resultados do emprego de modelagem numérica, com as elipses de maré observadas por Beardsley et al. (1995), e essa comparação se dá com as elipses de maré $\mathrm{M}_{2}$ dos níveis mais rasos de cada fundeio. A Figura 91 mostra a distribuição vertical de correntes idealizada. A subtração de um valor fixo de velocidade semelhante aos observados em superfície causa, não só a inversão das correntes próximas ao fundo, como a intensificação destas. Com isso, podemos ter correntes de maré internas intensas próximas ao fundo que não são reais, tendo sido geradas pelo método empregado. 


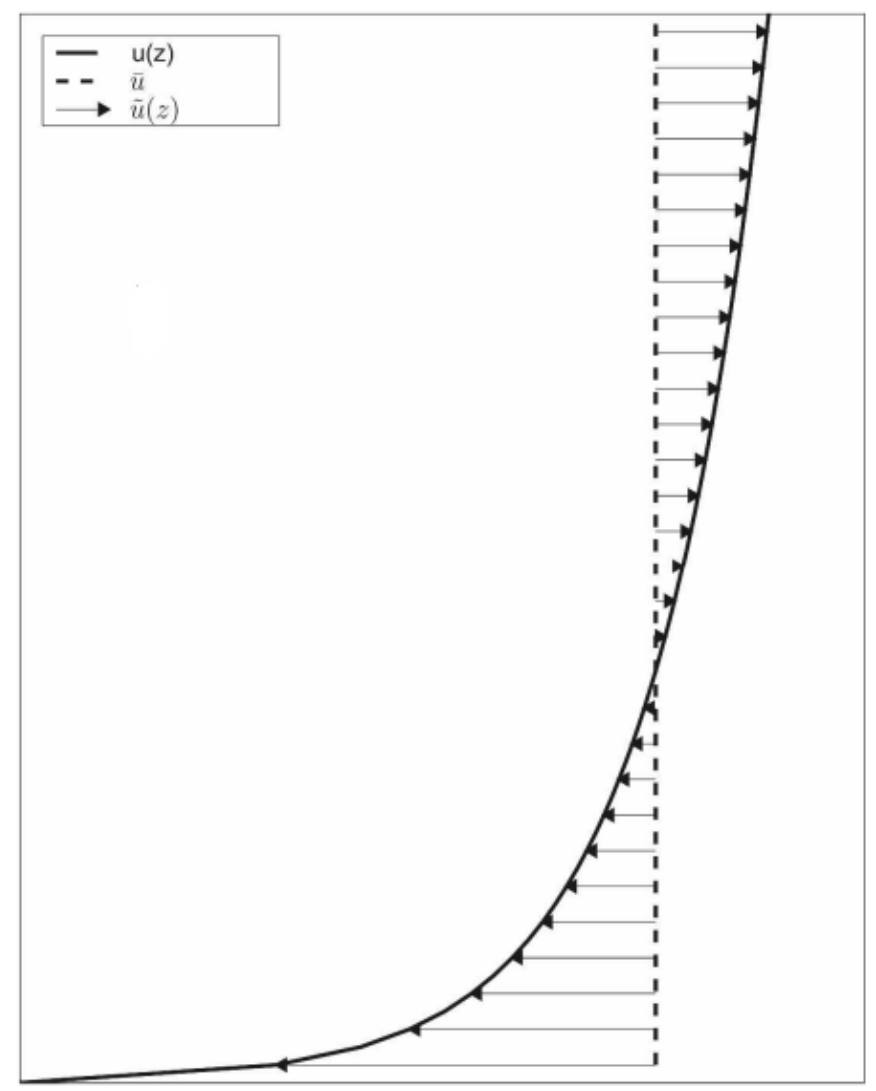

Figura 91: Possível efeito da subtração da velocidade barotrópica num fluxo com camada limite de fundo. A linha contínua corresponde à $u(z)$, a linha pontilhada corresponde à $\bar{u} \mathrm{e}$ as flechas mostram a magnitude e a direção de $\tilde{u} \equiv u(z)-\bar{u}$. Adaptado de Edwards e Seim (2008).

A direção preferencial das correntes baroclínicas nas maiores profundidades, no ponto F2 (54 m e $62 \mathrm{~m}$ ) e no ponto F3 (93 m), Figuras 52 e 53, mostra movimentos quaseparalelos às isóbatas forçados pela maré barotrópica, que na região é quase-perpendicular às isóbatas locais. Possivelmente as ondas de maré interna são advectadas pelo fluxo básico dominante na região, que é para NO.

A metodologia empregada nas Seções 6.2.1, 6.2.2 e 6.2.3 não foi capaz de avaliar a intermitência das marés internas na região bem como os processos responsáveis por tal comportamento. A intermitência pode afetar a análise harmônica e espectral, diminuindo a amplitude da componente semi-diurna ao longo do período analisado. Para estimar a intermitência das marés internas e avaliar os modos barotrópico e baroclínico de oscilação, 
empregamos a análise das Funções Ortogonais Empíricas. De forma a evitar erros inerentes ao método das FOE repartimos a série de 65 dias em 9 sub-séries de 7 dias, 1/4 do mês lunar e o aplicamos em cada uma dessas sub-séries.

A aplicação deste método foi capaz de separar o modo barotrópico do baroclínico. Entretanto, o fez com sucesso apenas para a velocidade quase-perpendicular $u$ (Figuras $54,55,56,84,86$ e 87). Analisamos então, o $2^{\circ}$ modo estatístico ou $1^{\circ}$ modo baroclínico em busca de sinais semi-diurnos, como mostrado nas Figuras 57 a 65. Comprovamos, na análise dessas figuras, que as marés baroclínicas são processos intermitentes e que o modo baroclínico corresponde, em determinadas ocasiões, a quase $10 \%$ da energia total (Figura 54), quase o dobro do proposto por Beardsley et al. (1995).

A partir daí, procuramos respostas às marés baroclínicas semi-diurnas nas propriedades físicas das águas da PCA: anomalias de salinidade e temperatura. Este trabalho é consonante com o trabalho de Linhares (1995) ao afirmar que a temperatura responde, principalmente, às variações diurnas de aquecimento e resfriamento relativos à insolação. Comparando a anomalia de salinidade com o $1^{\circ}$ modo baroclínico (Figuras 66 a 74) percebe-se a influência inversa das velocidades baroclínicas na anomalia de salinidade. Observamos que as velocidades positivas causam anomalias negativas de salinidade e velocidades negativas causam anomalias positivas. A sub-série 9 (Figuras 74 e 83), de 07/04/1990 a 14/04/1990, mostra um exemplo claro da influência de oscilações semi-diurnas da componente baroclínica da velocidade quase-perpendicular na anomalia de salinidade. A correlação entre essas é alta quando as oscilações semi-diurnas são claras.

A velocidade observada quase-paralela à isóbata no ponto F2 apresentou altas correlações com a anomalia de salinidade na maioria das séries (Figuras 75 a 83). A partir das análises espectrais das sub-séries (Figura 85) e do desenvolvimento progressivo da densidade espectral da frequência semi-diurna (Figura 90), constatamos que essas altas correlações entre as séries provavelmente se devem às oscilações em outras frequências, possivelmente de maior período, que atuam nessa direção quase-paralela. A Figura 90 mostra, ainda, que a densidade espectral do $1^{\circ}$ modo baroclínico das correntes quase- 
perpendiculares e da anomalia de salinidade apresentam a mesma tendência, oscilando em fase.

Salientamos as diferenças observadas pelos métodos empregados para encontrar a componente baroclínica da velocidade. A metodologia descrita nas Seções 5.2.2, 5.2.1, como já dito anteriormente, não é capaz de contabilizar a intermitência das marés internas, fato esse que pode ser crucial para as diferenças encontradas em superfície entre estas metodologias e o método das FOE. Entretanto, pela utilização deste último método, constata-se a influência direta da componente baroclínica das correntes quaseperpendiculares na anomalia de salinidade, mostrando que as variações em superfície desta se devem à passagem de marés internas semi-diurnas. Assim, avaliamos o método das FOE como mais apropriado para a caracterização das marés internas e avaliação de sua intermitência. 


\subsection{Conclusões}

Os dados de quatro cruzeiros e três fundeios oceanográficos provenientes do projeto AMASSedS foram estudados através dos métodos de análise definidos na Seção 5, norteando as seguintes conclusões:

1. Marés internas podem ser geradas na Plataforma Continental Amazônica e sua formação é sensível às condições de vazão do Rio Amazonas.

2. Em épocas de vazão máxima (Junho de 1990), não há condições propícias à geração de marés internas semi-diurnas.

3. Em épocas de vazão decrescente (agosto de 1989), há condições de geração de marés internas principalmente na quebra da plataforma e talude continental. Há também a possibilidade teórica de geração próxima à isóbata de 20 m na plataforma média.

4. Em épocas de vazão mínima (novembro de 1991), a geração ocorre preferencialmente na quebra da plataforma e talude continental. Entretanto, assim como no caso de vazão decrescente, há condições teóricas para a formação de marés internas na plataforma média.

5. Em épocas de vazão crescente (fevereiro-março de 1990), a geração só é possível novamente na quebra da plataforma e talude continental.

6. Obtivemos marés baroclínicas $\mathrm{M}_{2}$ nos 3 pontos de fundeio. A velocidade de corrente da maré $\mathrm{M}_{2}$ baroclínica decai com o aumento da distância da costa, com velocidades maiores próximo ao ponto $\mathrm{F} 1$, na plataforma interna e menores no ponto F3, plataforma externa.

7. Na plataforma interna a maré baroclínica apresenta correntes em superfíce quaseparalelas às isóbatas e próximo ao fundo quase-perpendiculares. Na plataforma média essas correntes, apresentam-se quase-perpendiculares e pouco intensas em superfície, aumentando com o incremento da profundidade, tornando-se quaseparalelas às isóbatas próximo ao fundo. 
8. A aplicação das FOE foi capaz de separar as correntes quase-perpendiculares às isóbatas para o ponto $\mathrm{F} 2$ em componentes barotrópica e baroclínicas. O $1^{\mathrm{o}}$ modo estatístico (modo barotrópico) somado ao $2^{\circ}$ modo $\left(1^{\circ}\right.$ modo baroclínico), corresponde à $98 \%$ da energia, entretanto, em profundidade (54 m e $62 \mathrm{~m})$, o $3^{\circ}$ modo, somado ao $4^{\circ}$, pode corresponder, em alguns casos, a velocidades de até $20 \mathrm{~cm} / \mathrm{s}$.

9. A energia do $1^{\circ}$ modo baroclínico, nas 9 sub-séries analisadas, variou de até $10 \%$.

10. Os resultados da aplicação das FOE mostram o modo barotrópico energético e dominante com oscilações semi-diurnas. $\mathrm{O} 1^{\mathrm{o}}$ modo baroclínico apresenta-se como oscilações intensas em superfície em direção ao largo, frequentemente com período semi-diurno, intermitente, causando variações negativas na anomalia de salinidade.

11. O método das FOE mostrou-se mais adequado para a caracterização das marés baroclínicas, bem como na avaliação da intermitência deste processo, do que os demais métodos empregados nesta Dissertação.

12. As marés baroclínicas ocorrem na PCA como correntes intermitentes. Entretanto, não foi possível avaliar os processos responsáveis por tal comportamento.

13. O conjunto de dados utilizado não possui resolução espacial ideal para estudo mais completo de marés internas. Entretanto, foi suficiente para constatar a importância do processo na região da Plataforma Continental Amazônica e para quantificar alguns de seus aspectos. 


\section{Referências}

ALESSI, C. A.; LENTZ, S. J.; BEARDSLEY, R. C.; CASTRO, B. M.; GEYER, W. R. A multidisciplinary amazon shelf sediment study (amasseds): Physical oceanography moored array component. (Technical Report, WHOI-92-36 ), 1992.

BAINES, P. On internal tide generation models. Deep Sea Research Part A. Oceanographic Research Papers, Elsevier, v. 29, n. 3, p. 307-338, 1982.

BEARDSLEY, R. C.; CANDELA, J.; LIMEBURNER, R.; GEYER, W. R.; LENTZ, S. J.; CASTRO, B. M.; CACCHIONE, D.; CARNEIRO, N. The M2 tide on the Amazon shelf. Journal of Geophysical Research: Oceans, v. 100, n. C2, p. 2283-2319, 1995.

BECKER, J.; SANDWELL, D.; SMITH, W.; BRAUD, J.; BINDER, B.; DEPNER, J.; FABRE, D.; FACTOR, J.; INGALLS, S.; KIM, S. et al. Global bathymetry and elevation data at 30 arc seconds resolution: Srtm30_plus. Marine Geodesy, Taylor \& Francis, v. 32, n. 4, p. 355-371, 2009.

BJORNSSON, H.; VENEGAS, S. A. A manual for EOF and SVD analyses of climate data. CCGCR Report No. 97-1, McGill University, Montréal, Québec, p. 52, 1997.

BLUMBERG, A. F.; MELLOR, G. L. A description of a three-dimensional coastal ocean circulation model. Coastal and Estuarine Sciences, American Geophysical Union, v. 4, p. 1-16, 1987.

CASAGRANDE, G.; STEPHAN, Y.; VARNAS, A. C. W.; FOLEGOT, T. A novel empirical orthogonal function (EOF)-based methodology to study the internal wave effects on acoustic propagation. IEEE Journal of Oceanic Engineering, v. 36, n. 4, p. 745-759, 2011.

CASTRO, B. de; MIRANDA, L. de. Physical oceanography of the western atlantic continental shelf located between $4 \mathrm{~N}$ and $34 \mathrm{~S}$. The Sea, John Wiley \& Sons: New Yor, v. 11, p. 209-251, 1998. 
CASTRO, B. M. de; MIRANDA, L. B. de; BEARDSLEY, R. C. Observações de correntes na quebra da plataforma continental amazônica. Resumo em II Simpósio sobre Oceanografia, IOUSP, p. 129, 1991.

CAZENAVE, F. Internal waves over the continental shelf in south Monterey Bay. 117 p. Dissertação de Mestrado — The Faculty of Moss Landing Marine Laboratories. San Jose State University, San José, California, EUA, 2008.

CRAIG, P. Solutions for internal tidal generation over coastal topography. Journal of Marine Research, Sears Foundation for Marine Research, v. 45, n. 1, p. 83-105, 1987.

CURTIN, T. B. Physical observations in the plume region of the Amazon River during peak discharge-ii. water masses. Continental Shelf Research, Elsevier, v. 6, n. 1, p. 53-71, 1986.

DOMMENGET, D.; LATIF, M. A cautionary note on the interpretation of EOFs. Journal of Climate, v. 15, n. 2, p. 216-225, 2002.

EDWARDS, C. R.; SEIM, H. E. Complex EOF analysis as a method to separate barotropic and baroclinic velocity structure in shallow water. Journal of Atmospheric and Oceanic Technology, v. 25, n. 5, p. 808-821, 2008.

EMERY, W. J.; THOMSON, R. E. Data Analysis Methods in Physical Oceanography. Second and revised edition, third impression. USA: Elsevier, 2004. 638 p.

FENG, M.; MERRIFIELD, M. A.; PINKEL, R.; HACKER, P.; PLUEDDEMANN, A. J.; FIRING, E.; LUKAS, R.; ERIKSEN, C. Semidiurnal tides observed in the western equatorial pacific during the Tropical Ocean - Global Atmosphere Coupled Ocean - Atmosphere Response Experiment. Journal of Geophysical Research: Oceans, Wiley Online Library, v. 103, n. C5, p. 10253-10272, 1998.

FFIELD, A. North Brazil Current rings viewed by TRMM Microwave Imager SST and the influence of the Amazon Plume. Deep Sea Research Part I: Oceanographic Research Papers, Elsevier, v. 52, n. 1, p. 137-160, 2005. 
FONTES, R.; CASTRO, B.; BEARDSLEY, R. Numerical study of circulation on the inner Amazon Shelf. Ocean Dynamics, Springer, v. 58, n. 3-4, p. 187-198, 2008.

FONTES, R. F. C. Estudo Numérico da Circulação na Plataforma Continental Amazônica (PCA). 198 p. Tese (Doutorado) - Instituto Oceanográfico da Universidade de São Paulo, 2000.

FOREMAN, M. G. G. Manual for tidal heights: analysis and prediction. Pacific Marine Science Report, v. 77-10, p. 97, 1977a.

FOREMAN, M. G. G. Manual for tidal heights: analysis and prediction. Pacific Marine Science Report, v. 79-6, p. 70, 1977b.

GABIOUX, M. Influência da lama em suspensão sobre a propagação da maré na Plataforma Amazônica. 109 p. Dissertação de Mestrado - COPPE, Universidade Federal do Rio de Janeiro, Rio de Janeiro, 2002.

GARRETT, C.; KUNZE, E. Internal tide generation in the deep ocean. Annu. Rev. Fluid Mech., Annual Reviews, v. 39, p. 57-87, 2007.

GERKEMA, T.; ZIMMERMAN, J. T. F. An introduction to internal waves. Lecture Notes, Royal NIOZ, Texel, 2008.

GEYER, R. C.; KINEKE, W. R. Observations of currents and water properties in the Amazon frontal zone. Journal of Geophysical Research: Oceans (1978-2012), v. 100, n. 25, p. 2321-2339, 1995.

GEYER，R. W.; BEARDSLEY，R.; LENTZ，S.; CANDELA，J.; LIMEBURNER, R.; JOHNS, W.; CASTRO, B.; I.D, S. Physical oceanography of the Amazon shelf. Continental Shelf Research, Elsevier, v. 16, n. 5, p. 575-616, 1996.

GIBBS, M. T.; MIDDLETON, J. H. Barotropic and baroclinic tides on the Sydney continental shelf. Continental Shelf Research, Elsevier, v. 17, n. 9, p. 1005-1027, 1997.

GILL, A. E. Atmosphere-Ocean Dynamics. Vol 30, international geophysics series. USA: Academic Press, 1982. 662 p. 
GODIN, G. TIDES. Ensenada, Baja Califórnia, Mexico: CICESE, 1988. 290 p.

HELLAND-HANSEN, B.; NANSEN, F. The norwegian sea - its physical oceanography based upon the norwegian researches 1900-1904. Report on Norwegian Fishery and Marine Investigations, Det Mallingske Bogtrykkeri, Kristiania, v. 2, n. 2, p. 390, 1909.

HOLLOWAY, P. E.; CHATWIN, P. G.; CRAIG, P. Internal tide observations from the Australian north west shelf in summer 1995. Journal of Physical Oceanography, v. 31, n. 5, p. 1182-1199, 2001.

HOLLOWAY, P. E.; MERRIFIELD, M. A. Internal tide generation by seamounts, ridges, and islands. Journal of Geophysical Research, American Geophysical Union, v. 104, n. C11, p. 25937-25, 1999.

HUTHNANCE, J. Internal tides and waves near the continental shelf edge. Geophysical \& Astrophysical Fluid Dynamics, Taylor \& Francis, v. 48, n. 1-3, p. 81-106, 1989.

JACKSON, C. R.; APEL, J. R. An Atlas of Internal Solitary-like Waves and their Properties. 2004. Disponível em: <http://www.internalwaveatlas.com/>. Acesso em: 01 Out.2013.

JOHNS, W.; LEE, T.; BEARDSLEY, R.; CANDELA, J.; LIMEBURNER, R.; CASTRO, B. Annual cycle and variability of the North Brazil Current. Journal of Physical Oceanography, v. 28, n. 1, p. 103-128, 1998.

KANTHA, L. H.; TIERNEY, C. C. Global baroclinic tides. Progress in Oceanography, Elsevier, v. 40, n. 1, p. 163-178, 1997.

KUNZE, E.; ROSENFELD, L. K.; CARTER, G. S.; GREGG, M. C. Internal waves in Monterey submarine canyon. Journal of Physical Oceanography, v. 32, n. 6, p. 1890-1913, 2002.

KURAPOV, A. L.; EGBERT, G. D.; ALLEN, J.; MILLER, R. N.; EROFEEVA, S. Y.; KOSRO, P. The M2 internal tide off Oregon: Inferences from data assimilation. Journal of Physical Oceanography, v. 33, n. 8, p. 1733-1757, 2003. 
LEBLOND, P. H.; MYSAK, L. A. Waves in the Ocean. 1st, oceanographic series 20. ed. The Netherlands: Elsevier, 1978. 620 p.

LENTZ, S. J. Seasonal variations in the horizontal structure of the Amazon Plume inferred from historical hydrographic data. Journal of Geophysical Research, v. 100, p. 2391-2400, 1995.

LENTZ, S. J.; LIMEBURNER, R. The Amazon River plume during AMASSEDS: Spatial characteristics and salinity variability. Journal of Geophysical Research, American Geophysical Union, v. 100, n. C2, p. 2355-2375, 1995.

LERCZAK, J. A.; WINANT, C.; HENDERSHOTT, M. Observations of the semidiurnal internal tide on the southern California slope and shelf. Journal of Geophysical Research: Oceans, v. 108, n. C3, 3068, 2003.

LINHARES, V. P. Circulação e Massas de Água na Plataforma Continental Externa Amazônica. 191 p. Dissertação de Mestrado - IOUSP, Instituto Oceanográfico da Universidade de São Paulo, São Paulo, 1995.

LODER, J. W.; PETRIE, B.; GAWARKIEWICZ, G. The coastal ocean off northeastern North America: A large-scale view. The Sea, John Wiley \& Sons: New York, v. 11, p. 105-133, 1998.

MEADE, R. H. Suspended sediments of the modern Amazon and Orinoco Rivers. Quaternary International, Elsevier, v. 21, p. 29-39, 1994.

MEADE, R. H.; DUNNE, T.; RICHEY, J. E.; SANTOS, U. de M.; SALATI, E. Storage and remobilization of suspended sediment in the lower Amazon River of Brazil. Science, American Association for the Advancement of Science, v. 228, n. 4698, p. 488$490,1985$.

MIRANDA, L. B. de; CASTRO, B. M. de; BEARDSLEY, R. C.; GEYER, W. R. An intercomparison between the S4 and the SD2000 currentmeters on a subsurface mooring. Resumo em AGU Fall Meeting, p. 190, Dez. 1990.

MIRANDA, L. B. de; CASTRO, B. M. de; KJERFVE, B. Princípios de Oceanografia Física de Estuários. 2a ${ }^{\text {a }}$ ed. São Paulo: Editora da Universidade de São 
Paulo, 2012. 426 p.

MULLER-KARGER, F. E.; MCCLAIN, C. R.; RICHARDSON, P. L. The dispersal of the Amazon's water. Nature, Nature Publishing Group, v. 333, n. 6168, p. 56-59, 1988.

MUNK, W. Internal waves and small-scale processes. Evolution of Physical Oceanography, The MIT Press, p. 264-291, 1981.

MUNK, W. Once again: once again — tidal friction. Progress in Oceanography, Elsevier, v. 40, n. 1, p. 7-35, 1997.

NITTROUER, C. A.; DEMASTER, D. J. The Amazon shelf setting: tropical, energetic, and influenced by a large river. Continental Shelf Research, Elsevier, v. 16, n. 5 , p. $553-573,1996$.

NOBLE, M.; CACCHIONE, D. A.; SCHWAB, W. C. Observations of strong mid-Pacific internal tides above Horizon Guyot. Journal of Physical Oceanography, v. 18 , n. 9, p. 1300-1306, 1988.

OLTMAN, R. E. Reconnaissance investigations of the discharge and water quality of the Amazon River. USA: US Government Printing Office, 1968.

OSBORNE, J.; KURAPOV, A.; EGBERT, G.; KOSRO, P. Spatial and temporal variability of the M2 internal tide generation and propagation on the Oregon shelf. Journal of Physical Oceanography, v. 41, n. 11, p. 2037-2062, 2011.

PAWLOWICZ, R.; BEARDSLEY, B.; LENTZ, S. Classical tidal harmonic analysis including error estimates in MATLAB using T_TIDE. Computers \& Geosciences, Elsevier, v. 28, n. 8, p. 929-937, 2002.

PEDLOSKY, J. Waves in the ocean and atmosphere: introduction to wave dynamics. USA: Springer Verlag, 2003. 636 p.

PERCIVAL, D. B.; WALDEN, A. T. Spectral Analysis for Physical Applications: Multitaper and Conventional Univariate Techniques. United Kingdom: Cambridge University Press, 1993. 583 p. 
PEREIRA, A.; CASTRO, B.; CALADO, L.; SILVEIRA, I. da. Numerical simulation of M2 internal tides in the South Brazil Bight and their interaction with the Brazil Current. Journal of Geophysical Research: Oceans, v. 112, n. C4, 2007.

PETRUNCIO, E. T.; ROSENFELD, L. K.; PADUAN, J. D. Observations of the internal tide in Monterey Canyon. Journal of Physical Oceanography, v. 28, n. 10, p. 1873-1903, 1998.

RATTRAY, M. On the coastal generation of internal tides. Tellus, v. 12, n. 1, p. $54-62,1960$.

RICHEY, J. E.; MEADE, R. H.; SALATI, E.; DEVOL, A. H.; NORDIN, C. F.; SANTOS, U. D. Water discharge and suspended sediment concentrations in the Amazon River: 1982-1984. Water Resources Research, v. 22, n. 5, p. 756-764, 1986.

RUDNICK, D. L.; BOYD, T. J.; BRAINARD, R. E.; CARTER, G. S.; EGBERT, G. D.; GREGG, M. C.; HOLLOWAY, P. E.; KLYMAK, J. M.; KUNZE, E.; LEE, C. M. et al. From tides to mixing along the Hawaiian Ridge. Science, American Association for the Advancement of Science, v. 301, n. 5631, p. 355-357, 2003.

SANGRÀ, P.; BASTERRETXEA, G.; PELEGRÍ, J. L.; ARÍSTEGUI, J. et al. Chlorophyll increase due to internal waves in the shelf-break of Gran Canaria Island (Canary Islands). Scientia Marina, Institut de Ciències del Mar de Barcelona (CSIC), v. 65, p. 89-97, 2001.

SAWYER, C. A satellite study of ocean internal waves. NOAA Technical Memorandum ERL PMEL-46, Pacific Marine Environmental Laboratory Seattle, Washington, p. $74,1983$.

TOMCZAK, M. An Introduction to Physical Oceanography. 2000. Disponível em: <http://www.es.flinders.edu.au/ mattom/IntroOc/>. Acesso em: 01 Out.2013.

UNESCO. Background papers and supporting data on the international equation of state of seawater 1980. Unesco Tech. Pap. in Mar. Sci, v. 38, p. 1-192, 1981.

UNESCO. Algorithms for computation of fundamental properties of seawater. Unesco Tech. Pap. in Mar. Sci, v. 44, p. 53, 1983. 
VLASENKO, V.; STASHCHUK, N.; HUTTER, K. Baroclinic tides: theoretical modeling and observational evidence. United Kingdom: Cambridge University Press, 2005. $351 \mathrm{p}$.

WELCH, P. D. The use of a fast fourier transform for the estimation of power spectra: A method based on time averaging over short modified periodograms. IEEE Transactions of Audio and Electromagnetics, v. 15, p. 70-73, 1967.

WUNSCH, C. Internal tides in the ocean. Reviews of Geophysics, Wiley Online Library, v. 13, n. 1, p. 167-182, 1975.

ZEILON, N. On the tidal boundary waves and related hydrodynamical problems. Kungl Svenska Vetenskapsakademiens Handl., v. 47, n. 4, p. 46, 1912.

ZEILON, N. Experiments on boundary tides. Goteborg Kgl. Vetensk. Vitterhets Samhaelles Handl., v. 5, p. 1-8, 1914. 